\title{
Factors Influencing Consumer Trust in Mobile Payments in the United Arab Emirates
}

\author{
By
}

Ahmed Shuhaiber

A thesis submitted to Victoria University of Wellington in partial fulfilment of the requirements for the degree of Doctor of Philosophy in Information Systems

Victoria University of Wellington

2016 


\begin{abstract}
While mobile payments have been adopted by a huge number of businesses, the body of knowledge regarding user trust in mobile payments shows that trust is a major issue in its adoption and development. The purpose of this study was to better understand the factors that influence consumer trust in mobile payments in one significant country in this region; The United Arab Emirates (UAE) as the research region. The UAE is one of the leading economies in the Middle East Arab region, and mobile technology is well advanced and widely utilised.
\end{abstract}

An analysis of relevant literature provided the basis for the development of a conceptual model. The model, classified into five logical groups (consumer characteristics, environmental influences, provider characteristics, perceived risks and mobile-device characteristics), was further explored, validated, extended and tested through a mixedmethod methodology, combining both qualitative (phase one) and quantitative (phase two) approaches, with semi-structured interviewing in exploratory focus groups and an online survey being used respectively

The findings of the qualitative phase were used to clarify the appropriateness of the preliminary Consumer Trust in Mobile Payments (CTMP) model, which was accordingly revised and extended. The second phase (the quantitative approach) was based on a survey of 340 respondents in the UAE. The collected data were analysed by using Structural Equation Modelling with the Partial Least Squares (PLS-SEM) approach. Many of the factors in the qualitative CTMP model were successfully validated and statistically significant. The resulting, quantitatively weighted CTMP model shows that users' awareness and provider's trustworthiness are the most positive influential factor, followed by perceive security levels and device-design suitability. Customers' uncertainty avoidance, on the other hand, is the most negatively influential factor on trust, followed by perceived privacy risks associated with m-payments. The model contributes towards better acceptance and usage of mobile payments. The findings also provide a number of theoretical implications for academic research and useful information for practitioners. 


\section{Acknowledgements}

My sincerest thanks and praise to Allah, my lord and creater, who guided me into the straight path, and taught me everything I know. I am also grateful to his prophet Mohammed, peace be upon him, whose teachings support me in seeking knowledge along life. The prophet said "He who does not thank the people is not thankful to Allah". I would like to express my deep appreciation to the people who made my $\mathrm{PhD}$ possible and gave support along my research journey, including:

My family members: Parents (Haitham and Sahar), for your endless support, kindness, patience, care and prays. My brothers (Jawad and Muhannad) and sister (Farah), for your motivation and financial support. And my wonderful wife (Nour) and my lovely small daughter (Tamara), for your love, encouragement and understanding.

My supervisory team: Hans Lehmann (Primary supervisor), Val Hooper and Tony Hooper. Thank you for your directions, continued help and guidance. Without your academic support, this research never would have happened.

My examiners: Benoit Aubert, Ananth Srinivasan and Key Pousttchi. Thank you for your insightful and helpful feedback. A special thank to Benoit for the extraordinary follow up and guiding advises.

I also would like to thank Laila Faisal and Deborah Laurs from the student learning centre at Victoria University for their support by acting as a 'sounding board' for ideas on this research.

For my friends, work collegues and research mates: thank you all. 


\section{Table of Contents}

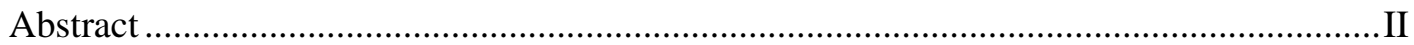

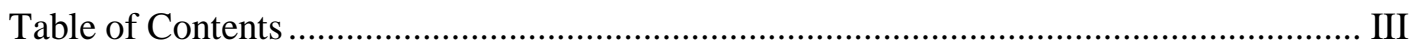

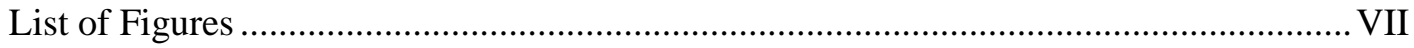

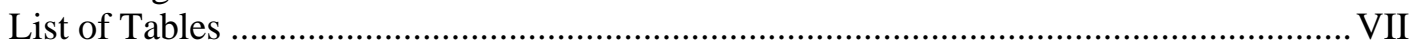

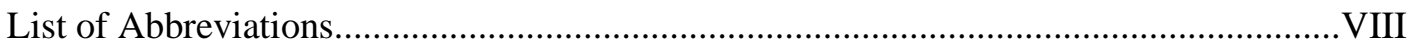

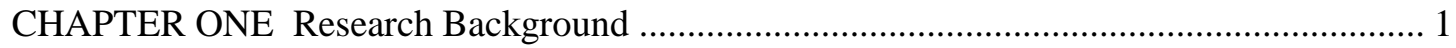

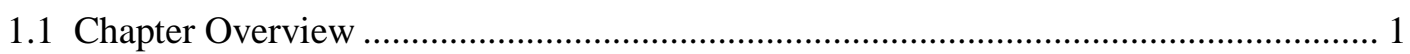

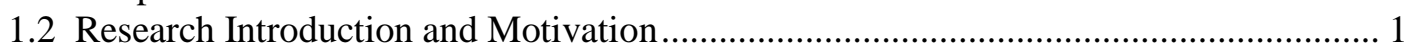

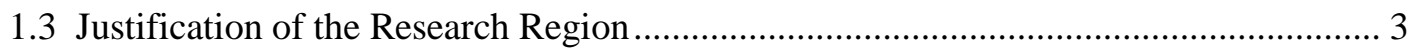

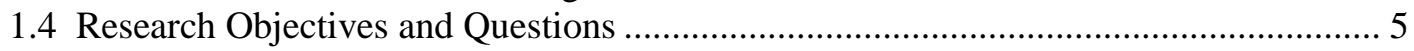

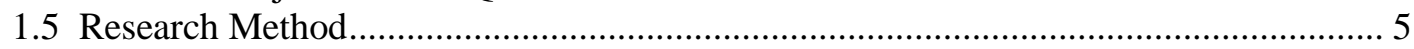

1.5.1 The Qualitative Method (Phase One) …………................................................. 5

1.5.2 The Quantitative Method (Phase Two)................................................................... 6

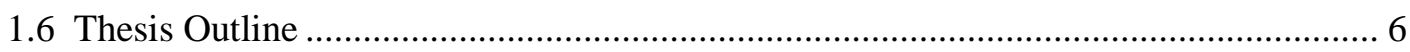

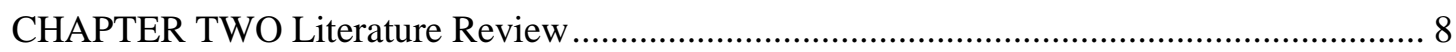

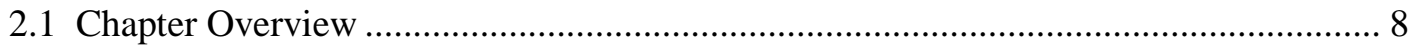

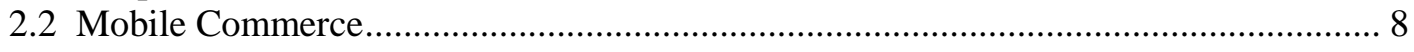

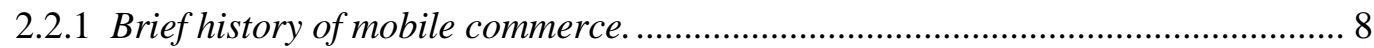

2.2.2 Definitions of mobile commerce .......................................................................... 9

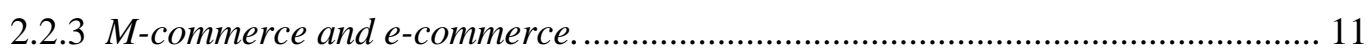

2.2.4 M-commerce services and applications ............................................................. 14

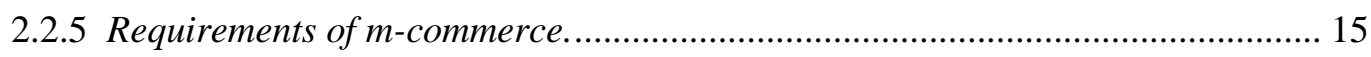

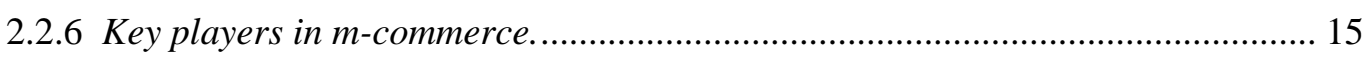

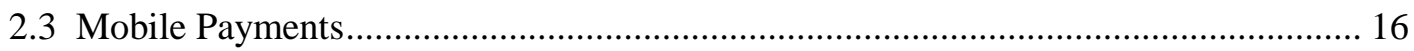

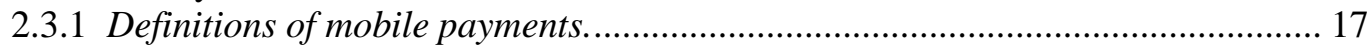

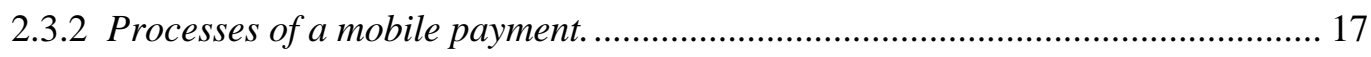

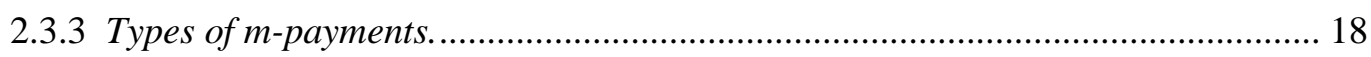

2.3.4 M-payments in developing and developed countries (examples and statistics).... 20

2.3.5 M-payments in the Middle East and Arab countries. ......................................... 22

2.3.6 M-payments in the Emirates. .......................................................................... 23

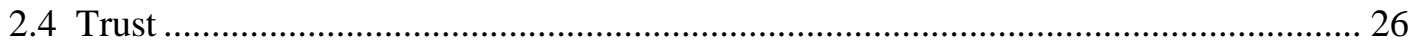

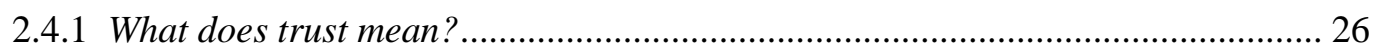

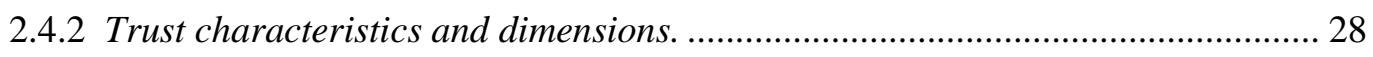

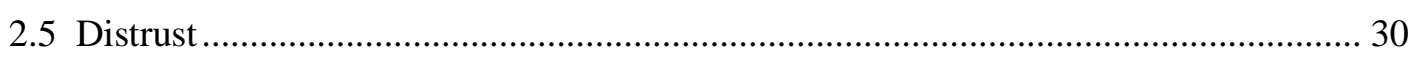

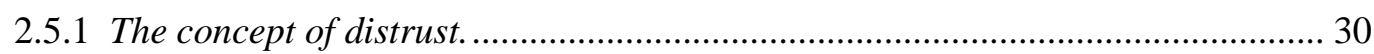

2.5.2 Relationship between trust and distrust.......................................................... 32

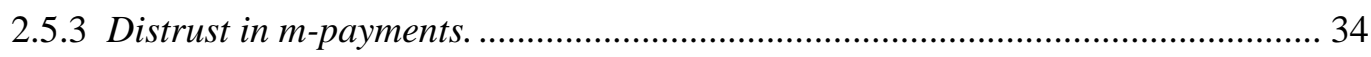

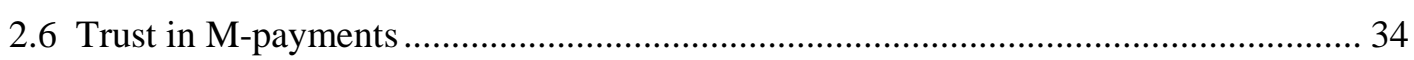

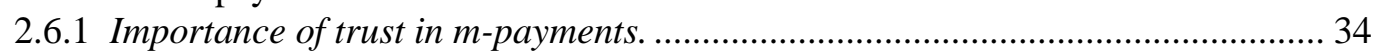

2.6.2 What is the problem with consumer trust in m-payments? .................................. 36

2.6.3 It is harder to build trust in m-payments than other e-payments.......................... 36

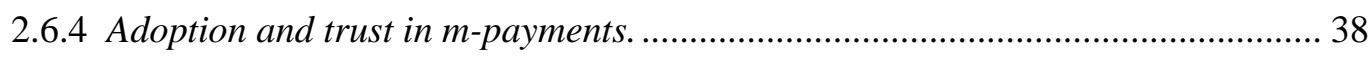

2.6.5 An overview of factors influencing consumer trust in m-payments. ..................... 38 
2.6.6 Studies about trust in m-payments in the Emirates and surrounding Middle

Eastern and Arab countries.

2.6.7 Summary of the factors influencing consumer trust in m-payments. ..................... 58

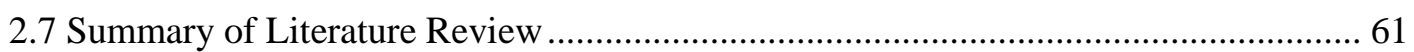

2.8 A Proposed Conceptual Model and Research Propositions ............................................6. 62

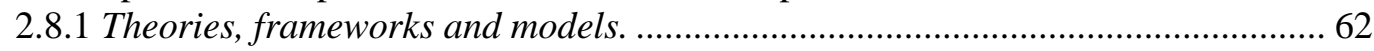

2.8.2 The CTMP model and research propositions...................................................... 62

CHAPTER THREE Research Design and Qualitative Methodology for Phase One .............. 65

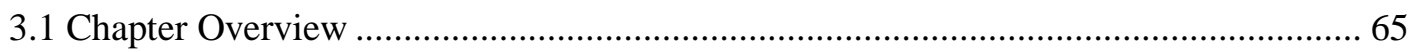

3.2 The Epistomological Perspective (Research Paradigm) .................................................6 65

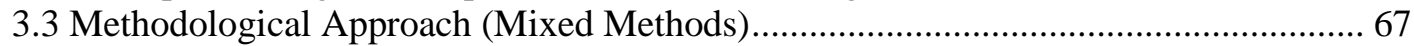

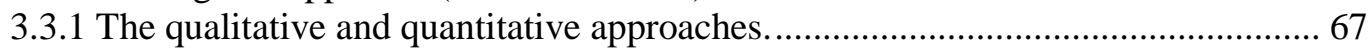

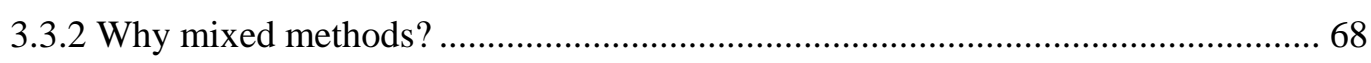

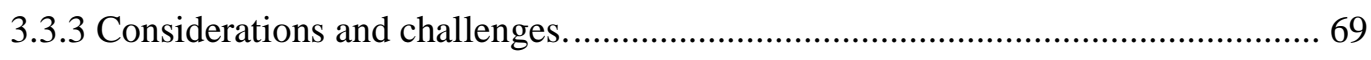

3.4 Phase One (A Qualitative Method: Focus Groups Interviews) ....................................... 69

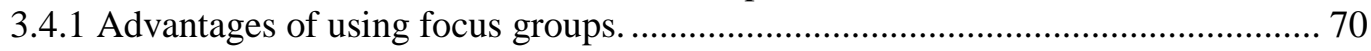

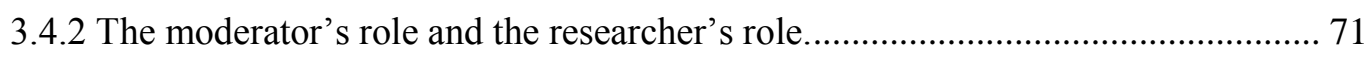

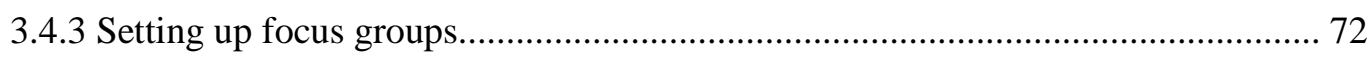

3.4.4 Reliability and validity of the focus group discussions. ......................................... 78

3.4.5 Summary of the methodology and data collection. ........................................... 80

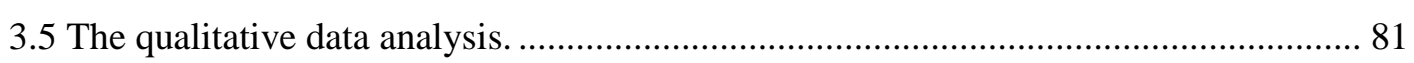

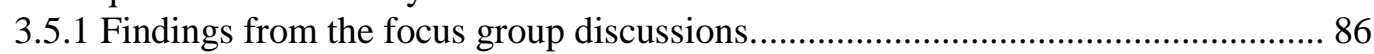

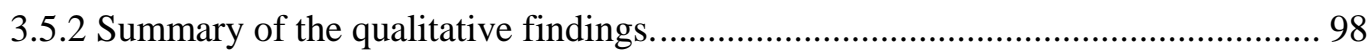

3.5.3 The qualitative findings in the context of the literature review ......................... 100

3.6 Research Hypotheses and Revised CTMP Model....................................................... 101

CHAPTER FOUR Research Design and Quantitative Methodology for Phase Two ........... 103

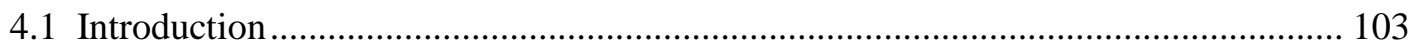

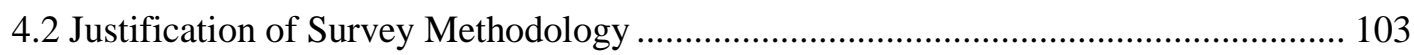

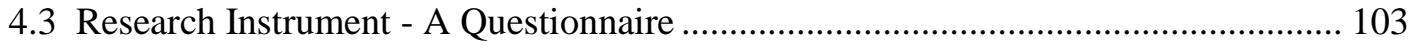

4.3.1 Questionnaire development and design...................................................... 104

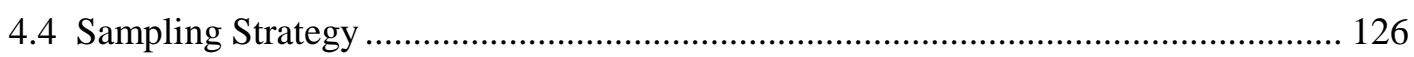

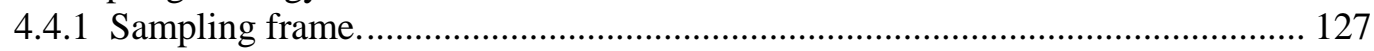

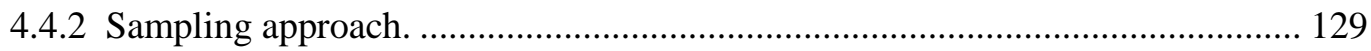

4.4.3 Representative sampling........................................................................... 130

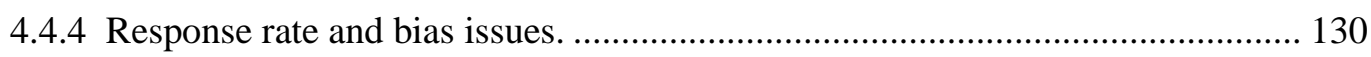

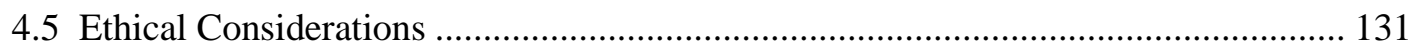

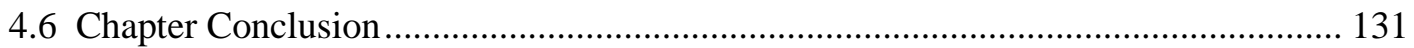

CHAPTER FIVE Analysis and Findings of Survey Data ................................................ 133

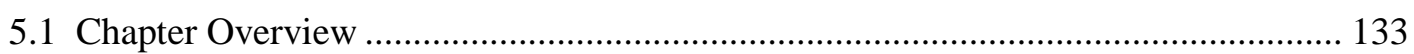

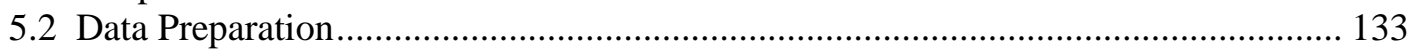

5.3 Sample Profiles and Respondent Characteristics ................................................. 135

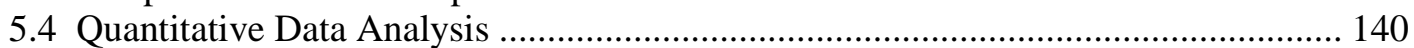

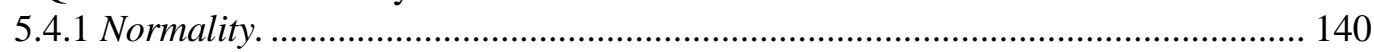

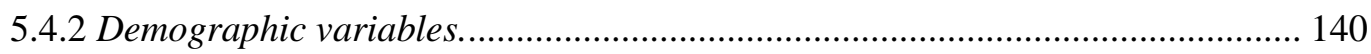

5.4.3 Common method variance .............................................................................. 143 


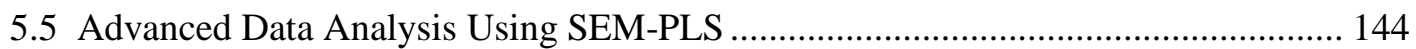

5.5.1 Structural Equation Modelling (SEM)........................................................... 144

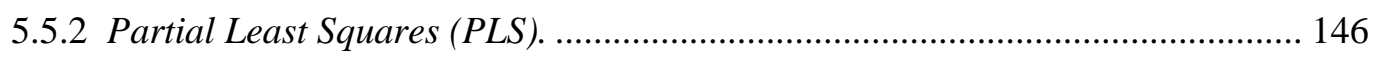

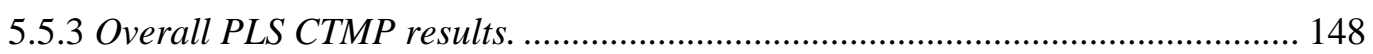

5.5.4. Summary of the Hypotheses Results ................................................................ 161

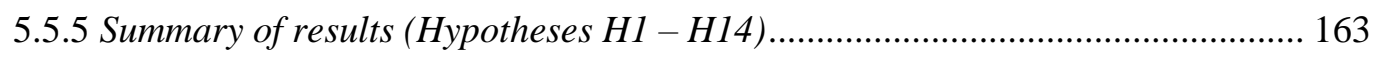

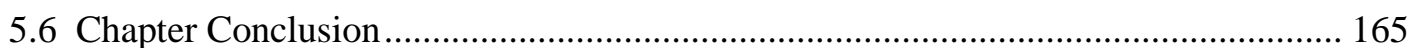

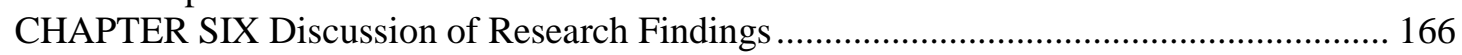

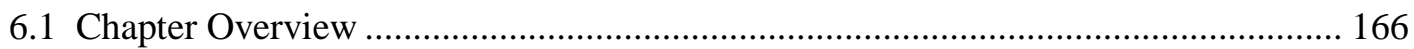

6.2 Summary of the Research Model based on the Qualitative Findings ........................ 166

6.3 Summary of the Research Hypotheses and Model based on the Quantitative Findings

6.4 Discussion of the Hypotheses Results

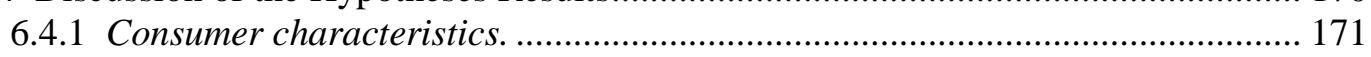

6.4.2 Environmental influences (Trust Environment)................................................ 173

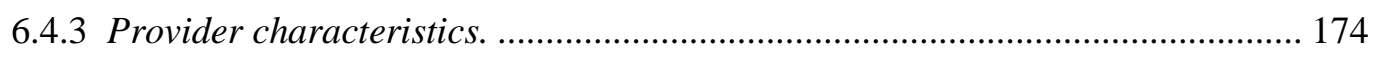

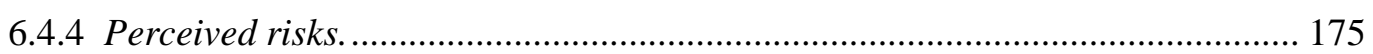

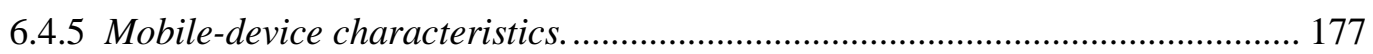

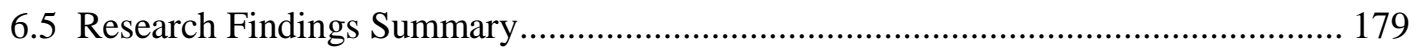

CHAPTER SEVEN Research Conclusion and Implications ............................................ 182

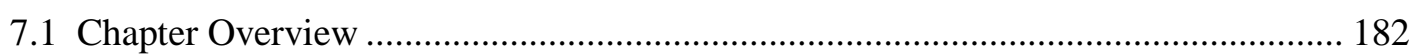

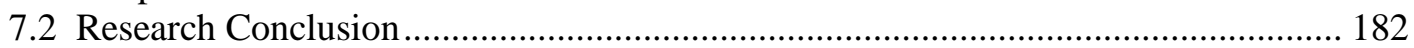

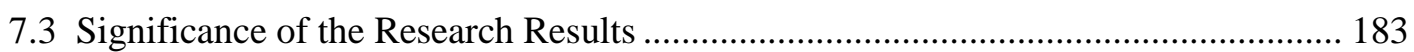

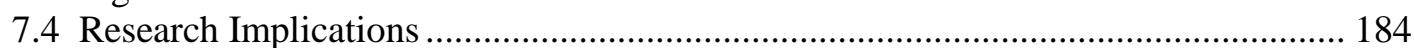

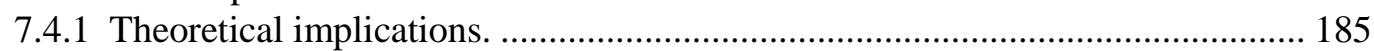

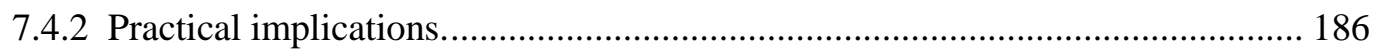

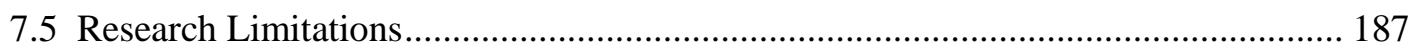

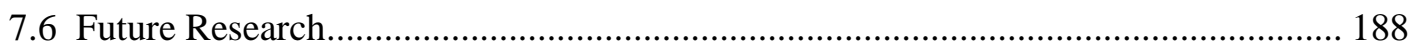

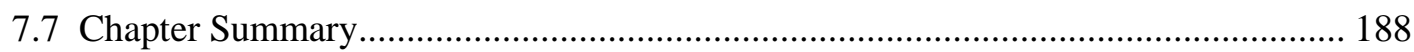

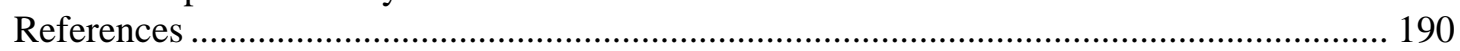

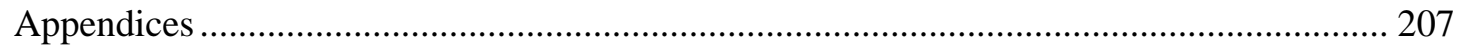

Appendix A - Focus Group Protocol ............................................................................. 208

Appendix B - Focus Group Interview Guide................................................................. 209

Appendix C - Consent Forms for Focus Group Participation (in English and Arabic) .... 210

Appendix D - List of Main Codes and Categories ........................................................ 212

Appendix E - Originally cited and adapted items as in literature ................................... 213

Appendix F - Information Sheet and Questionnaire Surveys (in English and Arabic) .... 215

Appendix G - Normality through Skewness Measures ................................................. 227

Appendix H - Cross Tabulating between Age and Usage .............................................. 229

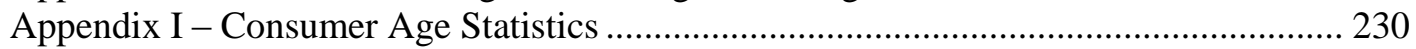




\section{List of Figures}

Figure 2.1 The Relationships amongst Electronic and Mobile Business and Commerce ......................12

Figure 2.2 The Relationships amongst E-Payments, M-Commerce and M-Payments.............................16

Figure 2.3 Trust Continuum and Distrust Continuum (Adapted from Lewicki et al., 1998) .................. 32

Figure 3.1 Revised CTMP Model Following the Focus Groups Interviews ......................................102

Figure 5.1 Revised CTMP Model with the Quantitative Analysis Results ........................................164

Figure 6.1 The CTMP Model Based on the Qualitative Findings ..................................................... 167

Figure 6.2 The CTMP Model Based on the Quantitative Findings ...................................................170

\section{List of Tables}

Table 2.1 Categories of the Types of Mobile Payment (Adapted from Goode (2006) and Vatsavayi \& Mukkamala (2008))

Table 2.2 Trust Referent Characteristic-based Definition Categories (adapted from McKnight \&

Chervany, 2001)

Table 2.3 Supporting References for the Constructs Used for the CTMP Model---------------------- 58

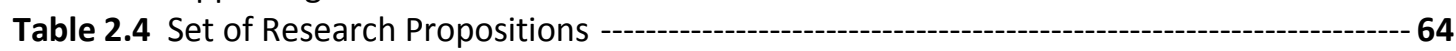

Table 3.1 Comparison of the quantitative and qualitative approaches (Adapted from Biemans (2003), Creswell (2009), Cavana et al. (2001) and Neuman (2005)) ----------------------- 68

Table 3.2 An Example of the Translation Process - A section of FG1 on September $20^{\text {th }}, 2011$-- 76

Table 3.3 Focus Group Members and Descriptions ------------------------------------------------------- 81

Table 3.4 Pattern and Frequency of M-Payment Usage Between the Focus Groups -------------- $\mathbf{8 2}$

Table 3.5 Perceived Factors Influencing Consumer Trust in Mobile Payments----------------------- 99

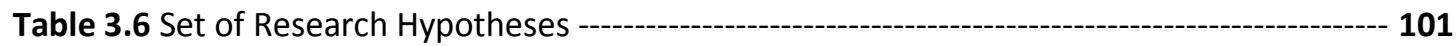

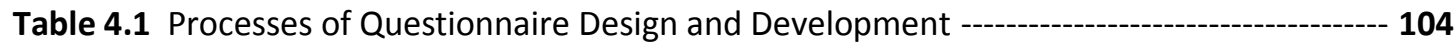

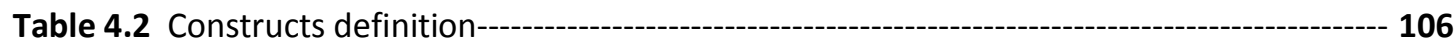

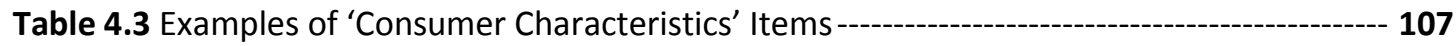

Table 4.4 Example of 'Trust Environment' Item -------------------------------------------------- 108

Table 4.5 Examples of 'Provider Characteristics' Items -------------------------------------- 109

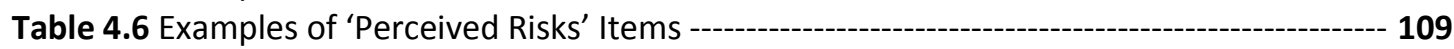

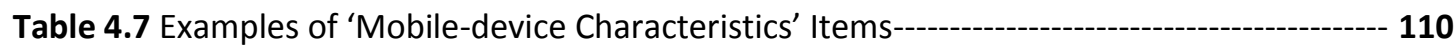

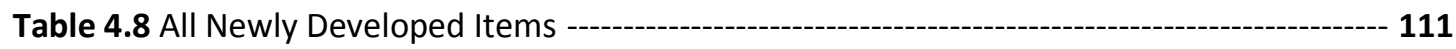

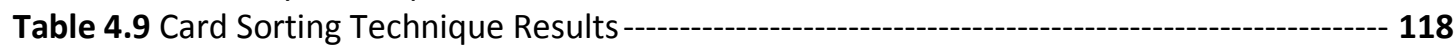

Table 4.10 Some of the Changes Made to the Questionnaire through the Pre-testing Process 120

Table 4.11 Scales details (wording, source and status) ------------------------------------------------ 121

Table 4.12 A Comparison of Survey Methods (Adapted from Cavana et al., 2001, Malhotra et al., 2004, Neuman, 2003; Zikmund, 2008)

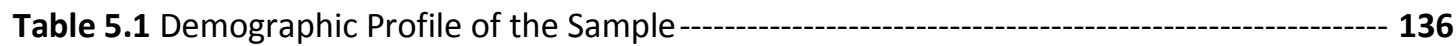

Table 5.2 Mobile Payment Usage Profile ------------------------------------------------------------------ 137

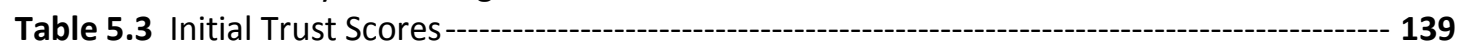

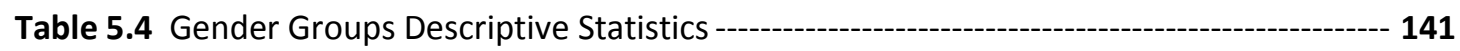

Table 5.5 Experience Groups Descriptive Statistics ------------------------------------------------ 141

Table 5.6 Age Groups Descriptive Statistics---------------------------------------------------------------- 142

Table 5.7 Outer Model Measurements - Items Loadings ----------------------------------------------- 149

Table 5.8 Outer Model Measurements - Cross Loadings------------------------------------------------ 153

Table 5.9 Average Variance Explained and Reliability Estimates of the Constructs --------------- 156

Table 5.10 Correlation Matrix among Construct Scores ---------------------------------------- 159

Table 5.11 Partial Least Squares Results for the CTMP Model ------------------------------------- 161

Table 5.12 Results of Hypotheses Testing ------------------------------------------------ 163

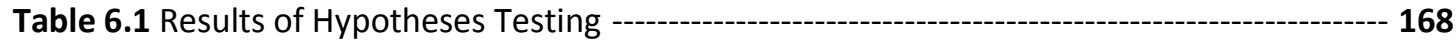

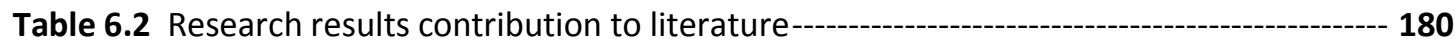




\section{List of Abbreviations}

AED - Arab Emirates Dirham

B2B - Business to Business

B2C - Business to Consumer

CTMP - Consumer Trust in Mobile Payment

C2C - Consumer to Consumer

E-Business - Electronic Business

E-Commerce - Electronic Commerce

G2C - Government to Citizen

ICT - Information Communication Technology

M-Banking - Mobile Banking

M-Business- Mobile Business

M-Commerce - Mobile Commerce

M-Payment - Mobile Payment

M-Wallet - Mobile Wallet

NFC - Near Field Communisation

PDA - Personal Digital Assistant

RFID - Radio Frequency Identification

SMS - Short Message Service

The Emirates - The United Arab Emirates

USD - United States Dollar

WAP - Wireless Application Protocol 


\section{CHAPTER ONE \\ Research Background}

\subsection{Chapter Overview}

This chapter provides the background to the research. Firstly, a general introduction is given and the motivations behind the research are explained. Then, the research justification, research questions and the methodology of the research are reviewed. Next, the methodology of the research is discussed, and, finally, an outline of the thesis is presented.

\subsection{Research Introduction and Motivation}

Some ten years ago, we have entered a new 'all mobile' era, in which mobile devices are used as phones, messaging devices, internet connections, organizers, jukeboxes, games consoles, shopping tools, and more recently, a device with mini-applications that can perform a wide variety of social and commercial interactive functions. The utilisation of mobile devices in commercial applications has led to the concept of mobile commerce. Mobile commerce (mcommerce) refers to exchanging products and services via mobile telecommunications networks, and has many applications such as mobile shopping, mobile marketing and advertising, mobile banking, mobile entertainment and others. The monetary transaction that is associated with most m-commerce transactions is the mobile payment (m-payment), which is defined as "a payment where a mobile device is used to initiate, authorize and confirm an exchange of financial value in return for goods and services" (Au \& Kauffman, 2008, p.141).

Over the last one and a half decades, these m-payments have achieved considerable commercial success worldwide. By 2010, the value of m-payments for digital and physical goods, money transfers and other mobile transactions had already reached USD 170 billion, and the scale of global m-payments is expected to rise nearly 8 times to more than USD 1.3 trillion in 2017 (Juniper Research, 2012). M-payments show huge potential and present a great opportunity. The immediacy of m-payments, along with the portability of mobile devices, makes it possible for consumers to conduct commercial transactions in many situations in a rapid and comfortable 
manner. However, in spite of its potential, literature shows that some issues are impeding the adoption of m-payments, and that trust in m-payments is one of them.

Trust in m-payments is complex and not easy to understand. It is a multi-disciplinary term, and has many facets and dimensions (Alqatan et al., 2012). Despite the remarkable development of m-payments, it seems from the literature review that more research is needed to know how consumers perceive this form of payment and, more specifically, what may influence consumer trust in m-payments. Most previous m-payments research has been undertaken from the perspective of adoption, rather than with the focus on trust. Existing studies also indicate that consumers have a lack of trust in m-payments, and that their trust needs to be developed (e.g. Alqatan et al., 2012; Corbitt \& Thanasankit, 2003; and many others ${ }^{1}$ ). In addition, many factors that influence consumer trust have been investigated in the context of m-commerce, but not specifically, for m-payments where they are likely to be more sensitive and risky transactions. The literature also indicates that m-payments have different characteristics from other electronic payment methods (such as portability, localisation and reachability) and are prone to greater risk, which may make the incident, level and strength of trust in m-payments more complicated to investigate.

Significantly, Middle Eastern Arab countries ${ }^{2}$, which are considered the second fastest growing region (after the US and Canada) in mobile and telecommunication adoption, have been experiencing m-payments services and applications since 2003 through different marketing and technological strategies (Alhosni et al., 2010). However, no sufficient level of consumer satisfaction has yet been achieved (Alhosni et al., 2010; and others), and many m-commerce applications have failed to meet consumers' expectations (Bhatti, 2008). Although several studies indicated the importance of trust for consumers to accept and use m-payments in the Middle Eastern Arab region (e.g. Alhosni et al., 2010; and others), trust in m-payments in this region has not yet been sufficiently empirically studied.

\footnotetext{
${ }^{1}$ For full references, refer to Chapter 2 (Section 2.6.2).

${ }^{2}$ Middle Eastern Arab countries include Bahrain, Iraq, Jordan, Kuwait, Lebanon, Oman, Palestine, Qatar, Saudi Arabia, Syria, United Arab Emirates, and Yemen.
} 
For these reasons, research into consumer trust in mobile payments is an area worthy of academic research. A number of practical and theoretical considerations emphasise the importance of this research, justify its focus and highlight its potential contribution to the domains of m-payments as well as consumer trust. The United Arab Emirates, a Middle Eastern Arab country, considered significant in terms of finance, economics, technology, and ethnic diversity of m-payment users was chosen as the research region.

\subsection{Justification of the Research Region}

Several empirical studies have examined consumer trust in m-commerce and m-payments in different regions in the world, such as in the United States, Japan, China, Singapore, Malaysia, and New Zealand (e.g. Amoroso \& Magnier-Watanabe, 2012; and others). With respect to the Middle Eastern and Arab countries, the sparse scholarly research (Al-Mamari, 2007; and others) has indicated trust as a significant factor in m-payments adoption, but how such trust is to be achieved and the factors influencing it have not yet been sufficiently investigated. As a result, we do not fully understand the factors that influence consumer trust in m-payments in Middle Eastern Arab countries. Therefore, the current research has filled an important gap in the literature. The research was carried out in an important country in that region; the United Arab Emirates, which was selected for several reasons:

- The Emirates was ranked in the top position among Arab countries and in the $27^{\text {th }}$ position among the 40 most advanced economies, according to The Arab World Competitiveness Report (2011) issued by the World Economic Forum. The report states that the efficient economic management has contributed to stabilizing the Emirati macroeconomic environment, and strengthening public and private institutions. It also determines that the Emirati infrastructure was positioned $8^{\text {th }}$ in the worldwide ranking in 2011, showing the country's advanced stage of financial and economic development. The UAE's overall competitiveness reflects the high quality of its infrastructure, as well as its highly efficient goods markets and inward and outward investments for the last decades. Strong macroeconomic, political and financial stability and some positive aspects of the country's institutions such as high public trust in politicians and high government efficiency, round up the list of the UAE's competitive advantages over other Arab and Middle Eastern countries. 
- The Emirates is also a technologically leading country in the Middle Eastern Arab world, and plays a central role in spreading technology to other surrounding countries. For instance, the Emirates was the first country in the region to embrace an online payment service (called CashU) in 2002, which later quickly spread and extended to customers in more than 51 countries in Arabic speaking and surrounding countries (Rouibah, 2012). In addition, the Emirates was among the first countries to adopt mobile payment services (in 2007), and to adopt other electronic services (e-services) in public and private sectors, such as e-government, e-shopping, e-learning and other e-applications in the Middle East region (Al-Mamari, 2007; Rouibah, 2012). The Emirates were then regarded as a technology hub in the Middle Eastern Arab region for adopting up-to-date technologies.

- The people in the Emirates are familiar with the m-payment concept. M-payments first appeared in the Emirates in 2007 by a major telecommunications company called Etisalat. Afterwards, several m-payment services were launched by the second telecom company called DU, and through business alliances between major financial companies, such as 'Mashreq' and 'PayMate', which resulted in the launch of an integrated mobile payment service in 2009. This reasonably early adoption of m-payment services increased awareness of m-payments among the people in the Emirates, and has helped them to understand the characteristics and functions of mobile payments. Other countries in the same region (such as Saudi Arabia, Egypt and Jordan) have a later and lower adoption level of m-payments (Alhosni et al., 2010).

- The Emirates are a diverse and multicultural society. Specifically, the ethnicity of the Emirates is made up of Emiratis (19\%), other Middle Eastern peoples (other Arabs and Iranians 29\%), South Asians (34\%), and Westerners and East Asians (18\%) (Central Intelligence Agency, 2013). This mix of backgrounds and ethnicities provides the researcher with the advantage of exploring a wider range of insights into the factors that influence consumer trust in m-payments. In addition, it may contribute to a possible generalisation of the findings of the current research to other Middle Eastern Arab countries and to general population. 


\subsection{Research Objectives and Questions}

The objectives of the current research include understanding the factors that influence consumer trust in m-payments in the Emirates, and understanding the extent to which such factors influence consumer trust in m-payments in the Emirates and in what direction. Therefore, the overarching research questions guiding this study are:

RQ1: What factors influence consumer trust in mobile payments in the Emirates?

RQ2: To what extent do such factors influence consumer trust in mobile payments in the Emirates, and in which direction?

To address these two research questions, a research approach was designed to yield a model of factors that influence Consumer Trust in Mobile Payments (CTMP) was developed. This CTMP model includes the factors found in the relevant literature, as well as those newly identified during the first methodological (qualitative) phase, and then explored and tested qualitatively and quantitatively according to their influence on trust in m-payments. The final CTMP model also shows the influencing power of the factors and the direction of their impact (positive or negative) on consumer trust. The method used in the current research is briefly set out below.

\subsection{Research Method}

A mixed method of qualitative and quantitative approaches was used for the current research. As the result of an analysis of the extant literature, a factorial CTMP model was established in synthesis of previous research. Next, this first model was validated and extended in a series of qualitative semi-structured focus group interviews to identify and re-organise the initial model from observed facts and express it as a framework of hypotheses for further analysis. An online survey was then used to collect quantitative data, which was finally analysed into a Structural Equation Model, using the Partial Least Squares (PLS-SEM) method. These methodologies are introduced briefly in this section, and then detailed more comprehensively in Chapters Three and Four.

\subsubsection{The Qualitative Method (Phase One).}

Exploratory research should be undertaken when little is known about the research issue in order to explore perceptions that could be tested later, and to validate the general propositions established from the literature analysis. The qualitative research in this phase involved a series of 
four semi-structured in-depth focus group interviews in which data was collected and analysed to explore the research objective. The focus group study was undertaken with a sample of people in the Emirates who were identified on the basis of their awareness and familiarity with mobile payments. New aspects of interest were identified from the four group sessions that were audiotaped, transcribed and analysed manually. From these findings, a revised and extended conceptual model of Consumer Trust in Mobile Payments (CTMP) was constructed.

\subsubsection{The Quantitative Method (Phase Two).}

The second phase of the research was based on the development of an online survey questionnaire which allowed for the measurement of the factors that were distilled qualitatively. The development of the survey followed a logical two-step process. In the first step, items were generated from the extant literature relating to m-payments and consumer trust. The items pertaining to factors which had been added from the qualitative research were then constructed. The second step entailed pre-testing through different techniques to assess the content and layout of the survey. By following this procedure a psychometrically sound survey instrument (constructed in both English and Arabic versions) to address the hypotheses presented in the current research was developed. The administration of the survey instrument followed a webbased self-administered method.

A comprehensive analysis of the quantitative data presented in the input-CTMP model was conducted via PLS-SEM to identify validity, reliability and path coefficients of the influence strengths and directions of the factors in the final CTMP model.

\subsection{Thesis Outline}

In the following six chapters the thesis is presented. Chapter Two builds a theoretical foundation for the study by analysing the relevant literature with the particular focus on consumer trust in mpayments studies. The key issues, and a range of factors associated with understanding consumer trust in the m-payments context, are identified and discussed. From this basis, a preliminary conceptual model of Consumer Trust in Mobile Payments (CTMP) and the general research propositions are introduced. 
Chapter Three presents the methodology and research design adopted for the study. It first justifies the choice of pragmatism as the predominant research paradigm. Then the qualitative methodology (first phase of data collection and analysis), involving exploratory semi-structured focus group interviews, is discussed. Based on the findings of the four focus group interviews, the proposed hypotheses and revised CTMP model are detailed.

Chapter Four details the methodology of the quantitative methodology (phase two of data collection and analysis) and the instrument development process. The reasons justifying the choice of an online survey are presented. A discussion of the survey design and the development process, the sampling selection procedures and the ethical consideration is provided.

Chapter Five presents the results of the data analysis for phase two. Quantitative data preparations are presented, followed by the analysis of sample profiles and respondent characteristics. This is followed by the advanced data analysis using PLS, through inner and outer measurement model testing. The results of the CTMP model testing along with supporting or non-supporting research hypotheses are demonstrated.

Chapter Six provides a detailed discussion of the important research findings, in terms of the CTMP model and research hypothesis, encompassing the perceived factors that influence consumer trust, revealed in both the qualitative phase (discussed in Chapter Three) and the quantitative phase (discussed in Chapter Five) along with the literature (Chapter Two).

Finally, Chapter Seven presents the research conclusion, and provides a number of theoretical and practical implications. Afterwards, the academic and practitioner implications, limitations of the study and suggestions for future research are presented. 


\section{CHAPTER TWO \\ Literature Review}

\subsection{Chapter Overview}

The review begins with introducing the concepts of $\mathrm{m}$-commerce and $\mathrm{m}$-payments, and explaining future expectations and challenges in this field. Then, this chapter discusses the differences between m-payments and other electronic payment methods. The second section explores the concept of trust, and describes its characteristics and types. The third section discusses trust in m-commerce, and the importance of trust in m-payments. Afterwards, section four discusses the case of trust in m-payments, why it is hard to build trust in m-payments, and most importantly, what factors influence consumer trust in mobile payments. The chapter concludes with a summary of the research gaps identified within the various components of the literature review, proposed research model and research propositions.

\subsection{Mobile Commerce}

This subsection provides details about m-commerce; its history, definition, requirements, services and applications, and the key players associated with m-commerce transactions.

\subsubsection{Brief history of mobile commerce.}

Mobile commerce first came to prominence in 1997 in Helsinki, Finland (Asif, 2011). Coca-Cola vending machines were installed that accepted monetary payments from mobile phones through the use of Short Message Service (SMS) technology (Ahmed \& More, 2011). The first mobile phone-based banking service was launched in 1997 by Merita Bank of Finland, also using SMS (Asif, 2011). In 1998, the first sales of digital content as downloads to mobile phones were made possible when the first commercial downloadable ringtones were launched in Finland by 'Radiolinja' (now part of the Finnish telecommunications company 'Elisa Oyj'). Afterwards, two major national commercial platforms for m-commerce were launched in 1999: Smart Money in the Philippines, and NTT DoCoMo's i-Mode mobile internet service in Japan (Ahmed \& More, 2011). 
The Japanese service, i-mode, was the world's most successful mobile Internet service, with over 34 million subscribers to NTT DoCoMo (MacDonald, 2003). It was a successful platform with a careful balance of technology, strategy, content and marketing. By using mobile phones, i-mode users have access to various services such as e-mail, sports results, weather forecasts, games, financial services and ticket booking (MacDonald, 2003). This service opened the doors for the mobile concept to be implemented widely in business and commercial services and applications. Subsequently, m-commerce related services spread rapidly in early 2000. Norway launched mobile parking payments, Austria offered train ticketing via mobile devices, and Japan offered mobile purchases of airline tickets (Asif, 2011).

\subsubsection{Definitions of mobile commerce.}

Mobile commerce is often called wireless electronic commerce, mobile electronic commerce, and most often m-commerce (Hsieh, 2007; Luarn \& Lin, 2005; Tarasewich et al., 2001). Mcommerce can have many definitions from various perspectives. Yen and Lancaster (2008, p. 18) define m-commerce as "the ability to conduct electronic commerce transactions over wireless media". In accordance with this definition, many authors categorise m-commerce as a subset of electronic commerce, enabled by wireless communication (Buckler \& Buxel, 1999; Deitel, 2002; Huang, Wang, \& Day, 2007; Turban, king, Warkentin, \& Chung, 2008; Varshney \& Vetter, 2002). With respect to processes and devices, m-commerce is defined as "the promotion, buying, and selling of goods and services through electronic data communication networks that interface with wireless (or mobile) devices" (Tarasewich et al., 2001, p. 435). This can be conducted through an agreement between the buyer and the seller on an item, price, delivery and payment through a wireless device (Yen \& Lancaster, 2008).

However, m-commerce is a relatively new concept evolving with time, and it has several definitions that could be interpreted in a variety of ways. Some common elements in the mcommerce definitions which found in the literature are: electronic commercial transactions, wireless communication networks, mobile devices, exchanging goods and services, and wireless handheld devices. There is consensus that the medium used to conduct m-commerce transactions is wireless networks, through the use of wireless mobile devices (handheld devices, such as Smart phones and tablets). However, some definitions are general and perhaps more suitable for the concept of mobile business, while others could better suit some parts of the m-commerce 
transaction (the payment part). For instance, the definitions given by Turban et al. (2008) and Cronin (2003) suit the term mobile business (m-business) better than suiting the term $\mathrm{m}$ commerce. Turban et al. (2008) define m-commerce as 'any business activity', and Cronin (2003) defines m-commerce as 'all data-driven business transactions'. Although the terms business and commerce are used interchangeably, they are distinct concepts. The term business is more general and broad than the term commerce (Andam, 2003; Turban et al., 2008), which refers to all activities undertaken by a firm in order to produce and sell goods and services. Activities such as manufacturing, production, monitoring, human resources management and internal management processes are considered as business related activities rather than commercial activities (Andam, 2003; Tiwari, Buse, \& Herstatt, C., 2006). The term commerce is usually associated with buying and selling and exchanging goods and services (inter-organisational activities), the term business extends this to include intra-organisational activities (e.g. transforming organizations' processes) and other external activities (collaborating with business partners) (Andam, 2003; Turban et al., 2008).

Scornavacca, Barnes and Huff (2005) define m-business as the use of mobile information technologies, including wireless internet, for organisational communication and coordination, as well as management of the firm. This definition makes it clear that $\mathrm{m}$-business is not exclusively for exchanging goods and products, as commerce is often defined, but in a broader sense, encompasses organisational communication, coordination, and management, in addition to commercial transactions. Therefore, m-business represents all business processes that enable a company to service an m-commerce transaction. Accordingly, the researcher considers mcommerce as a subset of m-business.

In sum, the definition of m-commerce considered appropriate for this research follows the OECD's (2008) description since it comprises various sources about the nature of m-commerce. Thus, m-commerce is defined as "commercial transactions and communication activities conducted through wireless communication services and networks by means of short message services, multimedia messaging services, or the Internet, using small, handheld mobile devices that typically have been used for telephonic communications" (OECD, 2008, p. 2). 


\subsubsection{M-commerce and e-commerce.}

As mentioned earlier, m-commerce is most often understood as 'mobile e-commerce'. Hsieh (2007) and Tarasewich et al. (2001) argue that m-commerce represents a subset of all ecommerce, including both B2C and B2B (Business-to-Business). In addition, Moshin, Mudtadir and Ishaq (2003) state that m-commerce is regarded as e-commerce over wireless devices (see also Luarn \& Lin, 2005; Varshney \& Vetter, 2002; Yen \& Lancaster, 2008). Following many studies in the literature, m-commerce has the same characteristics and business models of ecommerce, and few of its own. However, m-commerce can also be considered beyond the scope of e-commerce subsets (Barnes, 2002). Feng et al. (2006) suggest that m-commerce implies more than e-commerce due to its different interaction style, usage pattern and value chain. The latter authors argue that $\mathrm{m}$-commerce is a new and innovative business opportunity with its own unique characteristics and functions, such as mobility and broad reachability. Zhang \& Yuan (2002) outlined differences between e-commerce and m-commerce, by studying three dimensions: technology, nature of the services, and business models.

Whereas it is agreed that m-commerce is viewed as a subset of e-commerce, there are certain differences in some technological components. The interaction style in m-commerce, for instance, is different due to the constraints of terminal devices, and the usage patterns differ from those of traditional desktop computers, however, the services offered in both variations are handled electronically by computer-mediated networks and are accessible via telecommunications networks (Tiwari, Husain, Srivastava, \& Singh, 2011). Therefore, it is argued that m-commerce is closely related to e-commerce, and is one of its subsets. Figure 2.1 helps to illustrate the relationships between the concepts of m-commerce and e-commerce, and how they are related to the terms e-business and mobile m-business in this study. 


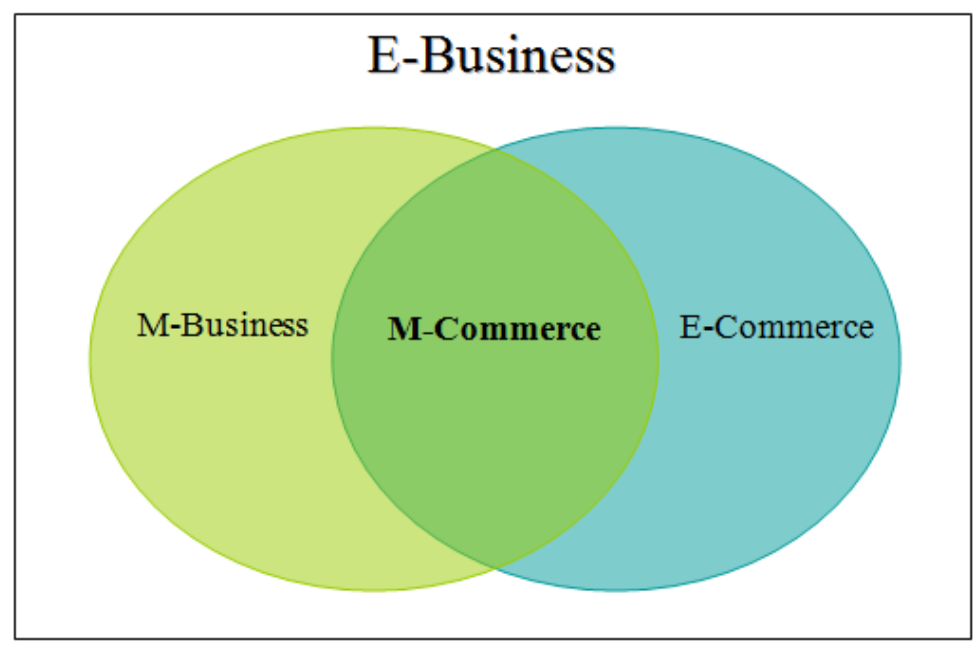

Figure 2.1 The Relationships amongst Electronic and Mobile Business and Commerce

As shown in Figure 2.1, the term e-business is a broad and general concept that comprises ecommerce and other business models (e.g. collaborating electronically with business partners, and managing personnel affairs). M-business can be characterized as a division of electronic business (e-business) that uses mobile devices. In addition to web-based extensions and business enterprise and computer-based solutions, mobile phone/handheld terminal-based solutions are used to improve business productivity and performance. Combining e-business and mobility produces m-business. Using a mobile device to conduct a commercial business transaction leads to the term m-commerce. Therefore, m-commerce belongs to e-commerce through the usage of mobile devices, and belongs to m-business specific by conducting commercial transactions, all under the e-business 'umbrella'. Specifically, the m-commerce area is an intersection of the two areas: e-commerce and m-business. All three areas are subsets of the e-business field.

In general, m-commerce represents the subset of internet and e-commerce beyond the static infrastructure of personal computers and fixed networks into a more flexible anytime and anywhere context (Hsieh, 2007; Huang et al., 2007). M-commerce has the following advantages over traditional e-commerce:

1) Portability. Mobile devices, owing to their light weight and small size, are able to be readily carried for long periods of time (Junglas \& Watson, 2006). This characteristic makes mcommerce transactions more convenient than e-commerce transactions as users do not have 
to be physically in front of desktop computers, and can use opportunities for instant decisions for purchases while they are shopping (Goode, 2006; Hsieh, 2007).

2) Accessibility. A user can conduct an m-commerce transaction on an almost anytime and anywhere basis. (Cook \& Goette, 2006; Hsieh, 2007; Tarasewich, Nickerson, \& Warkentin, 2002). Junglas and Watson (2006) adds that the principle of anytime and anywhere accessibility is possible "assuming that the mobile network coverage is sufficient" (p. 574). Users have the opportunity to do shopping, pay bills and invoices, and exchange credit and digital money without being limited to the plug-in level of e-commerce transactions (Junglas \& Watson, 2006). This helps users of mobile devices to engage in activities such as receiving information and conducting commercial transactions with ease and greater flexibility (Andreou et al., 2001; Goode, 2006).

3) Localisation. Localisation is the ability to locate the position of a mobile person (Junglas \& Watson, 2006). Mobile users should have access to local information and services. This can be accomplished by having service providers know the location of mobile users in order to promote their products and services directly to their consumers in a local environment (Andreou et al., 2001). These services, called 'location-based services', may include geographic information about the individual himself/herself or location information about the other parties contacted (Junglas \& Watson, 2006). Localisation is essential when providing geographically specific value-added services, and is expected to be the most distinct characteristic of m-commerce compared to e-commerce (Junglas \& Watson, 2006).

4) Reachability. A person can be in touch with and reached by other people or business entities 24 hours per day, 7 days per week, assuming that mobile network coverage is adequate and the mobile device is switched on (Junglas \& Watson, 2006; Liang, Huang, Yeh, \& Lin, 2007). The user might also limit his/her reachability to particular persons or at particular times. This characteristic enables mobile users to be connected permanently, without explicitly establishing a connection, unlike the settings of e-commerce, where reachability is limited to the computer level or the plug-in level (Junglas \& Watson, 2006).

Many researchers and academic scholars expect that wireless and m-commerce will be the next phase of e-business growth (Hsieh, 2007; Matthew, Sarker, Varshney, 2004; Ngai \& Gunasekaran, 2007; Urbaczewskj, Valacich, \& Jessup, 2003), and anticipate that m-commerce is 
expected to drive fundamental changes in the way commerce is conducted in many aspects of its applications and services (Hsieh, 2007). However, m-commerce also has drawbacks or disadvantages that need to be addressed. These are summarised in the following points:

1) Compared to desktop terminals, mobile devices have low resolution graphics and the screen size is smaller. This may limit the complexity of the application and the interaction with users (Cook \& Goette, 2006; Siau \& Shen, 2003). Battery life is short on mobile and wireless handheld devices (Cook \& Goette, 2006; Siau \& Shen, 2003; Tarasewich et al., 2002). This could put certain 'time pressure' on consumers, so that they are forced to complete their transactions quickly to avoid disconnection (Andreou et al., 2001).

2) The technical limitations of the network services. For instance, connectivity, bandwidth, high cost and non-standardised protocols are technical barriers for adopting $\mathrm{m}$-commerce transactions. (Cook \& Goette, 2006; Siau \& Shen, 2003; Tarasewich et al., 2002; Park \& SuJin, 2006). The limitation of connectivity can limit the absolute 'anywhere' and 'anytime' characteristics argued by Hsieh (2007) and Cook and Goette (2006). This limitation becomes a concern especially when mobile users move into an area with poor or no coverage during the transaction, or become exposed to signal transmission interruptions in the same connecting area.

Limitations related to the technology of mobile devices are being addressed through the development of new generations of mobile phones and their technologies, but the technical barriers are still hard to deal with. Technological and technical limitations aside, perhaps another significant challenge is about achieving consumers' trust in the m-commerce technology and wireless environment.

\subsubsection{M-commerce services and applications.}

Mobile devices enable products and services to be offered directly to an "individual's pocket" (Hsieh, 2007, p. 95). The major m-commerce applications, according to Tiwari et al. (2006), include mobile shopping (mobile purchasing of goods and services), mobile ticketing (for public transportation, parking, air and rail traffic, sport and cultural events), mobile marketing (direct marketing, announcing for organisational events, mobile couponing), mobile information services (mobile newsletters, tracking services), mobile banking, and mobile entertainment (downloading music, videos, digital images, or location-based games services). Additional m- 
commerce applications are suggested by $\mathrm{Hu}$, Lee, \& Yeh, (2004), such as mobile ERP (Enterprise Resource Planning) activities.

\subsubsection{Requirements of m-commerce.}

Some components are required in order to conduct an m-commerce transaction. These components are wireless networks, wireless devices, and communication infrastructure. A wireless network is defined as a number of nodes/devices that communicate with each other over a wireless channel (Gupta \& Kumar, 2000). Some wireless networks have a wired backbone with only the last node being wireless (Gupta \& Kumar, 2000). The wireless devices (also called terminals) should have the ability to deal with wireless networks. These wireless devices could be cellular phones, smart phones, laptops, palmtops, handhelds, PDAs, vehicle-mounted technologies, and others (Hsieh, 2007; Tarasewich et al., 2001). All of these are considered mobile devices. With regard to laptop computers, these could be considered wireless and mobile devices, but, due to their relatively larger sizes, they may not be useful for conducting mcommerce transactions, especially ones that are conducted instantly while shopping in a conventional, literal sense and performing transactions.

Another category is the communication infrastructure, which enables m-commerce devices and applications to work in practice. The communication infrastructure includes services, technologies and wireless protocols. SMS and Wireless Application Protocol (WAP) have been "the most popular mobile services that enable most of the m-commerce applications today" (Hsieh, 2007, p. 88). SMS provides users with the ability to send and receive text messages to and from their mobile phones. WAP is an open framework for presenting information and delivering internet content and applications to wireless handheld mobile devices. WAP also provides protocol translation and optimizes data transfer to and from the wireless devices (Hsieh, 2007). Other communicational technologies such as infrared and Bluetooth can be used for light data transfer and exchange between mobile devices.

\subsubsection{Key players in m-commerce.}

A telecommunications company is usually the service provider for $\mathrm{m}$-commerce technologies and applications (including the wireless networks and communication infrastructure). A bank or a financial institution could have a major role if a consumer's bank accounts and credit cards are part of the transaction. A third party such as a governmental agency could be an optional entity. 
Adding the consumer and the merchant as the main entities, the mentioned parties are basically the ones who are involved in conducting an m-commerce transaction. However, the involvement of each player differs by the application and the type of m-payment. For instance, some B2C transactions may not require a bank's involvement to conduct a micro m-payment for car parking. As another example, there is no merchant role in governmental m-payment services offered to citizens.

\subsection{Mobile Payments}

The m-payment system is a significant component of an m-commerce service, because it makes an m-commerce transaction possible by dealing with the exchange of the financial values of mobile transactions. The term m-payments also share some characteristics with other electronic payments in using an electronic device to conduct a financial transaction on order to complete a commercial process. Thus, m-payments have common denominators among $\mathrm{m}$-commerce and epayments, as illustrated in figure 2.2

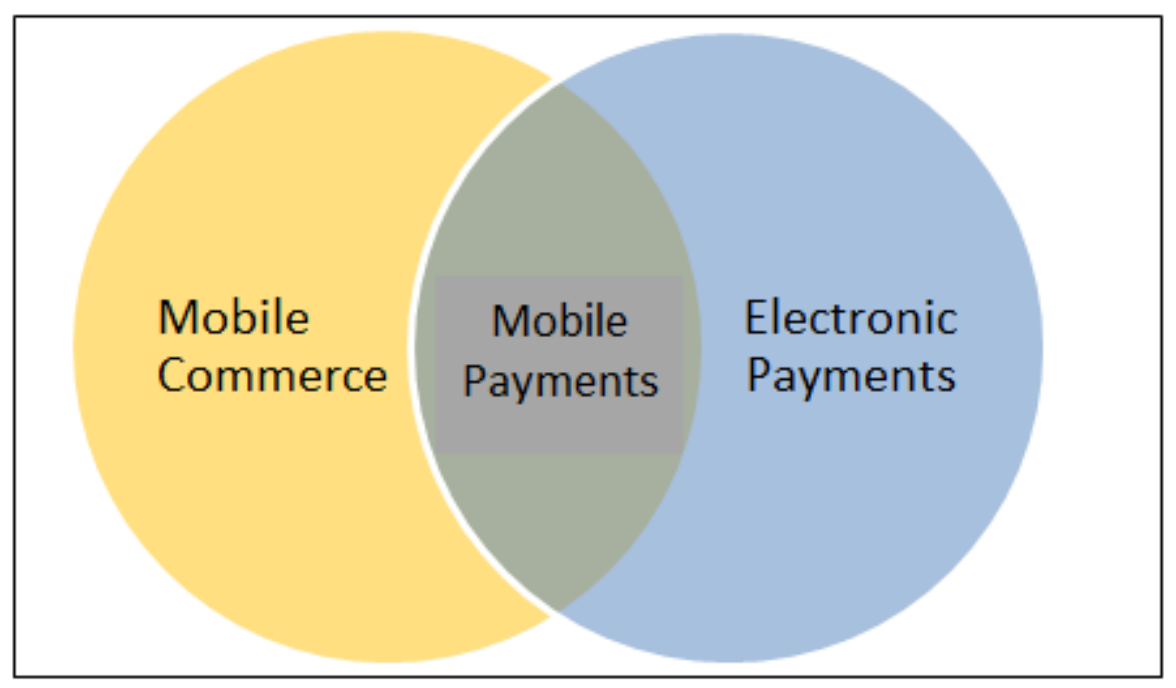

Figure 2.2 The Relationships amongst E-Payments, M-Commerce and M-Payments

Further details about m-payments; including types, processes and characteristics of m-payments are included in the subsequent sections. 


\subsubsection{Definitions of mobile payments.}

The term m-payment is less contentious than the term m-commerce. Several definitions illustrate that m-payments are financial transactions that are conducted by mobile devices to exchange products and services. According to Au and Kauffman (2008, p. 141), an m-payment is "any payment where a mobile device is used to initiate, authorise and confirm an exchange of financial value in return for goods and services". Similarly, Karnouskos (2004), followed by Carr (2008), argue that "any payment where a mobile device is used in order to initiate, activate, and/or confirm this payment can be considered a mobile payment" (p. 44). Apart from describing the processes of conducting an m-payment, simple definitions given by Tiwari et al. (2006) and Dahlberg, Mallat, Ondrus, \& Zmijewska, (2008) show m-payments as payments for goods, services and bills with a mobile device (such as a mobile phone, smartphone, or PDA). The previous definitions highlight the mobile device and exchanging values as the main elements of an m-payment. For this research, the definition given by Au and Kauffman (2008, p. 141) is followed. Thus, an m-payment is defined as "payment where a mobile device is used to initiate, authorize and confirm an exchange of financial value in return for goods and services". This definition gives a clear view of m-payments, and provides a comprehensive understanding of this concept.

\subsubsection{Processes of a mobile payment.}

The definitions given by Kauffman (2008) and Karnouskos (2004) illustrate three main processes to conduct an m-payment: initiation, authorisation and confirmation. Vatsavayi and Mukkamala (2008) extend these processes to include payment submissions and authentication. In sum, the main processes for conducting an m-payment transaction, (Vatsavayi \& Mukkamala, 2008), are:

1) Registration. This is offered to consumers by the service provider.

2) Payment submission. This is done through the mobile device after selecting goods or services.

3) Authentication. The merchant authenticates the consumer.

4) Authorisation. The service provider sends authorization information to the merchant.

5) Confirmation. A message is sent to the consumer informing him/her that the transaction is completed. 
However, the process of conducting an m-payment could be more complex and include more steps, depending on the number of parties that are involved. Buhan, Cheong and Tan (2002) proposed the phases of conducting an m-payment, where four main parties are engaged: the consumer, the content provider (the vendor), the payment service provider (e.g. a telecom company) and a trusted third party (e.g. a bank). These processes are illustrated in Figure 2.3.

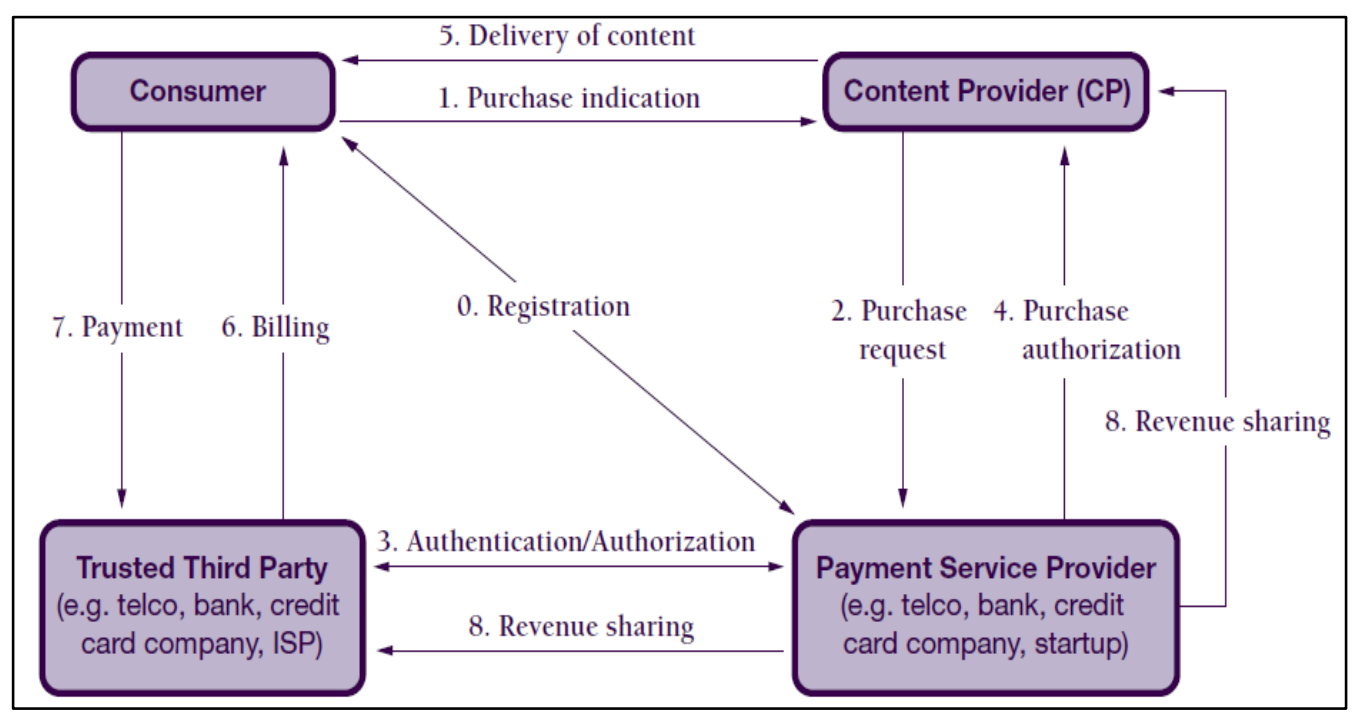

Figure 2.3 Processes of Mobile Payment (Buhan et al., 2002, p. 10)

The first five steps of the payment process proposed by Buhan et al. (2002) are similar to the ones proposed by Vatsavayi and Mukkamala (2008). However, Buhan et al. (2008) extend the processes that come after delivering the sold content: by ensuring the payment is checked by a trusted third party and sharing the revenue between the three involved parties. Overall, the researcher believes that the main processes required to conduct an m-payment are the five suggested by Vatsavayi and Mukkamala (2008), whereas the model of Buhan et al. (2002) includes a few extra optional processes.

\subsubsection{Types of m-payments.}

M-payment systems differ according to payment amount, payment place, parties involved, payment technology used and other criteria. For example, m-payments, like other electronic payments, could be categorised as B2C, B2B, C2C (Consumer-to-Consumer), or under another classification. In terms of finance, m-payments could be prepaid (debit) through which consumers pay in advance to obtain the service they desire, or it could be post-paid (credit) when 
consumers receive the desired service before paying. An m-payment could also be a micro or macro payment, based on the amount of money it holds. There are also several transactional types of m-payment: Pay Per View (PPV), Pay Per Unit (PPU), and recurrent subscription. PPV type is used when a consumer pays once for each view or increment of the desired service (e.g. paying a bill via a mobile device), where PPU is considered when the consumer pays once for each successfully completed unit (time or volume) of the desired service (e.g. purchasing timeduration-access to a mobile online game) (Buhan et al., 2002). Recurrent subscription payment is involved when the consumer pays a recurring amount to access a service on an unlimited basis during a period of time (Buhan et al., 2002).

In terms of the payment method, m-payments could be conducted 'contactless', which is enabled by NFC (Near Field Communications) technology. This method of payment is transacted when a consumer opens an application or electronic wallet and waves the smartphone near a receiver terminal or device. Some examples of the contactless m-payment approach are Google Wallet, VISA V.me, and MasterCard PayPass. Another approach is centred on migrating m-payment from offline to online through the protocol WAP (Wireless Access Protocol). Another type is SMS m-payments, through which the consumer sends a payment request via an SMS text message to a short code and a premium charge is applied to their phone bill or their online wallet. The merchant involved is then informed of the successful payment and can then release the goods paid for (popular for delivering digital music, ringtones, wallpapers, or purchasing from vending machines). Further categories and types of m-payment are shown in Table 2.1. 
Table 2.1 Categories of the Types of Mobile Payment (Adapted from Goode (2006) and Vatsavayi \& Mukkamala (2008))

\begin{tabular}{|c|c|c|c|c|}
\hline Category & Type 1 & Type 2 & Type 3 & Type 4 \\
\hline Money model & Token based & Notational (cash) & & \\
\hline Proximity & Remote payments & Local payments & & \\
\hline Time & Pre-paid & Pay-now & Post-pay & \\
\hline Seller/Buyer & $\mathrm{P} 2 \mathrm{P} / \mathrm{C} 2 \mathrm{C}$ & B2C & $\mathrm{B} 2 \mathrm{~B}$ & G2C \\
\hline $\begin{array}{c}\text { Clearing and } \\
\text { settlement }\end{array}$ & Bilateral & Multilateral & $\begin{array}{c}\text { Using } \\
\text { Intermediaries }\end{array}$ & \\
\hline $\begin{array}{c}\text { Mode of } \\
\text { registration }\end{array}$ & $\begin{array}{c}\text { Registration } \\
\text { required }\end{array}$ & $\begin{array}{l}\text { Registration not } \\
\text { required }\end{array}$ & & \\
\hline $\begin{array}{c}\text { Type of } \\
\text { transaction } \\
\end{array}$ & Pay Per View (PPV) & $\begin{array}{c}\text { Pay per unit } \\
(\text { PPU) }\end{array}$ & $\begin{array}{c}\text { Recurrent } \\
\text { Subscription }\end{array}$ & \\
\hline Payment size & Pico-payment & Micro-payment & Macro-payment & \\
\hline $\begin{array}{l}\text { Validation } \\
\text { payment }\end{array}$ & $\begin{array}{c}\text { Online validation } \\
\text { (Web-based) }\end{array}$ & $\begin{array}{c}\text { Offline } \\
\text { validation }\end{array}$ & $\begin{array}{l}\text { Semi-online } \\
\text { validation }\end{array}$ & \\
\hline $\begin{array}{l}\text { Technology } \\
\text { used (Model) }\end{array}$ & $\begin{array}{c}\text { SMS (Short Test } \\
\text { Messaging) }\end{array}$ & $\begin{array}{c}\text { Contactless } \\
\text { (NFC, RFID, } \\
\text { FeliCa) } \\
\end{array}$ & $\begin{array}{l}\text { Smartphone } \\
\text { Application }\end{array}$ & $\begin{array}{c}\text { WAP (Wireless } \\
\text { Access Protocols) }\end{array}$ \\
\hline
\end{tabular}

There is no specific characteristic or type of m-payment that this research attempts to address. However, the cell entries in bold are the characteristics that have been seen as the most prevalent and consistent with the characteristics of the m-payment services discussed in the literature, and offered in many countries, including the Emirates.

\subsubsection{M-payments in developing and developed countries (examples and statistics).}

M-payment services are expected to have a huge potential worldwide in the near future. According to the Juniper Research report in August 2012, the value of m-payments for digital and physical goods, money transfers and other mobile transactions had already reached USD 170 billion by 2010 (Juniper Research, 2012). The same study specified that the top three regions for m-payments are: Far East \& China, Western Europe and North America. The Middle East and Africa, according to the study, are also expected to be important future mobile markets, since the need for mobile financial services is increasing, especially in their remote areas. The report also noted the growing importance of the mobile device as a means of enabling both domestic and international money transfer, although it stressed that in many markets service adoption was being inhibited by national regulatory requirements and by a lack of interoperability between services. However, the cited figures allude to the opportunity that m-commerce presents. Though 
in their infancy, m-payment services are already paving the way for the increasingly dynamic, value-rich services of the future and the consumer market that will follow (VeriSign, 2007).

M-payment systems are available locally and internationally, in both developed and developing countries. In developed countries, for instance, 'Vodaphone M-Pay Bill' internationally supports virtual point-of-sale (POS) for micro and small payments. Another example is 'TextPayMe' which allows person-to-person payments from mobile phones and web browsers in the US. In the UK and Germany, the service 'LUUP' allows consumers to use their mobile phone like a wallet to shop with retailers. The Japanese service ' $\mathrm{i}$-Mode', which is provided by the pioneer and the largest network provider in Japan, allows access to various financial, social and entertainment services, such as e-mail, sports results, weather forecasts, games and ticket booking (Vatsavayi \& Mukkamala, 2008).

M-payment systems are also widely offered in developing countries. For instance, two mpayment SMS-based services 'G-Cash' and 'Smart Money' have been provided by the Philippines' two largest GSM companies since 2004 (Vatsavayi \& Mukkamala, 2008). Other similar m-payment services are offered in the Democratic Republic of the Congo (Donner, 2007). Interestingly, a highly successful m-payment service called M-PESA that has been launched in Kenya in 2007 by Safaricom is now used by over 17 million Kenyans, equating to more than two-thirds of the adult population (The Economist, 2014). M-PESA lets people transfer cash using their phones and allows microfinance loan repayments to be made by phone, reducing the costs associated with handling cash and thus making possible lower interest rates. The M-PESA service has been viewed by market evaluators as the world leader in the mobile money sector (The Economist, 2014) due to: its low cost, being the dominant market share, clear and effective marketing campaigns, operating an efficient system to move cash among clients, and most intriguingly, due to certain political issues. Adoption of M-PESA has started to be seen in other countries; including Tanzania, Afghanistan and India. Some developing countries in the Arab world have recently offered various m-payments services, such as in Egypt, Saudi Arabia, Jordan, Kuwait, Oman, and the Emirates (Alhusni et al., 2010; Al-Mamari, 2007; Manochehri \& AlHinai, 2008; Rouibah, 2007). The subsequent sections discuss in details the case of m-payments in the Middle East and Arab countries in general, and in the Emirates specifically. 


\subsubsection{M-payments in the Middle East and Arab countries.}

In its early stages, the mobile market in this region had been mostly characterized as monopolistic where mobile operators benefited from the relative lack of competition and were able to achieve impressive revenues (Rouibah, 2008). There had also been limited coordination between private and public sectors to provide m-commerce services. However, many Middle Eastern countries have recently been starting to open their mobile markets to new operators to create more mature markets (Alhosni et al., 2010). For instance, in 2012, PayPal partnered with Aramex to launch its operations in the Middle East (Farhat, 2014). Farhat (2014) also stated that in the same year, an m-payment company called MOBIbucks partnered with Middle East payment services to bring the service to Lebanon, Jordan, Iraq, and the Emirates. The same reference mentioned that in 2011, McDonald's in Kuwait partnered with mobile payment app SEQR to allow customers to pay using their mobile phones. Overall, a shift in the m-commerce market in the Middle East has been noted over the last few years, resulting in considering region as the second fastest growing region, after the US and Canada, in mobile and telecommunication adoption (Alhosni et al., 2010).

In general, it seems that the infrastructure and the technology of m-payments are very similar worldwide. In comparing the technology of m-payments in Europe (Pousttchi, 2004), Japan, South Korea, and the United States (Bradford, 2007), and in India (Kumar, Martin, \& O’Neill, 2011) with the Middle Eastern context (Alhosni et al., 2010), the main differences noticed are related to the adoption trend, and the extent of collaboration between telecom operators and financial institutions. Likewise, several studies found and indicated that the infrastructure of $\mathrm{m}$ commerce and m-payments is similar for all nations where the differences occurred in the people profiles (Alhosni et al., 2010; Al-Mamari, 2007; Dai \& Palvia, 2009; Rouibah, 2012). The main players (merchant, telecom company, bank, and others), scenarios (classifications of transactions such as B2C, B2B, etc.), technologies and methods (contactless, SMS, smartphone applications, and WAP), and m-payments applications in the Middle East would not seem different than the general case in other regions. In addition, the same telecom operator may provide m-payment services in many developing and developed countries, such as Vodafone and Telefónica, and deploy almost identical m-payment services and applications (e.g. 'Ingenico' m-payments which 
is available in over 70 developing and developed countries worldwide, and the PayPal mpayment application which is used worldwide).

However, m-payments are not widely accepted by consumers in Middle Eastern Arab countries (Gouda, 2014; Khidhir, 2014). Although m-payments have been adopted for several years in the region, Cash-on-delivery enjoys the lion's share in the growing e-commerce and m-commerce markets, according to the report issued by the German secondary research organization yStats.com (The PAYPERS, 2014). A further point to consider is the preference of many Arab people to deal face-to-face when building trust (Hill et al., 1998). In addition, Arab people in the Middle East prefer traditional and more personal ways of communication, and they are characterised as less self-confident in ICT (Information Communication Technology), perhaps because of limited capabilities, lack of resources, and insufficient training for advance technology (Alhosni et al., 2010).

In summary, Arab countries in the Middle East have been experiencing m-payments services and applications for several years through different strategies, but no sufficient level of consumer satisfaction has yet been achieved (Alhosni et al., 2010; Khidhir, 2014). Alhosni et al. (2010) theoretically argue that one of the top five causes of users' dissatisfaction with m-commerce and $\mathrm{m}$-payments in the region is that being perceived as unreliable services, which could significantly affect the adoption of such services. Therefore, m-payment opportunities to success can be very significant if service providers and technology developers understand consumers very closely. By achieving this, they would be able to develop m-payment services that would be trustworthy, especially in the Middle East in general, and specifically in the Emirates, where m-payments are still not widely used (Khidhir, 2014). Such studies around consumer trust are thus considered relevant in terms of identifying which factors contribute to achieving trust and intention to use m-payments, as it is a recent technology in Middle Eastern Arab countries (Rouibah, 2012). Details about m-payments in the Emirates are given in next section.

\subsubsection{M-payments in the Emirates.}

There is significant potential for m-commerce initiatives in the Emirates. According to Khidhir (2014), the country recorded the highest mobile phone prevalence rate in the world at nearly $193 \%$, while smartphone usage rate reaches $78 \%$. This is due to the trend of rising multi-SIM 
ownership where subscribers attempt to gain special offers and different deals (Han-fen, 2010). Characteristics of the m-payment market in the Emirates could be described through the following observations:

(a) The mostly adopted technologies are SMS and WAP, rather than contactless using NFC.

(b) M-payments are often used for micropayments.

(c) The dominant scenarios are G2C and informal C2C, rather than other classifications such as $\mathrm{B} 2 \mathrm{~B}, \mathrm{~B} 2 \mathrm{C}$, or point of sale m-payments.

Many m-payment services and applications are currently available in the country, first appearing in 2007 (as previously indicated in section 1.3). For instance, governmental e-services for paying bills for electricity and water are widespread in the main cities, such as in Dubai (service called DEWA), Abu Dhabi (ADEWA), Sharjah (SEWA) and others. Traffic departments in Dubai and Abu Dhabi have enabled m-payments services for road toll services (SALIK) and car parks (MAWAQEF). Other governmental m-payment services include immigration payments and court fee payments. There are also some commercial m-payment applications offered in the Emirates such as that offered by Etihad Airlines and Emirates Airlines in the form of mobile applications for ticket payments and air bookings. In addition, mobile shopping applications are also available (provided by 'Carrefour' and 'Lulu' hypermarkets), and cinema tickets provided by Grand Cinema.

In addition, several m-payment services have recently been launched in the Emirates, while others are to be launched in the near future. For instance, Etisalat, the largest telecommunications operator and the first found in the Emirates, has an m-payment service called 'Mobile Pay', which allows subscribers to register their credit card with Etisalat mobile online services, in order to pay their Etisalat bills. Etisalat and WireCard (a global leader in payment innovations) launched an NFC interface in 2012 to facilitate contactless payments via Smartphone. Emirates NBD (National Bank of Dubai) too, by partnering with Etisalat and Visa, launched a nextgeneration m-payments solution in 2012, called 'MoneyMobile'. MoneyMobile is a contactless payment solution that will enable consumers to pay for purchases with a single wave of their contactless mobile device. 
More recent projects including Etisalat's agreements with Dubai for mobile government payments in 2013 as well as the telecom company's partnerships with MasterCard and Research in Motion (RIM) complement Abu Dhabi Commercial Bank's P2P venture with Mobibucks, a US company (MasterCard, 2012). The second largest telecommunications operator in the Emirates, DU Company provides m-payment services for subscribers to pay for post-paid and pre-paid plans. Several m-payment projects are expected to take place in the near future. For instance, NFC-enabled smartphones sold by Etisalat will come with a NFC-enabled SIM card. Existing consumers will be able to update their cards in stores. In addition, Etisalat is aiming to extend its future mobile wallet service beyond payments to include couponing and loyalty solutions.

Despite the availability of m-payment services worldwide, reports show that potential users may not be using these systems (Carat, 2002; Rouibah, 2009; Venkatesh \& Davis, 2000). The same circumstances are applicable in the Emirates, where many consumers do not make m-payments, indicating that the country relies heavily on card payments and cash transactions (Alhosni et al., 2010; Khidhir, 2014). In general, m-payments in developing and developed countries have been transacted successfully without experiencing serious technical problems that result in financial losses, and this is indicated by the huge volume of funds transferred through these systems (see section 2.2.4.). Dahlberg et al. (2008), Rouibah (2009) and other researchers suggest that further studies need to be conducted to draw attention to the factors that attract consumers, merchants and banks, and make m-payments more acceptable and trustworthy to them. The current research therefore attempts to fill this important gap, particularly in view of the fact that existing studies have not included the Middle Eastern Arab region, which is an emerging player in the global mpayment market. Trust in m-payments in this region is a focused research area that is considered fertile ground for further study. One of the obstacles faced in this regard in the current research is the rarity of sources and limited number of studies conducted (theoretical rather than empirical).

The subsequent sections highlight the 'trust' concept, discuss trust as an important factor in influencing consumer acceptance and usage of m-payments systems, and factors that influence consumer trust in m-payments. 


\subsection{Trust}

Trust is fundamental when it comes to dealing with one another. Good relationships require a high level of trust. This section introduces the concept of trust and its characteristics from various points of view.

\subsubsection{What does trust mean?}

Although the trust concept is used frequently in our daily life, it is not easy to define because it is a complex concept that can have many meanings, dimensions and facets (McKnight \& Chervany, 2001b). Furthermore, trust is a multi-disciplinary term; it has been researched in various domains: psychology, management, communication, sociology, economics and political science (McKnight \& Chervany, 2001a). Psychologists see trust as a personal attribute. Sociologists view it as a social structure, whereas economists perceive trust as a mechanism of an economic choice (Lewicki, 2006). Scholars in one discipline may not agree with the view of trust held in other disciplines. For instance, Lewis and Weigert (1985) are sociologists who argue that trust cannot be reduced to certain personal attributes, as argued by psychologists. Thus, trust definitions differ among disciplines, which in turn increase the difficulty of defining it precisely and accurately.

It is important to have a comprehensive understanding of the trust concept. More than 60 years of systematic research on trust in organisations has been conducted to date. In the early stages, scholars associated trust with individuals' perceptions of confidence in others' intentions and motives (Mellinger, 1956; Read, 1962). For instance, Mellinger (1956) defined trust as an individual's confidence in another person's intentions and motives, and the sincerity of that person's word. Read (1962) extends Mellinger's understanding of trust, arguing that individuals who place trust in others require their interests to be supported by those they trust and feel confident about sharing and disclosing full and frank personal information.

More recent trust research focuses on understanding the efficiencies of trust and explaining its emergence. For example, trust "indicates a positive belief about the perceived reliability of, dependability of, and confidence in a person, object, or process" (Araujo \& Araujo, 2003, p. 3), cited in Rempel, Holmes, \& Zanna (1985) and Rotter (1980)). In a more detailed description of trust, it is "the willingness of a party to be vulnerable to the actions of another party based on the 
expectation that the other will perform a particular action important to the trustor, irrespective of the ability to monitor or control that other party" (Mayer, Davis, \& Schoorman, 1995, p. 712). From the previous definitions, some implicit elements that are related to trust can be noticed, such as belief, reliability, confidence, sincerity, ability, vulnerability, and expectations.

Other terms, found in literature related to trust in e-commerce (which can inform m-commerce) could be added to the previous elements: perceived security and a risky situation. A feeling of security means that one feels safe, assured and comfortable (not fearful or anxious) about depending on the trustee (Lewis \& Weigert, 1985; Rempel, 1985). A risky situation means that there is a possibility of negative consequences in unfamiliar or uncertain situations (Fung \& Lee, 1999; McKnight \& Chervany, 2001). Trust involves uncertainty and risk in that there can be no guarantee that the trustee will live up to the trustor's expectation (Siau \& Shen, 2003). McKnight \& Chervany (2001) recommend adding the phrase "with a feeling of relative security in a situation of risk" to one's trust definition (p. 45). However, although security and risk are strongly related to the trust concept, "trust is not taking risk per se, but rather it is a willingness to take risk" (Mayer et al., 1995, p. 712). Thus, adding this phrase to a trust definition could be meaningful if trust is defined in a certain threatening situation, not to a general trust definition.

Overall, trust is established between two parties: a trustor and a trustee, and is based on honesty and benevolence in order to achieve a mutual benefit. By bringing trust to the commerce arena, the trustor will be the consumer, while the trustee will be the merchant. Trust could be defined as a state which involves a consumer's confident positive expectations about a merchant's attitude in situations entailing risk (Boon \& Holmes, 1991). In other words, trust is conceptualised as a set of consumer beliefs and perceptions about a merchant's characteristics and behaviour with respect to abilities, benevolence and integrity (Bhattacherjee, 2002; Gefen, Karahanna, \& Straub, 2003; Jarvenpaa, Tractinsky, \& Vitale, 2000). In addition to transaction parties, the mediating technology, such as mobile devices and networks, is another object of trust between consumers and sellers (Grabner-Kräuter \& Kaluscha, 2003; Jarvenpaa et al., 2000; McKnight, Kacmar, \& Choudhury, 2004). This results in extending the definition of trust to include an object (e.g. the mediating technology) rather than considering only the two subjects (the trustor and the trustee). 
This may well add to the complexity of the trust term, but nonetheless needs to be considered as it is part of the transaction between the two subjects.

For this research, the definition of trust given by Araujo and Araujo's (2003) will be followed because it is comprehensive, convenient and fits with the nature of this research. Thus, trust is defined as "a positive belief about the perceived reliability of, dependability of, and confidence in a person, object, or process" (p. 3). Parallels can be drawn between this definition and the definitions given by Rempel (1980) in that trust can be considered as a belief. The definition is also consistent with Mellinger (1956), Read (1962) and Rempel (1985) through describing some trust-related concepts such as confidence and dependability. It is also compatible with the definitions of McKnight et al. (2004) and Jarvenpaa et al. (2000), in that it involves trust-related objects in the relationships between the trustor and the trustee in the e-commerce area. This definition can provide a better understanding of the trust concept and a holistic view of trust characteristics and trust parties as well.

\subsubsection{Trust characteristics and dimensions.}

It is easier to understand the trust concept by producing a taxonomy that gives a holistic view of trust from the various disciplines (McKnight \& Chervany, 2001b). To produce an acceptable taxonomy, McKnight and Chervany (2001b) analysed trust definitions from about eighty articles and books on trust from the fields of psychology, sociology, economics, political science and management and communications. Their analysis show that trust definitions fall into two general groupings. The first category is 'different conceptual types', such as attributes, beliefs, behaviours, and dispositions, whereas the second one is 'different referents', such as trusting something, or someone, or in a specific characteristic of an individual (p. 39). In addition to the taxonomy, 16 categories of trust characteristics are identified, as shown in Table 2.2. 
Table 2.2 Trust Referent Characteristic-based Definition Categories (adapted from McKnight \& Chervany, 2001)

\begin{tabular}{|c|c|c|}
\hline Trust-related characteristics & Definition count & $\begin{array}{l}\text { Conceptual category with total } \\
\text { relevant counts and percentage }\end{array}$ \\
\hline Competent & 14 & \multirow{3}{*}{ Competence (20), $20.4 \%$} \\
\hline Expert & 3 & \\
\hline Dynamic & 3 & \\
\hline Predictable & 6 & Predictability (6), $6.1 \%$ \\
\hline Good, moral & 6 & \multirow{4}{*}{ Benevolence (38), $38.8 \%$} \\
\hline Good will & 10 & \\
\hline Benevolent, caring & 18 & \\
\hline Responsive & 4 & \\
\hline Honest & 11 & \multirow{4}{*}{ Integrity (26), $26.5 \%$} \\
\hline Credible & 1 & \\
\hline Reliable & 8 & \\
\hline Dependable & 6 & \\
\hline Open & 3 & \multirow{4}{*}{ Other (8), $8.2 \%$} \\
\hline Careful, Safe & 3 & \\
\hline Shared understanding & 1 & \\
\hline Personally attractive & 1 & \\
\hline
\end{tabular}

The taxonomy includes four main categories of trust belief concepts. These categories are competence, predictability, benevolence and integrity. As shown in Table 2.2, the most frequently used category is 'benevolence', since its components (morality, good will, care, and responsiveness) have the highest percentage (38.8\%) of the total analysed studies. More than a quarter of surveyed trust papers and textbooks have used 'integrity' as a trust-related category that includes the characteristics: honest, credible, reliable and dependable. The competence category (including competent, expert, and dynamic) accounts for around $20 \%$ of the trust studies, while $6.1 \%$ of trust literature uses a 'predictability' category with its single characteristic when defining the trust term. Other related concepts, such as open, careful, and shared understanding have been used without including them into certain categories. In summary, the four categories (competence, benevolence, integrity, and predictability) cover $91.8 \%$ of the characteristics-based trust definitions studied by McKnight and Chervany (2001b). 
Other dimensions of trust come from psychology and economics, called 'dispositional trust' (McKnight \& Chervany, 2001b). Dispositional trust is concerned with trust in others generally across a broad spectrum of situations and persons, and means that one has a general propensity to be willing to depend on others regardless believing others to be trustworthy (Mayer et al., 1995). Another dimension of trust that comes from sociology is 'institutional trust', which means trust in the situation or structures. Institution-based trust is "situation-specific but cross-personal because it means that one trusts the specific situation but does so irrespective of the specific people in that situation" (McKnight and Chervany, 2001b, p.43). However, the dispositional, institutional and interpersonal trust dimensions are all categorised in the basis of research disciplines.

From another perspective, Siau and Shen (2003) suggest two dimensions of trust based on the time factor; either initial trust or ongoing (continuous) trust. Initial trust formation requires no information gathering about the trustee, but starts with the first transaction which could be based on a reward attraction to consumers. Continuous trust development involves evaluation of consumer satisfaction over repeated transactions, resulting in either the consumer dropping out due to distrust or forming firm consumer loyalty. However, it is hard to judge on the final outcomes by offering distinct choices ranging from achieving consumer distrust to firm loyalty. Consumer trust scale may be suggested instead, which indicates the categories: distrust, lowlevel trust, average trust, or high-level trust towards achieving consumer loyalty. Having mentioned the term distrust, further details about this concept are provided in the subsequent section.

\subsection{Distrust}

Are trust and distrust considered as opposite ends of a single continuum? Can we study the trust concept without studying the distrust concept? This section answers these questions, and discusses the relationship between the trust and distrust concepts.

\subsubsection{The concept of distrust.}

When studying trust, it is important to understand the term distrust, because it allows one to avoid negative consequences and risky paths in dealings with others, such as being unreliable 
and undependable (Deutsch, 1977; McKnight \& Chervany, 2001; Lewicki, 2006). The traditional notion of trust dimensions is that trust and distrust are bipolar opposites (Lewicki, McAllister, \& Bies, 1998). Trust is one's positive belief in a person, object or process, whereas distrust is defined as one's lack of such belief. However, opinion is shifting to acknowledge that trust and distrust exist along separate dimensions. Several scholars argue that trust and distrust are separate, linked constructs that may exist simultaneously (Komiak \& Benbasat, 2008; Lewicki et al., 1998; Lewicki, 2006; McKnight \& Chervany, 2001), while others (Schoorman, Mayer, \& Davis, 2007) argue that, after revising some of the decisions that they made earlier, they can find no credible evidence to support a concept of distrust that is conceptually different from trust (Mayer et al., 1995). There are elements that contribute to the growth and decline of trust, and there are elements that contribute to the growth and decline of distrust (Komiak \& Benbasat, 2008; Kramer,1999). It is possible for people in interactions to both trust and distrust one another, given different experiences within the various aspects of interpersonal relationships (Lewicki, 2006).

Definitions of the term distrust differ according to two main views. Scholars who see distrust as not differing conceptually from trust define distrust as a lack of confidence in the other and a belief that this individual does not care about one's welfare or intends to act harmfully (Grovier 1994; Schoorman et al., 2007). On the other hand, scholars who view trust and distrust as different constructs define distrust as a confident negative expectation regarding another's conduct (Komiak \& Benbasat, 2008; Lewicki, et., 1998). A more descriptive definition from the latter group is given by Sitkin and Roth (1993) that distrust is a "belief that a person's values or motives will lead them to approach all situations in an unacceptable manner" (p. 373). Distrust is exhibited when a distruster believes that the other party either will not or cannot perform the desired behaviours, and will act negatively towards the distruster (McKnight \& Chervany, 2001b). The definition given by Sitkin and Roth (1993) will be followed, which is "a belief that a person's values or motives will lead them to approach all situations in an unacceptable manner" (p. 373).

While both trust and distrust involve confidence in another's conduct, the nature of that confidence and the emotional and behavioural attitudes that come with it will differ considerably 
(Moody, Galletta, \& Lowry, 2010). That is, trust evokes a feeling of hope and a demonstrated willingness to depend on the trustee. Distrust, on the other hand, evokes fear and actions to buffer oneself from the harmful relationship with the other party (Lewicki, 2006). This distinction is represented in Figure 2.4, which shows a trust continuum and a distrust continuum with different measures.

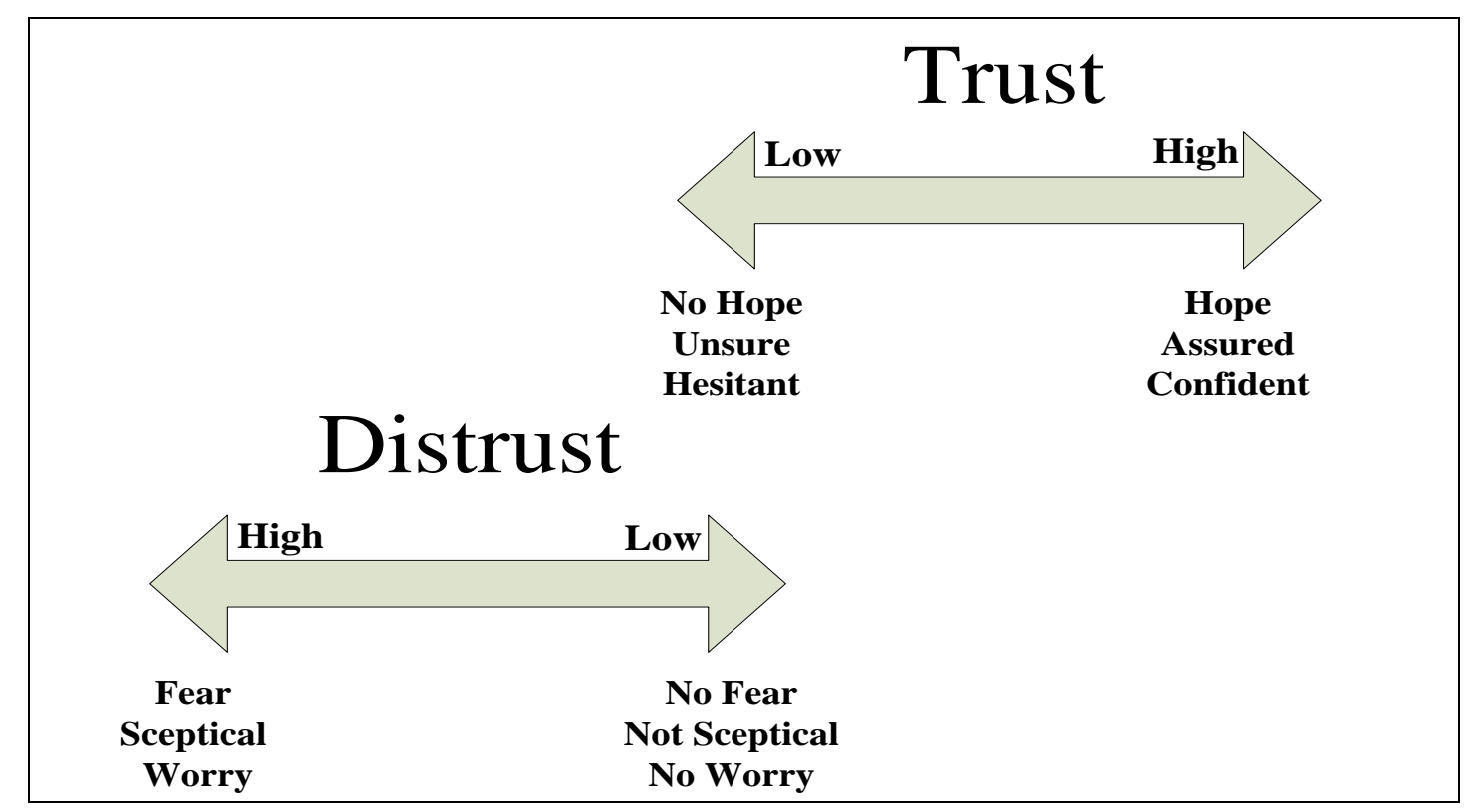

Figure 2.2 Trust Continuum and Distrust Continuum (Adapted from Lewicki et al., 1998)

As shown in Figure 2.4, low trust is not the same as high distrust; the former evokes a lack of hope, an unsure assessment of the other's attitudes and hesitancy, whereas the latter evokes fear, scepticism and worry. On the other hand, high trust is not necessarily translated into low distrust: the former suggests hope, assurance, and confidence, whereas the latter suggests an absence of fear, scepticism, and worries when interacting with the other party. Thus, trust and distrust in the current study are not seen as opposite ends of a single continuum. The subsequent section discusses more about the relationship between trust and distrust as different concepts.

\subsubsection{Relationship between trust and distrust.}

Viewing trust and distrust as existing along separate dimensions increases the importance of the generally complex and multidimensional relationships with others (Moody, Galletta, \& Lowry, 2010). In addition, trust and distrust behaviours are strongly related to circumstances (Kramer, 1999; McKnight \& Chervany, 2001). We may trust someone in some contexts, but not in others. 
Another point is that certain situations require a high level of trust while others do not. The greater the variety of contexts and conditions in which we interact with others, the more complex and multifaceted the trust relationship becomes. By integrating trust and distrust, Figure 2.5 illustrates the effective measures of these constructs in a two-dimensional relationship.

\begin{tabular}{c|c|c}
$\begin{array}{c}\text { High Trust } \\
\text { Characterised by: }\end{array}$ & Interdependence promoted & Trust but verify \\
$\begin{array}{c}\text { Hope } \\
\text { Confidence } \\
\text { Assurance }\end{array}$ & Opportunities persuaded & Opportunities persuaded \\
\hline $\begin{array}{c}\text { Low Trust } \\
\text { Characterised by: }\end{array}$ & New initiatives & $\begin{array}{c}\text { Vulnerabilities continually } \\
\text { monitored }\end{array}$ \\
$\begin{array}{c}\text { No Hope } \\
\text { No Confidence } \\
\text { Hesitance }\end{array}$ & Limited interdependence & Undesirable eventualities \\
& Bounded transaction & Harmful motives assumed \\
& Professional courtesy & Interdependence management \\
& Low Distrust & High Distrust \\
& Characterised by: & Chacterised by: \\
No Fear & Fear \\
Absence of scepticism & Whsence of worry & Worry
\end{tabular}

Figure 2.5 Integrating Trust and Distrust (Adapted from Lewicki et al., 1998 and Lewicki, 2006)

Lewicki (2006) argues that when someone is asked whether a one trust or distrusts another, the proper answer is not "yes" or "no" but "to do what?" (p. 1003). The researcher believes that both a person's belief and the situation he/she is involved in determine the trust-related action. If someone has low trust and low distrust beliefs in a certain context, then his/her actions will be bounded. On the other hand, if someone is characterised as having high trust and high distrust, then trust-related action will be considered after verifying and recognising opportunities and risk. A person with high trust and low distrust characteristics is seen as an entrepreneur and capable of promoting interdependence relationships with others. A high distrust and low trust person tends, 
in most situations, to perceive undesirable eventualities and to assume harmful motives when conducting a trust-related action.

\subsubsection{Distrust in m-payments.}

A consumer may distrust in m-payments because of some of its characteristics, or due to certain circumstances. For instance, a consumer's perceived security and privacy or negative past experiences in conducting m-payments could result in his or her distrust in m-payments. However, the scholarly research conducted in the Emirates, and other Gulf and Arab states, indicates that there is a 'lack of consumer trust' in m-payments, rather than 'consumer distrust' in m-payments (Alhosni et al., 2010; Al-Mamari, 2007; Bhatti, 2008; Manochehri \& AlHinai, 2008). Therefore, the term distrust had not been studied in the current research; rather, the focus was on consumer trust levels in m-payments in that region.

\subsection{Trust in M-payments}

Consumers' trust in m-payments means that they have a positive belief and confidence in its services and applications. This section discusses consumer trust in m-payments and the factors that influence it. Trust in m-payments in this research is based on consumers' voluntary readiness to use m-payment services and applications, since using this technology is not compulsory at the institutes and organisations in the Emirates, and is not an explicit payment method used there.

\subsubsection{Importance of trust in m-payments.}

According to Bhattacherjee (2002), Grabner-Kräuter \& Kaluscha (2003), Mallat, Rossi, \& Tuunainen, (2004) and McKnight, Choudhury, \& Kacmar, (2002), trust is important in mcommerce for several reasons: (1) mobile transactions are often effected with spatial and temporal separation between buyer and seller (Mallat, Rossi, Tuunainen, \& Öörni, 2008); (2) buyers are required to provide delicate and sensitive personal information such as credit card numbers, account numbers and telephone numbers to the seller, and make purchases; (3) trust plays a central role in helping consumers overcome perceptions of risk and insecurity (McKnight \& Chervany, 2001b); (4) trust makes consumers comfortable with acting on m-payment provider advice, the issue which is essential to widespread adoption of e-commerce and m-commerce (McKnight et al., 2002). So, trust provides consumers with comfort, reliability and safety when 
thinking of conducting an m-payment transaction. From a more macro level, trust is a valuable asset which is firmly linked with economic success (Fukuyama, 1995).

Many studies have linked consumer trust and m-commerce adoption, and indicated that there is a strong relationship between trust in m-payment and its adoption, but without deep understanding of how to achieve this trust and what the factors are that influence it (Alqatan et al., 2012; Aw, Nor, Abu Shanab, \& Sutanonpaiboond, 2009; Chandra et al., 2010; Eze, Gan, Ademu, \& Tella, 2008; Gerpott \& Kornmeier, 2009, Hollingswoth \& Dembla, 2013; Piao et al., 2012; Wong \& Hsu, 2008; Xin et al., 2013). In fact, trust is often studied as one component of m-payment adoption factors rather than being studied independently. In these studies, trust is considered as an independent variable or as a mediating variable that influences the main constructs of user adoption of m-payment services. For instance, Eze, Gan, Ademu, and Tella (2008) have modelled user trust as an independent variable that influences m-payment adoption, and found that trust affects the perceived intention to use, ease of use and perceived usefulness of an mpayment service. Another example is the study of Chandra et al. (2010) that models trust as a mediating variable between 'mobile technology and service characteristics' and 'perceived usefulness and ease of use'. Other studies (Gerpott \& Kornmeier, 2009; Pousttch \& Wiedemann, 2007; Rehman \& Coughlan, 2011; Zmijewska, Lawrence, \& Steele, 2004) indicate that consumer trust is of high importance in accepting m-payment.

Consumers' trust in m-payments significantly influences their intention to adopt mobile payment. This is consistent with previous m-payments studies (Chandra et al. 2010; Keramati, Taeb, Larijani, \& Mojir, 2011; Thair, Luo, \& Peter, 2010; Xin et al., 2013). This indicates that trust in m-payments is a critical factor that consumers consider when making mobile payment adoption decisions (Chandra et al., 2010; Xin et al., 2013). It is also crucial with respect to gaining the consumer's trust in promoting the adoption of m-commerce in developing countries (Alqatan et al., 2012; Guangming \& Yuzhong, 2011). However, trust in m-payments needs to be better understood and recognised. Siau et al. (2003) believe that m-payment services have tremendous potential. To achieve this potential, "the trust issue needs to be more fully understood and directly addressed by vendors and providers of m-commerce technologies and services" (p. 89). The subsequent section highlights the problem associated with trust in m-payments. 


\subsubsection{What is the problem with consumer trust in m-payments?}

Many scholars in the field of m-commerce argue that there is a lack of trust in m-payments and wireless transactions (Corbitt \& Thanasankit, 2003; Hillman et al., 2011; Kim et al., 2010; Lee, Lee, \& Kim, 2007; Yeh \& Li , 2010; Luarn \& Lin, 2005; Park \& SuJin, 2006; Siau et al., 2003; Wu \& Wang, 2005). Others argue that consumers' trust in m-commerce and its payments needs to be at least enhanced (Lu, Yu, \& Liu, 2005; Qingfei et al., 2008; Saghafi, Mohammadi, \& Fasanghari, 2009; Siau \& Shen, 2003). One reason is that bank balances and financial data are subject to change in the course of m-payment transactions without the consumer's prior knowledge; a matter that affects consumer's trust in these transactions (Wu \& Wang, 2005).

Potential risks from immature technologies are perceived to cause distrust amongst some users, while others hesitate before trusting online transactions and payments (Wu \& Wang, 2005). Some consumers are distrustful or suspicious of the reliability of the services provided by their $\mathrm{m}$-commerce vendors, which are third party providers of $\mathrm{m}$-commerce transactions and services (Araujo \& Araujo, 2003). In fact, there are many possible reasons behind the lack of consumer trust in m-payments.

In essence, the majority of consumers do not trust most web providers enough to engage in relationship exchanges involving money and personal information (Hoffman et al., 1999). Because internet social cues are minimal, trust is difficult to establish (Gefen \& Straub, 2002). M-commerce, as an emerging subset of e-commerce, faces the same problems plaguing ecommerce plus a few of its own (Siau et al., 2003), such as possible security breaches via wireless networks and the technological limitations of the mobile devices to conduct a full mcommerce transaction (displaying products, authenticating consumers, authorising merchants and banks, and transferring funds). Overall, lack of trust is considered a major obstacle in initiating consumer relationships, which negatively impacts $\mathrm{m}$-commerce adoption and development despite its potential (Siau et al., 2003; Yeh \& Li, 2009).

\subsubsection{It is harder to build trust in m-payments than other e-payments.}

Trust in m-payments is harder to build than in other traditional e-payments for several reasons:

(1) The development of m-payments is still in its early stages, and consumers have less 
experience in m-payment services and applications (Min et al., 2008; Piao et al., 2012). These payments have not yet been widely adopted by businesses and telecom companies so far, compared to other e-payments. According to Alqatan et al. (2012), m-payments are still in their infancy, and a very limited choice of products and applications is available for consumers, and thus, trust is considered a significant factor that affects the proposed use of m-payments more than other e-payments.

(2) The m-payments transaction platform extends to more direct and personal mobile environments from the Internet, and the changed environment easily makes consumers worry about the leaking of their sensitive information (Min et al., 2008; Piao et al., 2012).

(3) M-payments technology is still not perfect. For instance, small mobile terminals, complex operations, increasingly sophisticated smartphones and handheld tablets, and the connection instability of the telecommunication network technology could result in delays in transactions or losing them, the thing that makes SMS and NFC m-payments systems being deemed slow and unreliable (Amoroso \& Magnier-Watanabe, 2012; Hollingsworth \& Dembla, 2013).

(4) There are some limitations associated with using mobile devices for transacting payments; the design of mobile devices for instance. Mobile-design features, such as small screens, lowresolution displays, and tiny multifunction keypads, could make developing user-friendly interfaces and graphical applications that are convenient for conducting payments a real challenge (Hsieh, 2007; Siau, Lim, \& Shen, 2001, Tarasewich et al., 2001). Another example, mobile handsets are also limited in computational power, memory, and battery life (Siau \& Shen, 2003), which constraint the payment process, time and condition.

(5) The high risk associated with m-payments could influence the establishment of consumer trust, in a negative direction (Alqatan et al., 2012; Hollingswoth \& Dembla, 2013; Piao et al., 2012). The potential security threats that discourage consumers from m-payments continue to confound the mobile-technology industry (Ghosh \& Swaminatha, 2001; Kao, 2009). As discussed in sections 2.2.1 and 2.2.3, potential risks from security system failures may occur from loss and theft of the mobile device (Dahlberg et al., 2008; Park \& SuJin, 2006). In addition, 
the payment itself could be vulnerable and easy to tap into if it is not well secured, through intercepting and logging data traffic that passes over the telecommunication network.

(6) M-payments are considered a technology that changes over time (Veijalainen, 2007), which makes the process of building trust in m-payments time-consuming to engender, difficult to establish, fragile and easy to lose (Qingfei et al., 2008; Siau \& Shen, 2003). This justifies why the process of continuous trust development warrants extra attention from businesses and merchants.

\subsubsection{Adoption and trust in m-payments.}

Overall, m-payments are not a simple extension of e-payments. M-payments have their own technological infrastructure, different characteristics, new business models and applications, and new values for consumers (Hillman, Neustaedter, \& Bowes, 2011). As a result, trust in mpayments is difficult to understand, and no consensus about its influential factors has been

achieved yet. Hence, it requires new thinking for its trust and adoption. In addition, although many studies indicated that trust influence consumer usage of m-payments (see section 2.6.1), some research indicated no relationship between trust in m-payments and its adoption. For instance, Susanto et al. (2012) found that trust in smartphones to conduct a monetary banking payment does not influence continuance intention to use this Korean m-payment system. Similarly, Pousttchi \& Wiedemann (2007) empirically found that perceived trustworthiness had no significant influence on users' intention to use m-payments in Germany. Overall, we are not sure whether trust impact m-payment adoption and in what context, which in turn makes the process of understanding trust more complex and complicated. Therefore, it is argued that the only way to achieve consumer trust in m-payments is to perform an in-depth investigation of the factors that influence it from various perspectives and aspects. The subsequent section discusses these factors and explores their impact on trust in m-payment.

\subsubsection{An overview of factors influencing consumer trust in m-payments.} Gaining consumer trust in m-payments could be achieved by considering certain psychological, technical, technological, cultural and social factors together, and allowing the balance of power to shift towards a more cooperative interaction between the m-payment provider party and its consumers. The majority of IS researchers and scholars have concentrated on trust in e- 
commerce in general, but not many have published conclusions about trust in m-commerce, and trust in m-payment specifically, and little is known about the mechanisms involved in generating consumer trust on a mobile platform (Alqatan et al., 2012; Piao et al., 2012; Hillman et al., 2011; Siau \& Shen, 2003; Wu \& Chen, 2005; Yeh \& Li, 2009). To address this gap in the literature, this research will discuss and test the factors that influence consumer trust in m-payment. Firstly, these factors are discussed, and then tested in subsequent stages. Five main categories of factors obtained from the literature are included. These categories are: consumer characteristics, environmental influences (cultural and social influences), provider characteristics, perceived risks, and mobile-device characteristics. In some instances, insights from m-commerce are presented to provide a better assessment of a factor.

\subsubsection{Consumer's Characteristics.}

Trust characteristics of individuals are mainly from cultural background, psychological characteristics and experiences (Guangming \& Yuzhong, 2011). Four factors were found in the literature relating to trust in m-payments that indicate the specified dimensions of consumers: propensity to trust, awareness, uncertainty avoidance, and past experience. Several studies indicate that a consumer's general propensity to trust can influence his/her trust in m-payments (Alqatan et al., 2012; Kim et al., 2010; Li \& Li, 2008; Piao et al., 2012), and draw attention to the impact of consumer awareness on trust in m-payments (Alqatan et al., 2012; Cho et al., 2007; Hollingsworth \& Dembla, 2013; Li \& Li, 2008; Piao et al., 2012). Further, it is important to include consumer past experience in m-payments or relevant mobile technology, as it plays a significant role in trust in m-payment (Alqatan, et al., 2012; Hillman et al., 2011; Jari \& Heikki, 2007; Joubert \& Van Belle, 2009; Siau et al., 2003). Additionally, consumer demographics such as gender and age may also have an impact on trust in m-payments (Chandra et al., 2010; Salo \& Karjaluoto, 2007; Xin et al., 2013). A detailed discussion is presented for each mentioned factor.

(1) Propensity to Trust. Existing research suggests that trust is based on relatively stable characteristics of individuals embedded in a person's values. For instance, Rotter (1980) conceptualises a general tendency for trust to be associated with increased compliance, increased credibility, increased help offering, and decreased cheating. Tendency to trust may include dimensions of personality, such as levels of emotional stability and degrees from introversion to extroversion (Stack, 1978). Specifically, propensity to trust is the foundation of the initial trust 
that represents a person's disposition to rely on others in various situations (McKnight et al., 2004). This term is deeply rooted in a person's personality and psychological development during the early stage of her/his life (Lee \& Turban, 2001; Rotter, 1980). An individual's trust tendency consists of faith in humanity, in which a person believes in the reliability and dependability of people; and a trusting stance, in which a person believes that he or she will be better off when he or she deals with people as if they are reliable (McKnight et al., 2004).

Thus, consumer's propensity to trust plays a role in determining initial confidence in his/her commerce counterpart (Kim et al., 2010). Studies show that consumer propensity to trust is considered an important component of the consumer's personal values that influence his/her trust in conducting an electronic transaction (Connolly \& Bannister, 2007; McKnight et al., 2002). In other words, propensity to trust is considered as a personal psychological value that can greatly influence a consumer's trust in e-payments (Chen \& Dhillon, 2003; Gefen, 2000; Kim et al., 2010). In m-commerce, trust propensity or trust disposition means consumers feel safe, and hope or tend to depend on mobile sellers (Meng et al., 2008; Piao et al., 2012). In addition, propensity to trust is empirically found to have a significant influence on consumer trust in m-payments (Alqatan et al., 2012; Guangming \& Yuzhong, 2011; Kim et al., 2010; Li \& Li, 2008; Piao et al., 2012). Based on the given discussion, trust in m-payments may be reliant on propensity to trust, thus propensity to trust was included in the current research.

(2) Consumer Awareness. The link between awareness and trust is a well-accepted topic in psychology, sociology and computer science (Alqatan et al., 2012; Li \& Li, 2008). In ecommerce, trust has been shown to have a required antecedent of awareness (Gefen, 2000), and a precondition or prerequisite of trust (Yao \& Li, 2008). Awareness is defined by Gefen (2000) as an understanding that allows the user to reduce uncertainty in a subjective manner and when combined with trust, a general belief that a person has about the actions of another person toward them. Trust and awareness are distinctly different from each other, and trust is significantly affected by awareness and familiarity (Gefen, 2000; Wong \& Hsu, 2008). Specifically, knowledge-based awareness has a significant influence on trust in e-commerce transactions through a rich understanding of e-vendors and websites (Gefen \& Heart, 2006). 
One definition of awareness in the field of m-commerce is described as "consumers have experience shopping through a mobile terminal and are familiar with mobile platforms and mobile sellers to some degree" (Piao et al., 2012, p. 27). Awareness with respect to m-payments is certainly associated with learning about the mobile technology and its platform, but might not be associated with past personal experience despite the strong relationship between them, because there are many resources for delivering knowledge about it to the individual. However, increased awareness means a better understanding of the transaction process with $\mathrm{m}$-commerce (OECD, 2008). People tend to trust what they are aware of, and where awareness is obtained through frequent exposure, this has the potential to engender trust in m-commerce (Siau \& Shen, 2003). Awareness in the use of mobile devices also acts as a catalyst to induce trust in the use of mobile commerce (Cho et al., 2007), and is able to influence initial trust in m-commerce (Li \& $\mathrm{Li}, 2008)$. A strong positive relationship exists between awareness and trust; the more consumers are aware of m-commerce, the higher the trust in the mobile transaction platforms (Piao et al., 2012)

Indeed, awareness is found to relate significantly to trust in m-commerce (Alqatan et al., 2012; Hollingsworth \& Dembla, 2013; Kim et al., 2010; Yeh \& Li, 2009). For instance, Yeh and Li (2009) revealed through empirically testing that consumers are more willing to trust an mcommerce brand service that they are aware of. Similarly, Hollingsworth and Dembla (2013) proposed a model of $\mathrm{m}$-commerce adoption, modelling trust as one of the factors of $\mathrm{m}$-commerce adoption and that familiarity in m-commerce was a main influencer of trust in that model. In addition, and through their hypothetical model of consumer trust in m-commerce, Alqatan et al. (2012) found that familiarity of tourists with mobile commerce services influences tourists' trust in the adoption of this technology in developing countries. Furthermore, Piao et al. (2012) indicated in his empirical study that awareness has a positive influence on trust in m-commerce. Therefore, in the current research, the relationship between consumer awareness in m-payments and trust will be investigated to ascertain whether awareness has substance in the m-payments trust context.

(3) Consumer's Past Personal Experience. Several studies in the e-commerce field pointed out that trust is influenced by a consumer's experience and past electronic conducted transactions 
with web and online retailers (Corbitt et al., 2003; McKnight et al., 2002; Pavlou, 2003). As consumers gain experience with the e-vendor, cognitive considerations based on the first experience gain prominence and trust starts to be affected (Gefen et al., 2003). Where trust beliefs and personal values are a trust credit, experience can provide a more rational interpretation of trust condition and details; acknowledging the consumer with the what, who, how, and when of what is happening (Gefen et al., 2003). Thus, one of the most basic of trustbuilding tenets is the fact that experience with the object of trust promotes trust in the object (McKnight et al., 2002).

Likewise, experience in m-payments is associated with trust in many studies in the context of mcommerce (Cho et al., 2007; Kao, 2008; Li \& Yeh, 2010; Mogenahalli, et al., 2008; Siau \& Shen, 2003). Consumer experience in conducting m-commerce transactions is perceived as the conclusion drawn from the quality of prior experience and past practices with m-commerce (McKnight et al., 2002; Stewart, 2006). Consumers' direct experience of the m-payment provider during their transactions stimulates the formation of the trust relationship. Moreover, Kao (2008) argues that experience-based trust has a significant bearing on consumer trust in m-payments. This experience could be either positive or negative, and influence trust accordingly. Specifically, positive direct experiences are considered the strongest trust signal with the highest potential for reducing perceived risk (Siau \& Shen, 2003). If consumers have already had a satisfactory experience with the provider, they form a higher level of trust on the basis of prior experience (Yeh \& Li, 2009). It is thus expected that a pleasant user experience will increase his/her trust in the m-commerce transaction and its provider (Mogenahalli et al., 2008).

Importantly, past personal experience with m-payments is critical because personal experiences may impact a consumer's perceptions, attitudes and intentions significantly (Kong \& Hung, 2006; Pavlou, 2003; Susanto et al., 2010). Siau et al. (2003) found that a consumer's past experience with a service provider has an influence on consumer trust in the provider. Similarly, Jari and Heikki (2007) and Joubert and Van Belle (2009) examined this factor and found that it impacts consumer trusting beliefs and intention towards m-commerce adoption.

For the current research, consumers' past personal experience in m-payments in the Emirates could be gained from many sources that are related to trust in m-commerce. The direct and major 
source of this past experience is gained by conducting an m-payment transaction. Another source of past experience is the experience gained through dealing with a telecom company or $\mathrm{m}$ payment provider in one of its services or products. These sources of personal experience shape consumer knowledge concerning m-payments and wireless technology. Based on this discussion, consumer past personal experience may be considered as a factor with respect to trust in $\mathrm{m}$ payments, and thus included in the current research. If a consumer had no prior m-payment transaction experience, then he/she will rely more on the peripheral (environmental) factors such as certain social influences, or may rely more on the company's reputation (both are discussed in sections 2.5.6.2. and 2.5.6.3.).

(4) Uncertainty Avoidance. Researchers have adopted and examined the cultural dimensions of trust in mobile and electronic commerce, especially those proposed by Hofstede (Cyr, 2008; Dai \& Palvi, 2009; Min \& Li, 2009; Rahmati, 2004). Hofstede (2001) constructed his social dimensions from his research into national culture that focused on IBM employees from over 70 countries around the world, with a sample size of over 88,000. He proposed five cultural dimensions: power distance, uncertainty avoidance, individualism and collectivism, masculinity and femininity, and orientation.

Few studies in the literature have investigated Hofstede's cultural dimensions in m-commerce adoption and usage, mostly for the purpose of studying cross-cultural comparisons (Dai \& Palvi, 2009; Harris, Rettie, \& Rettie, 2005; Kao, 2009). However, some studies were interested in some dimensions more than others. For instance, Min, Li, and Ji (2009) were interested in two dimensions: uncertainty avoidance and individualism/collectivism to explore the effects of individual-level culture on m-commerce. Sikolia, Weiser, Biros, and Romano (2010) included one dimension (individualism/collectivism) in their study, which examined the effect of culture on trust in m-banking services.

For the current research, uncertainty avoidance was considered to have a potential influence on trust in m-payments in the Emirates. Uncertainty avoidance relates to the level of anxiety of people in the face of an ambiguous and unknown future (Hofstede, 2001). This means the extent to which a person tries to avoid uncertain situations. Uncertainty avoidance is categorised into 
high or low levels. According to Hofstede (2001), people with a low level of uncertainty avoidance, such as the United States of America, may feel much more comfortable with unknown and ambiguous situations and tend to be easy-going, open-minded, accepting of personal risk and less aggressive. Conversely, people with a high level of uncertainty avoidance tend to look for structure in their organisations and relationships. In societies characterised by a high level of uncertainty avoidance, people, such as in the Middle East, tend to be conservative, more resistant to change, slow to modernise, and often characterized by more elaborate rituals or religious practices (Hofstede, 2001), which may affect m-payment services in terms of there being some degree of resistance to trust such a new payment method (Rouibah, 2012).

Uncertainty avoidance was also selected in the current research for other reasons. Many studies have found convincing evidence that uncertainty avoidance is closely related to the construct of trust in the e-commerce arena (Doney et al., 1998; Jari \& Heikki, 2007; Vance, Elie-Dit-Cosaque, \& Straub, 2008). In addition, uncertainty avoidance, as the most frequently cited cultural dimension (Min \& Li, 2009), has extra importance in this research, among other factors, because of the novel nature of m-payments in the Middle East in general and in the Emirates specifically, which indicates that the people in the Emirates could feel threatened by this new technology, and this would affect their trust in it. As such, the relationship between uncertainty avoidance and trust in m-payments warrants further investigation.

Regarding consumer demographics, few studies indicate the relationship between them and trust in m-payments. For instance, Salo and Karjaluoto (2007) suggest that individual demographics (such as gender and age) have a strong influence on the development of the trusting belief. However, it is controversial if these demographic variables are valid with respect to their influence on consumer trust in m-commerce and m-payments (Chandra et al., 2010; Xin et al., 2013). With respect to consumer age, a measurement of specific interpersonal trust in a specific other developed by Johnson-George and Swap (1982) in social psychology sciences illustrates that males and females look for slightly different qualities in another person when assessing his/her trustworthiness. For males, the scale includes factors of reliability, emotional trust, and general trust, whereas in the females' scale, reliability and emotional trust aspects emerge. In the field of m-commerce, the effect of gender on trust has been examined with no general consensus 
results. On closer examination, consumer gender has been shown to have an impact on trust in IS trust and adoption studies (Awad \& Ragowsky, 2008). On the other hand, gender has not been indicated as a differentiator in using mobile wallets (Amoroso \& Magnier-Watanabe, 2011) and has no influence on trust in m-payment systems (Chandra et al., 2010; Xin et al., 2013). Xu et al. (2005) also found that consumer gender has no significant influence on trust in location-based mcommerce. What makes the role of gender unclear in m-payment trust is that no studies have been identified with focus on trust in m-payments in the Emirates. As such, the relationship between gender and trust in m-payments warrants further investigation, and thus consumer gender was considered in the current research to establish whether it significantly influences trust in m-payments.

Similar to gender, the other socio-demographic variable; consumer age was examined in several studies with respect to its influence on trust in m-commerce, but with different findings. For instance, Chen \& Dhillon (2003) and Li \& Yeh (2010) examined the influence of consumer age and found it to be an important factor of trust in m-commerce transactions. On the other hand, Chandra et al. (2010) did not find the age factor to have a significant influence on m-payment systems. In addition, $\mathrm{Xu}$ et al. (2005) found that consumer age has no significant influence on trust in location-based mobile commerce. As a result, and similar to the gender factor, the relationship between age and trust in m-payments requires further investigation. It is also worth exploring the age factor in the current study as it had not been studied previously with respect to trust in m-payment in the Middle Eastern Arab region. What further justifies its inclusion is that many studies investigating m-commerce trust have utilised university students as consumers to participate in their research (Kao, 2009; Kim et al., 2010; Li \& Yeh, 2010; Mallat, 2007; Yeh \& Li, 2009). This type of study sample may not reveal the effect of the consumer's gender or educational level on trust in m-payment, since it deals with a limited category of consumers. This issue was handled in the current research by extending the sample to other categories (see section 5.4.2), which reveals the findings about consumer gender and age.

\subsubsection{Environmental influences (Trust environment).}

Scant literature indicated a relationship between trust environment and consumer trust in the $\mathrm{m}$ commerce and e-commerce fields. Cheung and Lee (2000), followed by Borchers (2001) and Connolly and Bannister (2007) associated trust environment with consumer trust in internet 
shopping, by examining the levels of trust existing in a consumer's family and society. The mentioned studies were conducted in the countries: China, USA, and Ireland. In addition to the family and society dimensions, Cheung and Lee (2000) exclusively added the two dimensions friends and community as part of a consumer's environment, indicating that the level of trust of those around a person could interpersonally affect the level of trust he/she has. In addition, the trust-environment factor was investigated in a study of intention to use e-commerce in the Arab countries: Saudi Arabia and the Emirates, by Siddiqui (2008). In her study, Siddiqui intended to involve this factor to discover whether it has an impact on e-commerce adoption, by comparing between the (Saudi and Emirati) environments. It is worth noting that this factor has been primarily studied in cultural and cross-cultural comparison studies.

However, no studies have yet been found in the m-payment literature identifying the relationship between the trust environment and consumer trust in m-payments. Based on the belief that the trust environment may be associated with consumer trust in m-payments in the Emirates, this factor was added in the current research for further investigation.

\subsubsection{Provider's characteristics.}

Characteristics of the provider such as reputation and trustworthiness are considered important in influencing a consumer's trust towards a firm (Chen \& Dhillon, 2003; Doney \& Cannon, 1997). The provider in this context is the company that provides m-payment services. Each of these provider's attributes were discussed with regard to consumer trust in m-payments.

(1) Provider's Reputation. Provider's reputation in m-commerce can be defined as the consumers' opinion and their provided feedback regarding the services provided by the $\mathrm{m}$ commerce vendors (Mogenahalli et al., 2008). Reputation reflects a firm's history and past behaviour as viewed through consumers' eyes (Siau \& Shen, 2003). According to Guangming \& Yuzhong (2011) and Xin et al. (2013), a provider's reputation is an important factor in generating trust in electronic commerce, especially in the initial confidence-building stage. This is because consumers at this stage have no experience to go on, and thus, can depend only on a reputable business that has a good image in their eyes. In addition, because of the novel nature of m-commerce, extra importance and emphasis should be placed on developing the company's reputation (Siau \& Shen, 2003). 
A provider's reputation or image in the consumers' eyes is either good or bad. A good reputation suggests certainty and less risk in conducting business, and thus helps foster consumer trust (Siau $\&$ Shen, 2003). This is because consumers feel more comfortable and confident doing business with a reputable vendor (Mogenahalli et al., 2008). With a good reputation, providers may easily catch the consumers' sight and gain their initial trust ( $\mathrm{Li} \& \mathrm{Li}, 2008$ ). On the other hand, Ba (2001) states that consumers who perceive a bad reputation on the part of a service provider would be discouraged from trusting and conducting online transactions with that provider.

Several studies have scrutinised the relationship between a provider's reputation and trust in $\mathrm{m}$ commerce (Chandra et al., 2013; Liu, Min, \& Ji, 2009; Siau \& Shen, 2003; Xin et al., 2013). For instance, Siau and Shen (2003) argue that a good reputation on the part of a firm implies the integrity of that business, thus fostering consumer trust in mobile commerce. In a mobile banking study, Liu et al (2009) also demonstrate a positive relationship between the reputation of a mobile banking service provider and consumer trust. Overall, results identify the reputation of a mobile service provider to be an important trust-building factor in the context of m-payment (Chandra et al., 2013).

Similarly, reputation in the e-commerce arena is considered one of the major antecedent factors of trust (Chiravuri \& Nazareth, 2001; Yao \& Li, 2008), and considerable trust literature in ecommerce shows that the provider's reputation is strongly associated with trust in e-commerce (Friedman, Kahn, \& Howe, 2000; Hsu, 2008; Jarvenpaa et al., 1999; Kim \& Prabhakar, 2000; Koufaris \& Hampton-Sosa, 2004; McKnight et al., 2002; Yao \& Li, 2008; Yan \& Holtmanns, 2008; Yao \& Li, 2008). However, the provider in the e-commerce context is often the vendor or the seller company owning the website, whereas the provider of m-payments is the mobile service provider. Overall, and based on the given discussion, the relationship between the provider's reputation and consumer trust in m-payments will be investigated in the current research.

(2) Provider's trustworthiness. As discussed in section 2.4.2, trustworthiness attributes, similar to trust beliefs, consist of the four elements: benevolence, honesty, competence and predictability (Colquitt, Scott, \& Lepine, 2007; Jari \& Heikki, 2007; McKnight \& Chervany, 2006). Although 
these elements may sound similar, each has its own meaning. Benevolence means that a provider takes the consumer's benefit into consideration when using or making a decision concerning the consumer's information (Lee \& Turban, 2001). Honesty (sometimes called integrity) means that a provider makes reliable decisions and honours the terms that they guarantee (Siau \& Shen, 2003). Competence refers to the provider's ability to achieve the expected result and deliver what he/she promises and, finally, predictability means that the provider's actions in given circumstances can be predicted from his or her past behaviour (McKnight \& Chervany, 2002).

These four categories of provider's trustworthiness (benevolence, honesty, competence and predictability) are highly cited, and have been used widely in many disciplines and fields, including e-commerce and m-commerce, to measure consumer trust in many applications. Many scholars continue to include these categories in their conceptual models and frameworks when studying trust beliefs with respect to e-commerce providers (Bhattacherjee, 2002; Chen \& Dhillon, 2003; Cody-Allen \& Kishore, 2006; Connolly \& Bannister, 2007; Corbitt et al., 2003; Gefen et al., 2003; Gefen, 2000; Jari \& Heikki, 2007; Kong \& Hung, 2006; Lee \& Turban, 2001; McKnight et al., 2004; McKnight \& Chervany, 2006; Pavlou, 2003; Salam, Iyer, Palvia, \& Singh, 2005; Salo \& Karjaluoto, 2007; Yan \& Holtmanns; 2008). Similarly, this construct has been adopted widely in the m-commerce trust literature (Chandra et al., 2010; Cho et al., 2007; Kim et al., 2010; Meng, Min, \& Li, 2008; Min et al., 2008; Mogenahalli et al., 2008; Piao et al., 2012; Xin et al., 2013; Xu et al., 2005; Yeh \& Li, 2009; Zhou, 2011).

However, it is noteworthy that the factor 'provider's trustworthiness' (sometimes called 'trust beliefs in provider') has been employed in the m-commerce literature in several different ways: as an independent variable that influences general trust in mobile vendors (Min et al., 2008), and in many other instances as a measurement of consumer trust itself (Chandra et al., 2010; Cho et al., 2007; Li \& Yeh, 2010; Meng et al., 2008; Piao et al., 2012; Susanto et al., 2012; Xin et al., 2013; Xu et al., 2005; Yeh \& Li, 2009), or as a measure of initial trust (Zhou, 2011). It was also observed that only one study included this factor as a focal construct that includes all four dimensions: benevolence, honesty, competence and predictability (Mogenahalli et al., 2008). For the purpose of this research, 'provider's trustworthiness' is perceived to differ from consumer 
trust in m-payments, and thus, this factor was perceived as a characteristic of the provider that may have an influence on consumer trust in m-payments.

\subsubsection{Perceived risks.}

Perceived risks associated with electronic payments may lead consumers to have doubt in the technology and its ability to deliver e-payment services (Xin et al., 2013). The situation with regard to perceived risks in $\mathrm{m}$-commerce is more complicated, because the user is exposed to a higher perceived risk if he or she chooses to trust and engage in m-payment instead of alternative electronic means of payment (Alqatan, 2012; Clarke, 2008). In this research, perceived risk is defined as the consumer's likelihood of yielding unexpected outcomes or uncertain consequences when conducting an m-payment transaction. However, many researchers have ignored the role of risk perceptions in trust, possibly due to the complex nature of trust and risk (Gefen et al., 2003; Joubert \&Van Belle, 2009).

In general, two types of perceived risks have been commonly found and frequently cited in association with trust in the electronic environment; security and privacy risks. These perceived risks have been utilised to understand consumers' behaviour towards purchasing products and services in e-commerce (Featherman \& Pavlou 2003; Jinlong, Wei, \& Guangming, 2011; Lee \& Lee, 2007), and m-commerce (Alqatan, 2012; Chandra et al., 2010; Li \& Li, 2008; Xin et al., 2013; Zhou, 2011). Therefore, the two perceived risk types (security and privacy) were included in the current research for further investigation, as discussed below.

(1) Perceived Security Levels. From a consumer's perspective, the perceived security level could be defined as the subjective probability with which consumers believe that their commercial transactions will not be viewed, altered or manipulated during the process by inappropriate parties (Alqatan, 2012; Pavlou, 2001). Consumers are typically concerned about security when engaged in online activities and electronic payments (Jari \& Heikki, 2007; Zhou, 2011). If the payment always stays in states that are allowed, and users can only perform actions that are allowed, then the payment is secure. Jari and Heikki (2007) argue that the feeling of security makes the trusting intention stronger, and increases a consumer's willingness to depend on their trusted party, as they feel more comfortable. The authors also consider security control as a significant antecedent of initial trust and critical factors for the long-term success and future 
of e-commerce. In general, Building trust in e-commerce is difficult due to security concerns ( $\mathrm{Li}$ \& Li, 2008; Yeh \& Li, 2009)

As m-payments deal with financial information, great uncertainty and risk for users are involved (Zhou, 2011). Consumer perceptions of m-payment security have increased (Alqatan et al., 2012; Au \& Kauffman 2008; Eze et al. 2008) although various methods of security controls provide safeguards, encryption mechanisms, digital signatures, and authorisation to support the $3 \mathrm{G}$ mobile technology (Cheon, 2008; Karnouskos \& Fokus, 2004; Siau \& Shen, 2003; Veijalainen, 2007). Perceived security risks are considered a real challenge for m-payments providers (Rehman \& Coughlan, 2011) and a major obstacle in initiating trust relationships in m-commerce (Eze et al. 2008; Piao et al., 2012; Yeh \& Li, 2009). The security needed to cultivate online trust is equally important for m-commerce technology, especially in the early stages, since disappointing performance of the wireless communication system will make consumers suspicious of its ability to deliver on promises (Siau \& Shen, 2003). Further, Alqatan et al. (2012) argue that m-commerce is more exposed to risk of insecurity than with e-commerce. This is due to the weak links between the associated parties in the m-payment process, and it becomes easy for intruders to snoop on financial information in the m-commerce environment.

Another dimension of perceived security risks is the financial/monetary loss (Kim et al., 2010; Xin et al., 2013). M-payments involve sharing consumers' accounts and financial information with a mobile service provider, which means that consumers who believe that their financial assets will be protected against transaction loss would have strong trust in m-commerce transactions (Xin et al., 2013). In addition, Chandra et al. (2010) argued that the risk of financial losses cannot be eliminated in the m-payment scenario as it occurs in virtual space, caused by the lack of appropriate security safeguards and encryption mechanisms. This is also supported by Kao (2009). Specifically, m-payment data transmission is wireless, hence there is a possibility of interception of the radio transmission which leads to financial risks. For example, the masquerader may be able to gain access to confidential information stored in the mobile device, and modify the content of a transaction leading to financial loss (Misra \& Wickamasinghe, 2004). Therefore, financial risks could be a negative-effect factor of trust in consumer m-payments. 
In summary, many consumers are reluctant to be involved in m-commerce transactions such as selling and buying as they fear that their personal and financial details might be stolen by hackers and other cyber criminals (Alqatan et al., 2012). The encryption of transaction data transmitted through mobile networks and WAP services that control unauthorized access and maintain data security are another issue in the security of m-commerce (Piao et al., 2012). In addition, mcommerce security concerns are similar to those in e-commerce; involving authentication (data exchanged during the payment restricted to legitimate users only), confidentiality (data exchanged during the payment read and understood only by intended users), non-repudiation (participants of the transaction unable to deny their participation in the payment), and data integrity (accurate data exchanged during the payment) (Amoroso \& Magnier-Watanabe, 2011). However, additional perceived risks with m-payments could be related to mobile network malfunctioning and interruptions, the device technicalities, and perhaps the weak links between the associated parties in the m-payment process (Alqatan et al., 2012). Such types of perceived security risks can play a negative role in influencing consumer trust in conducting m-payments. Therefore, in the current research, the relationship between perceived security risks and consumer trust in m-payments was investigated to ascertain if it has substance in the Emirati context.

(2) Perceived Privacy Risks. When presenting perceived risks in e-commerce and m-commerce, scholars often couple security risks with privacy risks (Chandra et al., 2010; Li \& Li, 2008; Susanto et al., 2012; Veijalainen, 2007; Xin et al., 2013). However, privacy differs from security although they are closely related (Veijalainen, 2007). Privacy relates to consumers' concerns about the inappropriate use of their personal information (Nyshadham, 2000), such as the disclosure or misuse of private and financial information without consumers' permission when engaged in electronic and online activities (Grami \& Schell, 2004; Jari \& Heikki, 2007; Lee et al., 2007). Privacy is seen as fundamental in order to gain consumers' trust and establish a base where m-payment services that require personal context-sensitive information can also flourish (Karnouskos \& Fokus, 2004).

A review of $\mathrm{m}$-commerce studies suggests that consumers express great concerns about privacy in m-payments (Au \& Kauffman 2008; Xin et al., 2013). Consumers may have concerns about possible opportunistic behaviours of m-payment service providers that may result in the loss of 
their private information (Xin et al., 2013). Some consumers may also feel that they are in a vulnerable position because they have no control over transactions, and their financial details and their own privacy might be put at risk due to external parties such as company's trading partners and mediating third parties (Chandra et al., 2010). In m-banking transactions, Kim et al. (2010) argued that it is not only the protection of these payments that is important, the protection of individual privacy and transactional confidentiality should also be achieved to attain consumer trust. Protecting privacy is often the responsibility of the m-payment provider (Xu et al., 2005), such as Privacy policies posted on m-commerce websites (Mogenahalli et al., 2008). However, third-party privacy seals and device-based privacy-enhancing features could also address mpayment associated privacy risks (Xu et al., 2005).

Studies have shown that perceived privacy risks are directly related to consumer trust in mcommerce and m-payments. For instance, Siau et al. (2003) in their rhetorical model, considered privacy of consumer information as one cornerstone of trust building in m-commerce, and privacy protection as a fundamental objective that maximises trust. Likewise, Piao et al. (2012) in their measurement of m-commerce trust stated that consumers' privacy should be protected on WAP websites through the encryption technique of the wireless network to improve consumer trust in m-commerce significantly. Another study conducted by Mogenahalli et al. (2008) pointed out that privacy policies have a positive influence in developing benevolence trust in $\mathrm{m}$ commerce vendors. Amoroso and Magnier-Watanabe (2012) in their empirical study found that perceived privacy strongly influences trust in the mobile wallet, in line with the findings of Chandra et al. (2010) and Xin et al. (2013).

Similarly, perceived privacy risks were considered a focus of attention in many studies in the ecommerce trust literature. For instance, Belanger, Hiller, and Smith (2002) related the privacy statement and vendor's privacy policy to trust in the e-vendor. Likewise, Pavlou (2003) identified privacy risks as most likely encountered from behavioural uncertainty, which affect consumer's trust in e-commerce transactions. In addition, the positive awareness of privacy and on the Internet is associated with the trust of consumers in purchasing the services and products provided by SMEs via the Internet (Alqatan, 2012). Where many studies linked perceived privacy risks with online trust (Hsu, 2008; Lee et al., 2007), perception of privacy control and 
protection as important antecedents of trust in Internet shopping (Cheung \& Lee, 2000; Jari \& Heikki, 2007; Kim et al., 2010; Siau \& Shen, 2003), some other studies did not find privacy risks to have a significant relationship to trust in e-commerce (Djahantighi \& Fakar, 2010; Van Dyke, Midha, \& Nemati, 2007). Since privacy risk appears as a common concern in m-commerce and e-commerce transactions, the researcher incorporated it as a part of perceived risk in the CTMP model for more investigation within the Emirati context.

\subsubsection{Mobile-device characteristics.}

The growth of $\mathrm{m}$-commerce has resulted in a greater understanding of how trust can be built on a mobile device. Mobile devices (e.g. a cellular phone, PDA or a smart phone) are the means for conducting m-payments. Thus, mobile devices act as a gateway to the network of the m-payment provider. It is therefore essential that the interface between the consumer and his/her mobile device is trustworthy and that trust can always be guaranteed (Kim et al., 2010; Lee \& Benbasat, 2003; Meng et al., 2008). If this does not hold true then the entire trust architecture may collapse and all other m-payment trust concerns may become secondary issues (Lee \& Benbasat, 2003).

Although m-payment systems are a progression from the e-payment systems, there are some marked differences, especially in terms of the mobile service provider involvement and mobile device limitations (Chandra et al., 2010). According to Siau and Shen (2003), trusting the mobile device and the m-payment provider are equally important in securing overall consumer trust in m-payments. Specifically, a devices' functionality, design features and security may impact users' trust in m-payments (Kim et al., 2010; Lee \& Benbasat, 2003; Yeh \& Li, 2009). These characteristics of the mobile device are considered challenges associated with m-commerce (Mogenahalli et al., 2008; Venkatesh et al., 2003) and weak points need to be addressed to improve m-commerce trust and adoption experiences. These characteristics are exclusively considered as the antecedents of trust in m-commerce because of the unique features of mobile devices, which would not be found in e-commerce trust literature.

Mobile devices significantly differ in embodying these unique features. For instance, a Smartphone (e.g., iPhone (Apple), Galaxy (Samsung), and BlackBerry (RIM)) integrates the multi-functionality of a mobile device with advanced communication and computing-enabled feature abilities (Kim, 2008) and overcomes the traditional mobile device's limitations such as a 
small display screen, inconvenient keyboard, functional services, and relatively greater insecurity (Kim et al., 2010; Lee \& Chung, 2009). In addition to the successful propagation of Smartphone devices, rapid growth of mobile-based payments and banking use has become evident (Susanto et al., 2012). The next section describes in detail the main characteristics of mobile devices and their influence on consumer trust in conducting m-payments.

(1) Device Capability. Mobile device capability is related to the performance of the hardware (device) and the software (operating system), both associated with the mobile device manufacturer, to conduct m-payment transactions (Kounelis \& Loeschner, 2012). Accordingly, consumer trust in the mobile device is achieved by trusting these two components (Kounelis $\&$ Loeschner, 2012). Some mobile handsets are functionally limited in their computational and processing power, memory and battery life (Mogenahalli et al., 2008; Siau \& Shen, 2003). Lee and Benbasat (2003), Chae and Kim (2003) and Yeh and Li (2009) agreed that the limited options of a mobile phone could hinder the development of trust in m-commerce. In addition, the embedded solutions in mobile devices required to conduct financial functions that should operate quite efficiently and in compatibility with the chipset, can make the payment easier, more comfortable and more trustworthy (Kim et al., 2010).

In addition, Lee and Benbasat (2003) and Chae and Kim (2003) depicted a positive relationship between the device capabilities and trust in m-commerce by agreeing that limited system functionalities (lower multimedia processing capabilities) can hinder the development of trust in $\mathrm{m}$-commerce. Basically, the functions of the mobile phone should effectively meet the needs of $\mathrm{m}$-commerce in order to establish consumer trust in it (Piao et al., 2012). Specifically, being capable of connecting to mobile communication networks, to initiate, authorize, and confirm a payment (Amoroso \& Magnier-Watanabe, 2011; Xin et al., 2013). As literature gives indication of the relationship between the device capability and consumer trust, device capability was added for further examination in the current research.

(2) Device Design Specifications. Whereas mobile devices are convenient for anytime payments, their design-related issues such as small screens (Chandra et al., 2010; Cho et al., 2007; Mogenahalli et al., 2008; Siau et al., 2003; Zhou, 2011), low-resolution displays (Meng et al., 2008; Min et al., 2008; Siau \& Shen, 2003; Siau et al., 2003; Zhou, 2011), inconvenient input 
and effective navigation (Mogenahalli et al., 2008; Zhou, 2011), and tiny multifunction keypads (Chandra et al., 2010; Mogenahalli et al., 2008) make developing user-friendly interfaces and mcommerce applications a challenge (Chandra et al., 2010; Siau \& Shen, 2003; Siau et al., 2003; Yeh \& Li, 2009). Lee and Benbasat (2003) and Chae and Kim (2003) argued that mobile devices with smaller screens can hinder the development of trust in m-commerce. Likewise, Xin et al. (2013) argue that mobile devices should be designed to foster consumer confidence, reduce their uncertainties and perceived risks to increase the likelihood of wider consumer acceptance, while Alqatan et al., (2012) and Siau and Shen (2003) suggest that device designers have to concentrate more on the design aspects to improve usability and allow consumers to conduct payments confidently, without forfeiting mobility and flexibility.

One specific design attribute, design aesthetics, was examined by $\mathrm{Li}$ and Yeh (2010) who indicated that trust in m-commerce could be increased by these means, by appealing to consumers and attracting their attention through a balanced, emotionally appealed interface. In ecommerce, the design factor has been examined in terms of the website design features, content and layout. For instance, the website design has been indicated as a factor influencing trust in an e-vendor's website (Nah \& Davis, 2002). Additionally, Katerattanakul and Siau (2003) stressed the importance of web site design as a factor for developing continuous trust in mobile vendors. Similarly, Lee and Turban (2001) pointed that the majority of the trust antecedents from a consumer perspective are perceptual in nature; consumers' trust may be influenced by the design of Internet storefronts. Based on the given discussion, device-design factor was included in the current research for further investigation.

(3) Device Security. Mobile devices that are more secure and more convenient could develop trust in m-payment and m-banking, and commercial transactions worldwide (Herzberg, 2003). As for device security, some current mobile phones use only simple pre-programmed processors, and therefore can be trusted to operate a payment securely. However, some devices support downloaded, general-purpose applications and may be vulnerable to the same threats as any other computer (Herzberg, 2003). From a non-technical perspective, mobile devices are prone to theft or loss, which makes the mobile owner more concerned about his/her mobile, since it holds credit card numbers and other personal data, which may result in hindering consumer trust 
(Amoroso \& Magnier-Watanabe, 2011; Chandra et al., 2010; Misra \& Wickamasinghe, 2004). However, scarce literature was found associating device security with consumer trust in $\mathrm{m}$ payments, thus further empirical examination on this factor was considered in the current research, to better understand its potential influence on m-payments trust.

Few studies associated trust with structural assurances in the form of agreements, contracts, regulations, policies, laws, feedback forums, guarantees, escrow services and others enhance initial trust between involved parties in a relationship (McKnight et al., 2004; Pavlou \& Gefen, 2004). Similarly, very few studies alluded to the relationship between word of mouth and trust in mobile payments, but no empirical testing was found. Since scant evidence of research into these factors found to influence consumer trust in m-payments, these two factors were not considered in the current research but were considered for future work. However, structural assurances are usually offered by the provider (telecom operator) in which consumers put their trust beliefs, and thus, all provider's characteristics might encompass these assurances in an indirect way. Likewise, the influence of the family and the environment on consumer trust was included in the current research as the 'trust environment' factor, it could dispense word of mouth to trust environment due to their relevance.

Overall, while m-payments adoption appears to vary from country to another, it seems that trusting m-payments is a global issue. A research-based report published in March 2013 by Ipsos MORI in Britain highlights the trust issue in m-payments (The Logic Group, 2013). Holding the title "Trust remains the biggest barrier to mobile payments", the report stated that while over half of those surveyed people (58\%) said that they will purchase products and services online, they are still building their confidence when it comes to shopping via their mobile device (who accounted for only $30 \%$ to trust m-payments). The report indicated that the majority of the surveyed people had not perceived retailers to be trustworthy enough to protect their personal information.

\subsubsection{Studies about trust in m-payments in the Emirates and surrounding Middle Eastern and Arab countries.}

Unfortunately, scant research attention has been given to the factors that influence consumer trust in m-payments in Middle Eastern and Arab countries; including the Emirates. However, 
Bhatti (2008) conducted an empirical study in the Emirates and found that there were positive relationships between perceived ease of use, subjective norms, behavioural control and intention to adopt m-commerce in the Emirates. In his study, the importance of trust in adopting mcommerce was indicated in an indirect way. In Kuwait, Rouibah (2007) explored the intention to use a new m-payment service recently introduced. By using a mixed method approach, Rouibah found that trust affected only female users' intention to use Mnet, regardless of users' experience, without determining the factors that influence the trust construct.

Al-Mamari (2007) found that most Omani consumers did not trust m-commerce in their transactions, claiming that they have some technological security concerns, without showing evidence of this. Al-Mamari argued that m-commerce in Oman "needs some effort and time to reach a high level of development and gain consumers' trust and satisfaction" (p. 67). This lack of trust highlights the importance of studying trust in m-commerce in Oman, and most probably the other Gulf countries. Manochehri and AlHinai (2008) indicated in their study of the attitudes of mobile users towards m-commerce in Gulf countries that security concerns play a significant role in decreasing the trust of Gulf people in m-commerce. Similarly, Alsultany (2012) pointed out that the security of m-commerce services could have a major impact on customers' trust when using them, and concluded that m-commerce in Bahrain needs more effort and time to reach a high level of development and gain customer trust. The levels of trust are, to a large extent, similar in other countries in the Arab world, where trust is considered a significant issue in adopting m-commerce, and that trust needs to be developed (Alhosni et al., 2010; Alsultanny, 2012; Barakat \& Sheikh, 2010; Yaseen \& Zayed, 2010).

However, a report based on a quantitative survey of the global m-payments landscape by MasterCard (2012) gauges the readiness for m-payments of 34 global markets, representing approximately $85 \%$ of the world's household consumption expenditure, including the Emirates and some other Arab and Middle Eastern countries. The report identified six main success factors of m-payments: consumer readiness, environment (economic, technological, and demographic), financial services, infrastructure (mobile phone and telecommunication industries), mobile commerce clusters (partnerships with external parties) and regulations. Regarding the Emirates results, the report indicated that the overall score of m-payments 
readiness index in the Emirates is about $37.9 \%$, above the index average (33.2\%). However, the report shows that consumer readiness value (which determines consumers' knowledge of, trust in and comfort with, and experience using m-commerce payments) accounted below the average for only around 7.5\%; the lowest percentage among the four other components. The report concluded by implying that this factor indicates a clear direction for marketing m-payments of all types to consumers in the Emirates.

Overall, trust is considered an important factor for m-payments adoption in the Emirates and the surrounding countries. Very few studies conducted in Arab countries indicate that the people there lack trust in m-payments. None of these studies have explored the factors that influence consumer trust. This results in little understanding of trust in m-payments and the way it can be developed. Thus, this research attempts to fill this gap, by investigating in-depth the factors that impact consumer trust in m-payments.

\subsubsection{Summary of the factors influencing consumer trust in m-payments.}

Consumer trust in m-payment depends on three main factors: the consumer, the firm and the mobile technology. The trust journey begins with the consumers, as they have their own trusting beliefs, personal attributes and experiences. They might be affected by environment and surrounding social influences. Consumers' risk perception of m-payments also influences their trust, such as technical, security and privacy concerns. The provider of m-payment services can play a significant role in developing its consumers' trust through its reputation and other attributes. The mobile device (with its characteristics and capabilities) can have an impact on consumers trust as well. All of these factors together can influence consumer trust in mpayments. The following Table (2.3) summarises each category and its factors as found in the literature.

Table 2.3 Supporting References for the Constructs Used for the CTMP Model

\begin{tabular}{|c|l|l|l|}
\hline Factor & $\begin{array}{c}\text { Mobile payment } \\
\text { literature }\end{array}$ & $\begin{array}{c}\text { Mobile commerce } \\
\text { literature }\end{array}$ & $\begin{array}{c}\text { Electronic commerce } \\
\text { literature }\end{array}$ \\
\hline Awareness & Kim et al. (2010) & $\begin{array}{l}\text { Alqatan et al. (2012); Cho } \\
\text { et al. (2007); Hollingsworth } \\
\text { and Dembla (2013); Li and } \\
\text { Li (2008); Piao et al. (2012) }\end{array}$ & $\begin{array}{l}\text { Chiravuri and Nazareth } \\
\text { (2011), Yao and Li (2008) }\end{array}$ \\
\hline
\end{tabular}




\begin{tabular}{|c|c|c|c|}
\hline $\begin{array}{l}\text { Propensity to } \\
\text { trust }\end{array}$ & None & $\begin{array}{l}\text { Alqatan et al. (2012), Kim } \\
\text { et al. (2010), Li and Li } \\
\text { (2008), Guangming and } \\
\text { Yuzhong (2011),Piao et al. } \\
\text { (2012) }\end{array}$ & $\begin{array}{l}\text { Connolly and Bannister } \\
\text { (2007), McKnight et al. } \\
\text { (2002), McKnight \& } \\
\text { Chervany (2006) }\end{array}$ \\
\hline $\begin{array}{l}\text { Uncertainty } \\
\text { avoidance }\end{array}$ & None & $\begin{array}{l}\text { Dai and Palvi (2009), Kao } \\
\text { (2009), Min et al. (2009), } \\
\text { Rahmati (2004), Sikolia et } \\
\text { al. (2010) }\end{array}$ & $\begin{array}{l}\text { Cyr (2008), Doney et al. } \\
\text { (1998), Gefen and Heart } \\
(2006), \text { Jari \& Heikki } \\
(2007), \text { Pavlou and Chai } \\
(2002)\end{array}$ \\
\hline $\begin{array}{c}\text { Past personal } \\
\text { experience }\end{array}$ & None & $\begin{array}{l}\text { Alqatan, et al. (2012); } \\
\text { Hillman et al. (2011); Jari } \\
\text { \& Heikki (2007); Joubert } \\
\text { \&Van Belle (2009); Siau et } \\
\text { al. (2003) }\end{array}$ & $\begin{array}{l}\text { Chiravuri and Nazareth } \\
\text { (2011); Gefen et al. (2003); } \\
\text { Kong \& Hung } \\
\text { (2006); McKnight et al. } \\
\text { (2002); Pavlou (2003) }\end{array}$ \\
\hline $\begin{array}{c}\text { Trust } \\
\text { environment }\end{array}$ & None & & $\begin{array}{l}\text { Borchers (2001),Cheung } \\
\text { and Lee (2000), Connolly } \\
\text { and Bannister (2007), } \\
\text { Siddiqui (2008) }\end{array}$ \\
\hline $\begin{array}{l}\text { Provider's } \\
\text { reputation }\end{array}$ & $\begin{array}{l}\text { Chandra et al. (2010) } \\
\text { Kim et al. (2010); Xin } \\
\text { et al. (2013) }\end{array}$ & $\begin{array}{l}\text { Guangming and Yuzhong } \\
\text { (2011), Li and Li (2008), } \\
\text { Liu et al, (2009), } \\
\text { Mogenahalli et al. (2008), } \\
\text { Siau \& Shen (2003), Siau et } \\
\text { al. (2003), Yeh and Li } \\
\text { (2009) }\end{array}$ & $\begin{array}{l}\text { Chen \& Dhillon (2003); } \\
\text { Chiravuri and Nazareth } \\
\text { (2011); Corbitt et al. } \\
\text { (2003); Doney \& Cannon, } \\
\text { (1997), Friedman et al. } \\
\text { (2000), Jarvenpaa et al. } \\
\text { (1999), Kim and Prabhakar } \\
\text { (2000), Koufaris \& } \\
\text { Hampton-Sosa (2004), } \\
\text { McKnight et al. (2001b); } \\
\text { McKnight \& Chervany } \\
\text { (2002); Pavlou (2003); Yan } \\
\text { et al. (2010), Yao and Li } \\
\text { (2008) }\end{array}$ \\
\hline $\begin{array}{c}\text { Provider's } \\
\text { trustworthiness }\end{array}$ & $\begin{array}{l}\text { Xin et al. (2013); Zhou } \\
\text { (2011) }\end{array}$ & $\begin{array}{l}\text { Min et al. (2008), } \\
\text { Mogenahalli et al. (2008), } \\
\text { Piao et al. (2012), Susanto } \\
\text { et al. (2012), Xin et al. } \\
\text { (2013), Xu et al. (2005), } \\
\text { Yeh \& Li, (2009) }\end{array}$ & $\begin{array}{l}\text { Bhattacherjee (2002), Chen } \\
\text { \& Dhillon (2003), Cody- } \\
\text { Allen \& Kishore (2006), } \\
\text { Connolly \& Bannister } \\
\text { (2007), Corbitt et al. } \\
\text { (2003), Gefen et al. (2003), } \\
\text { Gefen (2000), Jari and } \\
\text { Heikki (2007), Kong and } \\
\text { Hung (2006), Lee and } \\
\text { Turban (2001), McKnight } \\
\text { et al. (2004), McKnight and } \\
\text { Chervany (2006), Pavlou } \\
\text { (2003), Salam et al. (2005), } \\
\text { Salo and Karjaluoto (2007), } \\
\text { Yan and Holtmanns, (2008) }\end{array}$ \\
\hline
\end{tabular}




\begin{tabular}{|c|c|c|c|}
\hline $\begin{array}{c}\text { Perceived } \\
\text { security levels }\end{array}$ & $\begin{array}{l}\text { Chandra et al. (2010); } \\
\text { Hu, Li, \& Hu (2008); } \\
\text { Karnouskos and Fokus } \\
\text { (2004); Xin et al. } \\
\text { (2013); Zhou (2013) }\end{array}$ & $\begin{array}{l}\text { Alqatan, et al. (2012); } \\
\text { Amoroso and Magnier- } \\
\text { Watanabe (2012); Lee et al. } \\
\text { (2007), Hollingsworth and } \\
\text { Dembla (2013); Jari \& } \\
\text { Heikki (2007); Mogenahalli } \\
\text { et al. (2008); Misra and } \\
\text { Wickamasinghe (2004); } \\
\text { Piao et al. (2012); Rehman } \\
\text { \& Coughlan (2011); Siau et } \\
\text { al. (2003); Siau \& Shen } \\
\text { (2003); Susanto et al. } \\
\text { (2012); Veijalainen (2007); } \\
\text { Yeh \& Li (2009) }\end{array}$ & $\begin{array}{l}\text { Connolly and Bannister } \\
\text { (2007), Corbitt et al. } \\
\text { (2003), Hoffman et al. } \\
\text { (1999), Jari and Heikki } \\
\text { (2007), Lee \& Turban } \\
\text { (2001), Pavlou (2001), } \\
\text { Yan et al. (2010) }\end{array}$ \\
\hline $\begin{array}{c}\text { Perceived } \\
\text { privacy risks }\end{array}$ & $\begin{array}{l}\text { Au and Kauffman } \\
\text { (2008); Chandra et al. } \\
(2010) ; \text { Karnouskos and } \\
\text { Fokus (2004); }\end{array}$ & $\begin{array}{l}\text { Alqatan (2012), Amoroso } \\
\text { and Magnier-Watanabe } \\
\text { (2012); Hollingsworth and } \\
\text { Dembla (2013); Jari \& } \\
\text { Heikki (2007); Jinlong et } \\
\text { al. (2011); Lee \& Lee } \\
\text { (2007); Mogenahalli et al. } \\
\text { (2008), Piao et al. (2012), } \\
\text { Veijalainen (2007); Xu et } \\
\text { al. (2005) }\end{array}$ & $\begin{array}{l}\text { Belanger et al. (2002), } \\
\text { Cheung \& Lee (2000), } \\
\text { Connolly and Bannister } \\
\text { (2007), Djahantighi and } \\
\text { Fakar (2010), Featherman } \\
\text { \& Pavlou (2003); Grami \& } \\
\text { Schell (2004), Hoffman et } \\
\text { al. (1999), Hsu (2008), Jari } \\
\text { and Heikki (2007), Lee et } \\
\text { al. (2007), Nyshadham } \\
\text { (2000), Pavlou (2003), Van } \\
\text { Dyke et al. (2007) }\end{array}$ \\
\hline $\begin{array}{c}\text { Capability of } \\
\text { the mobile } \\
\text { device }\end{array}$ & & $\begin{array}{l}\text { Chae and Kim (2003), Kim } \\
\text { et al. (2010), Kounelis and } \\
\text { Loeschner (2012), } \\
\text { Mogenahalli et al. (2008), } \\
\text { Piao et al. (2012), Yeh and } \\
\text { Li (2009) }\end{array}$ & \\
\hline $\begin{array}{c}\text { Design } \\
\text { specifications }\end{array}$ & & $\begin{array}{l}\text { Chae \& Kim (2003); } \\
\text { Chandra et al. (2010), Cho } \\
\text { et al. (2007), Mogenahalli } \\
\text { et al. (2008), Min et al. } \\
\text { (2008), Siau and Shen } \\
\text { (2003); Siau et al. (2003), } \\
\text { Xin et al. (2013), Yeh \& Li } \\
\text { (2009), Zhou (2011) }\end{array}$ & \\
\hline $\begin{array}{l}\text { Security of the } \\
\text { mobile device }\end{array}$ & & $\begin{array}{l}\text { Amoroso \& Magnier- } \\
\text { Watanabe (2011), Chandra } \\
\text { et al. (2010), Herzberg } \\
\text { (2003), Misra and } \\
\text { Wickamasinghe (2004), } \\
\text { Yeh and Li (2009); }\end{array}$ & \\
\hline
\end{tabular}




\subsection{Summary of Literature Review}

Trust is highly significant with respect to m-payment, and is one of the important constructs that influence a consumer's intention to conduct an m-payment transaction, in both developing and developed countries. However, literature shows that there is a lack of consumer trust in conducting m-payments. This lack of trust could be caused by technological, cultural, social or other aspects. The literature also shows little understanding of consumer trust in m-payments and the factors that influence it, especially in the Middle East and Arab countries. As shown in Table 2.3, many factors that influence consumer trust have been investigated in the context of mcommerce, but not specifically, for m-payments. M-payment is likely to be more sensitive and risky than generic m-commerce. While consumers may be comfortable with ordering with their phones while paying on delivery (m-commerce), m-payments may be more critical as it deals directly with money and the credit in bank accounts. Thus, the factors found in the m-commerce literature could be with high relevance to be investigated in the m-payments research field, and will increase our knowledge of trust in m-payments.

In addition, trust is often studied in the literature theoretically, or as one component of $\mathrm{m}$ payment adoption factors rather than being studied independently. It is often used as an independent variable, with no certain influencing factors. Consequently, there is no focus on trust and the factors that influence it in the m-commerce arena. Thus, more attention needs to be given to the trust construct, in order to understand it and to get a better perception of it. In addition, none of the identified studies conducted in the Gulf and Arab countries, to date, have been found empirically examined the factors that influence consumer trust in m-payments. There are a few studies that indicate the lack of consumer trust in Gulf and Arab states, without discussing indepth how this trust could be better understood and achieved, and without presenting factors that influence it.

All of these reasons raise the need for this research to better understand trust and the factors that influence it in the m-commerce field. Thus, this research aims to address these gaps in literature, by investigating the factors that influence consumer trust in m-payments, in the specific case of a Middle Eastern Gulf country; the Emirates. The following section proposes the CTMP conceptual model. 


\subsection{A Proposed Conceptual Model and Research Propositions}

This section defines the terms theory, framework and conceptual model and differentiates between them. It then introduces the tentative conceptual framework that is proposed for this research, and highlights its characteristics and contents, followed by stating a set of the current research propositions.

\subsubsection{Theories, frameworks and models.}

A theory is defined as a "system of interconnected ideas that condenses and organises knowledge about the social world" (Neuman, 2005, p. 50), whereas a theoretical perspective is the "philosophical view informing the methodology and thus providing a context for the process of grounding its logic and criteria" (Crotty, 1998, p. 3). There are two main types of theory that many social researchers develop in their research: conceptual frameworks and conceptual models. According to Smyth (2004), conceptual frameworks are structured from a set of broad ideas and theories that help researchers to properly identify their research problem, frame their questions' domain and find suitable literature. A conceptual framework can guide research by providing a visual representation of theoretical constructs (and variables) of interest (Creswell, 2009). On the other hand, conceptual models are viewed as theoretical diagrams that represent a systematic view of phenomena by specifying relations among variables using a set of concepts/entities and relationships between them, based on the understanding of a certain domain (Creswell, 2009; Parsons and Cole, 2005). This research embraced a conceptual model, because it aims to determine the concepts (in the form of factors) that influence consumer trust in m-payments, modelled in one diagram.

The proposed model regroups the proposed factors that are expected to influence consumer trust in m-payments, as found in the extant literature.

\subsubsection{The CTMP model and research propositions.}

The proposed Consumer Trust in Mobile Payment model (CTMP) is mainly centred on the factors that directly influence trust in m-payments (Siau et al., 2003; Siau \& Shen, 2003). It takes the theoretical perspective of interpersonal and dispositional trust from McKnight et al. (2002) and McKnight \& Chervany (2001). It incorporates dimensions environmental influences 
(Cheung \& Lee, 2000; Hofstede, 2001), and includes other factors from trust and m-commerce literature. The model is shown in Figure 2.6.

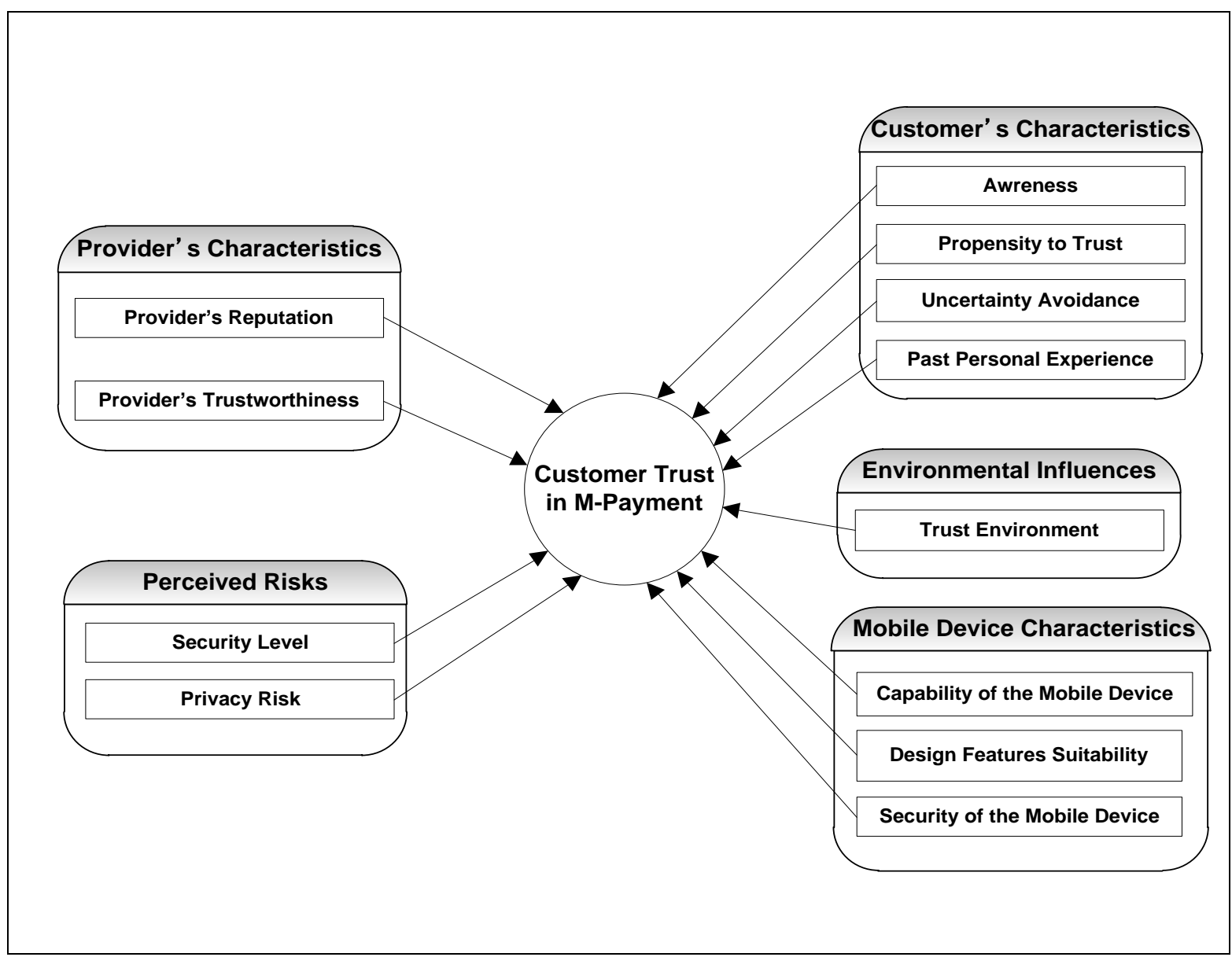

Figure 2.6 Proposed Model of Consumer Trust in Mobile Payments

Most academic researchers use conceptual models to collate and report on a range of answers that may address their research questions (Smyth, 2004). In order to answer this research questions and better understand the relationship between the factors that influence trust, the model was designed with five main categories of factors. As mentioned in section 2.5.6., these categories are: consumer characteristics, environmental influences, provider characteristics, perceived risks, and mobile-device characteristics. The proposed model in the current research gathers all of these categories and related factors in one diagram, as shown in Figure 2.6. As discussed in the literature review, each factor in these categories was proposed to have an influence on consumer trust in m-payments. These propositions are summarised in Table 2.4. 
Table 2.4 Set of Research Propositions

\begin{tabular}{|c|c|}
\hline No. & Research Propositions \\
\hline P1 & $\begin{array}{l}\text { The more the consumer awareness about mobile payments, the higher the trust in mobile } \\
\text { payments. }\end{array}$ \\
\hline $\mathrm{P} 2$ & The higher the consumer's propensity to trust, the higher the trust in mobile payments. \\
\hline P3 & $\begin{array}{l}\text { The higher the consumer's uncertainty avoidance the lower the consumers trust in mobile } \\
\text { payments. }\end{array}$ \\
\hline P4 & Consumer positive personal experience increases his/her trust in mobile payments. \\
\hline P5 & The higher the trust environment, the higher the consumers trust in mobile payments. \\
\hline P6 & $\begin{array}{l}\text { A provider's good reputation has a significant positive influence on consumers trust in mobile } \\
\text { payments. }\end{array}$ \\
\hline P7 & The higher the provider's trustworthiness, the higher the consumers trust in mobile payments. \\
\hline P8 & $\begin{array}{l}\text { The higher the perceived security levels in mobile payments, the higher the consumer trust in } \\
\text { mobile payments. }\end{array}$ \\
\hline P9 & Perceived privacy risks negatively influence consumer trust in mobile payments \\
\hline $\mathrm{P} 10$ & $\begin{array}{l}\text { The higher the capability of the mobile device, the higher the consumers trust in mobile } \\
\text { payments. }\end{array}$ \\
\hline P11 & $\begin{array}{l}\text { The more suitable the design of the mobile-device to conduct an m-payment, the higher the } \\
\text { consumers trust in mobile payments. }\end{array}$ \\
\hline P12 & $\begin{array}{l}\text { The higher the security of the mobile device, the higher the consumers trust in mobile } \\
\text { payments. }\end{array}$ \\
\hline
\end{tabular}

In order to get in-depth information and better understanding of the factors of consumer trust in m-payments in the Emirates, a qualitative investigation on these factors was initially carried out. The qualitative results were used to test the CTMP model and the propositions (see Table 2.4) which had been determined after reviewing the literature. The next chapter focuses on the focus group sessions as the first methodological approach in the current research and implies some new aspects regarding trust in m-payments. 


\section{CHAPTER THREE \\ Research Design and Qualitative Methodology for Phase One}

\subsection{Chapter Overview}

This chapter is divided into seven sections. Firstly, a description of the various research paradigms is given along with a justification for the choice of a post-positivism (pragmatism) approach as the epistemological perspective in the current research (section 3.2). In section 3.3, the stages of the research design are outlined. Following this, a discussion of the methodological approach (mixed method) is presented (section 3.4). Next, the qualitative method is presented as the first phase in the current study, and an examination of the validity and reliability of the interviewing method is presented (section 3.5), and the process involved in planning, managing and interpreting the semi-structured focus group sessions is discussed (section 3.7). Next, the data analysis and findings collected through qualitative interviewing is presented (section 3.8). Finally, concluding remarks are given in section 3.9, along with the revised CTMP model and the research hypotheses.

\subsection{The Epistemological Perspective (Research Paradigm)}

A paradigm reflects "a basic set of philosophical beliefs about the nature of the world... A research paradigm provides the guidelines and the principles associated with the way to conduct research" (Ticehurst \& Veal, 1999, p. 25). The methods and techniques of the research should be in harmony with these guidelines and principles. The five most common paradigms for social and behavioural research are: positivism, post-positivism, interpretivism (or constructivism), criticalism (critical theory), and pragmatism (Cavana, Delahaye, \& Sekaran, 2001; Creswell \& Clark, 2011; Orlikowski \& Baroudi, 1991; Pickard, 2007; Tashakkori \& Teddlie, 2003). This section justifies the selection of a philosophic stance for the research. 
Three paradigms were selected to be of use in the research, with 'Pragmatism' the overarching paradigm that encapsulates interpretivist and post-positivist approaches where appropriate. All three are characterised in the following paragraphs.

Interpretivism. Interpretive research is conducted on the basis that meanings are constructed by human beings as they engage with the world they are interpreting, and that reality is constructed through interaction between human beings and their world within a social context (Crotty, 1998; Orlikowski \& Baroudi, 1991; Pickard, 2007; Walsham, 1995). Interpretivism is based on belief that the world would have no meaning if phenomena were not interpreted by observers (Crotty, 1998). It uses the presumption that participants and their 'subjective view' form the understanding or meaning of a phenomenon. Specifically, "when participants provide their understanding, they speak from meanings shaped by social interaction with others and from their own personal histories" (Creswell \& Clark, 2011, p. 40). The philosophical stance of this research agrees with this worldview in that studying consumer trust in m-payment requires the participants to talk about their perceptions and experiences from a subjective view.

Post-positivism. Post positivist research is based on a social reality, but accepts that knowing this reality will always be inhibited by human imperfections in detecting its nature (Pickard, 2007). Post-positivists use the falsification technique to make a guess and then try to disprove it (Popper, 1980). Post-positivists argue for knowledge based on determinism or cause-and-effect thinking, detailed observations and measures of variables, and testing of theories that are continually refined (Creswell \& Clark, 2011; Slife \& Williams, 1995). The philosophical stance of this research is also consistent with this worldview in that consumer trust in m-payments could be based on a causal-law perception. Trust subsequently is a dependent variable, and other factors (as independent variables) need to be tested to check their influence on the dependent variable, and then either supported or not.

Pragmatism. Pragmatism draws on many ideas, including the employment of "what works", and using diverse approaches and valuing both objective and subjective knowledge (Creswell \& Clark, 2011, p.23). Pragmatists focus on the consequences of the research, the primary importance of the research question(s) rather than the methods, and multiple methods of data 
collection inform the problems under study (Creswell \& Clark, 2011; Tashakkori \& Teddlie, 2003). Because the research question is essential, the data collection and analysis methods chosen should provide insights into the question with no philosophical loyalty to any alternative paradigm. The pragmatism paradigm is considered as an "umbrella" that could embrace multiple paradigms for a single research project (Creswell \& Clark, 2011, p. 174).

Pragmatism has been identified as the most appropriate paradigm for the current research for several reasons. First, the researcher's worldview arises out of actions, situations, and consequences, and is associated with beliefs in singular and multiple realities (hypotheses are tested and multiple perspectives are provided from subjective and objective views). This ontology matches with the beliefs of pragmatism. Second, the researcher also believes in accepting external reality in order to achieve the research objectives and answer the research question, and pragmatism supports that belief. Third, the research question requires that the researcher is not committed to only one system of research paradigms. Instead, interpretivist and post-positivist views should be supported. The interpretivist view is related to the qualitative phase of this research. At the same time, the post-positivist view is supported in the quantitative

phase of the research. Trust is a dependent variable and other variables (factors) influence it with different hypotheses to be supported or not. These influences are probabilistic and change over time. Incorporating two paradigms (interpretivism and post-positivism) can be achieved in a pragmatist methodological framework

The next section discusses the methods used to conduct this research, why they have been chosen among alternatives, what advantages and disadvantages they have, and how they will be applied.

\subsection{Methodological Approach (Mixed Methods)}

This section discusses the research method (mixed methods of qualitative and quantitative) that was used in the current study, and justifies the reasons behind choosing this methodology.

\subsubsection{The qualitative and quantitative approaches.}

The current research utilised a combination of qualitative and quantitative approaches. This is an example of mixed methods research, through which a researcher combines elements of different research approaches for the purposes of breadth, depth of understanding and corroboration 
(Dellinger \& Leech, 2007; Gallivan, 1997; Lee \& Sarker, 2008; Mingers, 2001). Often the distinction between qualitative and quantitative research is framed in terms of using words (qualitative) rather than numbers (quantitative), or using closed-ended questions (quantitative hypothesis) rather than open-ended questions (qualitative interview questions) (Creswell, 2009). More differences between the two approaches are shown in Table 3.1.

Table 3.1 Comparison of the quantitative and qualitative approaches (Adapted from Biemans (2003), Creswell (2009), Cavana et al. (2001) and Neuman (2005))

\begin{tabular}{|l|l|l|}
\hline \multicolumn{1}{|c|}{ Quantitative approach } & \multicolumn{1}{|c|}{ Qualitative approach } \\
\hline Research objective & $\begin{array}{l}\text { Description, explanation and } \\
\text { prediction }\end{array}$ & $\begin{array}{l}\text { Description, exploration, and } \\
\text { discovery }\end{array}$ \\
\hline Research focus & $\begin{array}{l}\text { Theory is largely causal and } \\
\text { deductive }\end{array}$ & $\begin{array}{l}\text { Theory can be causal or non- } \\
\text { causal, and is often inductive }\end{array}$ \\
\hline Research approach & Focus on variables & $\begin{array}{l}\text { Focus on interactive } \\
\text { processes, events }\end{array}$ \\
\hline $\begin{array}{l}\text { Data collection } \\
\text { instrument }\end{array}$ & Questionnaire design & $\begin{array}{l}\text { In-depth interviews and focus } \\
\text { group discussion }\end{array}$ \\
\hline Sampling & Many cases, subjects & $\begin{array}{l}\text { Interview with discussion } \\
\text { guide }\end{array}$ \\
\hline Nature of data & $\begin{array}{l}\text { Fata are in the form of numbers } \\
\text { from precise management }\end{array}$ & $\begin{array}{l}\text { Data are in the form of words } \\
\text { from documents, observations } \\
\text { and transcripts }\end{array}$ \\
\hline Data analysis & Identify statistical relationships & $\begin{array}{l}\text { Search for patterns, themes, } \\
\text { and holistic features }\end{array}$ \\
\hline Results & Generalisable findings & $\begin{array}{l}\text { Particularistic findings, } \\
\text { multiple perspectives }\end{array}$ \\
\hline
\end{tabular}

\subsubsection{Why mixed methods?}

A mixed method has been selected for this research because both qualitative and quantitative approaches are required to answer the research question. The qualitative approach is needed for exploring the trust determinants in m-payment from the consumers' perspectives in the Emirates. Investigating consumers' perceptions and experiences requires listening to them talking about the factors that influence their trust in m-payments. On the other hand, the need for the quantitative approach arose out of the requirement for testing and assessing the factors of $\mathrm{m}$ payment trust in a greater sample of the consumers in the Emirates, and discovering the extent of their influence and direction on consumer trust, in order to generalise the findings and make it more representative of the Emirates society. 
The mixed methods approach can be used as a means of moving the analysis forward, with one method being used to inform the other (Denscombe, 2007). In this research, the second, quantitative, method is introduced specifically to address research issues arising from findings produced by the first, qualitative method: the development of the questionnaire was based on the analysis of the focus group findings. Combining the findings of the two approaches helped in providing a complete picture of the factors influencing the trust in m-payment from the perspectives of consumers in the Emirates.

Researchers using mixed methods research need to consider the order in which the methods are used (Bryman \& Bell, 2007; Denscombe, 2007). For this research, the qualitative research will facilitate the quantitative research. This means that the focus group sessions will be conducted initially to explore the factors that influence consumer trust in m-payments in the Emirates. Based on the existing literature and the findings of the focus groups, the questionnaire was developed.

\subsubsection{Considerations and challenges.}

There are several challenges with the mixed method approach. These include the time and cost required in using several methods (Johnson \& Christensen, 2004). The researcher needed to develop skills related to both qualitative and the quantitative approaches. This required a long time for the research design and the data collection.

Interviewing key informants in phase one will provide contextual understanding, while the survey method in phase two will provide a statistical test. Thus, when one method corroborates another's findings, the results become more valid. The two phases were sequential, beginning with the focus group interviews.

\subsection{Phase One (A Qualitative Method: Focus Groups Interviews)}

The focus group is a method of interviewing more than one person, usually at least four, at the same time to discuss and comment on the topic that is the subject of the research (Bryman \& Bell, 2007; Powell, Single, \& Lloyrd, 1996). The focus group technique has been used in social research, but possibly its most obvious use has been in market research where it is applied to "investigate consumer habits and preferences" (Pickard, 2007, p. 219), and to test consumer 
reactions to products or services (Bryman \& Bell, 2007). This stimulated this researcher to use this technique for the current research. The primary goal of the focus group sessions in the current research was to answer the research questions; understanding the factors that influence trust in m-payments in the Emirates, based on the identified factors within the literature review, and discovering to what extent such factors influence consumer trust in m-payments and in what direction, by discussing and reassessing the CTMP model dimensions based on participants' perceptions and experiences. Another goal was to discover whether there would be new factors that may arise during the focus group sessions. The CTMP model dimensions that emerged from the focus group discussions were analysed and, informed by the literature, formed the basis of the second methodology.

\subsubsection{Advantages of using focus groups.}

The following elements justify the researcher's choice of the focus group technique as the first data collection instrument.

1) The focus group technique aims to emphasise a specific theme or topic that is explored in depth, while individual or group interviews often span very widely with less focus on a certain topic (Bryman \& Bell, 2007). This research needed to focus on the issue of trust in m-payments as a particular, tightly defined topic. Therefore, the focus group technique was more appropriate than other qualitative research instruments.

2) What distinguishes the focus group technique from other data gathering techniques of qualitative research is "the insight and data produced by interaction between participants" (Gibbs, 1997, p. 2). The researcher was interested in how people respond to each other's views and build up a view from the interaction that takes place within the group. Participants are able to respond to the discussion by seeking clarification from others and by providing reflective comments prompted by the comments and ideas of others. Both previous points remove the risk of researcher bias and maximise the opportunity to explore a topic widely and in depth (Hennink, 2007).

3) The current research endeavoured to stimulate new ideas, creative concepts and impressions of consumer trust in m-payments. Lightly structured focus group interviews make this possible by encouraging interviewees to brainstorm and share knowledge and original thought. This would not be achieved by using individual interviews and is less possible in a structured group interview (Bryman \& Bell, 2007; Pickard, 2007). 


\subsubsection{The moderator's role and the researcher's role.}

The focus group sessions were conducted by two moderators (an experienced focus group moderator in combination with the researcher). For this research, the external moderator acted as the main moderator who was responsible for the smooth flow of the group discussions, encouraging participants to share their perceptions, keeping the discussions on track, and ensuring that specific issues are discussed and research questions are answered during the sessions. The external moderator was recruited from one of the academic institutions in the Emirates, and was informed about the research objectives, research question and other related information.

The researcher, as the minor moderator, organised the focus group sessions, observed participants' behaviours and took notes. The external moderator was provided with the required details about this research in order to get the anticipated benefits of the focus group sessions, and to keep the discussions on track. Therefore, a detailed research protocol and an interview guide were developed to support him in this purpose. Firstly, this protocol (as attached in Appendix A) included an overview of the research, the research objectives, the question the researcher is trying to answer, and a guide for organising and conducting the sessions. Developing such a protocol was important to ensure gathering the necessary data and the moderator's pursuit of further important concepts that mentioned during the panels (Malhotra, 2004). The use of a protocol could also increase the reliability of the research (Yin, 1994). Secondly, the interview guide included questions plan, and served as a guide for the moderator and included the questions to be asked in the sessions (attached as Appendix B). However, the researcher attended all of the sessions and monitored the discussion to prevent any deviation, to ensure that all of the questions of the focus group were answered and that the time limit for a certain section or question was not exceeded with no action taken by the moderator, and to intervene in the discussion where necessary to keep the session on track. However, all of the focus groups were well organised and were conducted appropriately.

Three of the focus group sessions were conducted in Arabic, since Arabic is the official language used in the Emirates, which is the same as the first language of both the researcher and external 
moderator, whereas the fourth will be conducted in English for the residents who do not speak Arabic.

\subsubsection{Setting up focus groups.}

To establish the focus groups, the researcher considered the following aspects: entities to reach the participants, number and nature of the groups, size of the groups, characteristics of participants and how to select them, organising and conducting discussions, digital recording issues, data transcription and analysis, data analysis, limitations of and risks in focus groups, and some ethical issues. Each aspect is discussed briefly in the subsequent points below.

(1) Entities to select participants from. The participants were reached through four main entities: telecommunication companies, banks, universities and online social groups and forums. These entities are Abu Dhabi Islamic Bank, University of Sharjah, and Etisalat Telecommunication Company. These were selected specifically because the term m-payment is closely related to telecom companies and banks, and their consumers are seen to be the most familiar with the m-payment concept and characteristics, have some knowledge about the concept, or have already used it. In addition, the researcher was able to contact certain individuals in these entities who expressed interest in helping to conduct the focus group sessions and contact participants. Choosing the four entities to select participants from offered diversity with respect to consumers' opinions and perceptions, and ensured, to some extent, participants' familiarity with the m-payment concept and applications.

Members from online social groups/forums provided the opportunity for consumers from the virtual world to participate in this research. They were likely to be comfortable with each other (since they share some common interests), which allowed more candid discussion of their perceptions with respect to m-payment trust.

(2) Number and nature of the groups. Four focus groups were conducted in order to provide insight into consumers' perceptions and viewpoints about trusting m-payment. The number of groups was related to the cities in which the suggested participants were approached. One group's members were nominated as bank consumers and workers, while another group's members were selected from an online social forum, and the other two groups' members were 
selected from a telecom company and a university. Participants' permissions were sought to help in this research, as documented in the consent letter (See Appendix C). Targeting only those four entities in this research may lead to some selection bias; however, the researcher minimised this potential bias by ensuring the sample representativeness. This is discussed in details in the subsequent points, when dealing with participants' selection method and criteria.

In order to maximise disclosure among focus group participants, occupation-based homogeneity between members of three focus groups was sought as a key consideration in establishing selection criteria for individual groups (Pickard, 2007). Each focus group contained participants with diverse personal characteristics and perceptions of trust in m-payments. This meant that focus groups may also be very helpful in the elicitation of a wide variety of different views in relation to factors of trust in m-payment and foster the generation of new ideas (Bryman, 2008).

(3) Size of the focus groups. Although the suggested number of focus group participants varies by author, the range tends to be similar. In general, authors identify studies that have used up to 15 participants and as few as four when conducting a focus group. Specifically, Creswell (2009) suggests 6 to 8 people in each focus group, while Pickard (2007) suggests groups of 6 to 10 participants. However, Morgan (1997) recommends smaller groups when topics are controversial or complex, or when participants are likely to have a lot to say on the research topic. Trust in mpayment is a multidimensional topic and participants are expected to raise many issues during the session. Based on the number of people suggested in the literature and to ensure that the focus group size is manageable and shows greater potential, three of the focus groups in the research included 7 participants, whereas one group included 6 participants, resulting in 27 participants in total. A backup of two participants for each session were listed in case those initially confirmed were unable to attend.

(4) Characteristics of the targeted participants (sample frame). The participants in the focus groups were selected for the following characteristics:

- Having some knowledge about m-payments (current user, previous experience, knowledge from providers of m-payment services, knowledge from media, or others).

- Over 18 years of age. 
- Having expressed interest in sharing their perceptions of trust in m-payments in a group discussion.

Both male and female participants were invited to participate. In one emirate/city (Sharjah), some religious and cultural values and traditions delimited mixed-gender participation in this group, because the mixing of males and females in one closed room was not totally acceptable there. This limitation encouraged the researcher to select one of the focus groups (in Sharjah) as all-female, in order to ensure equal involvement between the two genders. To adapt to this situation, a female moderator was recruited, and the video recording option was not implemented to respect the local custom. For this group, the researcher relied on two audio recorders and notes taken during the session

(5) Selecting the participants. Depending on the criteria described above, a convenience sampling strategy was used to identify research participants for these focus group discussions. While this set of characteristics generates a very broad basis of potential participants, both institutes (a telecom company, a bank) nominated around 20 people in the sample frame (telecom consumers and bank consumers) to participate in a focus group. The institutes subsequently informed the nominees about the research and the voluntary nature of participation in the focus group sessions. The participants who were interested in taking part in the sessions contacted the researcher. Then, the researcher checked that the selected participants have the required characteristics and subsequently selected 9 of them (two persons on a stand-by basis should some participants be absent). The selection criterion was based on the diversity of ages, educational levels and past personal experiences in m-payments to enrich the discussions and increase the interaction between the participants.

Participants from the university were directly approached through a social contact person whom organised the session and played the linkage role between the researcher and the participants. On the other hand, forum members were approached through several stages. Firstly, a large active online social forum was identified. This forum or group was selected using search engines to identify forums that are popular in the Emirates (several online social forums in the Emirates have already been identified as possible candidates for this research). It was preferable that $\mathrm{m}$ - 
payments issues or other concepts related to m-commerce be among the interests of the selected social forum members. This could be identified by searching previous conversations on the forum. Second, the researcher joined the targeted forum, posted an invitation form with the authentication letter, and invited expressions of interest.

(6) Organising and conducting sessions. In order to organise the focus group sessions, a protocol and an interview guide were developed. As mentioned earlier, the focus group protocol identified activities that must take place before and during the sessions. The protocol managed the communications between the moderator and the participants, by including steps to be followed by the moderator, and ways to organise the discussions and the flow of information.

(7) Digital recording issues. During the course of the focus groups, it would be difficult for the researcher to note all that the participants say, the respective speakers and the manner in which statements are made. In addition, he would be looking for a collectively constructed meaning within each session. This would also be difficult to achieve solely by taking notes, because of the need to keep track of who says what. Furthermore, the way interviewees express their perceptions, emotions and gestures has valuable meaning, which would be lost if relying on notes alone. This justifies the need for a video recorder. However, notes were taken to record the main points and follow up the discussion. In addition to video recording, two audio recorders were used as a second tool for recording participants' discussions and for back up purposes. The recordings and notes were transcribed by the researcher, as detailed in the next section.

(8) Data transcription and translation. The focus group session would work best if it is recorded and subsequently transcribed (Bryman \& Bell, 2007). It is preferable that the researcher transcribes the material generated from the focus group session, because this could be helpful to understand the main issues in the discussion, and consequently, this helps in the analysis phase. Based on these points, the researcher transcribed the notes and the recordings after conducting each focus group on paper and on a computer in Arabic and English. Then data from these resources were integrated into a final transcription report which covers all information relevant to the research question. This final collective report in English included a total of 12776 words. This report was also used later to verify that the participants' perceptions match the transcribed 
content for trustworthiness and authenticity purposes, and then the data were analysed. Afterwards, the report in Arabic was translated by the researcher into English.

In order to exemplify the translation process of the Arabic transcript into English, the two paragraphs presented in Table 3.2 demonstrate small part of the discussion in one group in both languages.

Table 2.2 An Example of the Translation Process - A section of FG1 on September 20 ${ }^{\text {th }}, 2011$

\begin{tabular}{|c|c|}
\hline 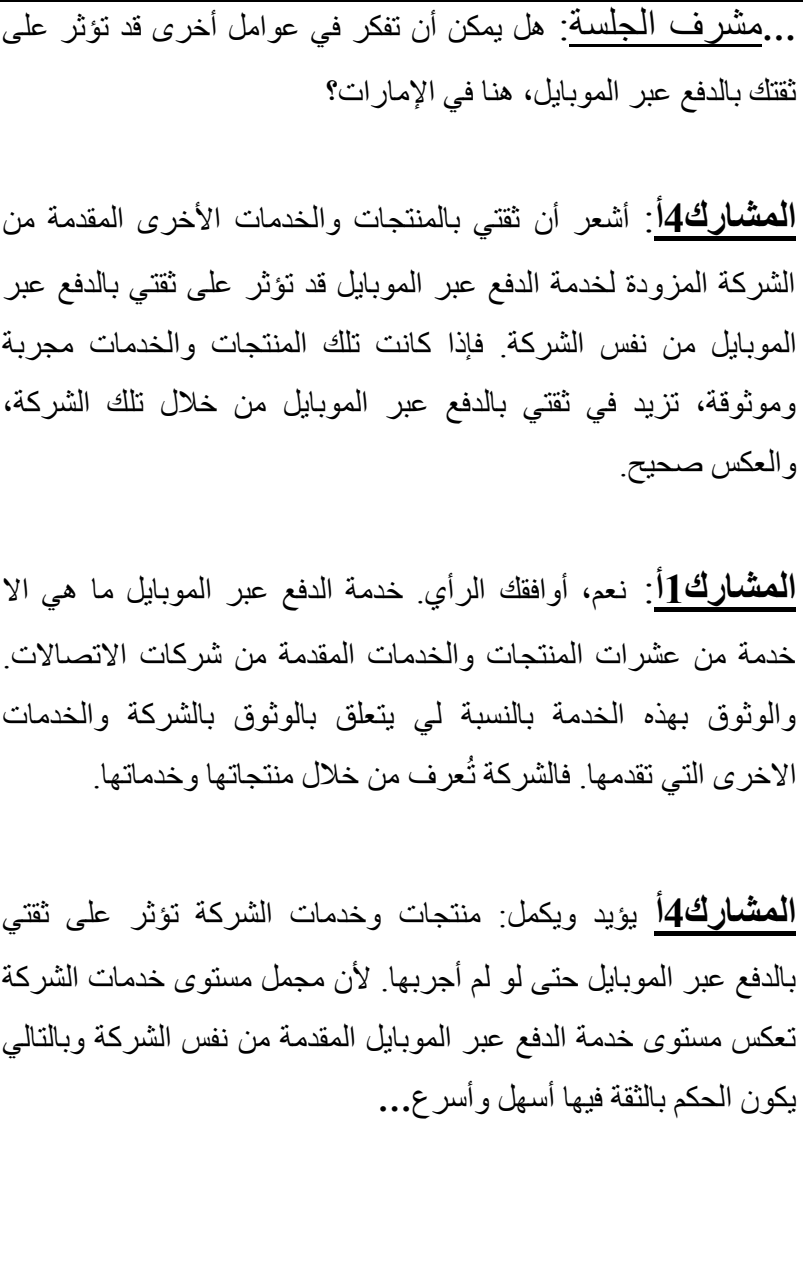 & $\begin{array}{l}\text {...Session Moderator: could you think of other } \\
\text { factors that could influence your trust in m-payments, } \\
\text { here in the Emirates? } \\
\text { Participant } 4 \mathbf{A} \text { : I feel that the trust levels in products } \\
\text { and services offered by the m-payments provider may } \\
\text { influence my trust in m-payments provided by the same } \\
\text { company. If these products and services to be } \\
\text { trustworthy, then my trust in m-payments would } \\
\text { increase, and vice versa. } \\
\text { Participant1A: Yes, I agree. The m-payment service } \\
\text { is just one of the tens of services provided by } \\
\text { telecommunication companies, and trusting this service, } \\
\text { to me, relates to trust in the company and its other } \\
\text { provided services. } \\
\text { Participant } 4 \mathbf{A} \text { agreed and continued: company's } \\
\text { products and services could influence my trust in m- } \\
\text { payments even without trying the m-payment itself. This } \\
\text { is because the overall level of the products and services } \\
\text { provided by the company indicate the level of the m- } \\
\text { payment service offered by the same company, and thus, } \\
\text { easier and faster judgement of trust... }\end{array}$ \\
\hline
\end{tabular}

During the translation process, the researcher ensured the semantic equivalence of the transcripts across the two languages; referring to the words and sentence structure in the translated text expressing the same meaning as the source language (English). In addition, the researcher considered the equivalence at a contextual (social, cultural) level across the participants in all the 
focus group, which relates to the practical uses and perception of words and phrases in a given context. In terms of reliability and integrity, five sections of the translated materials were randomly selected and checked by a registered translator to ensure transcription accuracy. As a result, very few changes were suggested to some words and phrases; for instance, the translation of the word 'culture' was amended, where the researcher and the translator agreed on an Arabic term that is equivalent to culture in the social science background, as there are different Arabic synonyms associated with this term. Another example is the translation of the phrase 'but you cannot say that' which was refined as this is a common expression in Arabic which cannot be translated literally. Overall, the selected sections in the two languages were found linguistically matching to a large extent, and thus there was no need suggested to go through the remaining transcript file. Subsequently, certain ethical issues were addressed as follows.

(9) Ethical issues. Ethical considerations for focus groups are the same as for most other methods of qualitative research (Gibbs, 1997). In the current research, the first concern was to ensure full disclosure about the purpose and use of participants' data. This was managed by providing an information sheet to each participant prior to the focus group session. This sheet was approved by Victoria University's School of Information Management Human Ethics Committee prior to being given to the participants.

The second ethical concern was obtaining participants' and institutions' consent to participate. Consent means that they understand what they are agreeing to, accept what is being asked and are comfortable in providing the information, such as sharing and recording their views. Participants were asked to sign a consent form allowing their data to be used in this research. They were also informed about what was expected of them, by giving a description at the start of each focus group session.

Another issue was handling sensitive material and confidentiality. Confidentiality is concerned with keeping the identity of the participants secret when using data provided by them (Pickard, 2007). In this research, care was taken when confidential information was passed on by the participants of the focus groups. This information included all participants' perceptions, and therefore, it was shared and revealed with openness and bluntness on the part of participants. The 
researcher also protected the privacy of participants and institutions, by using nick names in the final research.

\subsubsection{Reliability and validity of the focus group discussions.}

Researchers need to make sure that their findings and interpretations are valid and accurate, and

of a high quality (Creswell \& Miller, 2000). Reliability and validity are common criteria used by quantitative researchers to establish and assess the quality of the research (Bryman, 2004). Authenticity and trustworthiness are commonly used by qualitative researchers to establish and assess the quality of the research (Creswell \& Miller, 2000). The researcher will apply these two criteria to evaluate the quality of the qualitative findings.

Creswell and Miller (2000) identify trustworthiness and authenticity as measures of validity. Trustworthiness of qualitative research means the value of findings and their authenticity (Denzin \& Lincoln, 1994). The most common concepts used by qualitative researchers to establish trustworthiness of their research are credibility, transferability, dependability and confirmability (Pickard, 2007), while authenticity, as a different measure according to Creswell and Miller (2000) refers to five criteria: fairness, ontological authenticity, educative authenticity, catalytic authenticity, and tactical authenticity (Guba \& Lincoln, 2005). This research will utilise credibility and confirmability in order to achieve trustworthiness, whereas fairness, ontological authenticity and educative authenticity will be used to achieve authenticity.

1. Trustworthiness: Credibility. Credibility means how believable the findings are. According to Bryman (2008), credibility parallels internal validity. An often used technique is to establish credibility by member checking. This technique ensures the accuracy of the findings by taking the final report back to the participants for verification (Bryman, 2004; Creswell \& Miller, 2000), and helps in improving the quality of the final report (Pickard, 2007). In this research, the focus group transcriptions were returned to the interviewees, to verify that the interpretations match the interviewees' perceptions. Before member checking, a prior verification was done by the researcher to check if the report answers the research question. Afterwards, the transcript was sent to each participant by email, and asked to verify the content of his/her views presented in the discussion. Most of the participants replied to the email and totally agreed to the content (except one female participants who suggested a different spelling in her name), whereas five participants did not reply. Therefore, email reminders were sent to ensure the member checking 
verification among all participants; accordingly, three of them replied and indicated no changes to the transcript, whereas the two others did not respond. Another round of email reminder was sent in a week time, and finally, all responses were received with no alterations indicated. In summary, transcripts were verified and were demonstrated credibility.

Trustworthiness: Dependability. Dependability is to 'adopt an auditing approach', by ensuring that complete records are kept of all phases of the research process (Bryman, 2008, p. 378). Dependability parallels reliability (Bryman, 2008). The researcher has kept records on the selection of research participants, fieldwork notes, transcripts of the focus group interviews and data analysis decisions in an accessible manner for confirmation of research dependability.

Trustworthiness: Confirmability. This is to ensure that the research findings are not influenced by the personal values and prior assumptions of the researcher (Bryman, 2004). Confirmability parallels objectivity (Bryman, 2008). Confirmability could be achieved by making sure that the results can be traced to the raw data of the research (Pickard, 2007). In this research, the constant comparative analysis technique was used to show how each theme or category is developed from the raw data. In addition, participants' perceptions were quoted and used to support all claims and conclusions. In addition, a second person was recruited to check some randomly-selected sections of the coding. This person was the same academic who was engaged in moderating the focus groups, because of his awareness of the data.

Authenticity: Fairness. As advised by Bryman (2004), the research needs to fairly represent different viewpoints among members of the social setting. This means that all the participants in the setting should have an equal chance to be included in the research. In this study, this criterion was achieved by giving an equal chance for all the interviewees in each focus group session to participate and share their opinions. Therefore, the moderator encouraged all members to participate equally in the discussion, and made sure that no single participant dominated it. Furthermore, the use of the multichannel approach for selecting the targeted consumers ensured that a wide range of perceptions about m-payments are elicited.

Authenticity: Ontological authenticity. According to Lincoln and Guba (1985), the researcher needs to help the individuals to raise their awareness and understanding of the social setting in 
which they exist. This criterion was achieved by giving the participants adequate information about the study including the aims, background information and what is hoped to be achieved from this study.

Authenticity: Educative authenticity. The moderator also needs to help the participants to understand and appreciate other participants' perspectives of their social setting (Lincoln \& Guba, 1985). For this research, this criterion was accomplished by ensuring that the role of the moderator would not be intrusive and disturbing. However, if the discussion had gone off on a tangent, then the moderator would carefully refocus the participants' attention to the topic. In addition, at the end participants were provided with a summary of the research findings, which would help to bring the participants within the reality of their setting as viewed by them and other participants.

\subsubsection{Summary of the methodology and data collection.}

The focus group discussions followed a semi-structured guide, which was tested with a pilot group of five participants. The group was consistent with the research design, and thus there was no need for major modifications to the guide. Four focus group sessions took place in the Emirates, in the four main emirates (Dubai, Abu Dhabi, Sharjah and Al-Ain). Three of these sessions were conducted in Arabic, while one was in English. Details of each group (including gender, occupation, age and language of participants) are shown in Table 3.3. In order to promote rich discussion and at the same time to be able to control the groups easily, the group sizes varied between six and seven participants, as recommended by Bryman and Bell (2007), Morgan (1998), and Pickard (2007), resulting in a total number of 27 for all sessions. The interviews lasted between 70 to 90 minutes, and refreshments were provided as consistent with the Emirati culture. 
Table 3.3 Focus Group Members and Descriptions

\begin{tabular}{|c|c|c|c|}
\hline FG & $\begin{array}{l}\text { Group (Participants } \\
\text { number, gender and } \\
\text { nationalities) }\end{array}$ & $\begin{array}{c}\text { Description (Occupation, Age, and } \\
\text { Language) }\end{array}$ & $\begin{array}{l}\text { (Source, } \\
\text { Location, } \\
\text { Date) }\end{array}$ \\
\hline 1 & $\begin{array}{l}\text { Professional adults (7) } \\
\text { Mostly males. } \\
\text { Emirati (3), Jordanian (2), } \\
\text { Syrian (1), Palestinian (1) }\end{array}$ & $\begin{array}{c}\text { Young professionals and work colleagues } \\
\text { who have entered banking and finance } \\
\text { fields, most between } 30-45 \text { years old. } \\
\text { (Arabic session) }\end{array}$ & $\begin{array}{l}\text { Abu Dhabi Islamic } \\
\text { Bank (Abu Dhabi, } \\
\text { Sept 27, 2011) }\end{array}$ \\
\hline 2 & $\begin{array}{l}\text { Lecturers and students (7) } \\
\text { Mostly females. } \\
\text { Emirati (2), Syrian (1), } \\
\text { Jordanian (1), Sudanese(1), } \\
\text { Palestinian (2) }\end{array}$ & $\begin{array}{c}\text { University lecturers and students. Students } \\
\text { in their early twenties whereas lecturers } \\
\text { were between } 32-52 \text { years old. } \\
\text { (Arabic session) }\end{array}$ & $\begin{array}{l}\text { University of } \\
\text { Sharjah (Sharjah, } \\
\text { Sept 21, 2011) }\end{array}$ \\
\hline 3 & $\begin{array}{c}\text { Young adults (6) } \\
\text { Mixed gender. } \\
\text { Emirati (1), Omani (1), } \\
\text { Egyptian(1), Jordanian (1), } \\
\text { Palestinian (2) }\end{array}$ & $\begin{array}{l}\text { Young professionals who have entered the } \\
\text { IT industry, most between } 25 \text { and } 35 \text { years } \\
\text { old. (Arabic session) }\end{array}$ & $\begin{array}{l}\text { Etisalat } \\
\text { Telecommunication } \\
\text { Company (Dubai, } \\
\text { Sept 20, 2011) }\end{array}$ \\
\hline 4 & $\begin{array}{c}\text { Adults (7) } \\
\frac{\text { Mixed gender. }}{\text { Indian (3), Pakistani (2), }} \\
\underline{\text { Spanish (1), American (1) }}\end{array}$ & $\begin{array}{l}\text { Parents of small children, housewives and } \\
\text { young professionals, most between 30-50 } \\
\text { years old. (English session). }\end{array}$ & $\begin{array}{l}\text { Social networks } \\
\text { (physical and online } \\
\text { groups) (Al-Ain, } \\
\text { Sept 29, 2011) }\end{array}$ \\
\hline
\end{tabular}

The 27 participants shared an awareness of m-payment concepts, technologies and experiences in m-payments services in the Emirates. The transcribed sessions were then offered to the participants for checking and validation. Arabic transcripts were translated into English and prepared for analysis.

\subsection{The qualitative data analysis.}

Participants were firstly asked to indicate their level of trust in m-payments in the Emirates on a scale of $0-10$. The average score was 7.13 out of 10 with scores ranging from 3 to 10 . Further details about the participant's usage pattern and frequency of m-payments are shown in Table 3.4. With regard to usage, the most frequently identified m-payment applications were paying bills for power and water, car parking, paying for traffic registration and fines, and making charitable donations. It is worth mentioning that these m-payment applications are highly widespread in the cities of the Emirates and considered as micro-payment applications. As for the payment amounts, it was found that micro m-payments (amounts between AED 100-500 $\approx$ USD 28-137) were more trustworthy than macro m-payments from the participants' perspectives. However, it is noteworthy that the members in the first focus group (professionals and work colleagues who 
have entered banking and finance fields) showed trust in larger amounts of money through their mobile devices (amounts between AED 500-1000 $\approx$ USD 137-273). A plausible explanation for this finding might be because those people are more familiar with the m-banking and mcommerce services, and tend to be more open when dealing with big amounts of money as part of their daily basis activities, and thus might be more willing to trust in macro m-payments.

Table 3.4 Pattern and Frequency of M-Payment Usage Between the Focus Groups

\begin{tabular}{|c|c|c|c|}
\hline $\begin{array}{l}\text { Focus } \\
\text { Group }\end{array}$ & $\begin{array}{l}\text { M-payment } \\
\text { applications }\end{array}$ & $\begin{array}{l}\text { Usage experience of } \mathbf{m} \text { - } \\
\text { payments }\end{array}$ & $\begin{array}{c}\text { Trustworthy } \\
\text { amount of } \\
\text { m-payment }\end{array}$ \\
\hline FG1 & $\begin{array}{c}\text { Paying bills (power, water), } \\
\text { Booking airline tickets }\end{array}$ & $\begin{array}{l}\text { Several times in a lifetime } \\
\text { (4-8 times) }\end{array}$ & $\begin{array}{l}\text { AED 500-1000 } \\
\text { (USD137-273) }\end{array}$ \\
\hline FG2 & $\begin{array}{c}\text { Paying bills (power, water), } \\
\text { car parking, traffic } \\
\text { registration and fines, } \\
\text { charitable donations }\end{array}$ & $\begin{array}{l}\text { Many times } \\
\text { in a lifetime so far } \\
\text { (+15 times })\end{array}$ & $\begin{array}{l}\text { AED } 100-500 \\
\text { (USD 28-137) }\end{array}$ \\
\hline FG3 & $\begin{array}{l}\text { Mobile banking, paying } \\
\text { bills, car parking, traffic } \\
\text { registration and fines }\end{array}$ & $\begin{array}{l}\text { Many times in a lifetime so far } \\
\qquad(+10 \text { times })\end{array}$ & $\begin{array}{l}\text { AED100 - 500 } \\
\text { (USD 28-137) }\end{array}$ \\
\hline FG4 & $\begin{array}{l}\text { Games and entertainment, } \\
\text { telecom and internet } \\
\text { services }\end{array}$ & $\begin{array}{l}\text { Several times in a lifetime so far } \\
\text { (3-6 times) }\end{array}$ & $\begin{array}{l}\text { AED100 - 500 } \\
\text { (USD 28-137) }\end{array}$ \\
\hline
\end{tabular}

To qualitatively analyse the data relating to the factor of trust in m-payments from the participants' perspectives, Pickard (2007) suggests the Constant Comparative Analysis (CCA) method that is applied widely in qualitative research. The CCA method consists of three processes: open codes, axial codes, and selective codes. The three processes were applied to this research manually and no specialist software was utilised.

The issue of using specialist software for manipulation and analysis of qualitative data brings a great difference of opinions (Williamson \& Johanson, 2013), since "the hard work of coding data is intellectual, not mechanical" (Dohan \& Sanches-Jankowski, 1998, p.482). Williamson \& Johanson (2013) suggest that the decision of using such software may vary from project to project, depending on several factors such as the size of the project, the complexity of the 
research project, the number of the researchers involved and the forms of the collected data. In the current project, the data collected was in one form of textual data material, and relatively not in a large amount. In addition, that collected data were found manageable through the hard and soft copies of the transcript report. It is also believed in the current research that the insertion of a machine between the researcher and the qualitative data can create uncomfortable distance (Fielding \& Lee, 1998). Therefore, the researcher did not use specialist software for the qualitative data analysis.

The process of the interpretation began with open coding, whereas towards the end of the whole analytical process, selective coding comes more to be fore (Flick, 2006). The three processes of the CCA (open coding, axial coding, and selective coding) applied in the current research are detailed below.

(1) Open coding. The first step in CCA is open coding, which is the process of identifying concepts and discovering their dimensions by breaking down, comparing, conceptualizing, and categorizing data (Fontana \& Frey, 1998; Strauss \& Corbin, 1998). During this process, the researcher examined the transcript file for salient concepts, and classifying participant's expressions by their units of meaning (single words, short sequences of words) in order to attach annotations and above all concepts to them, as suggested by Flick, 2006). During the open coding process, the research had become familiar with the participants' perspectives through repetitive reading and careful examination of the transcribed report. Applying codes was done through labelling these categories with the instances that represent these categories. Some of the labels were borrowed from the literature (e.g. 'Aware'), where others were taken from participants' expressions (e.g. 'Knowledge'). The text below shows a section of a focus group session transcript, and some of the codes attached to these paragraphs. 


\section{Section ofFG2 on September 21st, 2011}

Participant7B: I think what is significant to trust in m-payments is to what extent customers are aware of this service and how much they know about it (Paticipant1D and Participant2D agree). Customers in Emirates may have low trust in m-payments because they think that it is scary, risky and not safe (Participant3D and Participant4D agree).

*CODES: aware, know, risk, safe

Participant4B: I think the staff members are the persons who should provide customers with information about this service, so that customers feel it trustworthy.

*CODES: information about MP services

Participant7B agreed and continued: the educational technique of educating customers about this service could have different forms. Universities can contract telecom companies to market this service and make it more trustworthy. Lectures and seminars could be given to spread the knowledge about this service and increase customers' understanding in it.

*CODES: educating customers, marketing, customers' understanding

Participant4B: it could be that the service is secure but people do not know that.

Participant7B: the warranty issue is also supportive, through which the provider can ensure that the service is $100 \%$ secure.

*CODES: service warranty, secure

Participant3B: employee staff also could play a role in this, by talking friendly to the customers who are waiting in queues to do their payments. Traditional marketing campaigns are not enough; someone should talk to customers about this service in a nice and simple way, in order to give some knowledge about the service, its characteristics, steps to do it and other details, and then, people would consider trusting it.

*CODES: marketing campaigns, talking to customers, knowledge about m-payments

(2) Axial coding. This process was used to group the codes developed during open coding into categories. In axial coding, the "coding occurs around the axis of a category, linking categories at the level of properties and dimensions" (Strauss \& Corbin, 1998, p. 123). The transcripts were inspected for similarities or differences and grouped into groups of conceptual units. In specific, the researcher was looking for causal conditions, phenomenon, actions, interactions, intervening conditions and consequences that may 
relate to a certain code. For instance, all the participants' stories, cases, perceptions, ideas and thoughts centred on participant's knowledge on m-payments were compared, and then, associated with the code 'awareness' discussed in a single session, and afterwards, across the remaining sessions. In this research, 'awareness' and other codes function as criteria for the systematic comparison of the transcript file. By comparing, it becomes evident that some codes can be grouped together because they are similar with regard to certain criteria (e.g. 'Understanding', 'Knowledge', 'perception'...), whereas other codes such as 'safe' and 'risk' could be grouped into different category. One challenge which faced the researcher during this process was that some codes were able to belong to more than one category. For example, the code 'built-in features' could belong to both categories 'device security' and 'device functionality'. However, and according to Flick (2006), a concept should be attached to one central category and one central phenomenon. In such cases, the researcher referred to the context in which the code was used and then weighted the categories, resulted in referring the code 'built-in feature' to the category 'device security' for the previously given example. After categorising codes, the relations between the categories were elaborated, and then categories were basically differentiated and refined.

(3) Selective coding. In the last step, selective coding was used to integrate and refine the categories merged during axial coding at a higher level of abstraction, by identifying a single core category as the central phenomenon (Strauss \& Corbin, 1998). The researcher, during this process, related the main codes to other categories and filling in categories that need further refinement, and selective coding of data to theoretically saturate the core and related concepts. The saturation process, as strongly recommended by Strauss \& Corbin (1998) and Flick (2006), was achieved through constant comparison of incidents in the data to elicit the properties and dimensions of each category, and until further coding and enrichment of categories no longer provides or promises new knowledge concerning the factors of trust in m-payments. On a higher level of comparison and categorisation, the researcher compared the final categories and grouped them according to the themes they are describing (e.g. Grouping 'awareness' and 'past experience' into the 'consumer characteristics' group). Overall, selective coding process resulted in generating theoretical codes which integrate a 
theory by weaving the fractured concepts into hypotheses that work together in a theory explaining the main concern of the focus groups' participants (Strauss \& Corbin, 1998). In other words, the researcher was able to apply the theoretical CTMP model to the generated data, not forced by the literature, but had emerged during the comparative process.

Regarding the coding process, the codes were written on hard copies of each document next to the related section, whereas the core categories and associated main codes are recorded in a separate file, as shown in Appendix D. The frequencies of the codes were not calculated. Although it has been suggested that counting how often codes occur is helpful in clarifying whether reality is in accordance with the overall impressions gained by the researcher (Silverman, 1993), this view is disputed (Morse, 1995, Saint-German, Bassford, \& Montano, 1993). Therefore, counting the frequencies of the codes was not considered in the current research.

In order to assess the quality of the coding process in qualitative research, a recommended criterion was followed; the establishment of thick description and audit trail (King \& Horrocks, 2010). This is intended to allow other individuals to understand and evaluate how the data was coded and categorised, why data was placed into these codes and categories, and how these were clustered to answer the research questions (Lincoln \& Guba, 1985). Therefore, thick description was provided in the current research for better understating how the researcher reached the conclusion from the data available, by including details about the development of the analytic process itself, and providing illustrations and commentary on the way the CCA method applied. Such details constitute an audit trail that documents the development of the researcher's thinking as the analysis progressed.

\subsubsection{Findings from the focus group discussions.}

In the following sections the key themes from the focus group discussions are identified. The major issues and factor groups that emerged to have played a role in affecting consumer trust in m-payments are dealt with in detail below and, where appropriate, are formulated as the working hypotheses for the next research phase.

\subsubsection{Consumer characteristics.}

The focus group discussions exposed some personal characteristics and intrinsic values of consumers that could influence their trust in m-payments. These characteristics include consumer 
awareness, propensity to trust, uncertainty avoidance, and consumer past personal experiences in m-payments, along with some consumer demographics (age and gender).

The majority of participants argued that consumer knowledge in and awareness of m-payments services and applications would influence their trust in m-payments. In one participant's words, "a significant issue that relates to trust in m-payments is the extent to which consumers are aware of the service and how much they know about it". According to one participant, awareness of m-payments means "to be aware of m-payment services, applications, its characteristics and details". This awareness could be associated with several sources of knowledge. For example, one participant argued that education and profession are some sources of consumer awareness of m-payments, by saying: “a person who completes his/her master's degree in IT and works in the telecommunication sector would be aware of the pros and cons in the field of m-payment, and generally would be capable of sharing knowledge with others, and of advising them about whether m-payment is safe or not, or whether or not to proceed in this regard. So, I would say his/her education and profession grant him/her awareness of m-payments". Another participant argued that literacy is related to awareness. "I would say that a consumer's knowledge and his/her awareness of such services in addition to what extent he/she is technologically literate together play a major role in trust". One participant illustrated the relationship between awareness and trust, by stating "Well, I would say that people who have limited or no understating of m-payment applications and services or who are unfamiliar with its methods and processes are less likely to trust in mobile payments". In general, many participants related consumer awareness of m-payments to trust. This finding supports the literature trust that there is a strong link between consumer awareness and trust in m-payments (Alqatan et al., 2012; Piao et al., 2012, Yeh \& Li, 2009). Therefore, and based on the preceding discussion, it is hypothesised that:

H1: The more the consumer awareness about mobile payments, the higher the trust in mobile payments.

Many participants also argued that trust in m-payment and the degree of that trust differs from one person to another, depending on his/her tendency and willingness to trust in people and things in general. One participant said: "trust in mobile payments or any other electronic payment method depends primarily on the person himself/herself, it is something inside the 
person, and it could be a personal belief or a value that makes him/her regard these payments as trustworthy". Similarly, another participant said: "Of course, it [propensity to trust] is the first part of trust in m-payments, I think it is a default setting that everyone has to either start to trust in this new payment method [m-payment] easily or with difficulty, especially if it has not been used... I would consider my friend to have a high propensity to trust; she is willing to trust in mobile payments easily and without thinking deeply or hesitating...I don't see myself like her in this regard". One agreed and continued: "Maybe she has a higher propensity to trust than you do, and I am not saying that as a judgement... tendency to trust is a personal attribute and differs to experience or knowledge, it is like a background to a person's attributes, which may be uncontrollable, such as being positive or optimistic". In general, participants agreed that propensity to trust is a personal intrinsic value that can influence consumer trust in m-payments. This finding is consistent with the literature as many studies indicated that consumer propensity to trust have an impact on his/her trust in m-payments (Guangming \& Yuzhong, 2011; Kim et al., 2009; Li \& Li, 2008), and thus the following hypothesis is presented:

H2: The higher the consumer's propensity to trust, the higher the trust in mobile payments.

In addition, some of the participants specified a specific part of someone's culture or background, the uncertainty avoidance. One participant indicated that consumers' mentalities are formed within the culture they live in, and this affects their trust in new technologies including mpayments, by arguing: "To me, the mentality of people does matter in trust. What I mean is how people think about m-payments; some of them may say: "No, No, No, I would not trust such a thing", without even trying it or hearing about it from others. It is related to their culture, mentality, or the country they live in". Another participant agreed and continued: "there are people who are open minded to new technologies, whereas others may be afraid of trying a new technology especially when it comes to money... it could also be related to the environment surrounding them". Another participant talked about culture and uncertainty avoidance in relation to age, saying: "I know many people here, especially those of older age, who I always see hesitate when it comes to trusting in such things [mobile payments], I don't know if it is a matter of age, culture, low level of practicing new technology or preferring the traditional way of payment due to concerns in this regard, maybe all of these factors together". This level of qualitative support of the relationship between uncertainty avoidance and trust in m-payments is 
consistent with results of other studies in the e-commerce literature (Doney et al., 1998; Jari \& Heikki, 2007; Min \& Li, 2009), and thus deserves more investigation in the m-commerce context. Therefore, it is hypothesised that:

H3: The higher the consumer's uncertainty avoidance, the lower the consumers trust in mobile payments

In terms of experience and practice, the majority of participants argued that consumer past personal experience in using m-payments services can strongly influence their trust in conducting an m-payment. For instance, one participant argued: "Previous experience in mpayments is a factor of trusting it... My personal experience in conducting an m-payment determines my trust in it”. Another participant argued that trust in m-payments could be gained through cumulative practices and past experiences of this payment method, by saying: "Trust increases or decreases by usage. To me, at the beginning of launching m-payment services in the Emirates, I had some concerns in using them, but these concerns faded away when I started using the services, and trust has increased and increased". Another participant concurred and pointed out that the initial experience in using an m-payment service or application significantly influences trust in m-payments. He said: "previous experience [either good or bad] is definitely connected with someone's trust in m-payments, especially the first-time payment". Similarly, another participant agreed and argued: "my trust in m-payments is associated with the first time trial". Several participants illustrated the relationship between consumers' past personal experience in m-payments and trusting them, as dependent on positive and negative practices and past experiences he/she had with m-payment services and applications. One participant argued: “The more positive the consumer's experience in transacting m-payments, the higher the level of trust he/she will have in m-payments, and vice versa”. Overall, it was not surprising to identify 'past experience' as a factor of consumer trust in m-payments, as this finding was found in line with many studies in the literature that indicated its high relevance to trust (Cho et al., 2007; Kao, 2008; Li \& Yeh, 2010; Siau \& Shen, 2003). Based upon the above discussion, the following hypothesis is presented:

H4: Consumer positive personal experience increases his/her trust in mobile payments.

Some participants indicated that the age of consumers could influence their trust in m-payments. For instance, one participant argued that age is associated with trust in technologies in general, 
and with m-payments specifically, in a direct relationship. "I would say age plays a significant role in trust in m-payments... I would say the older the age, the less the trust”. Other participants preferred to use the term generation instead of age. For instance, one participant argued: "I agree that age is a factor of trust. I cannot say the older the people the less the trust, perhaps it is a matter of generations. Our generation has grown up with this technology... The older generation are more conservative and take a while to pick up and use such new technology". Additionally but arguably, very few participants indicated a relationship between gender and trust in mpayments. For example, one participant argued: "I feel males are more likely to trust in $\mathrm{m}$ payments than females". Another person disagreed with him, arguing that "females tend to trust in m-payments without thinking deeply... They may not consider security and technical issues when conducting the payment, so they trust in it more than males". However, the majority of participants did not see any relationship between gender and trust in m-payments in the Emirates. Accordingly, both age and gender were measured to see if there were significant differences in these variables. However, these are considered as control variables, thus no hypotheses were generated.

Other participants talked individually about some personal intrinsic values and characteristics of consumers, such as openness to the use of technology, technology savviness, scepticism, conservatism, mentalities and others. Some of them were not discussed as other participants did not see them as related to trust, while other terms could be related to trust environment and thus will be discussed in the next section.

\subsubsection{Environmental influences.}

The participants viewed trust environment as the level of the trust atmosphere the consumer is living in. Many participants considered the trust environment as an important factor that influences consumer trust in m-payments. One participant argued: "our living environment shapes our behaviour, personality and most of the time our beliefs". Another participant agreed and continued: "yes, I think the degree of trust in a person, a thing, or a payment is affected by the level of trust of the whole society he lives in, regardless his background and from where he originally comes from". 
Moreover, one participant attempted to relate trust environment to technology and m-payments, saying: "if you come from a high trust environment that tends to easily trust new technology, then you would easily trust in mobile payments, and vice versa". Participants who specified the trust environment factor were then asked to give examples on 'high-trust' and 'low-trust' environment. Most of them considered the Emirates as a relatively high-trust environment, but unfortunately were not able to provide specific examples on low-trust environments. However, one participant partially disagreed with the last argument, by saying that "it is hard to classify the Emirates environment in terms of high trust or low trust because of the diversity in culture and backgrounds of the people in the Emirati society... I do not think I can judge this by myself'. It is noteworthy mentioning that this factor has been scarcely indicated in the literature of trust in mpayments, but has been examined within the e-commerce literature. However, since many participants believe that trust environment can influence a person's trust in m-payments, it is hypothesised that:

H5: The higher the trust environment, the higher the consumers trust in mobile payments.

\subsubsection{Provider's characteristics.}

The focus group discussions indicated that trusting the provider of m-payment services is significant with respect to trusting in m-payments. The provider in this context, as determined by the participants, is mainly a telecom company. The participants talked specifically about the characteristics of two main providers in the Emirates; Etisalat Company and DU Company. They pointed out some characteristics of the providers that are related to trust in m-payments, such as reputation of the provider, trust level in products and services, and some other attributes of the provider (honesty, competency, and predictability).

A large majority of the participants pointed out that the reputation of the provider is strongly related to their trust in m-payments. They used the terms goodwill, image and reputation while discussing the factor of the provider's reputation. For instance, one participant argued that "the reputation of the company and its image in consumers' eyes is important when it comes to trusting in its products and services". Similarly, another participant argued: "to me, trusting in m-payments is a result of how I see the service provider and what I heard about it. For example, I do not trust in the m-payment service provided by DU because I do not trust in DU itself, and 
this is because I hear about its problems frequently". Some of the participants expressed the influence of a provider's reputation on their trust in m-payments. One participant said: "If the reputation of the provider is not that good, I would not trust and use its services... If the company has a bad reputation, I avoid dealing with it or using its services unless I have to". However, the factor 'provider's reputation' has been widely been indicated and tested in the m-commerce literature as a factor of consumer trust. From the above findings, it is hypothesised that:

H6: A provider's good reputation has a significant positive influence on consumers trust in mobile payments.

Arguably, some participants discussed the influence of their trust level in the firm's products and services (other than the m-payment service) on their trust in m-payments, by indicating that trusting in some recognised brands offered by the provider has a psychological influence on consumer trust in m-payment services. One participant argued: “provider's brands are influential factors of trust, and that is a part of psychological effects". Another participant agreed and continued: “Other provider's products have hidden effects on our trust... some brands give an idea about the provider and its services, and thus it secretly affects our trust in all provided services... it is natural that trusting in provider's products and services lead to trust in the provided m-payment service without even using it". In contrast, very few others pointed out that trust in other brands provided by the same provider is used for branding and marketing purposes rather than relating it to trust. For instance, one participant argued: "I don't think other brands and services are related to my trust in m-payments... other services might not be good, whereas m-payments might be good... ". However, many participants stayed neutral about this potential factor and did not express their opinions in this regard, whereas few of them argued that provider's branded products and services have an influence on consumer trust in m-payments. It was worthy studying the influence of the trust level in provider's products and services on the provided m-payment service, given that this factor has not been found yet examined in the literature. Therefore, another hypothesis relating to provider's characteristics is presented:

H9: $\quad$ The higher the level of trust in provider's products and services, the higher the consumers trust in mobile payments.

Importantly, many participants identified some other characteristics of the provider that are associated with its attitude and performance in serving customers and offering services. In specific, many participants agreed that the provider should be honest in order to be trustworthy. 
For instance, one participant argued that "it is important to feel that my provider is honest in order to trust it and its products". Another participant argued that the m-payment provider should be competent, by saying that “... I would not trust any provider if I believe it is not showing full competency and has been showing ability to perform its tasks efficiently...that's why it is not easy for me to trust in m-payments". Other participants in the same group agreed on theses participant's words. Another concept appeared in one of the sessions was provider's predictability. For example, only one participant indicated that “... nothing to worry about the provider as long as I get good service and have not received unexpected actions and reactions, especially in case of something went wrong". This finding is considered consistent with the trust literature, as provider's attributes (honesty, competence, predictability, and benevolence)were classified as trust beliefs in the provider (McKnight et al., 2004), and have been used widely in the m-commerce research field, a indicated earlier in the literature review (Chandra et al., 2010, Kim et al., 2009; Ming et al., 2008; Piao et al., 2012; Yeh \& Li, 2009). Only one attribute, benevolence, was not discussed as an attribute of the provider in association with trust. However, it hypothesised that

H10: The higher the provider's trustworthiness, the higher the consumers trust in mobile payments.

However, some other provider's attributes such as generosity and social responsibility were individually raised amongst participants, but were not discussed seriously and were not agreed on, and thus were not included in the current research. Overall, three provider's characteristics were identified by the participants through the sessions: reputation, trust level in provider's products and services, and provider's trustworthiness.

\subsubsection{Perceived risks.}

A large majority of the participants agreed that m-payments are associated with some risks, and these risks influence their trust in these payments. They particularly discussed three types of risk: technical, security and privacy risks. The participants associated technical risks with mobile networks and telecommunications. Security risks were perceived as hacking possibilities, fraud cases, and stealing credit card numbers, whereas privacy issues were discussed as exposing personal information and details when conducting an m-payment transaction. Participants' main concerns were about security issues. Technical issues came second, whereas a few participants expressed privacy concerns. 
Many of the participants indicated that there are some technical issues associated with mpayments, and these issues can influence their trust. For instance, one participant argued: “...I cannot trust in m-payments blindly. Although the technology of m-payments is well developed here in the Emirates, most times I am scared of technical problems, such as getting disconnected or network malfunctioning”. Another participant illustrated other forms of potential technical troubles that influence her trust in m-payment. She argued: "Many technical faults may happen when conducting the payment, such as the system going down, servers going down, the speed of performing the payment slowing or the process failing to complete due to a fault in the service. For instance, what would happen if I lose my mobile connection while conducting a payment because of moving from one coverage area to another? My concern is that money will be paid without getting the service". It is worth mentioning that technical risks were not found to be an influencing factor in the literature of consumer trust in m-payments. By highlighting the relationship between technical risks and trust in m-payments by the participants in the current research, it is hypothesised that:

H11: Perceived technical risks negatively influence consumer trust in mobile payments.

The majority of the participants agreed that security risks influence their trust in m-payments, such as hacking, fraud, and stealing credit card numbers. For instance, one participant argued: " $I$ have some hacking concerns. A hacker can steal my credit card info and other personal details. However, I feel like my perceived security fears in m-payments do not lower my trust in mpayments". Likewise, another participant argued: "I think there are lot of security breaches while conducting an m-payment, hacking and so on. Hacking is spread all around the world, and people here are aware of it... I have other concerns, such as dealing with Visa Cards and some information about the card owner... hearing about all these security issues can lower my trust in m-payments". In addition, many participants linked the amount of money they will pay via their mobile devices with perceived security risks. They argued for higher trust in conducting micro m-payments more than conducting macro m-payments. In details, around half of the participants argued that they would not pay more than AED500 via their mobiles. One participant argued: "the amount of the m-payment I am a going to conduct is important to me and impacts on my trust. I do trust in m-payments but I have concerns regarding paying large sums of money via my 
mobile". Another participant agreed, and continued to describe the relationship between the amounts of money to be paid via mobile and his trust in m-payments. He said: "The larger the amount of money paid through the mobile, the more risky the transaction will be considered and the lower the level of trust people will have in m-payments". It was clear that participants perceived micropayments more trustworthy than micropayments, as consequences from any potential security risks would be less harmful and losses. However, there was no consensus on the ceiling trustworthy amount payable via mobile as some participants argued that it depends on the m-payment application, and also on the degree of safety they feel in the time of conducting that payment. Additionally, it was noteworthy that three participants in the fourth focus group (FG4, which was conducted in English) perceived more security concerns than other participants in the same group and other groups, due to some negative experience in m-payments in their home countries and in the Emirates. Overall, security risks were found with major influence on participants trust in m-payments, in line with the findings of many studies in the m-commerce literature (Alqatan et al., 2012; Au \& Kauffman, 2008; Eze et al., 2008). Thus, a hypothesis demonstrating the relationship between security levels and trust is presented:

H12: The higher the perceived security levels in mobile payments, the higher the consumer trust in mobile payments.

Regarding the privacy issue, some participants had concerns regarding privacy and argued that it can influence their trust in m-payments. For instance, one participant said: "I do have some privacy concerns. I understand their need for my credit card information, but I think that further details such as the balance of my bank account or unnecessary data such as my age are private matters that I do not like to share with others publicly”. Similarly, another participant argued: “...I know some people who fear breaches of privacy when using their mobiles for payments. They feel that others may be tracking their activities and behaviour online and accordingly they may not trust in paying via their mobiles". On the other hand, some other participants did not view privacy as an issue of trust in m-payments. One of these participants argued: "To me privacy is not an issue... when I conduct an m-payment my personal information would not be exposed to others because I deal directly with the system of the m-payment service, thus I do not fear breaches of privacy". Likewise, another participant said: "the privacy issue does not influence my trust in m-payments... we are living now in the iPhone era, and all of the data stored in our iPhones are open for Apple, so I can say that our data are exposed, but I don't care! 
I view this as a second directory for storing my data and all my apps, and this does not affect my trust in paying via my iPhone”. Given this level of qualitative support and literature support for associating privacy risks with trust in m-payments (Au \& Kauffman, 2009; Xin et al., 2013; Xu et al., 2005), it is hypothesised that:

H13: Perceived privacy risks negatively influence consumer trust in mobile payments

\subsubsection{Mobile-device characteristics.}

A few research participants argued that the mobile device characteristics have an impact on consumer trust in m-payments. In specific, participants of only one group (non-Arabic speakers) had a consensus that some characteristics of the device can influence their trust, such as the mobile design, brand name, battery life, and software issues, whereas others argued that these characteristics can influence the usage and adoption of m-payments rather than trust in these services.

During the sessions of the current research, a minority of the research participants argued that the capability of the mobile device has an influence on their trust, and that there are some mobile devices that are more functionally based on payments than others. For instance, one participant argued: "some mobile devices are more capable for conducting m-payments than others, in terms of their options, features, operating systems, whereas other devices demonstrate less payment capabilities. For example, I would trust in smartphone devices rather than the old mobile

phones". Similarly, another participant argued: "In the Emirates, some mobile devices are provided with certain settings to connect them with banks for shopping. For instance, BlackBerry has special built-in software that connects the user with the telecom and the Abu Dhabi National Bank to ease the process of purchasing online. This service distinguished BlackBerry from other mobile devices such as Nokia or Samsung, and made m-payments more trustworthy". Thus, few participants supported the opinion that some mobile device functions can make m-payment more trustworthy than on other devices. Based upon the above discussion, and as indicated in few studies in the m-commerce trust literature (Amoroso \& MagnierWatanabe, 2011; Piao et al., 2012), the following hypothesis is presented:

H14: The higher the capability of the mobile device, the higher the consumers trust in mobile payments 
Another attribute of mobile devices was discussed and agreed by the minority of the participants cited device design suitability as conditioning trust during the discussions. For example, one participant argued: "the device could play a role in my trust, especially when using a touchscreen mobile". Another participant agreed and gave some justifications, arguing: "my concern with respect to the device is the touch screen option. This can cause incorrect numbers and amounts of money to be entered, or cause the sum to be transferred to someone else's account". It seems that inconvenient design options in the mobile device could hinder consumer trust in mpayments. However, the importance of linking the design features concerning the device with consumer trust in paying through that device was indicated in the literature for more investigation (Lee \& Benbasat, 2003; Li \& Yeh, 2010; Siau \& Shen, 2003). Therefore, an additional hypothesis highlighting a relationship between the design features concerning the mobile device and consumer trust in m-payments is added. In particular, it is hypothesised that:

H15: The more suitable the design of the mobile-device to conduct an m-payment, the higher the consumers trust in mobile payments.

Few other participants indicated that their lack of trust in m-payments could be related to the security of the mobile device; in either its software or hardware components. On the other hand, some other participants argued that the mobile technology, especially the recently developed Android environment, is secure enough to be trusted for conducting an m-payment. For instance, an interesting conversation took place between three members of one group (group 3). Participant_A started: "I am not sure I would trust my mobile device to conduct a payment; this is for security reasons. I cannot be sure that my iPhone is secure enough from hacking, accessing my mobile data and other threats that target smartphones and tablets". Participant_B replied by saying: "I may not agree with this, I think all Android technology is supported with protection against unauthorized access to mobile data, viruses and even hacking... I have iPhone too, and I am not worried about its security for making a payment... to me, Galaxy mobile devices are less secured than iPhone or LG. Thus, I would trust in iPhone or LG for my mpayments more than Galaxy mobiles". Participant_A replied: "but you cannot say that these threats are not there, and if any of them occurred while making a payment, the loss will be doubled...', 
Few other participants had similar concerns surrounding mobile device software security, and deemed device security to have an impact on their trust in using the devices to make payments. Another facet of mobile device security is its hardware. Participant_A continued: "Also, what if my mobile device were lost or stolen? In this case anyone who had my mobile device would be able to make payments”. Participant_C replied: “you can lock your iPhone with a password, as other mobile devices can have password access as I believe”. Participant_B agreed and added: "in these cases, you can contact your telecom company and ask the employee to deactivate your mobile device or lock it, and the thief or the person who has your mobile device will not be able to use it at all". Participant_A said: “Well, this is a good advice, but still I am not sure whether I will place my trust in a mobile device for a monetary transaction". Overall, it seems that mobile devices with high security options would increase consumer trust in m-payments, and vice versa. Based on the given discussion and the opinions of other participants regarding device security, and the literature indication of further investigation of the influence of this factor on consumer

trust in m-payments (Amoroso \& Magnier-Watanabe, 2011; Herzberg, 2003; Chandra et al., 2010), another hypothesis relating to the mobile device is presented:

H16: The higher the security of the mobile device, the higher the consumers trust in mobile payments.

\subsubsection{Summary of the qualitative findings.}

The qualitative findings suggest that trust in m-payments is conditioned by 14 factors, categorised into five main groups; consumer characteristics (awareness, past experience, propensity to trust, uncertainty avoidance), environmental influences (trust environment), provider characteristics (reputation, trust level in products and services, trustworthiness), mobiledevice characteristics (capability, design suitability, device security) and perceived risks (technical, privacy, and security level). In addition, it was found that consumer past personal experiences, consumer awareness, uncertainty avoidance, provider's reputation, security levels and technical risks are the most agreed on factors that influence consumer trust in m-payments. Table 3.6 shows all factors with their proposed effect on trust and their perceived degree of influence among participants. A scale was developed for the purpose of this research to specify degree of consensus among participants by grouping them into categories, as follow: 


\begin{tabular}{|c|c|c|c|c|c|c|c|} 
No. of Participants & $1-2$ & $3-5$ & $6-10$ & $11-13$ & $14-19$ & $20-24$ & $24-27$ \\
\hline Category & Individual & Few & Minority & Some & Many & Majority & Large Majority
\end{tabular}

Findings also indicate that the most frequent applications for m-payments include paying bills (power and water), car parking, traffic registrations and fines, and mobile-banking payments. The most trustworthy amount of payment to be conducted using a mobile device varied from

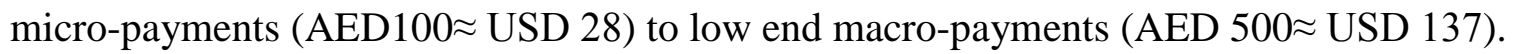

Table 3.5 Perceived Factors Influencing Consumer Trust in Mobile Payments

\begin{tabular}{|c|c|c|}
\hline $\begin{array}{l}\text { Trust Determinants } \\
\text { Group }\end{array}$ & Contributing Factor & $\begin{array}{c}\text { Perceived Degree of Influence } \\
\text { among Participants }\end{array}$ \\
\hline \multirow[t]{4}{*}{ Consumer characteristics } & - Past personal experiences & Majority (20-24) \\
\hline & - Consumer awareness & Majority \\
\hline & - Propensity to trust & Many (14-19) \\
\hline & - Uncertainty avoidance & Some \\
\hline Environmental influences & - Trust Environment & Many \\
\hline \multirow[t]{3}{*}{ Provider characteristics } & - Reputation & Large majority ( > 24) \\
\hline & $\begin{array}{l}\text { - Trust level in provider's } \\
\text { products and services }\end{array}$ & Few (controversial) \\
\hline & - Provider's trustworthiness & Many \\
\hline \multirow[t]{3}{*}{ Perceived risks } & - Technical risks & Many \\
\hline & - Security levels & Majority \\
\hline & - Privacy risks & Some \\
\hline \multirow[t]{3}{*}{ Mobile-device characteristics } & - Capability & Minority (6-10) \\
\hline & - Design suitability & Minority \\
\hline & - Security & Few \\
\hline
\end{tabular}

By considering the factors that were identified as most influential on trust in m-payments, it is concluded that consumer trust in m-payments in the Emirates is mainly associated with consumers' usage and awareness of the m-payment services and applications and their knowledge relating to their processes and procedures. Providers, on the other hand, would have their influence on consumer trust through their business image and the way they behave in fulfilling their customers' needs (such as being honest and competent), which in turn could make consumers feel more confident and more trusting in m-payments. However, there are still some technical and security risks which were perceived with main negative impact on consumer trust in m-payments. While the mentioned factors were considered important, other factors were perceived with minor impact, such as the ones related to the mobile-device characteristics, and provider's branded products and services. However, participants during the sessions had no 
consensus about whether consumer's age and gender could influence people's trust in mpayments in the Emirates.

\subsubsection{The qualitative findings in the context of the literature review}

In conjunction with the literature review, the focus group discussions supported the proposed research model of factors that influence consumer trust in m-payments (CTMP) in Section 2.8.2. The qualitative findings supported all the proposed factors of influence on consumer trust in mpayments. In particular, the participants' perceptions confirmed that consumers trust in mpayments is influenced by their awareness of m-payments, propensity to trust, past personal experience in conducting m-payments, and uncertainty avoidance. The participants also confirmed that consumers trust is associated with the provider's reputation, and some attributes associated with provider's trustworthiness (honesty, competency, and predictability). Moreover, they supported the point that trust in m-payments is associated with some security levels and privacy risks that can influence their trust, and that trust could be related to some characteristics of the mobile device such as its capability and design suitability. Some of these factors were perceived more influential than others. For instance, and as shown in Table 3.5, factors such as consumer awareness, provider's reputation and security risks got high consensus among the participants, whereas factors such as consumer's age and gender, and device security were perceived with less influence. Overall, the discussions confirmed the five groups of factors illustrated in the initially proposed CTMP model that were identified within the existing literature review, which are (1) consumer characteristics, (2) environmental influences, (3) provider characteristics, (4) perceived risks, and (5) mobile-device characteristics.

In addition to the mentioned factors, two factors of trust in m-payments emerged from the focus group discussions: trust level in provider's branded products and services and perceived technical risks. Originally, trust level in provider's products and services was perceived with an impact on trust as Emirati consumers might judge an m-payment provider by assessing its offered brands, and consequently, their trust in the m-payments literacy could be affected. Similarly, perceived technical risks were also considered a trust determinant to the participants, arguing that hardware and software technical faults which might be associated with m-payments over a telecommunication network and could influence consumers' trust. In addition, the three characteristics of the mobile device (capability, design suitability, and security) were originally 
identified as factors which influence consumer trust. However, all of the deduced factors enabled the researcher to develop a set of hypotheses for the current research, as presented in Table 3.6. These hypotheses were originally proposed in Chapter 2 (section 2.8.2), but were checked and modified when required with regard to the qualitative findings.

Table 3.6 Set of Research Hypotheses

\begin{tabular}{|c|c|}
\hline No. & Hypothesis \\
\hline H1 & $\begin{array}{l}\text { The more the consumer awareness about mobile payments, the higher the trust in mobile } \\
\text { payments. }\end{array}$ \\
\hline $\mathrm{H} 2$ & The higher the consumer's propensity to trust, the higher the trust in mobile payments. \\
\hline H3 & $\begin{array}{l}\text { The higher the consumer's uncertainty avoidance the lower the consumers trust in mobile } \\
\text { payments. }\end{array}$ \\
\hline $\mathrm{H} 4$ & Consumer positive personal experience increases his/her trust in mobile payments. \\
\hline H5 & The higher the trust environment, the higher the consumers trust in mobile payments. \\
\hline H6 & $\begin{array}{l}\text { A provider's good reputation has a significant positive influence on consumers trust in mobile } \\
\text { payments. }\end{array}$ \\
\hline $\mathrm{H} 7$ & $\begin{array}{l}\text { The higher the level of trust in provider's products and services, the higher the consumers trust in } \\
\text { mobile payments. }\end{array}$ \\
\hline H8 & The higher the provider's trustworthiness, the higher the consumers trust in mobile payments. \\
\hline H9 & Perceived technical risks negatively influence consumer trust in mobile payments. \\
\hline H10 & $\begin{array}{l}\text { The higher the perceived security levels in mobile payments, the higher the consumer trust in } \\
\text { mobile payments. }\end{array}$ \\
\hline H11 & Perceived privacy risks negatively influence consumer trust in mobile payments. \\
\hline H12 & $\begin{array}{l}\text { The higher the capability of the mobile device, the higher the consumers trust in mobile } \\
\text { payments. }\end{array}$ \\
\hline H13 & $\begin{array}{l}\text { The more suitable the design of the mobile-device to conduct an m-payment, the higher the } \\
\text { consumers trust in mobile payments. }\end{array}$ \\
\hline H14 & The higher the security of the mobile device, the higher the consumers trust in mobile payments. \\
\hline
\end{tabular}

\subsection{Research Hypotheses and Revised CTMP Model}

In addition to the research hypotheses, the findings from the focus group interviews enabled the researcher to revise the proposed conceptual model of consumer trust in m-payments (CTMP) as shown in Figure 3.1 for the current study. Following on, Chapter Four focuses on the second phase of the quantitative data collection process which was designed to test the model of consumer trust in m-payments and the developed hypotheses. 


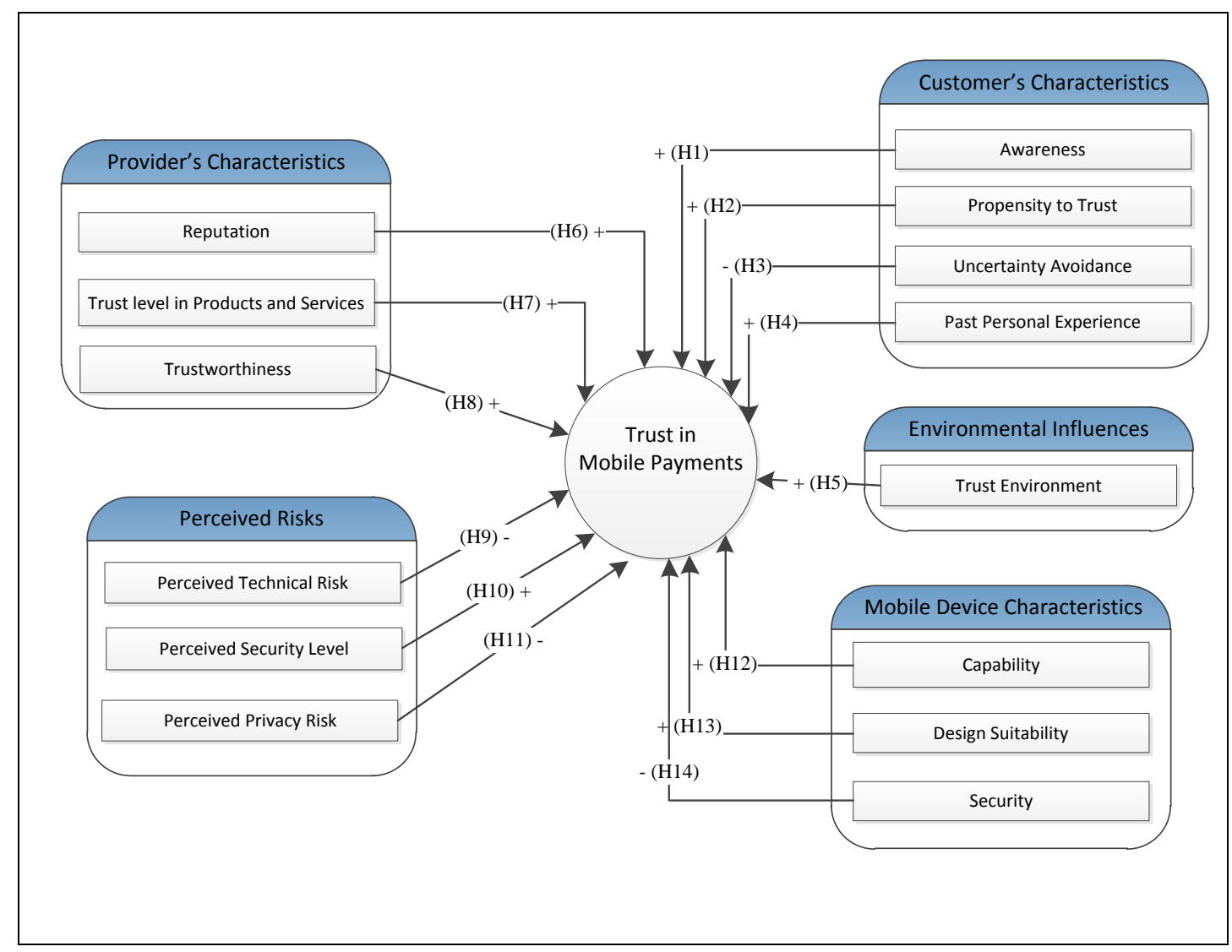

Figure 3.1 Revised CTMP Model Following the Focus Groups Interviews

Although the focus group technique is considered as a qualitative research instrument, it is also used to link to quantitative research (Pickard, 2007). The focus groups technique is used when generating research hypotheses that can be submitted for further research and testing using more quantitative approaches (Stewart \& Shamdasani, 1990). Focus groups also facilitate the development of quantitative research tools by learning what participants talk about regarding the phenomenon of interest (Pickard, 2007). The selected focus groups for this research are expected to indicate salient issues in trust in m-payment. The researcher, then, needs to test and generalise the findings from the focus group to a wider population, to be more representative of the people in the Emirates. In addition, he may need to discover other issues that will not be raised in the focus groups. This can be achieved through distributing questionnaires among the people in the Emirates. Thus, the researcher decided to establish a second phase for surveying people about their trust in m-payments. The next chapter will discuss the questionnaire surveying processes as the second methodological phase. 


\section{CHAPTER FOUR \\ Research Design and Quantitative Methodology for Phase Two}

\subsection{Introduction}

This chapter discusses the quantitative methodology used in the second phase of this study. The purpose of this second phase was to test, in a larger sample, the issues identified in the focus groups. For this purpose a survey instrument was created. The results of the survey were then used to find out if the results contradicted, confirmed or complemented the findings of the interviewing sessions.

This chapter is divided into six sections. Following the chapter introduction, section 4.2 presents a justification of employing a survey methodology in the second phase of the current research. The data collection instrument including the development of measures, questionnaire design and administration are detailed in section 4.3 , while section 4.4 details the data sampling strategy and approach. Next, section 4.5 describes the ethical considerations related to the data sampling process, and finally, the last section (4.6) presents the chapter conclusion.

\subsection{Justification of Survey Methodology}

For the current study, the use of a survey was deemed appropriate because of its ability to collect quantitative data to test the hypotheses (Zikmund, 2008). In addition, logical comparisons can be made through quantitative research in order to account for the variance in some phenomena, and measure quantity, intensity and frequency (Denzin \& Lincoln, 1994). The following section details the process used to design and develop the survey to gather adequate date information about the research problem (Malhotra et al., 2004; Neuman, 2003).

\subsection{Research Instrument - A Questionnaire}

Survey research is considered as the most common method of collecting primary quantitative data in information systems and social sciences research (Neuman, 2005; Pinsonneault \& Kraemer, 1993; Straub, 1989). Survey researchers sample many respondents who "answer the 
same questions, measure many variables, test multiple hypotheses, and infer temporal order from questions about past behaviour, experiences, or characteristics” (Neuman, 2005, p. 276).

\subsubsection{Questionnaire development and design.}

The questionnaire's design and development is a systematic process that includes a sequence of logical activities that directly affects the quality of the collected data (Bryman \& Bell, 2007; Cavana et al., 2001; Lyberg et al., 1997; Pickard, 2007).

The set of concepts that had been developed in the first phase was now translated into a set of specific items to elicit the data required to answer research question 2, i.e. "To what extent do factors influence consumer trust in m-payments and in what direction". In this phase the required survey items were created (adapted and newly developed) and formulated to be easily understood by respondents (Lyberg et al., 1997; Pickard, 2007). To improve the quality of the collected data and minimise response error, attention was also given to the questions' format and wording, the logical order and the scale of the answers (Lyberg et al., 1997; Malhotra et al., 2004; Pickard, 2007).

The survey instrument was developed in a series of steps, following guidelines presented in the existing social and information research literature for the quantitative methods. Table 4.1 illustrates these steps, each of which is described in the subsequent sections.

Table 4.1 Processes of Questionnaire Design and Development

\begin{tabular}{|c|l|}
\hline Step 1 & Specifying the data needed and operational definition \\
\hline Step 2 & Checking the question content, wording and structure \\
\hline Step 3 & Determining the scale and response format \\
\hline Step 4 & Assessing the reliability and validity of the survey \\
\hline Step 5 & Pretesting and revising the questionnaire \\
\hline Step 6 & Determining the survey method \\
\hline Step 7 & Administrating the questionnaire \\
\hline
\end{tabular}




\subsubsection{Step 1-Data specification and operational definition.}

The first step in the survey design process was concerned with linking the survey with the theoretical content of the research, through determining the data needed to answer the research questions (Creswell, 2009; Forza, 2002; Zikmund, 2008). Therefore, an important element of good research design involves designing a questionnaire that addresses the needs of the research and serves as a tool to obtain the relevant information (Creswell, 2009). A review of the relevant literature in Chapter Two, and the findings of the exploratory phase of the data collection (Chapter Three), enabled the researcher to identify a number of relevant variables to answer the research questions. However, prior to collecting the data for these variables, the conceptualisation and operationalisation of the research constructs was undertaken so that they could be measured (Forza, 2002; Sekaran, 2003).

Operational definitions of the constructs. Defining abstract constructs and being able to measuring them requires discussing two processes: conceptualisation and operationalisation (Neuman, 2003; Sekaran, 2000). These two processes represent two basic elements that measure the focal constructs in the proposed CTMP conceptual model. Conceptualisation refers to the process of applying conceptual or theoretical definitions to constructs; that is, identifying what is meant by the construct (Neuman, 2003; Sekaran, 2000). In the current research, consideration was given to provide clear and unambiguous definitions that link the CTMP model to the research context (Forza, 2002; Neuman, 2003). Operationalisation, on the other hand, is concerned with transforming theoretical constructs into a set of tangible indicators that can be measured (Smith, 1988). These specific operational definitions describe a concept in terms of its observable characteristics (Neuman, 2003). Through the process of operationalisation, the units of analysis are defined (Forza, 2002). In the current research, the construct items were selected because of their alignment with the conceptual definitions of their constructs (Forza, 2002; Neuman, 2003; Sekaran, 2000). The definitions of all constructs, either extracted from the literature or from the focus group discussions, are given in the following table (Table 4.2). 
Table 4.2 Constructs definition

\begin{tabular}{|c|c|c|}
\hline Construct & Adapted Definition & Reference(s) \\
\hline Propensity to trust & $\begin{array}{l}\text { The foundation of the initial trust that represents a person's disposition } \\
\text { to rely on others in various situations }\end{array}$ & $\begin{array}{l}\text { McKnight et al. } \\
\text { (2004) }\end{array}$ \\
\hline $\begin{array}{l}\text { Consumer } \\
\text { awareness }\end{array}$ & $\begin{array}{l}\text { An understanding that allows the user to reduce uncertainty associated } \\
\text { with the phenomenon in a subjective manner. }\end{array}$ & Gefen (2000) \\
\hline $\begin{array}{l}\text { Uncertainty } \\
\text { avoidance }\end{array}$ & $\begin{array}{l}\text { the level of anxiety of people in the face of an ambiguous and unknown } \\
\text { future of m-payments }\end{array}$ & (Hofstede, 2001) \\
\hline Past experience & $\begin{array}{l}\text { The quality of prior experience and past practices with m-payments, } \\
\text { including all m-payment transactions personally conducted by a person. }\end{array}$ & $\begin{array}{l}\text { McKnight et al. } \\
(2002) ; \text { Stewart } \\
(2006)\end{array}$ \\
\hline Trust environment & $\begin{array}{l}\text { The level of trust of those people around a person, including family } \\
\text { members, friends, colleagues, and others exist in the same environment. }\end{array}$ & $\begin{array}{l}\text { Cheung and Lee } \\
\text { (2000); McKnight } \\
\text { et al. (2004) }\end{array}$ \\
\hline $\begin{array}{l}\text { Provider's } \\
\text { reputation }\end{array}$ & $\begin{array}{l}\text { Consumers' opinion and their provided feedback regarding the services } \\
\text { provided by the m-payment vendors }\end{array}$ & $\begin{array}{l}\text { Mogenahalli et al. } \\
(2008)\end{array}$ \\
\hline $\begin{array}{l}\text { Trust level in } \\
\text { Provider's products } \\
\text { and services }\end{array}$ & $\begin{array}{l}\text { The degree of consumer trust in provider's products and services, other } \\
\text { than the provided m-payment service(s). }\end{array}$ & $\begin{array}{l}\text { Identified by the } \\
\text { participants in the } \\
\text { focus group } \\
\text { discussions }\end{array}$ \\
\hline $\begin{array}{l}\text { Provider's } \\
\text { trustworthiness }\end{array}$ & $\begin{array}{l}\text { Trust beliefs in the m-payment provider, which consist of the attributes: } \\
\text { benevolence, honesty, competence and predictability }\end{array}$ & $\begin{array}{l}\text { McKnight et al. } \\
\text { (2004) }\end{array}$ \\
\hline $\begin{array}{l}\text { Perceived technical } \\
\text { risks }\end{array}$ & $\begin{array}{l}\text { Consumer's concerns about technical issues associated with mobile } \\
\text { telecommunication network and platform. perception }\end{array}$ & $\begin{array}{l}\text { Identified by the } \\
\text { participants in the } \\
\text { focus group } \\
\text { discussions }\end{array}$ \\
\hline $\begin{array}{l}\text { Perceived security } \\
\text { levels }\end{array}$ & $\begin{array}{l}\text { Personal views about how persons think that their m-payments will not } \\
\text { be viewed, altered or manipulated during the process by inappropriate } \\
\text { parties }\end{array}$ & Pavlou (2001) \\
\hline $\begin{array}{l}\text { Perceived Privacy } \\
\text { risks }\end{array}$ & $\begin{array}{l}\text { Consumers' concerns about the inappropriate use of their personal } \\
\text { information (such as the disclosure or misuse of private and financial } \\
\text { information without their permission when engaged in m-payments). }\end{array}$ & $\begin{array}{l}\text { Lee et al. (2007); } \\
\text { Nyshadham, } \\
(2000)\end{array}$ \\
\hline $\begin{array}{l}\text { Capability of the } \\
\text { mobile device }\end{array}$ & $\begin{array}{l}\text { The ability of the mobile device, including hardware (device) and the } \\
\text { software (operating system), to preform m-payments }\end{array}$ & $\begin{array}{l}\text { Kounelis \& } \\
\text { Loeschner (2012) }\end{array}$ \\
\hline $\begin{array}{l}\text { Suitability of the } \\
\text { mobile-device } \\
\text { design }\end{array}$ & $\begin{array}{l}\text { The degree of convenience of device layout (including the design of the } \\
\text { screen and the keypad) to conduct m-payments. }\end{array}$ & $\begin{array}{l}\text { Chandra et al. } \\
\text { (2010), Zhou } \\
\text { (2011) }\end{array}$ \\
\hline $\begin{array}{l}\text { Security of the } \\
\text { mobile device }\end{array}$ & $\begin{array}{l}\text { Perceived level of the protection system of mobile devices that can } \\
\text { secure the device and ensures that no one can get access to the data on } \\
\text { the device without owner's permission. }\end{array}$ & $\begin{array}{l}\text { Corbitt et al. } \\
\text { (2003), Wei et al. } \\
(2008)\end{array}$ \\
\hline
\end{tabular}

Regarding the operationalisation process, one way to achieve low measurement error when developing the instrument is to draw items from already validated measures (Churchill \& Iacobucci, 2009). By applying this process, an initial item pool for each of the construct was generated. Afterwards, items need to be checked for applicability to research, and then checking whether all dimensions of a construct were covered by those items. If not, new items should be added (Moore \& Benbasat, 1991). Finally, all items need to be re-evaluated and revised in terms of clarity and context. As a result, most of the measurement items of the constructs in the current research were originally sourced or adapted from existing m-commerce literature and, if not 
found, from e-commerce literature, whereas few items were newly developed for the specific case of the current research. Some of the items employed from the literature are discussed in the following section (by giving two examples of items on each group of factors), followed by the discussion relating to the newly developed items. All other items are provided in Appendix E.

\section{(1) Measuring Consumer Characteristics (propensity to trust, uncertainty avoidance,} awareness, and past personal experience)

The group 'Consumer Characteristics' includes consumer propensity to trust, uncertainty avoidance, awareness, and past personal experience. Both consumer propensity to trust and awareness are chosen as examples of measuring consumer characteristics, to demonstrate the development process of both original and adapted items. Items of propensity to trust were found to have been measured by several scholars from two main perspectives. For instance, Chen and Barnes (2007) and Lee and Turban (2001) used almost the same items to measure propensity to trust, by determining the ease with which someone or something is trusted, whether by having sufficient knowledge about it or not. On the other hand, Kim et al. (2009) developed their items by connecting propensity to trust with consumer uncertainty avoidance with respect to the use of new technologies. For the current research, items were originally cited from the first cohort of authors, because of their direct linkage to the construct, and, on the other hand, uncertainty avoidance was studied as a separate construct.

Items of consumer awareness were adapted from Gefen's (2006) study about trust in ecommerce. Table 4.3 illustrates how the items of consumer awareness and propensity to trust were adapted to relate specifically to the CTMP model.

Table 4.3 Examples of 'Consumer Characteristics' Items

\begin{tabular}{|c|c|c|}
\hline $\begin{array}{c}\text { Propensity to } \\
\text { trust }\end{array}$ & $\begin{array}{c}\text { Items from literature } \\
\text { "I tend to trust a person/thing, even }\end{array}$ & $\begin{array}{c}\text { Modified items used in this study } \\
\text { "I tend to trust a person, even though I } \\
\text { have little knowledge about him/her". }\end{array}$ \\
\hline Awareness & $\begin{array}{c}\text { "I am familiar with the processes of } \\
\text { purchasing books on the internet". }\end{array}$ & $\begin{array}{c}\text { "I am aware of the steps required to } \\
\text { conduct a mobile payment". }\end{array}$ \\
\hline
\end{tabular}




\section{(2) Measuring environmental factors (Trust Environment)}

As discussed in the literature review, studies to date have focused on trust in m-payments with scant attention paid to the construct 'trust environment'. The items of this construct were found to have been measured through focusing on how the trust environment influences people's trust in e-commerce. For instance, Connolly and Bannister (2007) measured trust environment through the level of trust that exists in families and society, and to what extent people in the society tend to trust new technologies. The items were found most relevant to the current research and were originally cited, as exampled in Table 4.4.

Table 4.4 Example of 'Trust Environment' Item

\begin{tabular}{|l|l|l|}
\hline & Items from literature & Items used in this study \\
\hline Trust Environment & "I am living in a high trust society". & "I am living in a high trust society". \\
\hline
\end{tabular}

(3) Measuring provider characteristics (Reputation, Trust level in products and services, and Provider's trustworthiness)

Provider characteristics include a provider's reputation, trustworthiness, and the trust level in provider's products and services. For instance, a provider's reputation was measured by the degree of goodness or badness perceived by consumers in the web retailer's reputation in the market, the degree to which provider's products and services were perceived reputable, and whether the provider is recognised widely (Chen \& Barnes, 2007; Kim et al., 2009; Pavlou, 2003). Items in the current research were adapted from those studies. Using other perspective, Chandra et al. (2010) measured the perceived reputation of the m-payments provider through the degree of consumer belief in the provider's reputation in being good, fair, and honest, followed by Xin et al. (2013). This perspective would partially intersect with the items measuring 'provider's trustworthiness' and may not measure reputation directly; thus was not considered for the current research.

Another provider's characteristic, 'provider's trustworthiness' includes competence, benevolence, integrity and predictability. Competence, as an example, was originally developed by McKnight et al. (2002). Several items of competence were developed to measure it, adapted by Corbitt et al. (2003), Connolly and Bannister (2007) and Wang and Benbasat (2005) in ecommerce literature. McKnight et al. (2002) measured a provider's competence by determining 
its ability to act in the consumer's best interests. Wang and Benbasat (2005) measured competence by determining the ability to understand consumer needs and preferences about certain products, whereas Connolly and Bannister (2007) measured it as a vendor's ability to handle web sales transactions. In the current research, competence was measured by using the most simple and meaningful item, best compatible with the Arabic-translated item. Table 4.5 shows examples on adopting two items to the current research from the literature to measure 'provider's reputation' and 'provider's trustworthiness'.

Table 4.5 Examples of 'Provider Characteristics' Items

\begin{tabular}{|l|l|l|}
\hline & Items from literature & Modified items used in this study \\
\hline $\begin{array}{l}\text { Provider's } \\
\text { Reputation }\end{array}$ & $\begin{array}{l}\text { "This web retailer has a good } \\
\text { reputation in the market". }\end{array}$ & $\begin{array}{l}\text { "I believe that my provider of mobile } \\
\text { payments has a reputation for being } \\
\text { trustworthy". }\end{array}$ \\
\hline $\begin{array}{l}\text { Trust Beliefs } \\
\text { in Provider }\end{array}$ & $\begin{array}{l}\text { "I believe that } \\
\text { LegalAdvice.com is competent } \\
\text { and effective in providing legal } \\
\text { advice". }\end{array}$ & $\begin{array}{l}\text { "I believe that my provider of mobile- } \\
\text { payments is competent (that is the } \\
\text { provider's ability to achieve the expected } \\
\text { result and deliver on its promises)". }\end{array}$ \\
\hline
\end{tabular}

\section{(4) Measuring perceived risks (Technical, Privacy, Security level)}

Perceived risks categories include technical, security level, and privacy risks. For instance, perceived security level, which is most frequently cited in mobile and e-commerce trust literature, is measured by determining safeguards and technological protections to secure mpayments. For instance, Chandra et al. (2010) stated that consumers believe that mobile technology has sufficient safeguards and well-protected technological structures that can make them feel comfortable in conducting m-payments. Wei et al. (2008) and Wiedmann et al. (2010) measured security risks by determining consumers' thoughts surrounding payments made through m-commerce channels as to whether they were processed securely or not. Similarly, Table 4.6 shows an item of the perceived security risks adapted for the current research.

Table 4.6 Examples of 'Perceived Risks' Items

\begin{tabular}{|l|l|l|}
\hline & Items from literature & Modified items used in this study \\
\hline $\begin{array}{l}\text { Perceived Security } \\
\text { level }\end{array}$ & $\begin{array}{l}\text { "In general, the mobile technology } \\
\text { provides a robust and safe environment } \\
\text { to perform mobile payments". }\end{array}$ & $\begin{array}{l}\text { "I believe that the mobile technology } \\
\text { provides a robust and safe environment to } \\
\text { perform a mobile payment". }\end{array}$ \\
\hline
\end{tabular}




\section{(5) Measuring mobile-device characteristics (Capability, Design, and Security)}

Characteristics of a mobile device include capability, design suitability and the device security. To exemplify the measure development of one construct, mobile-device capability, Wiedmann et al. (2010) measured the functionality of the device by determining whether it worked well, met consumer expectation and performed its tasks effectively. Siau et al. (2003) measured the capability of the device by its usability to conduct a mobile payment, and by its features and functions. Based on these previous studies, items relating to mobile device capability in the current research were developed by focusing on its ability to perform payments effectively and efficiently, and examining its capability to perform a payment from a consumer perspective. One example of the items is shown in Table 4.7.

Table 4.7 Examples of 'Mobile-device Characteristics' Items

\begin{tabular}{|l|l|l|}
\hline & Items from literature & Modified items used in this study \\
\hline $\begin{array}{l}\text { Mobile-Device } \\
\text { Capability }\end{array}$ & $\begin{array}{l}\text { "I worry about the performance } \\
\text { of my mobile assistant". }\end{array}$ & $\begin{array}{l}\text { "I feel worry about the performance of my } \\
\text { mobile device in conducting a mobile } \\
\text { payment". }\end{array}$ \\
\hline
\end{tabular}

\section{(6) New items development}

The self-developed items were developed by using an inductive approach. The inductive approach is based on asking a sample of participants to provide descriptions on their perceptions and experiences about certain issues or describe some aspects of behaviour (Hinkin, 1998). For instance, the dimensions of the 'mobile-device design' given by the participants during the focus group sessions (general layout, screen layout, and the keypad layout) were considered the components of the measuring items of this construct. Another example is that the items measuring the construct 'device security' were developed in the basis of the details given by the participants, such as whether the device contains software that can secure the device and make the data stored unavailable to others, and that no one can get access to the data on the mobile device without the owner's permission.

Two other individual items associated with two different constructs were developed in the basis of the perceptions of the focus groups' participants as additional items to cover all aspects of each construct. For instance, an item associated with the construct 'perceived technical risks' was developed to include the dimension of the technical malfunctions and troubles that might be 
associated with m-payments, as identified by the participants. Another example is the item associated with the 'trust environment' that was added to describe the tendency of people in someone's society to avoid trusting in new payments methods, such as m-payments. Table 4.8 shows all newly developed items with regard to their associated constructs.

Table 4.8 All Newly Developed Items

\begin{tabular}{|c|c|}
\hline Construct & Newly developed item \\
\hline \multirow[t]{2}{*}{ Awareness } & I am aware of mobile payments applications in the Emirates \\
\hline & I am aware of mobile payments services in the Emirates. \\
\hline Trust environment & $\begin{array}{l}\text { People in my society always tend to avoid trusting in new payment methods, } \\
\text { such as mobile payments. }\end{array}$ \\
\hline $\begin{array}{l}\text { Perceived technical } \\
\text { risks }\end{array}$ & $\begin{array}{l}\text { I believe that mobile payments are protected from technical malfunctions and } \\
\text { issues. }\end{array}$ \\
\hline \multirow[t]{3}{*}{ Mobile-device design } & $\begin{array}{l}\text { I believe that the design of a mobile device can enable it to conduct a } \\
\text { payment. }\end{array}$ \\
\hline & $\begin{array}{l}\text { I believe that the screen design of a mobile device can enable it to conduct a } \\
\text { payment. }\end{array}$ \\
\hline & $\begin{array}{l}\text { I believe that the keypad design of a mobile device can enable it to conduct a } \\
\text { payment. }\end{array}$ \\
\hline \multirow{3}{*}{$\begin{array}{l}\text { Mobile-device } \\
\text { security }\end{array}$} & I believe that mobile devices are secure enough for conducting a payment. \\
\hline & $\begin{array}{l}\text { I believe that mobile devices contain software that can secure the device and } \\
\text { make the data stored unavailable to others. }\end{array}$ \\
\hline & $\begin{array}{l}\text { I believe that no one can get access to the data on my mobile without my } \\
\text { permission. }\end{array}$ \\
\hline Trust in M-payments & In general, I trust in m-payments \\
\hline
\end{tabular}

By choosing the items thoroughly from the generated pool, the qualitative results were revisited to make sure that participants' perceptions provided in the focus group discussions (discussed in Chapter 3) were considered in the process of developing the research instrument. As a result, some items were newly and self-developed in four categories: consumer characteristics, trust environment, perceived risks, and device characteristics. Specifically, as shown in Table 4.8, eleven self-developed items were added to five constructs as follows: 2 items to 'awareness', 1 item to 'trust environment', 1 item to 'perceived technical risks', 3 item to 'mobile-device design', 3 items to 'mobile-device design security', and one item to 'trust in m-payments'. Both constructs 'mobile device design' and 'mobile-device design security' were emerged from the focus group discussions, and thus, all their items were self-developed according to the qualitative data analysis generated from participants' perceptions. The items added to 'trust environment', 'perceived technical risks' and 'awareness' also resulted from the qualitative data analysis, but 
were added to cover the dimensions and aspects raised in the focus group discussions which were not found on the literature.

When developing the new items for the current research, the researcher paid careful attention to the directional relationship between the construct and the measures, as recommended by Straub (1989). As a result, the two new constructs 'mobile-device design' and 'mobile device security' were carefully developed as reflective variables, ensuring that both variables presented a common latent factor with reflective indicators, and showing that a change in the latent variable causes variation in all measures simultaneously (Freeze \& Ronald, 2007) (More details about the reflective variables are presented in next chapter, section 5.5.2).

In terms of each construct's items, there is no fixed rule guiding the number of items that should be associated with a construct, but "keeping a measure short is an effective means of minimising response biases caused by boredom or fatigue" (Hinkin, 1998, p.109). According to Cook, Hepworth, Wall \& Warr (1981), adequate internal consistency reliabilities can be obtained with as few as three items (as cited in Hinkin, 1998). In the current research, the number of items for most of the constructs ranged from 3 to 5 items, based on the theoretical domain of the reviewed literature and the qualitative data findings, indicating the content domain for the constructs. However, few constructs, such as 'consumer past experience', 'mobile-device capability' and 'provider's reputation' included only two items, but these already had been found in the literature to have adequate levels of validity and reliability, and that no new dimensions of these constructs were suggested by the participants of the focus groups. Exceptionally, the dependent variable (trust in m-payments) was measured by one construct, which directly indicates the level of consumer trust in m-payments. The researcher was aware that a single-item construct is considered a poor measurement, but might be accepted in some cases; especially that most of the studies in trust literature used the dimensions of 'provider's trustworthiness' to measure trust in m-payments, which was considered inappropriate in this research.

Following the conceptualisation and operationalisation of the constructs in the proposed CTMP model of the current research, attention was then given to determine the most appropriate survey method with which to collect the data that will be used later to addresses the research question. 


\subsubsection{Step 2 - Determine the question wording, content and structure.}

The guiding principles of good question design were adopted to collect accurate and relevant information, to minimise response errors and, consequently, to enhance the validity of the collected data (Cavana, et al., 2001; Forza, 2002; Malhotra et al., 2004). Overall, issues such as the question content, wording, structure and sequence were considered. In terms of the question content, the questions were designed to be brief, necessary, relevant, and understandable (Bryman \& Bell, 2007; Cavana, et al., 2001; Creswell, 2009). Every effort was therefore made to ensure that they were complete and the meanings clear. Thus, the questions only dealt with one topic and were not double-barrelled or ambiguous. Abbreviations were avoided to improve understanding, such as using the full term 'mobile payments' instead of 'm-payments' where used. In terms of the questionnaire structure, a range of questions were employed (scaled, multiple-choice and dichotomous questions), with closed-ended questions used with a specific ordered choice (Likert scale, will be discussed later in this Chapter). The respondents were asked to choose the response that most closely corresponded to their opinion.

For the sequencing of the questions, simple and interesting opening questions were used to maximise respondent involvement; therefore, the questions were ordered as follows: introductory questions about m-payments were placed at the beginning. The most sensitive questions relating to trust in m-payments were placed in the middle of the questionnaire, whereas sensitive questions that require personal information were placed at the end, following accepted practice (Churchill \& Iacobucci, 2005; Rea \& Parker, 1992). This approach could help the respondents not to feel uncomfortable or vulnerable because of beginning with personal details, and could also help in anticipating sensitivities and address possible objections in advance, such as encouraging people who may be ready to quit. In addition, beginning the questionnaire with asking personally identifiable information might affect other answers on the survey (Churchill \& Iacobucci, 2005).

Importantly, the questions (items) were easily categorised into logically coherent groups (categories of factors) corresponding to the structure of the grouping of the CTMP model, and all sections were introduced by instructional statements. Grouping questions that are similar or associated with the same category would make the questionnaire easier to complete, and the 
respondent will feel more comfortable (Churchill \& Iacobucci, 2005). This is consistent with the layout of the survey was similar to traditional mail surveys in an attempt to maximise response rates (Malhotra et al., 2004), in a form of a vertical flow and instructions in order to ease the process of answering and completing the survey. All of these principles were followed to enable the researcher to collect accurate and relevant data, to increase the response rate and to minimise design measurement errors.

\subsubsection{Step 3-Determining the scales.}

Another important issue that cannot be ignored is the process of determining the scale and the response format of the questionnaire (Davis \& Cosenza, 1993; Neuman, 2003). Scaling is commonly used for measuring how people perceive or think about objects and actions (Cavana et al., 2001; Malhotra et al., 2004). In the current research, scaling had two primary purposes: facilitating the process of conceptualisation of the constructs and representing variables in quantitative measures to assist in testing the research hypotheses (Neuman, 2003; Zikmund, 2008).

A number of scaling techniques are commonly employed in social research: the Likert scale, the Semantic Differential scale, the Thurstone scale, the Bogardus Social Distance scale, and the Guttman scale (Churchill \& Iacobucci, 2005; Malhotra et al., 2004; Neuman, 2003; Singh, 2007). However, the most widely used scale in questionnaires and survey research is the Likert scale (Dumas, 1999; Hinkin, 1998; Neuman, 2003; Singh, 2007). In addition to its popularity, "the simplicity and ease of use of the Likert scale is its real strength. When several items are combined, more comprehensive and multiple indicator measurement are possible" (Neuman, 2006, p. 210). Ease of construction and administration via self-completion questionnaires, such as online surveys are further features of this scale (Malhotra et al., 2002). For all previously mentioned reasons, and after considering the main information needed by the study (factors influence trust in m-payments) and the characteristics of the respondents (as recommended by Churchill and Iacobucci, 2005), the Likert scale was chosen for the current research. The Likert scale consists of a series of complete statements pertaining to the given object, which provide evaluative response categories ranging from strongly disagree to strongly agree, with which the respondents are asked to indicate their level of agreement or disagreement (Malhotra et al., 2004; Neuman, 2003; Zikmund, 2008). 
The next step in scale development is to determine the appropriate number of response categories in each scale (Neuman, 2003). The recommended number of Likert scale points is from three to nine; further, they should be evenly balanced with a neutral point (e.g., undecided), where respondents can express a neutral response direction (Neuman, 2003). Many studies in 'trust in electronic and mobile commerce' literature measured trust by using a five-point Likert scale (Cho et al., 2007; Gupta et al., 2012; Head \& Hassanein, 2002; Lee \& Kassim, 2012; Piao et al., 2012; Shahibi \& Fakeh, 2001; Yeh \& Li, 2009) and a seven-point Likert scale (Ayass, 2008; Chellappa \& Pavlou, 2002; Chellappa, 2001; Kim et al., 2009; Lee \& Turban, 2001; Miller \& Mitamura, 2003; Susanto, 2012). However, scholars in trust literature measured trust in higher scale levels, such as a nine-point Likert scale (Portz, Stron \& Sundby, 2001), ten-point Likert scale (Ghinea \& Angelides, 2004; Ratnasingam, 2000) and eleven-point Likert scale (Naef \& Schupp, 2009).

In the current research, all the constructs that represent the factors that influence consumer trust in m-payments were measured on a nine-point Likert scale ranging from 'Strongly disagree' to 'Strongly agree' with 'Neutral' as a neutral point response, to effectively allow respondents to express their opinions in this research. The nine-point scale was selected because it offers a wider range of agreements to a statement than the five-point or seven-point scales. In addition, the researcher intended to use a many-point Likert scale to enable respondents to express their level of trust with greater accuracy by enabling extreme choices, so that they can stretch their answers based on their degree of agreement or disagreement with the question, and to keep the neutral selection by choosing an odd number of the points. With more scale points, respondents can make better decisions on their experience and give a clearer indication of their perceptions and opinions (O'Cass \& Pecotich, 2005). Therefore, the nine-point Likert scale was found to be the most appropriate and useful for the current research. The nine points ranged from one ('most strongly disagree') to nine ('most strongly agree'), with a 'neutral' point of five. To achieve questionnaire uniformity and to ensure ease of completion, all scale and response formatting was standardised to an identical number of points (nine) through the Likert scale (O'Cass \& Pecotich, 2005). 
As for the dependent variable, trust in m-payments was measured by 10-point Likert scale, in which respondents select the number (from 1 to 10) which is considered to reflect the perceived trust in m-payments. Through this scale (lowest level, highest level), the respondents were asked the choice of choosing a trust score between extreme opposites in a scale which is all-around better way to engage the respondents to get a true sense of their level of trust. The trust scale rating was given points from 1 (very low trust) to 10 (very high trust). In addition, respondents can rate their trust more precisely, by having a wider range of points to express their low or high trust levels. It is worth mentioning that the 9-scale variable, which varies from distrust to trust through a neutral point, was not considered ideal for the dependent variable (trust in $\mathrm{m}$ payments), as previously argued that trust and distrust are separate constructs (Chapter two, section 2.5.3), and that the case of trust in the Emirates is only about trust. Thus, the 10-scale dependent variable was found more appropriate to study trust by going through a scale from very low level of trust to a very high level. It also corresponds to the initial scale used in the first phase of the research.

The survey was available in two languages (Arabic and English). When translating the questionnaires, the researcher ensured that the meaning of the source language statement was preserved in the translation (called semantic equivalence) (Cavana et al., 2001). The questionnaire was originally designed in English, and was then translated into Arabic. The back translation method was used where the Arabic version was translated back into English by another bilingual person. The aim of this process was to achieve the two different language versions of the instrument to be conceptually equivalent; expressing the same meaning of the words and sentences for all the targeted people in the Emirates (Cavana et al., 2001), and to make sure the translation is acceptable by maintaining the content of the two versions not too literal or too dynamic. As a result, very few Arabic words were replaced with other terms, to best fit with the context of the Emirates.

Having determined the items to be included in the draft questionnaire, and having chosen the scale response format, the question sequence and design, and the survey layout, the next step was the pre-testing of the survey instrument on a small sample to ensure its validity, and to identify any changes needed prior to administering the final version (Malhotra, 2004). 


\subsubsection{Step 4-Assessing validity and reliability of the questionnaire.}

It is essential to check that the questionnaire will measure what it is supposed to measure (Straub, 1989). This checking may include aspects like the length of the questionnaire, its structure and sections (appropriateness and relevance), or its simplicity and ease. Validating the questionnaire could reduce bias by detecting ambiguities and misinterpretations which can then be minimised, which results in a high degree of objectivity (Sushil \& Verma, 2010). Validity needs to be assured for the constructs and content used, while reliability refers to the consistency of the results. This section discusses firstly the validity assessment of the questionnaire with respect to the current research, and then the assessed reliability was discussed.

The validity can be assessed in many ways, in terms of content, construct, convergent and discriminant validity. For instance, content validity is concerned with the degree to which the content of the factor contains all measures that should be included (Straub, Boudreau, \& Gefen, 2004; Straub, 1989). In other words, content validity represents the extent to which a measure represents all facets of a given construct (Neuman, 2003). Content validity is achieved in the current research by several procedures recommended by Cooper and Shindler (2010), Davis and Cosenza (1993) and Lawshe (1975). One procedure used for assessing content validity is called the card sorting technique. This technique aims to quantitatively identify the most decisive items for each group of factors while selecting the most appropriate items at the same time (Lawshe, 1975). The process of deciding which items to include or exclude is a complex task for researchers and items have to be chosen wisely so that the measures capture the essence of each construct (Straub et al., 2004). The card sorting technique in the current research consisted of 13 participants including academic staff, postgraduate students and administrative staff at Sharjah University in the Emirates, in order to gauge agreement among judges regarding how essential particular items are.

Using this approach, each of the judges respond to the following question for each item: "Is the skill or knowledge measured by this item 'essential,' 'useful, but not essential,' or 'not necessary' to the performance of the construct?" (Lawshe, 1975). The more items are rated as essential, the more content validity is given for this item. Using these assumptions, Lawshe (1975) developed a formula termed the content validity ratio: 


$$
\boldsymbol{C V R}=\frac{n e-\frac{N}{2}}{\frac{N}{2}}
$$

Where: CVR= Content Validity Ratio.

$\mathrm{Ne}=$ number of judges indicating "essential".

$\mathrm{N}=$ total number of judges included within the panel.

This formula generates values ranging from +1 to -1 . Positive values indicate that at least half the judges rated the item as essential. Lawshe's (1975) approach was used to evaluate the findings of the card sorting procedure. Hence, each participant was given the construct definition (as developed within the first judgment round) as well as a list of items for each construct. Subsequently, the participant was asked to rate each item as 'essential,' 'useful, but not essential,' or 'not necessary'. By applying the CVR formula on 13 judgement rounds of participants (two individuals, one group of two participants, three groups of three participants), the answers indicated the appropriateness of each item. In addition, respondents were encouraged to comment on items that appear unclear or worded ambiguously.

The card sorting technique resulted in 34 questions (out of 44) in the questionnaire receiving a CVR value of 1; which means that these items were seen as essential and strongly related to their constructs. The remaining 10 questions had a CVR greater than zero, as shown in Table 4.9

Table 4.9 Card Sorting Technique Results

\begin{tabular}{|c|c|}
\hline Question & CVR value \\
\hline B4 & .846 \\
\hline B5 & .846 \\
\hline B6 & .846 \\
\hline C1 & .230 \\
\hline C2 & .538 \\
\hline D5 & .692 \\
\hline D6 & .692 \\
\hline D7 & .692 \\
\hline E1 & .846 \\
\hline E2 & .846 \\
\hline
\end{tabular}


Items with a CVR value of less than 1 means that they are still considered essential but differ in their essentiality. However, items that have a relatively low CRV value, such as $\mathrm{C} 1$ and $\mathrm{C} 2$, were reviewed and discussed with the participants. They were rephrased as there were some linguistic issues resulting from the translation from English to Arabic.

The second type of validity that was assessed in the current research was construct validity. The construct validity measurement was constructed by both convergent and discriminant validity. "Convergent validity is evidenced when items thought to reflect a construct converge, or show significant, high correlations with each other, particularly when compared to the convergence of the items relevant to other constructs, irrespective of method" (Straub et al., 2004, p. 21). On the other hand, discriminant validity means that there should be little or no communality between an item that belongs to a certain construct and other constructs (Straub et al, 2004). The assessment of the convergent and discriminant validity of the CTMP model was done statistically in next chapter (Chapter 5 - the quantitative data analysis).

Straub (1989) argues that reliability would be a statement about measurement accuracy: "the extent to which the respondent can answer the same questions or close approximations in the same way each time" (p. 151). While construct validity is an issue of measurement between constructs, reliability (or internal consistency) is an issue of measurement within a construct (Straub et al. 2004). Reliability tests look at the items in the scale. In the current research, reliability was maximised by using clear conceptualisation of the factors and ensuring accurate measurements, in addition to operationalising each group of factors with multiple indicators (Neuman, 2003). Furthermore, the questionnaire was pre-tested and modified to ensure that it was easily understood. Statistically, reliability was measured through the internal consistency test, Cronbach's alpha (details in next chapter). Next, the items were pretested and revised, as advised by Straub (1989), by an expert panel to ensure its validity, and to identify any changes needed prior to determine the method of the final survey version.

\subsubsection{Step 5-Pretesting and revising the questionnaire.}

An important step in the survey development process involved pre-testing the questionnaire with a small sample of the target population to identify and eliminate any possible issues prior to administrating the survey, such as whether the questions are worded clearly, understood, and 
placed in the best order, or whether additional or specifying questions are needed or whether some questions should be eliminated (Cavana et al., 2001; Malhotra, 2004; Pinsonneault \& Kraemer, 1993). In the current study, the questionnaire was pre-tested in three stages. First, a copy of the English version of the questionnaire was assessed and reviewed by the researcher's supervisors. Then, the questionnaire was evaluated by a panel of four academics in the departments of information systems and e-commerce at Sharjah University in the Emirates and Al-Zaytoonah University of Jordan, paying a careful attention to the Arabic translated questionnaire and the translation. Thirdly, the questionnaire was assessed through a pilot study via online interviews with a pool of 15 potential respondents, selected on a convenience sampling basis. The participants were briefed about the questionnaire and then asked to complete the survey and to provide feedback on the questionnaire design, the clarity of the questions, wording and phrasing of the questions and any other related comments.

Based on participants' feedback, a number of sections in the survey were identified for improvement, predominantly in relation to refining question wording, evaluating the question sorting and the layout of the questionnaire. These processes resulted in 18 items being modified; 8 items were modified in each English and Arabic version, where two exclusive items in Arabic were amended. An example of the output of the pre-testing process is provided in Table 4.10.

Table 4.10 Some of the Changes Made to the Questionnaire through the Pre-testing Process

\begin{tabular}{|l|l|l|l|}
\hline \multicolumn{1}{|c|}{ Construct } & Question code & Changes made & \multicolumn{1}{c|}{ Examples } \\
\hline $\begin{array}{l}\text { Uncertainty } \\
\text { Avoidance }\end{array}$ & B4 & Wording changed & $\begin{array}{l}\text { I am always cautious in 'using' to } \\
\text { 'trying' new technologies. }\end{array}$ \\
\hline Awareness & B8, B9 & Wording added & $\begin{array}{l}\text { Adding the phrase 'in the Emirates' at } \\
\text { the end of the items. }\end{array}$ \\
\hline $\begin{array}{l}\text { Editorial questions } \\
\text { about mobile } \\
\text { payments }\end{array}$ & A2 & Item added & $\begin{array}{l}\text { 'What kind of mobile-payment services } \\
\text { and applications that you use regularly, } \\
\text { or that you prefer to use? (Choose as } \\
\text { many as you want to)'. }\end{array}$ \\
\hline
\end{tabular}

A summary of all items in the current research (originally cites, adapted or self-developed) is presented in Table 4.11, presenting the source of the items and their items' status. In result, 11 items were originally cited, 23 items were adapted from the literature, whereas 10 items were newly developed. 
Table 3.11 Scales details (wording, source and status)

\begin{tabular}{|c|c|c|c|c|}
\hline $\begin{array}{l}\text { Scale } \\
\text { no. }\end{array}$ & Construct & Scale wording & Scale source & $\begin{array}{l}\text { Scale } \\
\text { status }\end{array}$ \\
\hline \multicolumn{5}{|c|}{ Consumer Characteristics } \\
\hline 1 & \multirow{3}{*}{ Propensity to trust } & It is easy for me to trust a person. & Lee \& Turban (2001) & Original \\
\hline 2 & & My tendency to trust a person is high. & Lee \& Turban (2001) & Original \\
\hline 3 & & $\begin{array}{l}\text { I tend to trust a person, even though I have } \\
\text { little knowledge about him/her. }\end{array}$ & Lee \& Turban (2001) & Original \\
\hline 4 & \multirow{3}{*}{$\begin{array}{l}\text { Uncertainty } \\
\text { avoidance }\end{array}$} & $\begin{array}{l}\text { I am always cautious in trying new } \\
\text { technologies. }\end{array}$ & Kim et al. (2009) & Original \\
\hline 5 & & $\begin{array}{l}\text { If possible, it is always better to avoid } \\
\text { using new technologies for financial } \\
\text { transactions. }\end{array}$ & Kim et al. (2009) & Original \\
\hline 6 & & $\begin{array}{l}\text { In a new commercial relationship, I have to } \\
\text { be careful until I see the evidence of a } \\
\text { firm's trustworthiness. }\end{array}$ & Kim et al. (2009) & Original \\
\hline 7 & \multirow{4}{*}{$\begin{array}{l}\text { Consumer } \\
\text { awareness }\end{array}$} & I am very familiar with mobile payments. & Gefen (2006) & Adapted \\
\hline 8 & & $\begin{array}{l}\text { I am aware of mobile payments } \\
\text { applications in the Emirates. }\end{array}$ & & New \\
\hline 9 & & $\begin{array}{l}\text { I am aware of mobile payments services in } \\
\text { the Emirates. }\end{array}$ & & New \\
\hline 10 & & $\begin{array}{l}\text { I am aware of the steps required to conduct } \\
\text { a mobile payment. }\end{array}$ & Gefen (2006) & Adapted \\
\hline 11 & \multirow{2}{*}{$\begin{array}{l}\text { Consumer past } \\
\text { experience }\end{array}$} & $\begin{array}{l}\text { I have positive experience(s) in conducting } \\
\text { mobile payments in the Emirates. }\end{array}$ & $\begin{array}{l}\text { Connolly and Bannister } \\
(2007)\end{array}$ & Adapted \\
\hline 12 & & $\begin{array}{l}\text { I have negative experience(s) in conducting } \\
\text { mobile payments in the Emirates. }\end{array}$ & $\begin{array}{l}\text { Connolly and Bannister } \\
(2007)\end{array}$ & Adapted \\
\hline \multicolumn{5}{|c|}{ Environmental Influences } \\
\hline 13 & \multirow{3}{*}{ Trust environment } & A high degree of trust exists in my family. & $\begin{array}{l}\text { Connolly and Bannister } \\
\text { (2007) }\end{array}$ & Original \\
\hline 14 & & I am living in a high-trust society. & $\begin{array}{l}\text { Connolly and Bannister } \\
\text { (2007) }\end{array}$ & Original \\
\hline 15 & & $\begin{array}{l}\text { People in my society always tend to avoid } \\
\text { trusting in new payment methods, such as } \\
\text { mobile payments. }\end{array}$ & Kim (2008) & Adapted \\
\hline \multicolumn{5}{|c|}{ Provider's Characteristics } \\
\hline 16 & \multirow{5}{*}{$\begin{array}{l}\text { Provider's } \\
\text { trustworthiness }\end{array}$} & $\begin{array}{l}\text { I believe that my provider of mobile } \\
\text { payments is honest (that is the provider } \\
\text { makes reliable decisions and honours the } \\
\text { terms that it guarantees). }\end{array}$ & McKnight et al. (2002) & Adapted \\
\hline 17 & & $\begin{array}{l}\text { I believe that my provider of mobile } \\
\text { payments is benevolent (that is the } \\
\text { provider takes the customer's benefit into } \\
\text { consideration when making decisions } \\
\text { concerning the customer's information). }\end{array}$ & McKnight et al. (2002) & Adapted \\
\hline 18 & & $\begin{array}{l}\text { I believe that my provider of mobile } \\
\text { payments is predictable (that is the } \\
\text { provider's actions in given circumstances } \\
\text { can be predicted from its past behaviours). }\end{array}$ & McKnight et al. (2002) & Adapted \\
\hline 19 & & $\begin{array}{l}\text { I believe that my provider of mobile } \\
\text { payments is competent (that is the } \\
\text { provider's ability to achieve the expected } \\
\text { result and deliver on its promises). }\end{array}$ & McKnight et al. (2002) & Adapted \\
\hline 20 & & Overall, I believe that my provider of & McKnight et al. (2002) & Adapted \\
\hline
\end{tabular}




\begin{tabular}{|c|c|c|c|c|}
\hline $\begin{array}{l}\text { Scale } \\
\text { no. }\end{array}$ & Construct & Scale wording & Scale source & $\begin{array}{l}\text { Scale } \\
\text { status }\end{array}$ \\
\hline & & mobile payments is trustworthy. & & \\
\hline 21 & \multirow{2}{*}{$\begin{array}{l}\text { Provider's } \\
\text { reputation }\end{array}$} & $\begin{array}{l}\text { I believe that my provider of mobile } \\
\text { payments has a reputation for being } \\
\text { trustworthy. }\end{array}$ & Kim et al. (2009) & Adapted \\
\hline 22 & & $\begin{array}{l}\text { I believe that my provider of mobile } \\
\text { payments has reputable products and } \\
\text { services. }\end{array}$ & Kim et al. (2009) & Adapted \\
\hline 23 & \multirow{2}{*}{$\begin{array}{l}\text { Level of trust in } \\
\text { Provider's products } \\
\text { and services }\end{array}$} & $\begin{array}{l}\text { I believe that the branded products and } \\
\text { services offered by the provider are } \\
\text { trustworthy. }\end{array}$ & Yeh and Li (2008) & Adapted \\
\hline 24 & & $\begin{array}{l}\text { I trust in products and services that I have } \\
\text { received from my m-payments provider. }\end{array}$ & Pavlou (2003) & Adapted \\
\hline \multicolumn{5}{|c|}{ Perceived Risks } \\
\hline 25 & \multirow{3}{*}{$\begin{array}{l}\text { Perceived technical } \\
\text { risks }\end{array}$} & $\begin{array}{l}\text { I believe that mobile payments work very } \\
\text { well technically. }\end{array}$ & Wiedmann et al. (2010) & Adapted \\
\hline 26 & & $\begin{array}{l}\text { I believe that mobile payments are } \\
\text { susceptible to being accidentally altered or } \\
\text { destroyed during transmission over the } \\
\text { telecommunication network. }\end{array}$ & $\begin{array}{l}\text { Connolly and } \\
\text { Bannister (2007), }\end{array}$ & Adapted \\
\hline 27 & & $\begin{array}{l}\text { I believe that mobile payments are } \\
\text { protected from technical malfunctions and } \\
\text { issues. }\end{array}$ & & New \\
\hline 28 & \multirow{5}{*}{$\begin{array}{l}\text { Perceived security } \\
\text { level }\end{array}$} & $\begin{array}{l}\text { I believe that conducting mobile payments } \\
\text { can present financial risks. }\end{array}$ & Chen \& Barnes (2007) & Adapted \\
\hline 29 & & $\begin{array}{l}\text { I believe that mobile technology provides a } \\
\text { robust and safe environment to perform a } \\
\text { mobile payment. }\end{array}$ & Chandra et al. (2010) & Original \\
\hline 30 & & $\begin{array}{l}\text { I believe that the monetary information that } \\
\text { I provide on the mobile device while } \\
\text { conducting a payment is well protected } \\
\text { from hackers and penetrators. }\end{array}$ & Chen \& Barnes (2007) & Adapted \\
\hline 31 & & $\begin{array}{l}\text { I feel confident that encryption and other } \\
\text { technological safeguards on mobile } \\
\text { technology make it safe for me to make } \\
\text { mobile payments. }\end{array}$ & Chandra et al. (2010) & Original \\
\hline 32 & & $\begin{array}{l}\text { In general, I believe mobile payments are } \\
\text { secure. }\end{array}$ & Chandra et al. (2010) & Adapted \\
\hline 33 & \multirow{3}{*}{$\begin{array}{l}\text { Perceived privacy } \\
\text { risks }\end{array}$} & $\begin{array}{l}\text { I have privacy concerns regarding mobile } \\
\text { payments. }\end{array}$ & $\begin{array}{l}\text { Connolly and Bannister } \\
(2007) \text {, }\end{array}$ & Adapted \\
\hline 34 & & $\begin{array}{l}\text { I believe that my mobile payment provider } \\
\text { may use my personal information without } \\
\text { permission. }\end{array}$ & Chandra et al. (2010), & Original \\
\hline 35 & & $\begin{array}{l}\text { I feel concerned about divulging my } \\
\text { personal and financial data to other parties. }\end{array}$ & $\begin{array}{l}\text { Connolly and Bannister } \\
(2007)\end{array}$ & Adapted \\
\hline \multicolumn{5}{|c|}{ Mobile-Device Characteristics } \\
\hline 36 & \multirow{2}{*}{$\begin{array}{l}\text { Mobile-device } \\
\text { Capability }\end{array}$} & $\begin{array}{l}\text { I have concerns about the performance of } \\
\text { my mobile device when it comes to } \\
\text { conducting a mobile payment. }\end{array}$ & Chandra et al. (2010) & Adapted \\
\hline 37 & & $\begin{array}{l}\text { I am afraid that my mobile device may not } \\
\text { have the ability to conduct a payment. }\end{array}$ & Wiedmann et al. (2010) & Adapted \\
\hline 38 & $\begin{array}{c}\text { Mobile-device } \\
\text { design Suitability }\end{array}$ & $\begin{array}{l}\text { I believe that the design of a mobile device } \\
\text { can enable it to conduct a payment. }\end{array}$ & & New \\
\hline
\end{tabular}




\begin{tabular}{|c|c|c|c|c|}
\hline $\begin{array}{c}\text { Scale } \\
\text { no. }\end{array}$ & Construct & Scale wording & Scale source & $\begin{array}{c}\text { Scale } \\
\text { status }\end{array}$ \\
\hline 39 & & $\begin{array}{l}\text { I believe that the screen design of a mobile } \\
\text { device can enable it to conduct a payment. }\end{array}$ & & New \\
\hline 40 & & $\begin{array}{l}\text { I believe that the keypad design of a } \\
\text { mobile device can enable it to conduct a } \\
\text { payment. }\end{array}$ & & New \\
\hline 41 & \multirow{3}{*}{$\begin{array}{l}\text { Mobile-device } \\
\text { security }\end{array}$} & $\begin{array}{l}\text { I believe that mobile devices are secure } \\
\text { enough for conducting a payment. }\end{array}$ & & New \\
\hline 42 & & $\begin{array}{l}\text { I believe that mobile devices contain } \\
\text { software that can secure the device and } \\
\text { make the data stored unavailable to others. }\end{array}$ & & New \\
\hline 43 & & $\begin{array}{l}\text { I believe that no one can get access to the } \\
\text { data on my mobile without my permission. }\end{array}$ & & New \\
\hline 44 & Trust in m-payments & In general, I trust in m-payments & & New \\
\hline
\end{tabular}

Having determined the final version of the questionnaire in the pre-testing phase, the survey method was determined and assessed.

\subsubsection{Step 6-Determining the survey method.}

Survey data are often collected by several methods, such as personal face-to-face surveying, telephone surveying, observation, mail, email, or web-based surveying (Bryman \& Bell, 2007, Cavana et al., 2001, Malhotra et al., 2002; Pickard, 2007; Sekaran, 2003; Zikmund, 2008). Each data collection method has advantages and disadvantages and, therefore, the choice of the appropriate survey collection method is contingent upon the research objective, as well as the nature of the survey interaction and the mode of administration (Bryman \& Bell, 2007; Cavana et al., 2001; Malhotra et al., 2004). A comparison of these survey methods, including the relative strengths and limitations of each method, is presented in Table 4.12.

Table 4.12 A Comparison of Survey Methods (Adapted from Cavana et al., 2001, Malhotra et al., 2004, Neuman, 2003; Zikmund, 2008)

\begin{tabular}{|c|c|c|c|c|}
\hline Dimensions/Types & Online & Personal & Mail & Telephone \\
\hline Cost & Low & High & High & $\begin{array}{c}\text { Low to } \\
\text { moderate }\end{array}$ \\
\hline Speed of data collection & Very fast & $\begin{array}{c}\text { Moderate to } \\
\text { fast }\end{array}$ & $\begin{array}{c}\text { Moderate to } \\
\text { fast }\end{array}$ & Very fast \\
\hline Geographic flexibility & High & Limited & Limited & High \\
\hline Respondent cooperation & $\begin{array}{c}\text { Varies, } \\
\text { depending on } \\
\text { website }\end{array}$ & Excellent & Excellent & Good \\
\hline Response rate & Fair & High & High & Low \\
\hline Anonymity of respondent & High & Low & Low & Moderate \\
\hline Follow up & Difficult & Difficult & Difficult & Easy \\
\hline
\end{tabular}




\begin{tabular}{|c|c|c|c|c|}
\hline Degree of interviewer influence & None & High & High & Moderate \\
\hline Item non-response rate & High & Low & Low & Medium \\
\hline
\end{tabular}

In the current research, the researcher considered the online survey as the most appropriate method. Due to the growth in Internet usage, the use and application of Internet-based surveys has been growing recently in business and social research (Cavana et al., 2001, Neuman, 2003; Pickard, 2007), because it offers many advantages over traditional survey methods, such as low cost, rapid deployment, and fast turnaround, with perhaps the most important advantage being their geographic flexibility (Cavana et al., 2001; Dillman et al., 2008; Pickard, 2007). Furthermore, online surveys provide helpful facilities, such as the ease of administration of the survey by enhancing the implementation of accessing and updating questions electronically (Cavana et al., 2001; Zikmund, 2008). Another facility is the ability to transfer survey responses directly to a database, thus, eliminating transcription errors and preventing survey alteration by the survey respondents (Dillman et al. 2008; Pickard, 2007).

However, the disadvantage of this approach is that online respondents may not be representative of the general population (Cavan et al., 2002). For this reason, care was taken in selecting the most representative sample frame for the current research to counter this identified limitation. In addition, the web links of the survey were hosted in many web blogs, online forums and digital groups from several Emirates/cities of the Emirates. This is discussed briefly later in this Chapter.

\subsubsection{Step 7- Administering the questionnaire online.}

After designing the questionnaire, a sheet was enclosed describing certain details, such as the aim of the research, how to answer the questions, the time expected to complete it, the researcher's email address, other personal contact information, and some privacy concerns and ethical issues. This was done after Victoria University's School of Information Management Human Ethics Committee had reviewed the questionnaire. The survey can be found in its English version at https://www.surveymonkey.com/s/AhmedMPaymentEnglish, or in its Arabic version at https://www.surveymonkey.com/s/AhmedMPaymentsArabic. Copies of both questionnaires are included in Appendix F. 
The online questionnaire was created with a survey generator application, Survey Monkey. As previously outlined in step (2) the current study followed guidelines for established and emerging online survey design (Cavana, et al., 2001; Forza, 2002; Malhotra et al., 2004). Therefore, attention was given to designing an online survey that was user-friendly, and with features that promoted the logical flow of the questionnaire. Additionally, the inclusion of a motivational introductory screen, easy-to-follow instructions, the format, and the placement of questions and response boxes were continuously addressed (Bryman \& Bell, 2007; Forza, 2002). The introductory screen, which served as the introduction to the survey, included an informative title, information related to the research and researcher, and instructions on how to proceed to the next page and how to respond to the presented questions. As recommended by Dillman (2000) and Schonlau, Fricker, and Elliott (2002), a multi-item format (per screen) was used instead of only one question being shown per screen. The questionnaire was constructed to appear page by page, with each page containing a coherent set of questions. This approach assisted in reducing the completion time and lessened the possibility of missing data.

Depending on the specific questions, text boxes, drop-down menus, check boxes and radio buttons were used. The check boxes were applied to multiple-choice questions, with instructions to click beside the responses. The radio buttons were used for questions scaled on a nine-point Likert scale, which could be answered by placing a tick in the chosen button. Importantly, a progress indicator was included at the top of survey pages to reduce the possibility of respondents abandoning, and thus not completing all sections, in the questionnaire (Dillman \& Bowker, 2001). In addition, each page ended with instructions to click a 'Next Page' icon.

Surveying respondents by using questionnaires may face some problems, such as respondents' bias caused by them giving researcher-desirable responses, and a low response rate (Singh, 2007). Firstly, to deal with the bias issue, the questionnaire was designed with a high degree of neutrality, and respondents were not pressured to give certain answers. Furthermore, the questionnaire included both positively and negatively worded questions, as recommended by Cavana et al. (2001), so that the tendency of respondents to mechanically circle the points towards one end of the scale was minimised. Moreover, certain types of question were avoided 
such as leading questions (questions that lead the respondents to give the responses that the researcher would like them to give (Cavana et al., 2001)).

After the questionnaire had been completed, respondents were provided with the contact details of the researcher, should they wish to receive a summary of the final report. In addition, respondents were asked to click on the submit button where a note of appreciation for their participation was presented at the close of the survey, and were optionally asked to provide their email addresses if they wish to enter a prize draw for a gift voucher worth AED100. After clicking on the submit button, the data were transferred automatically to the host company server, where it was saved. The database was then downloaded and exported into SPSS for further data analysis. Regarding the prize, it was offered as an incentive in order to motivate people to participate in the research, as recommended by many researchers, such as Goeritz (2006) and Schonlau et al. (2002). To identify the prize winner, all collected email addresses were pooled within a Microsoft Excel Spreadsheet. Then, a random email address was selected using the formula $=$ INT $\left(\right.$ RAND ()$\left.^{*} \mathrm{n}+1\right)$, where $\mathrm{n}=$ total email addresses. Then, the participant with that email address was contacted accordingly, met and handed the prize. The winner, a male based in Dubai, was thanked again and asked to sign for a paper sheet to confirm receiving the voucher.

After discussing the administration process, the researcher had to identify which subjects to survey in order to obtain the necessary information to address the research objectives (Forza, 2002; Malhotra et al., 2004; Pickard et al., 2007). Therefore, the sampling strategy employed in the current research is discussed next.

\subsection{Sampling Strategy}

The sampling strategy requires the researcher to consider certain issues regarding the population to be surveyed, the sampling frame, the sample size, the sampling approach and sample representativeness (Churchill \& Iacobucci, 2005; Kumar et al., 2002; Zikmund \& Babin, 2007). The subsequent sections discuss these subjects in details. 


\subsubsection{Sampling frame.}

Within the current study, the population of interest consisted of all people in the Emirates. According to estimates from Internet World Stats (2013), the population of the Emirates as of December 2012 was 8,264,070. In the current study, a representative sample was selected from which to draw conclusions that would be generalisable across the entire population being examined (Sekaran, 2003; Zikmund \& Babin, 2007).

The same sampling frame determined in the qualitative phase was considered for surveying people in the Emirates. All survey participants had the following characteristics:

- Having some knowledge about m-payments (current user, previous experience, knowledge from providers of m-payment services, knowledge from media, or others).

- Over 18 years of age.

- Expressing interest in sharing their perceptions of trust in m-payments.

To determine an adequate sample size, two common ways were used for quantitative research. The first one was by considering the statistical methods used to analyse data, and the second one was by doing some calculations, considering the confidence interval and the size of the population. The researcher used both approaches to estimate a sufficient sample size of respondents for the current research.

According to Hinkin (1998), researchers should consider the statistical methods used to analyse the data. Given the research objective, the Partial Least Squares (PLS) analysis technique was chosen to evaluate the revised conceptual CTMP model. PLS, a Structural Equation Modelling (SEM) technique is a second generation of the multivariate analysis technique (Barclay, Higgins \& Thompsons, 1995), which was developed by Wold (1980) to analyse statistical models that involve a set of constructs and multiple indicators (Chin, 1998; Fornell \& Bookstein, 1982). The justification of using PLS technique for the current research was due to several advantages over other SEM techniques (discussed in next chapter). Prior PLS research suggests that a sample size of 100 to 200 is usually a good starting point in carrying out path modelling (Hoyle, 1995), but Wong (2013) suggests increasing the required sample size if the research objective is to explore low-value factor inter-correlations with indicators that have poor quality. According to Hair et al. 
(2013), the sample size considerations play a role in the application of PLS-SEM. This idea is fostered by the often-cited 10 times rule (Barclay et al., 1995; Hair et al., 2013), which indicates that the sample size should be equal to the larger of

1. 10 times the largest number of formative indicators used to measure a single construct, or

2. 10 times the largest number of structural paths directed at a particular construct in the structural model.

In the current research, the first point of the rule of thumb was not considered since all the indicators of the CTMP constructs were reflective. Hence, the minimum sample size for the current research should be 10 times the maximum number of arrowheads pointing at the latent variable anywhere in the PLS path model. Given that the number of the structural paths (arrowheads) in the CTMP model is 14, the sample size should exceed 140 cases. Alternatively, Hair et al. (2013) suggest using the $G^{*}$ Power program to determine the sample size by carrying out power analysis specific to model setups. By using this program in the current research, and specifying the number of predictors as 16 under the significance level of .05 , the total sample size calculated was 204 .

The second approach helped the researcher to determine the maximum sufficient number of respondents to take part in the current research. This was calculated using a software application. According to Singh (2007), there are three main points to consider: (i) precision in estimates the researcher wishes to achieve, (ii) statistical level of confidence hoped to be used and (iii) variability or variance expected to be found in the population. Under the most common values of the confidence interval (95\%) and a significance level of (5\%), the sample size was calculated by an online software application (creative research systems, 2011) and was found to be 384 respondents. This figure was calculated by estimating that $10 \%$ of the people in the Emirates (5 million in total, would be under the sampling frame (around 500,000) (Geohive, 2009). Numbers of respondents who represent the sample frame conditions are expected to be much less than 500,000 . Therefore, it was argued that the upper evaluation of a sufficient number of respondents to participate in this research is 384 .

Based on the current information obtained from the literature and calculated by the software, and by considering the lower and upper evaluations of the sample size (140 - 384), it was estimated 
that a sample size of 340 respondents will provide adequate data for the current study. This sample size met all recommendations found in the existing literature, and matched statistical calculations required for estimating quantitative research samples.

\subsubsection{Sampling approach.}

The researcher selected a suitable sample, representative of the people in the Emirates. This would be helpful in determining the characteristics of the whole population. For this research, selecting respondents randomly would not be appropriate because the respondents must have some knowledge of electronic wireless commerce, and should be aware of m-payments in the Emirates. Therefore, the appropriate sampling approach for this study is non-probability, which does not involve the process of random selection. The non-probability sampling approach has different subtypes, such as convenience sampling, quota sampling, expert sampling, snowball sampling, and others (Singh, 2007).

The sampling subtype selected for this study is the convenience sampling approach, supported by the snowball sampling technique. Convenience sampling enabled the respondents to voluntarily participate in the study, leaving the selection of sampling units up to the researcher (Dillon, Madden, \& Firtle, 1990). This approach was appropriate for the current study because the sample is readily available, and because of its accessibility to the researcher. In addition, there must be a few conditions and or a list of elements from which the sample may be drawn; called the sample frame (Zikmund \& Babin, 2007). The sample frame of the current frame is that participants: (1) should have some knowledge about m-payments (current users, previous experience, knowledge from providers of m-payment services, knowledge from media, or others), and (2) should be over 18 years of age. Snowball sampling was applied through the convenience sampling to employ the social networks that exist between members of a target population to build a sample, and to increase the response rate within the sample frame.

In order to reach the targeted respondents, the same entities as those used to determine the participants in the focus groups, were used to survey the respondents. Those four main entities (telecom companies, banks, universities, and social networks) were selected for the same reasons mentioned earlier for the qualitative data gathering, section 3.4.4. The respondents were sent links that are connected to a website (online). 


\subsubsection{Representative sampling.}

It was acknowledged that choosing convenience sampling for a quantitative analysis may lead to a less representative and generalisable sample (Neuman, 2005). To increase the sample representativeness of the study population, the questionnaires were distributed in several emirates or cities to reach the participants throughout the Emirates (Abu Dhabi, Al-Ain, Dubai, Sharjah, Fujairah, Ras Al-Khaimah, and Umm Al-Quwain). The questionnaire was also available in two languages (Arabic and English) in order to approach more respondents, especially those residents of different nationalities and origins. In addition, respondents were approached through numerous entities (telecom companies, banks, universities, online social forums, virtual groups and others). All this offered diversity with respect to consumers' opinions and perceptions, increased the sample representativeness of the population, and consequently, enabled the sample to be more generalisable to the consumers in the Emirates.

\subsubsection{Response rate and bias issues.}

Invitations to participate in the current study were sent through emails, Facebook posts, short text messages, and through the mobile application 'WhatsApp'. These emails informed participants of the purpose of the research and the length of the survey; they also assured them that the collected information would be treated confidentially and would be used only for the stated purpose of the research. In addition, a Web survey link was included in the email to grant respondents easy access to the questionnaire. In an endeavour to obtain a high response rate, an incentive was offered to respondents to complete the survey (a shopping voucher worth AED100).

The data collection for the study preliminarily ceased on the $2^{\text {nd }}$ of February 2013 and data were not collected after this date as it was made impossible to access the web page of the questionnaire. In total, 340 responses were received; around 22 of them were not usable. These 22 responses were deemed not to have been properly completed as it was noticed that certain participants had given the same score for all questions, and some others had completed only a very small portion of the survey. Thus, the researcher felt obliged to extend the duration of data gathering for a further 2 weeks and to remind and encourage people to take part in the survey. Finally, 340 responses were received. 
Secondly, to increase the response rate, the researcher followed several procedures. Firstly, the researcher wrote a covering letter that explained the reasons for the research, why the recipient had been selected, and provided a guarantee of confidentiality. This would improve the response rate and encouraged respondents to fill in the questionnaire (Bryman \& Bell, 2007). Second, the researcher followed Pickard's (2007) suggestion to encourage responses by directing attention towards the appearance and content of the questionnaire. Within this context, the questionnaire was well-organised, and the researcher's instructions were clear. Other design issues, such as an attractive layout, and not allowing the questionnaire to appear unnecessarily bulky were achieved to increase the response rate (Bryman \& Bell, 2007). Thirdly, follow up activities were conducted by sending reminders through phone, email and online notifications to certain groups and individuals if they hadn't responded by the deadline, to be shared with their contacts in the Emirates.

\subsection{Ethical Considerations}

The ethical standards expected to achieve moral research and correct decision-making (McMurray et al., 2004; Neuman, 2003) were maintained by following the ethical guidelines of The Human Ethics Committee of the School of Information Management at Victoria University. The study was granted ethical approval by the committee prior to the two-stage data collection process being undertaken.

Respondents' consent was also embedded in the first page of the online survey, as part of the 'information to participants' section. The detailed information on this page explained to participants' the benefits, rights and consequences of engaging in the study and outlined the nature and the purpose of the research. Moreover, the respondents were informed of the voluntary nature of the survey and, therefore, were encouraged to respond by being offered an incentive to participate, and to ensure their continued cooperation. No identifiable information

(for example, names and addresses) was requested so that the participants' personal privacy and anonymity were ensured.

\subsection{Chapter Conclusion}

This chapter has described the quantitative research methodology and survey design guidelines followed for the current research. The justification for the choice of survey over other 
quantitative methods was presented. This was followed by a discussion of the steps adopted in the survey design and development, including the data collection method, measurement process and online questionnaire design and structure. In addition, an online survey was chosen as the most appropriate data collection method to obtain the required information and to test the set of hypotheses developed in Chapter Three. The subsequent discussion detailed the sample selection procedures and certain associated issues. Finally, the ethical considerations relating to the data collection process were described. The next chapter (Chapter Five) will present the data analysis and results. 


\section{CHAPTER FIVE \\ Analysis and Findings of Survey Data}

\subsection{Chapter Overview}

This chapter presents the analysis and results of the online survey which was conducted as the second phase of data gathering. The research survey tested and explored, in a larger sample, the aspects identified in the first phase of this research (the qualitative data analysis presented in Chapter 3). The survey results were used to ascertain whether the findings contradicted, confirmed, or complemented the findings of the qualitative phase. The chapter is comprised of five sections. The second section (5.2) describes the data preparation for analysis, including data editing, coding and transcribing. Section 5.3 presents sample profiles and respondent characteristics. Next, section 5.4 discusses preliminary data analysis; including normality, demographic variable analysis and common method variance, while section 5.5 discusses the advanced quantitative analysis of the research model, and shows the results of the research hypotheses obtained through Partial Least Square analysis, as part of the Structural Equation Modelling technique (PLS-SEM). The last section (5.6) provides a summary of the chapter.

\subsection{Data Preparation}

Data preparation is the process of organising and manipulating the quantitative data for analysis, to reveal factors of interest concerning the research problem (Creswell, 2009; Neuman, 2005). The preliminary preparation of the data is essential to achieving a good data quality and a meaningful analysis (Neuman, 2003). In the current research, data were collected, transcribed, and coded in preparation for a subsequent analysis. Collected data (from both English and Arabic questionnaires) were downloaded from the databases of the online data collection software (SurveyMonkey.com). Afterwards, data were merged into one SPSS file, and checked for completeness and consistency. Finally, a code was assigned to each question through letters and numbers. 
By going through each of the cases, 22 questionnaires were detected as uncompleted for most of the variables (out of the 340). As recommended by Creswell (2009), these questionnaires were eliminated from the data analysis and the researcher extended the data collecting phase for a further two weeks in order to include another 22 valid questionnaires (considered late responses) with complete data responses. Those late responses contributed around $6.4 \%$ of the total responses. In terms of examining whether the late responses could affect trust scores, respondents were grouped as early respondents $(\mathrm{N}=318)$ and late respondents $(\mathrm{N}=22)$. The researcher compared the mean of the two groups, along with other statistics such as the standard deviation and effect size. Effect size is a name given to a set of indices that measure the magnitude of differences between two groups (Welch \& Barlau, 2013). By considering the 'univariate' statistical test through SPSS software, there was no significance difference between the mean values of each group $(\mathrm{P}>.05$, Mean difference $=0.172$, Std. deviation difference $=$ 0.176). The effect size was also calculated using a statistic called Cohen's $d$. Cohen defined $d$ as the difference between means, divided by the standard deviation of either group (Cohen, 1988). He also defined small $(d \leq 0.20)$, medium $(d=0.50)$, and large $(d \geq 0.80)$ effect sizes. The effect size was found equal to 0.078 , which demonstrates small effect size. Therefore, no differences were found between the responses of early and late respondents, and all responses are generalizable to the targeted population.

Afterwards, data were integrated and further assessed for the presence of missing values. As a result, no occurrences of missing data for the items measured were detected, as responses to all individual items were checked to ensure mandatory answering. However, it was noticed that four demographic variables (gender, age, educational level, and marital status) included some missing values, as respondents were given the freedom to choose whether or not to provide answers to these questions.

The data were also assessed for the presence of outlier scores, which can have an impact on the nature of the results (Creswell, 2009; Hair, Anderson, Tatham, \& Black, 1998). According to Hair et al. (1998), any data that falls outside the range of three to four standard deviations should be identified as an outlier. In the current research, and during the questionnaire development, the questionnaire design included selection tools (rather than type-in tools) for the range of answers, which in turn helped in avoiding the presence of outlier scores. Thus, no outlier scores/values were detected. 
It is worth mentioning that two items in the questionnaire (E2 and E4) were negatively-keyed items that required reverse coding before computing the scores on the sections directly relating to trust and before conducting the regression analysis. Negatively-keyed items are items that are phrased so that an agreement with the item represents a relatively low level of the attribute being measured. In terms of the scale implied (what an 'agree' or 'disagree' indicate), all negativelykeyed items should be reverse coded to ensure that all items (negatively and positively-keyed items) are consistent with each other. By applying the reverse coding technique, all responses of the negatively-keyed items (4 items associated with perceived privacy and security risks) were re-coded through transforming high scores to become low scores ( 9 becomes 1, 8 becomes 2, etc...), and keeping the same neutral point (5). By reverse-scoring all of the negatively-keyed items, the consistency among the items was achieved.

After preparing the data for analysis, the descriptive statistics relating to the respondents' profiles were analysed.

\subsection{Sample Profiles and Respondent Characteristics}

As mentioned in Chapter 4, data were gathered from a convenience sample and generated 340 respondents surveyed online. The data relating to respondents' characteristics were tabulated to gain a better understanding of the data (Sekaran, 2003). Therefore, the respondents' demographic profiles were grouped according to gender, age, education level, marital status, profession, nationality and the Emirate/city the respondent lives in (Table 5.1). Then, respondents' profiles regarding mobile-payment usage and their trust scores were discussed. 
Table 5.1 Demographic Profile of the Sample

\begin{tabular}{|c|c|c|}
\hline Demographic variable & Categories/Values & $\begin{array}{l}\text { Response information } \\
(\mathrm{N}=340)\end{array}$ \\
\hline Gender $($ missing $=11)$ & $\begin{array}{c}\text { Male } \\
\text { Female }\end{array}$ & $\begin{array}{l}54.1 \% \\
45.9 \%\end{array}$ \\
\hline Age (missing $=34)$ & $\begin{array}{c}\text { Less than } 20 \\
20-30 \\
31-40 \\
41-50 \\
\text { Greater than } 50\end{array}$ & $\begin{array}{c}10.8 \% \\
33.3 \% \\
44.1 \% \\
7.8 \% \\
3.9 \%\end{array}$ \\
\hline Educational level $($ missing $=18)$ & $\begin{array}{c}\text { Less than high school } \\
\text { High school } \\
\text { College degree } \\
\text { University degree } \\
\text { Higher education }\end{array}$ & $\begin{array}{c}0.9 \% \\
8.8 \% \\
13.2 \% \\
59.6 \% \\
16.4 \% \\
\end{array}$ \\
\hline $\begin{array}{l}\text { Marital Status } \\
(\text { missing }=23)\end{array}$ & $\begin{array}{c}\text { Single, never married } \\
\text { Married } \\
\text { Separated } \\
\text { Divorced } \\
\text { Widowed } \\
\end{array}$ & $\begin{array}{c}35.9 \% \\
49.4 \% \\
3.5 \% \\
2.6 \% \\
1.8 \% \\
\end{array}$ \\
\hline Occupation & $\begin{array}{c}\text { Employee } \\
\text { Self-employed } \\
\text { Student } \\
\text { Other (retired/jobless) }\end{array}$ & $\begin{array}{c}78.0 \% \\
2.4 \% \\
16.2 \% \\
3.5 \%\end{array}$ \\
\hline Ethnic Group & $\begin{array}{c}\text { Middle Eastern } \\
\text { Indian Sub continentals } \\
\text { Far East Asian } \\
\text { Pacific Islander } \\
\text { African } \\
\text { European } \\
\text { American } \\
\text { Other } \\
\end{array}$ & $\begin{array}{l}73.5 \% \\
7.4 \% \\
3.8 \% \\
4.1 \% \\
2.4 \% \\
4.4 \% \\
0.9 \% \\
3.5 \% \\
\end{array}$ \\
\hline Emirate/city & $\begin{array}{c}\text { Abu Dhabi } \\
\text { Ajman } \\
\text { Al-Ain } \\
\text { Dubai } \\
\text { Fujairah } \\
\text { Ras Al-Khaimah } \\
\text { Sharjah } \\
\text { Umm Al-Quwain }\end{array}$ & $\begin{array}{c}27.9 \% \\
11.5 \% \\
16.2 \% \\
25.9 \% \\
1.2 \% \\
3.2 \% \\
13.2 \% \\
0.9 \%\end{array}$ \\
\hline
\end{tabular}

(1) Demographic Profile of the Sample. As shown in Table 5.1, male respondents accounted for the majority of the sample (54.1\%) and respondents ranged from 31 to 40 years with a frequency percentage of $(44.1 \%)$. In relation to the educational level, about one tenth of the respondents reported completing secondary education, while more than three quarters of them (76\% of them) reported achieving a university degree. As for occupation, the majority of the respondents were employees (accounted for 78\%), whereas the second largest category were students accounting for $16.2 \%$ of the study sample. Further demographic statistics reported that the dominant respondents were Middle Eastern with (73.5\%), followed directly by the East Asian category with $11.2 \%$ of the sample. As mentioned earlier in section 1.3 , the latest UAE 
statistics on population and society in the Central Intelligence Agency world fact book (2013) reports a population estimate of $6,473,972$ for July 2013. The same source reports the following population composition: Emiratis 19\%, other Middle Eastern (Arab and Iranians) 29\%, South Asian 34\%, other expatriates (including Westerners and East Asians) 18\% of the population. This indicates that the targeted sample can be, to a great extent, considered representative of the population, and with an over representation of Middle Eastern people which makes it possible to generalise the findings of this study to the people in the Middle East and Arab countries.

In general, the respondents came from all of the seven emirates and cities of the Emirates. More than half of the respondents were based in Abu Dhabi (27.9\%) and Dubai (25.9\%), whereas respondents from the other main emirates: Al-Ain, Sharjah and Ajman accounted for 16.2\%, $13.2 \%$ and $11.5 \%$ respectively, representing the five largest and main emirates/cities in the country.

(2) Mobile-payments Usage Profile. To gain an insight into respondents' experiences with mpayments, they were required to indicate: (1) How they would describe their experience in conducting m-payments; and (2) What kind of mobile-payment services and applications they used regularly. These responses are presented in Table 5.2 and are discussed next.

Table 5.2 Mobile Payment Usage Profile

\begin{tabular}{|c|c|c|}
\hline Usage variable & Categories/Values & $\begin{array}{c}\text { Response } \\
\text { information }(N=340) \\
\end{array}$ \\
\hline $\begin{array}{l}\text { Respondents' experience } \\
\text { in conducting } \\
\text { m-payments }\end{array}$ & $\begin{array}{l}\text { Had no experience } \\
\text { One-time user } \\
\text { Few-times user } \\
\text { Many-times user }\end{array}$ & $\begin{array}{l}18.6 \% \\
13.2 \% \\
30.3 \% \\
37.9 \%\end{array}$ \\
\hline \multirow{14}{*}{$\begin{array}{l}\text { M-payment services and } \\
\text { applications } \\
\text { which respondents use } \\
\text { regularly }\end{array}$} & Mobile Banking & $42.60 \%$ \\
\hline & Entertainment (such as online games) & $38.20 \%$ \\
\hline & Bills (such as power and water) & $28.20 \%$ \\
\hline & Telecommunication and mobile services & $20.90 \%$ \\
\hline & Downloading audio and video files & $20.30 \%$ \\
\hline & Booking air tickets & $20.30 \%$ \\
\hline & Online shopping & $19.40 \%$ \\
\hline & Internet subscriptions & $17.60 \%$ \\
\hline & Car parking & $15.60 \%$ \\
\hline & Social community services & $15.00 \%$ \\
\hline & Road registrations and fines & $10.60 \%$ \\
\hline & Charity & $7.90 \%$ \\
\hline & Voting on TV channels & $5.30 \%$ \\
\hline & $\begin{array}{c}\text { Other (Black Berry services and } \\
\text { Grocery Delivery Payment) }\end{array}$ & $0.90 \%$ \\
\hline
\end{tabular}


With regard to m-payments usage, the largest segment of participants considered themselves as many-times users (37.9\%), while the second largest category were the few-times users with $30.3 \%$, whereas the categories 'had no experience' and 'one-time users' accounted for smaller percentages of $18.6 \%$ and $13.2 \%$ respectively. These responses suggest that there is a sufficient level of maturity in using m-payments in the Emirates among the targeted sample.

In addition, it is found that 63 persons out of the 340 targeted respondents (around 18.5\%) had no experience with m-payment services, whereas $81.5 \%$ had experience with conducting mpayments at least once. Those respondents who had no experience in m-payments had an average trust level of 5.19 out of 10 , lower than the average trust levels found for people experienced in this regard (6.68 out of 10). In addition, around $62 \%$ of those respondents who had no previous experience in conducting m-payments were found mostly trusting with respect to micro mpayments (less than AED100, equivalent to USD28) rather than macro payments. This indicates that by using m-payment services in the Emirates, experienced people tend to have higher trust in $\mathrm{m}$-payments than inexperienced people, and that lack of trust could be diminished to some extent by using such services.

In terms of the usage of m-payment applications, statistics indicate that the most widely used mobile application among the participants was mobile banking with $42.6 \%$, followed by entertainment (38.2\%). Mobile banking and bill paying are gaining popularity due to their simplicity, quickness and convenience. As for entertainment, although many online games are now offered and downloaded for free, many other attractive and useful mobile applications and software are prepaid and freemium (provided free of charge, but money (premium) is charged for advanced features), where a payment is still required.

Around one-fifth of the respondents reported using their mobile devices to pay for telecommunication services, online air tickets, or audio and video web files downloads. Some other applications are experiencing relatively reasonable levels of usage rates, such as paying for car parks (15.6\%), social community services (15\%), and road registrations and fines (10.6\%). However, charity m-payments, which account for $7.9 \%$ of the sample, may gain popularity as such facilities enable consumers to pay tiny amounts of money based on their preferences without the need to be physically present or pay additional money to deliver the charity. Furthermore, feelings of embarrassment are avoided if donated sums are small. 
(3) Respondents' initial trust scores. Respondents were asked to provide the amount of mpayment that they would be willing to trust. As shown in Table 5.3, only $2.6 \%$ of the respondents were willing to trust m-payments valued more than AED5000 (this amount is equivalent to USD1365). The amount for m-payment indicated by most participants was the 'AED 100-500' category (equivalent to USD 28-136), which accounted for $27.4 \%$, followed by the 'less than 100 ' category (USD 28), which accounted for $26.2 \%$. This result appears to be consistent with the number determined by the participants of the focus group discussions, as they specified their propensity to trust micro m-payments with a ceiling value of AED 500 (around USD 136). However, low-end macro m-payments (AED 500-5000 USD 136-1360) were treated by $43.8 \%$ of the participants.

Table 5.3 Initial Trust Scores

\begin{tabular}{||c||c||c|}
\hline Trust-score variables & $\begin{array}{c}\text { Categories/Values } \\
\text { (In AED) }\end{array}$ & $\begin{array}{c}\text { Response information } \\
(\mathrm{N}=340)\end{array}$ \\
\hline \hline \multirow{3}{*}{ Amount of money participants } & Less than 100 & $26.2 \%$ \\
were willing to trust when they & $100-500$ & $27.4 \%$ \\
make a mobile payment & $500-1000$ & $23.5 \%$ \\
(in Dirham) & $1000-5000$ & $20.3 \%$ \\
& More than 5000 & $2.6 \%$ \\
\hline \hline \multicolumn{1}{|c|}{} & & $1: 2.6 \%$ \\
Level of trust participants had & From 1 (low level of trust) & $3: 1.8 \%$ \\
in mobile payments in the & to & $4: 4.4 \%$ \\
Emirates & 10 (high level of trust) & $5: 16.2 \%$ \\
(a score from 1 to 10) & & $6: 15.6 \%$ \\
& & $7: 15.6 \%$ \\
& & $8: 15.3 \%$ \\
& & $9: 17.4 \%$ \\
\hline
\end{tabular}

In order to discover respondents' initial perceptions towards their general trust in m-payments, and compare it with the trust score obtained from the focus group participants, they were asked to directly answer the question associated with the dependent variable, by giving a score from 1 (low trust level) to 10 (high trust level) to measure their trust. It was found that the mean of respondents' trust scores was 6.44, with standard deviation of 2.11. This score is slightly smaller than the number determined by the participants of the focus group discussions, as the mean of their trust scores was 7.13. In addition, the most frequent trust score of 9 was given by $17.4 \%$ of the participants, whereas the trust score of two was the least frequent, which was given by only $1.8 \%$ of them. 


\subsection{Quantitative Data Analysis}

The data analysis used in the current research, as presented below, focused on evaluating the data via measures of normality, central tendency and dispersion; correlation analysis, independent samples T-test, one way ANOVA, exploratory factor analysis and reliability estimates.

\subsubsection{Normality.}

According to Tabachnick and Fidell (2001), an important beginning step in multivariate analysis is screening data for normality. Normality, the most fundamental assumption in multivariate analysis and common for statistical analysis, refers to the shape of the data distribution for an individual metric variable and its correspondence to the normal distribution (Field, 1998; Tabachnick \& Fidell, 2001). Normality tests examine the assumption that each variable is normally distributed (Hair et al., 1998; Tabachnick \& Fidell, 2001). One way of inspecting the normality of variables for large data samples is by assessing the values of skewness and kurtosis of the variables' curves (Tabachnick \& Fidell, 2001). In the current research, the analysis indicated that the data were normally distributed as all the variables' scores of skewness and kurtosis statistics fell within the acceptable range of -1.96 and 1.96 (Field, 2005) (see Appendix $\mathrm{G}$ for seeing descriptive statistics -skewness and kurtosis statistics for all items). As a result, all variables were ready for further advanced analysis.

\subsubsection{Demographic variables.}

Secondly, the demographic variables (consumer's gender, age and educational level) were examined by using Independent Samples T-test and One-Way ANOVA (Analysis of Variance), respectively. Independent Samples T-test analysis is a parametric statistical test that was used to investigate the significant difference between the mean values of two independent variables (Field, 2005). For the current research, this test was employed to examine whether there was significant difference between the means of the trust scores of the two groups: males and females. Another parametric test, One-Way ANOVA was employed to examine the significant difference between the mean values of more than two variables (Field, 2005). This test was found to be appropriate for the current research to investigate whether the five categories of the age variable had significantly different values of trust scores.

By examining the 'trust score' values grouped by the gender variable, Levene's Test in SPSS statistical results show that the two gender groups (male and female) have equal variances in the 
0.05 significant level ( $\mathrm{f}=0.249, \mathrm{p}=0.115>0.05$ ). Therefore, it was possible to compare between the means of the two gender groups. Accordingly, the P-value (2-tailed) generated from the t-test for equality of means was monitored. As a result, there was no significant difference between the mean values of the two gender groups (mean difference $=0.319, \mathrm{t}=01.375, \mathrm{p}=$ $0.170>0.05$ ), and accordingly, consumer gender was not found to be significantly associated with trust in m-payments. Statistics associated with this test, such as the mean and standard deviation values of trust scores of male and female respondents are shown in Table 5.4.

Table 5.4 Gender Groups Descriptive Statistics

\begin{tabular}{|rc|r|r|r|r|}
\hline & What is your gender? & N & Mean & Std. Deviation & Std. Error Mean \\
\hline Trust In M-Payments & Male & 178 & 6.58426 & 2.117 & .15867 \\
& Female & 151 & 6.26490 & 2.078 & .16906 \\
\hline
\end{tabular}

By using the similar approach, the quality of consumers' past experience with m-payments was also examined. The results show that the two groups (Positive experiences and negative experiences) had equal variances, and there was a significant between the mean values of the two groups (mean difference $=1.488, \mathrm{t}=8.50, \mathrm{p}=0.00<0.05$ ). Descriptive statistics about this variable are shown Table 5.5

Table 5.5 Experience Groups Descriptive Statistics

\begin{tabular}{|rl|r|r|r|r|}
\hline & \multicolumn{1}{|c|}{ Mean } & N & Std. Deviation & Std. Error Mean \\
\hline \multirow{2}{*}{ Pair 1 } & Positive Experience & 6.84 & 340 & 2.214 & .120 \\
& Negative Experience & 5.35 & 340 & 2.837 & .154 \\
\hline
\end{tabular}

With regards to the age of consumers, Levene's Test of homogeneity of variances indicated that equal variances were found for the five groups $(\mathrm{p}=0.239>0.05)$. For further analysis, and by testing the trust scores of the age groups ('less than 20', '20-30', '31-40', '41-50', 'greater than 50 '), a significant difference between the mean values of the five categories was detected $(\mathrm{n}=306$, $\mathrm{f}=8.345, \mathrm{p}=0.000<0.05)$. As shown in Table 5.6, young respondents aged less than 20 years were found with the least trust average (5.09 out of 10), whereas older people aged in the categories 31-40 and over 50 years old accounted for 7.0 out of 10 mean trust scores (mean and standard deviation values of the five categories are given in same table). This may indicate that mature people in the Emirates tend to trust m-payments more than young people, maybe because mature people are more experienced with electronic payments in general and specifically in m- 
payments, and thus are more willing to trust in such payments. In supporting figures, and by cross tabulating between age and usage (as shown in Appendix $\mathrm{H}$ ), the sampled respondents with the age group of less than 20 years old who had no experience with m-payments accounted for 15 out of 33 respondents, whereas mature people (31 years and above) with no experience in mpayments accounted for only 12 out of 171 respondents. Thus, it is possible to indicate that young people with no experience in m-payments tend to trust less in these payments than mature people in the Emirates.

In further age analysis and by investigating the Post Hoc multiple comparisons between the age groups using Scheffe test, the significant difference in the trust mean values was found within the following groups: (category 1 and 3), (category 1and 4), and (category 1 and 5). For more details about Post Hoc multiple comparisons statistics between each of the two groups of age category, see Appendix I. It is indicated that there was significant difference between the determined age categories the significant level of $5 \%(\mathrm{p}<0.05)$. Overall, consumer age was deemed to have a significant impact on trust in m-payments, as lowest age groups demonstrated substantially lower trust scores over others.

Table 5.6 Age Groups Descriptive Statistics

\begin{tabular}{|c|c|c|c|c|c|c|c|c|c|}
\hline \multirow[b]{3}{*}{ Category } & \multicolumn{9}{|l|}{ Trust Measure } \\
\hline & & \multirow[b]{2}{*}{$\mathrm{N}$} & \multirow[b]{2}{*}{ Mean } & \multirow{2}{*}{$\begin{array}{c}\text { Std. } \\
\text { Deviation }\end{array}$} & \multirow[b]{2}{*}{ Std. Error } & \multicolumn{2}{|c|}{$\begin{array}{c}\text { 95\% Confidence Interval for } \\
\text { Mean }\end{array}$} & \multirow[b]{2}{*}{ Min } & \multirow[b]{2}{*}{ Max } \\
\hline & & & & & & Lower Bound & Upper Bound & & \\
\hline 1 & Less than 20 & 33 & 5.09 & 2.185 & .380 & 4.32 & 5.87 & 2 & 9 \\
\hline 2 & $20-30$ & 102 & 5.99 & 1.726 & .171 & 5.65 & 6.33 & 2 & 9 \\
\hline 3 & $31-40$ & 135 & 7.00 & 2.102 & .181 & 6.64 & 7.36 & 1 & 9 \\
\hline 4 & $41-50$ & 24 & 6.75 & 2.090 & .427 & 5.87 & 7.63 & 3 & 9 \\
\hline \multirow[t]{2}{*}{5} & Greater than 50 & 12 & 7.00 & 1.279 & .369 & 6.19 & 7.81 & 5 & 8 \\
\hline & Total & 306 & 6.44 & 2.059 & .118 & 6.21 & 6.67 & 1 & 9 \\
\hline
\end{tabular}

Regarding consumers' educational levels, another One-Way ANOVA test was conducted. By examining the 'trust score' values of the five categories ('less than high school, 'high school', 'college degree', 'university degree', 'higher education'), Levene's Test in SPSS statistic results show that the five educational level groups have no equal variances in the 0.05 significant level ( $f=2.529, p=0.041<0.05)$. In addition, the P-value (2-tailed) generated from the t-test for equality of means was $(\mathrm{p}=0.713>0.05)$. As a result, there was no significant difference 
between the mean values of the five educational levels, and accordingly, consumer educational level was not found to be significantly associated with trust in m-payments. In summary, no evidence was found that consumer gender and consumer educational level had a significant influence on consumer trust in m-payments, whereas there were significant differences in trust scores for consumers' different age categories.

Having established the preliminary statistical tests of normality and nominal variables, the common method variance was assessed because such studies, which are dependent on selfreporting surveys, may introduce spurious associations among the variables (Howard, 1994).

\subsubsection{Common method variance.}

Common method variance refers to variance that is attributable to the measurement method rather than to the constructs the measures represent (Bagozzi \& Yi, 1991; Podsakoff, MacKenzie, Lee, \& Podsakoff, 2003). Behavioural research affected by Common Method Variance (CMV) suffers from false correlations and runs the risk of reporting incorrect research results or misleading conclusions (Campbell \& Fiske, 1959; Podsakoff et al., 2003). This is possible especially when self-reported questionnaires are used in which the predictor and criterion variables are gathered by the same method and/or from the same source (Chang, Witteloostuijn, \& Eden, 2010). However, this problem may be addressed via either multiple methods of measurement or the analysis of multitrait - multimethod matrix (Bagozzi \& Yi, 1991; Campbell \& Fiske, 1959). Alternatively, the factor analysis method is one of the most common approaches used to understand the presence of CMV (Lindell \& Whitney, 2001).

As this research used self-report surveys, data vulnerability to the common method variance problem was possible. Therefore, the effects of the common method variance were tested in the current research via Harman's one factor test (Igbaria, Zinatelli, Cragg, \& Cavaye, 1997; Podsakoff et al., 2003). The one factor test involves entering all items to measure the different constructs into a single factor analysis to determine the number of factors that account for the variance in the variables (Podsakoff et al., 2003). The dominance of one factor would indicate that the items were related because of the common method. By subjecting all of the items to the same factor analysis, 14 factors were extracted with eigenvalues higher than one, and the most covariance explained by one factor was $32.9 \%$. Thus, in the current research, a substantial 
amount of common variance was not evident; a single factor did not emerge and did not account for the majority of the variance in the CTMP model (Igbaria et al., 1997).

As further testing for the common method variance provided evidence of the non-existence of the common variance problem, this indicates that the data were ready for subsequent analysis. The following section provides the rationale for, and discussion of, the method used for testing the hypotheses; Structural Equation Modelling (SEM) using Partial Least Squares (PLS).

\subsection{Advanced Data Analysis Using SEM-PLS}

This section briefly explains the statistical technique selected for the treatment of survey data and presents the results of the statistical analysis. However, it begins with a review of the Structural Equation Modelling (SEM) along with a focus on the special form of SEM known as Partial Least Squares (PLS).

\subsubsection{Structural Equation Modelling (SEM).}

Structural Equation Modelling (SEM) is "a family of statistical models that explain the relationships among multiple variables" (Hair et al., 2000). Indeed, SEM is considered an advanced statistical modelling method, which enables researchers to answer a set of interrelated research questions in a single, systematic and comprehensive analysis (Gefen \& Straub, 2005). Basically, SEM is a second-generation comprehensive statistical data analysis approach that is more powerful than other first-generation multivariate techniques that can only measure single relationships one at a time (Gefen \& Straub, 2005; Hair et al., 1998). Specifically, advantages of SEM analysis over first-generation techniques (such as factor analysis and multidimensional scaling) include enabling researchers to incorporate unobservable variables measured indirectly by indicator problem, and accounting for measurement error on observed variables (Hair, Hult, Ringle, \& Sarstedt, 2013). SEM is also superior for "extending the possibility of relationships among the latent variables" by encompassing two components: a measurement model and a structural model (Schreiber, Nora, Stage, Barlow, \& King, 2006, p.325). Thus, SEM can be utilised to either validate a particular existing model or to advance theory development (MacCallum \& Austin, 2000). SEM also allows researchers to test theoretical propositions, such as the ones defined in this research, regarding how constructs are theoretically linked and the 
directionality of significant relationships (Schreiber et al. 2006). Overall, SEM permits complicated variable relationships to be expressed and gives a more complete picture of the entire model (Gefen \& Straub, 2005), it is being used more and more in behavioural science research (Hair et al., 2013) and in information technology and systems research (Gefen \& Straub, 2005; Straub et al., 2000). The preceding benefits associated with the use of SEM justify the consideration of this approach in the current research.

SEM is most commonly identified with two prevalent techniques: the Maximum Likelihood (ML) covariance analysis (represented via, for example, LISREL software) and a component-based variance analysis technique, referred to as Partial Least Squares (PLS) (Fornell \& Bookstein, 1982; Gefen \& Straub, 2005). The selection of an appropriate SEM technique is dependent upon several considerations, such as the objective of the variance analysis, required theory base, and sample size requirements (Gefen \& Straub, 2005). The PLS method was considered appropriate for the current study for several points. While ML is theory oriented and more useful for checking overall model fit, PLS is the preferred approach for causal-predictive analysis, especially in that it does not necessarily require a sound theory base. PLS is better suited for theory development than for theory testing (Urbach \& Ahlemann, 2010). In addition, PLS "avoids many of the restrictive assumptions underlying ML techniques and ensures against improper solutions and factor indeterminacy" (Fornell \& Bookstein, 1982, p.440). Moreover, PLS is advantageous over other ML approaches as PLS minimises the variance of all dependent variables instead of using the model for explaining the co-variation of all the indicators (Chin, 1998). Furthermore, ML techniques are population-based methods and require large samples to ensure accurate results, whereas PLS is suitable when small samples are employed for estimation and testing (Chin, 1998; Goodhue, William, Thompson, 2012). PLS has also an advantage over other techniques when analysing small sample sizes or data with non-normal distributions, effective in detecting actual paths, and not falsely detecting non-existent paths (Goodhue et al., 2012). Another supportive point is that PLS can be applied to complex structural equation models with a large number of constructs (Urbach \& Ahlemann, 2010). However, because "PLS (like regression) apparently does not compensate for measurement error, PLS and regression were consistently less accurate than LISREL" (Goodhue et al., 2012, p.984). Overall, using PLS in the current research was considered convenient for the given advantages, 
In the current study, the development of the proposed CTMP model, the sample size of 340 cases and the large number of associated constructs (15 constructs) all supported the use of PLS. Besides, it has been broadly utilised in various disciplines such as information technology and information systems (Chin, 1998; Davis, 1997; Urbach \& Ahlemann, 2010), psychology (Miller et al., 1993), and management (Hulland, 1999). Therefore, SEM using the PLS technique was used in the current study to test the overall structure of the CTMP model. A detailed discussion of the PLS analysis technique is presented next.

\subsubsection{Partial Least Squares (PLS).}

Partial Least Squares (PLS), originally developed by Wold (1980), extends the theory of fixedpoint estimation with unobservable variables, and provides substitute for other restrictive multivariate linear regression models (Fornell \& Bookstein, 1982). Specifically, PLS is an iterative process that "provides successive approximations for the estimates, subset by subset, of loadings and structural parameters" (Fornell \& Bookstein, 1982, p.441). Ultimately, PLS is a common methodological approach used to analyse statistical models that involve a set of constructs and multiple indicators (Chin, 1998; Fornell \& Bookstein, 1982).

Four main advantages of using the PLS method in the current study were considered. Firstly, PLS represents a popular method for soft modelling, which uses general and soft distribution assumptions, and works well with non-experimental data (Chin, 1998; Wold, 1980; Urbach \& Ahlemann, 2010). Secondly, this method has been proven against producing inadmissible solutions and factor indeterminacy (Fornell \& Bookstein, 1982; Urbach \& Ahlemann, 2010). Thirdly, PLS allows for the assessment of the psychometric properties of the measurement instruments, and generates variables' estimates for all cases in the data set (Chin, 1998; Fornell \& Larcker, 1981). The fourth advantage is that the use of PLS analysis is recommended when the structural model is complex - many constructs and many indicators (Hair et al., 2013), which makes the case valid for the current research in which the CTMP contains 15 variables and around 40 indicators. The preceding benefits associated with the use of PLS justify the consideration of this approach in the current research. In order to apply this method, it is important first to understand its components, which are discussed below.

The three main components of PLS analyses are: manifest variables, latent variables, and path relationships (Chin \& Newsted, 1999; Haenlein \& Kaplan, 2004). Latent variables are 
unobservable and are assessed indirectly via indicators or the manifest variables, which reflect the underlying construct (Chin \& Newsted, 1999; Haenlein \& Kaplan, 2004). Manifest variables are directly observable or measureable and represent the indicators of the latent variables (Hair et al., 1998). The fundamental principle of PLS is that all information between manifest variable blocks is conveyed by the latent variable, which may be exogenous and endogenous (Chin et al., 2003). According to Haenlein and Kaplan (2004), exogenous latent variables are variables which are not explained by the postulated model (for instance, act always as independent variables), whereas the endogenous variables are explained by the relationships contained in the model. In the current study, there was only one endogenous latent variable (trust in m-payments), whereas the rest of the constructs are considered exogenous latent variables.

A PLS model consists of three sets of latent variable path relations: inner relations, outer relations, and weight relations (Chin \& Newstead, 1999; Fornell \& Cha, 1994; Wold, 1980, 1985). The inner relations (the structural model) refer to the theory based relationships between the latent variables and, accordingly, relate to the hypotheses developed for the study (Chin, 1998). The outer relations (also referred to as the measurement model) depict the relationship between the latent constructs and the associated manifest variables (Urbach \& Ahlemann, 2010; Wold, 1980). The weight relations represent an estimation of the case value for the latent constructs as linear aggregates of their manifest variables (Fornell \& Cha, 1994; Wold, 1980).

The measurement model formulation depends on the direction of the relationships between the latent variables and the corresponding manifest variables (Fornell \& Bookstein, 1982; Vinzi, Trinchera, \& Amato, 2010). Two types of measurement model are available: the reflective model (or outwards directed model), and the formative model (or inwards directed model) (Fornell \& Bookstein, 1982; Sosik et al., 2009). Reflective indicators consist of items in given scales, which are similar to or highly correlate with one another, and are determined by the latent constructs (Fornell \& Bookstein, 1982; Sosik et al., 2009). For example, the latent variable 'Perceived ease of use' has been originally assessed by four observed indicators which are assumed to be caused by this variable. On the other hand, the formative indicators are viewed as causing the latent constructs Sosik et al., 2009). In other words, formative indicators consist of items, which are manifestations of the construct as they are not necessarily correlated (Sosik et al., 2009). The path between the reflective indicators and the latent constructs are interpreted from the factor loadings, whereas the coefficient linking formative indicators are based on regression weights 
(Sosik et al., 2009). For example, the latent variable 'social status' which arises from several different individual characteristics of a person that can cause this variable, such as occupation, ethnicity, religion, gender, voluntary associations, and several other formative facets (Hornung, 1977).

Both formative and reflective indicators may be used in one single model (called MIMIC model; Multiple Indicators Multiple Causes), in which the indicators of the dependent constructs are represented as reflective, and those of the independent constructs are represented as formative (Fornell \& Bookstein, 1982; Vinzi et al., 2010).

The distinction between formative and reflective measures is important because it may affect constructs' identification and validation, and may also lead to serious consequences for the theoretical conclusions drawn from the model (Freeze et al., 2007). A different point of view argues that formative and reflective measurement models are just two applications of formative measurement (Coltman, Devinney, Midgley, \& Venaik, 2008). However, the choice of the modelling constructs, with either formative or reflective indicators, is dependent on the research objective, the theory of the latent constructs and the empirical conditions (Chin, 1998; Fornell \& Bookstein, 1982). In this research, all the constructs in the CTMP model were modelled as reflective, as they were measured using multiple representative indicators. For instance, some constructs (such as 'provider's trustworthiness' and 'propensity to trust') were viewed as reflective as their relating measures were adapted from earlier research within the trust literature, whereas the others (for instance, 'security levels' and 'consumer awareness') were deemed reflective constructs as their relating measures share a common theme and reflect the meaning of the constructs.

In the current research, the CTMP model, theorised in Chapter Three and validated through the qualitative data analysis phase, was tested using the PLS graph approach, with SmartPLS 2.0 M3 Release. SmartPLS is a software application for (graphical) path modelling with latent variables. The PLS method is used for the latent variable path analysis in this software (Chin, 2001).

\subsubsection{Overall PLS CTMP results.}

The PLS model is usually analysed and interpreted in two stages; firstly, by assessing the reliability and validity of the measurement model (constructs and items); and secondly, by assessing the structural model through interpreting the path coefficients and identifying the 
adequacy of the research model (Hulland, 1999). This sequence ensures that the construct measures are valid and reliable before attempting to draw conclusions regarding the relationships among the constructs (Barclay et al., 1995; Hulland, 1999). In order to validate the measurement model, the adequacy of the reflective constructs was assessed by examining individual item reliability, constructs reliability, convergent validity and discriminant validity (Chin et al., 2003; Chin, 1998; Gefen \& Straub, 2005; Hulland, 1999; Wang et al., 2004).

\subsubsection{Measurement (Outer) Model - Outer Loadings.}

The convergent validity of the items was assessed in order to view the correlations between the latent variable and the reflective indicators, by examining the values of the outer loadings. According to Hair et al. (2013), indicators with outer loading above 0.7 should be retained, whereas indicators with outer loadings between 0.4 and 0.7 should be "considered for removal from the scale only when deleting the indicator leads to an increase in the composite reliability (or the average variance extracted) above the suggest threshold value" (p.103). Another consideration in the decision of whether to delete an indicator is that researchers frequently observe weaker outer loadings in social science studies, especially when newly developed scales are used (Hulland, 1999). However, indicators with very low outer loadings (below 0.4) should always be eliminated from the scale. Therefore, in order to accept the reflective items for the current phase, all outer loadings should be 0.4 or more (Hair et al., 2013; Hulland, 1999; Wong, 2013), which implies more shared variance between the construct and its measures than error variance.

In the current research, and as shown in Table 5.7, the vast majority of the items are above the acceptable level of (0.4), and thus demonstrating reliable items. However, only one item, as highlighted in the same table, E4 which was found with extremely low loading (.008). Therefore, as recommend by Hair et al. (2013), this item was eliminated from this study and was not involved in the further analysis.

Table 5.7 Outer Model Measurements - Items Loadings

\begin{tabular}{|c|l|l|c|}
\hline Construct & Item & Item wording & Loading \\
\hline \multirow{4}{*}{ Propensity to trust } & B1 & It is easy for me to trust a person. & .849 \\
\cline { 2 - 4 } & B2 & My tendency to trust a person is high. & .944 \\
\cline { 2 - 4 } & B3 & $\begin{array}{l}\text { I tend to trust a person, even though I have little knowledge about } \\
\text { him/her. }\end{array}$ & .854 \\
\hline $\begin{array}{c}\text { Uncertainty } \\
\text { avoidance }\end{array}$ & B4 & I am always cautious in trying new technologies. & .457 \\
\cline { 2 - 4 } & B5 & $\begin{array}{l}\text { If possible, it is always better to avoid using new technologies for } \\
\text { financial transactions. }\end{array}$ & .915 \\
\hline
\end{tabular}




\begin{tabular}{|c|c|c|c|}
\hline Construct & Item & Item wording & Loading \\
\hline & B6 & $\begin{array}{l}\text { In a new commercial relationship, I have to be careful until I see the } \\
\text { evidence of a firm's trustworthiness. }\end{array}$ & .901 \\
\hline \multirow{4}{*}{ Awareness } & B7 & I am very familiar with mobile payments. & .574 \\
\hline & B8 & I am aware of mobile payments applications in the Emirates. & .911 \\
\hline & B9 & I am aware of mobile payments services in the Emirates. & .917 \\
\hline & B10 & I am aware of the steps required to conduct a mobile payment. & .885 \\
\hline \multirow{2}{*}{ Past experience } & $\mathrm{B} 11$ & $\begin{array}{l}\text { I have positive experience(s) in conducting mobile payments in the } \\
\text { Emirates. }\end{array}$ & .949 \\
\hline & $\mathrm{B} 12$ & $\begin{array}{l}\text { I have negative experience(s) in conducting mobile payments in the } \\
\text { Emirates. }\end{array}$ & .500 \\
\hline \multirow{3}{*}{$\begin{array}{c}\text { Trust } \\
\text { environment }\end{array}$} & $\mathrm{C} 1$ & A high degree of trust exists in my family. & .810 \\
\hline & $\mathrm{C} 2$ & I am living in a high-trust society. & .775 \\
\hline & $\mathrm{C} 3$ & $\begin{array}{l}\text { People in my society always tend to avoid trusting in new payment } \\
\text { methods, such as mobile payments. }\end{array}$ & .704 \\
\hline \multirow{5}{*}{$\begin{array}{l}\text { Provider's } \\
\text { trustworthiness }\end{array}$} & D1 & $\begin{array}{l}\text { I believe that my provider of mobile payments is honest (that is the } \\
\text { provider makes reliable decisions and honours the terms that it } \\
\text { guarantees). }\end{array}$ & .600 \\
\hline & D2 & $\begin{array}{l}\text { I believe that my provider of mobile payments is benevolent (that is the } \\
\text { provider takes the customer's benefit into consideration when making } \\
\text { decisions concerning the customer's information). }\end{array}$ & .853 \\
\hline & D3 & $\begin{array}{l}\text { I believe that my provider of mobile payments is predictable (that is } \\
\text { the provider's actions in given circumstances can be predicted from its } \\
\text { past behaviours). }\end{array}$ & .900 \\
\hline & D4 & $\begin{array}{l}\text { I believe that my provider of mobile payments is competent (that is the } \\
\text { provider's ability to achieve the expected result and deliver on its } \\
\text { promises). }\end{array}$ & .696 \\
\hline & D5 & Overall, I believe that my provider of mobile payments is trustworthy. & .885 \\
\hline \multirow{2}{*}{$\begin{array}{l}\text { Provider's } \\
\text { reputation }\end{array}$} & D6 & $\begin{array}{l}\text { I believe that my provider of mobile payments has a reputation for } \\
\text { being trustworthy. }\end{array}$ & .916 \\
\hline & D7 & $\begin{array}{l}\text { I believe that my provider of mobile payments has reputable products } \\
\text { and services. }\end{array}$ & .890 \\
\hline \multirow{2}{*}{$\begin{array}{l}\text { Trust level in } \\
\text { provider's } \\
\text { products and } \\
\text { services }\end{array}$} & D8 & $\begin{array}{l}\text { I believe that the branded products and services offered by my provider } \\
\text { are trustworthy. }\end{array}$ & .861 \\
\hline & D9 & $\begin{array}{l}\text { I trust in products and services that I have received from my m- } \\
\text { payments provider. }\end{array}$ & .906 \\
\hline \multirow{3}{*}{ Technical risks } & E1 & I believe that mobile payments work very well technically. & .709 \\
\hline & E2 & $\begin{array}{l}\text { I believe that mobile payments are susceptible to being accidentally } \\
\text { altered or destroyed during transmission over the telecommunication } \\
\text { network. (Reverse coded) }\end{array}$ & .801 \\
\hline & E3 & $\begin{array}{l}\text { I believe that mobile payments are protected from technical } \\
\text { malfunctions and issues. }\end{array}$ & .510 \\
\hline \multirow{5}{*}{ Level of Security } & E4 & $\begin{array}{l}\text { I believe that conducting mobile payments can present financial risks. } \\
\text { (Reverse coded) }\end{array}$ & .008 \\
\hline & E5 & $\begin{array}{l}\text { I believe that mobile technology provides a robust and safe } \\
\text { environment to perform a mobile payment. }\end{array}$ & .779 \\
\hline & E6 & $\begin{array}{l}\text { I believe that the monetary information that I provide on the mobile } \\
\text { device while conducting a payment is well protected from hackers and } \\
\text { penetrators. }\end{array}$ & .862 \\
\hline & E7 & $\begin{array}{l}\text { I feel confident that encryption and other technological safeguards on } \\
\text { mobile technology make it safe for me to make mobile payments. }\end{array}$ & .831 \\
\hline & E8 & In general, I believe mobile payments are secure. & .842 \\
\hline \multirow[t]{2}{*}{ Privacy risks } & E9 & I have privacy concerns regarding mobile payments. & .774 \\
\hline & E10 & I believe that my mobile payment provider may use my personal & .734 \\
\hline
\end{tabular}




\begin{tabular}{|c|c|c|c|}
\hline Construct & Item & Item wording & Loading \\
\hline & & information without permission. & \\
\hline & E11 & $\begin{array}{l}\text { I feel concerned about divulging my personal and financial data to } \\
\text { other parties. }\end{array}$ & .699 \\
\hline \multirow[t]{2}{*}{ Device capability } & F1 & $\begin{array}{l}\text { I have concerns about the performance of my mobile device when it } \\
\text { comes to conducting a mobile payment. }\end{array}$ & .815 \\
\hline & $\mathrm{F} 2$ & $\begin{array}{l}\text { I am afraid that my mobile device may not have the ability to conduct a } \\
\text { payment. }\end{array}$ & .979 \\
\hline \multirow{3}{*}{$\begin{array}{l}\text { Device design } \\
\text { suitability }\end{array}$} & F3 & $\begin{array}{l}\text { I believe that the design of a mobile device can enable it to conduct a } \\
\text { payment. }\end{array}$ & .866 \\
\hline & $\mathrm{F} 4$ & $\begin{array}{l}\text { I believe that the screen design of a mobile device can enable it to } \\
\text { conduct a payment. }\end{array}$ & .894 \\
\hline & F5 & $\begin{array}{l}\text { I believe that the keypad design of a mobile device can enable it to } \\
\text { conduct a payment. }\end{array}$ & .817 \\
\hline \multirow{3}{*}{ Device security } & F6 & $\begin{array}{l}\text { I believe that mobile devices are secure enough for conducting a } \\
\text { payment. }\end{array}$ & .917 \\
\hline & F7 & $\begin{array}{l}\text { I believe that mobile devices contain software that can secure the } \\
\text { device and make the data stored unavailable to others. }\end{array}$ & .833 \\
\hline & F8 & $\begin{array}{l}\text { I believe that no one can get access to the data on my mobile without } \\
\text { my permission. }\end{array}$ & .765 \\
\hline
\end{tabular}

It is also observed from Table 5.7 that there are 6 items with loadings in the range of (0.4 and 0.7). These items are: B4, B7, B12, D1, D4, and E3. Each of these items is associated with different constructs. As recommended by Hair et al. (2013), these items were initially accepted, but were examined against the composite reliability and the average variance extracted, to check whether they could increase the validity of their associated constructs if they were under the acceptable level. More details about the potential deletion of these items are discussed in next section. In total, 41 validated items out of 43 were used to measure the dependent and independent variables (excluding the demographic variables). Additional testing of the items was considered to check the cross loadings with other constructs.

In order to examine the discriminant validity across the items, the pattern of item loadings across constructs in the model was examined (called cross loadings). Specifically, an item loading on the associated construct should be greater than all of its loadings on other constructs (Hair et al., 2013). In this research, the discriminant validity of nearly all items was demonstrated, since cross loadings among different constructs were greater than the determined cut off point (as shown in Table 5.8), with the exception of two items 'D6' and 'D7' (underlined in the same table), which load on the construct 'Provider's trustworthiness' with 0.643 and 0.744 , which were above the minimum associated item with 0.599. Because of this strong association, these 
two items (D6 and D7) were merged with the other items associated with the construct 'Provider's trustworthiness' to create only one construct. 
Table 5.8 Outer Model Measurements - Cross Loadings

\begin{tabular}{|c|c|c|c|c|c|c|c|c|c|c|c|c|c|c|c|}
\hline Item & $\begin{array}{l}\text { Propens } \\
\text { ity to } \\
\text { trust }\end{array}$ & $\begin{array}{l}\text { Uncertainty } \\
\text { avoidance }\end{array}$ & $\begin{array}{c}\text { Aware } \\
\text { ness }\end{array}$ & $\begin{array}{c}\text { Past } \\
\text { experienc } \\
\mathrm{e}\end{array}$ & $\begin{array}{c}\text { Trust } \\
\text { Environme } \\
\text { nt }\end{array}$ & $\begin{array}{c}\text { Provider } \\
\text { trustworthi } \\
\text { ness }\end{array}$ & $\begin{array}{l}\text { Provider } \\
\text { reputation }\end{array}$ & $\begin{array}{l}\text { Trust in } \\
\text { provider } \\
\text { product }\end{array}$ & $\begin{array}{l}\text { Techn } \\
\text { ical } \\
\text { risks }\end{array}$ & $\begin{array}{l}\text { Level } \\
\text { of } \\
\text { securit } \\
y\end{array}$ & $\begin{array}{l}\text { Privacy } \\
\text { risks }\end{array}$ & $\begin{array}{l}\text { Device } \\
\text { capabil } \\
\text { ity }\end{array}$ & $\begin{array}{l}\text { Device } \\
\text { design }\end{array}$ & $\begin{array}{l}\text { Device } \\
\text { security }\end{array}$ & $\begin{array}{c}\text { Trust in } \\
\text { MP }\end{array}$ \\
\hline B1 & 0.849 & 0.059 & 0.139 & 0.183 & 0.135 & 0.320 & 0.171 & 0.120 & 0.014 & -0.251 & -0.049 & 0.090 & 0.071 & 0.314 & 0.096 \\
\hline B2 & 0.944 & -0.045 & 0.223 & 0.195 & 0.165 & 0.324 & 0.220 & 0.150 & 0.053 & -0.320 & -0.070 & 0.095 & 0.088 & 0.288 & 0.195 \\
\hline B3 & 0.854 & -0.02 & 0.115 & 0.057 & 0.138 & 0.216 & 0.153 & 0.074 & 0.068 & -0.128 & 0.012 & 0.005 & 0.067 & 0.193 & 0.148 \\
\hline B4 & 0.031 & 0.456 & -0.056 & 0.019 & 0.125 & -0.015 & 0.079 & -0.073 & 0.137 & 0.180 & -0.044 & 0.102 & -0.077 & -0.123 & -0.038 \\
\hline B5 & -0.047 & 0.915 & 0.045 & -0.101 & -0.051 & 0.020 & 0.053 & 0.072 & 0.249 & -0.065 & -0.070 & 0.262 & 0.094 & -0.004 & -0.115 \\
\hline B6 & 0.032 & 0.901 & 0.077 & 0.022 & 0.083 & 0.105 & 0.182 & 0.101 & 0.273 & 0.001 & -0.09 & 0.263 & 0.048 & 0.026 & -0.040 \\
\hline B7 & 0.175 & 0.166 & 0.573 & 0.423 & 0.284 & 0.378 & 0.338 & 0.258 & 0.258 & -0.283 & -0.031 & 0.289 & 0.191 & 0.363 & 0.262 \\
\hline B8 & 0.210 & 0.095 & 0.911 & 0.335 & 0.150 & 0.352 & 0.286 & 0.234 & 0.229 & -0.287 & -0.154 & 0.181 & 0.116 & 0.361 & 0.542 \\
\hline B9 & 0.146 & -0.068 & 0.917 & 0.355 & 0.178 & 0.331 & 0.310 & 0.256 & 0.169 & -0.323 & -0.086 & 0.037 & 0.042 & 0.285 & 0.570 \\
\hline B10 & 0.119 & 0.010 & 0.885 & 0.340 & 0.231 & 0.358 & 0.318 & 0.291 & 0.238 & -0.315 & -0.057 & 0.101 & -0.003 & 0.282 & 0.484 \\
\hline B11 & 0.162 & -0.085 & 0.645 & 0.949 & 0.300 & 0.386 & 0.301 & 0.339 & 0.133 & -0.242 & -0.184 & 0.212 & 0.220 & 0.368 & 0.476 \\
\hline B12 & 0.062 & 0.038 & 0.134 & 0.500 & 0.206 & 0.195 & 0.243 & 0.105 & 0.112 & 0.042 & -0.120 & 0.261 & 0.041 & -0.097 & 0.173 \\
\hline $\mathrm{C} 1$ & 0.095 & 0.104 & 0.276 & 0.355 & 0.810 & 0.410 & 0.399 & 0.388 & 0.329 & -0.146 & -0.097 & 0.244 & 0.137 & 0.221 & 0.204 \\
\hline $\mathrm{C} 2$ & 0.227 & -0.070 & 0.236 & 0.349 & 0.774 & 0.458 & 0.400 & 0.408 & 0.192 & -0.382 & -0.112 & 0.236 & 0.169 & 0.469 & 0.174 \\
\hline $\mathrm{C} 3$ & 0.073 & -0.015 & 0.019 & 0.060 & 0.703 & 0.211 & 0.243 & 0.250 & 0.176 & -0.182 & -0.346 & 0.055 & 0.154 & 0.226 & 0.195 \\
\hline D1 & 0.102 & 0.124 & 0.430 & 0.373 & 0.354 & 0.599 & 0.318 & 0.306 & 0.210 & -0.321 & -0.052 & 0.343 & 0.228 & 0.294 & 0.298 \\
\hline D2 & 0.284 & -0.020 & 0.342 & 0.361 & 0.321 & 0.852 & $\underline{0.701}$ & 0.579 & 0.413 & -0.567 & -0.085 & 0.227 & 0.180 & 0.409 & 0.425 \\
\hline D3 & 0.328 & 0.017 & 0.304 & 0.243 & 0.441 & 0.900 & 0.671 & 0.564 & 0.344 & -0.610 & -0.121 & 0.225 & 0.101 & 0.470 & 0.370 \\
\hline D4 & 0.285 & -0.034 & 0.131 & 0.326 & 0.489 & 0.696 & 0.499 & 0.452 & 0.206 & -0.384 & -0.068 & 0.131 & 0.122 & 0.429 & 0.217 \\
\hline D5 & 0.270 & 0.065 & 0.375 & 0.324 & 0.475 & 0.885 & $\underline{0.773}$ & 0.560 & 0.369 & -0.557 & -0.137 & 0.146 & 0.056 & 0.524 & 0.341 \\
\hline D6 & 0.162 & 0.185 & 0.352 & 0.343 & 0.398 & $\underline{0.643}$ & 0.916 & 0.525 & 0.341 & -0.303 & -0.001 & 0.253 & 0.113 & 0.403 & 0.410 \\
\hline D7 & 0.220 & -0.010 & 0.294 & 0.274 & 0.425 & 0.744 & 0.890 & 0.594 & 0.323 & -0.494 & -0.141 & 0.155 & 0.077 & 0.531 & 0.360 \\
\hline D8 & 0.182 & 0.173 & 0.238 & 0.285 & 0.412 & 0.544 & 0.577 & 0.860 & 0.401 & -0.423 & -0.193 & 0.242 & 0.132 & 0.372 & 0.275 \\
\hline D9 & 0.062 & -0.045 & 0.291 & 0.304 & 0.395 & 0.509 & 0.520 & 0.906 & 0.338 & -0.474 & -0.211 & 0.168 & 0.064 & 0.502 & 0.331 \\
\hline $\mathrm{E} 1$ & -0.028 & 0.285 & 0.146 & 0.121 & 0.185 & 0.265 & 0.336 & 0.288 & 0.709 & -0.288 & -0.092 & 0.140 & 0.122 & 0.305 & 0.182 \\
\hline $\mathrm{E} 2$ & 0.072 & 0.179 & 0.251 & 0.090 & 0.255 & 0.341 & 0.388 & 0.328 & 0.801 & -0.370 & -0.247 & 0.266 & 0.057 & 0.154 & 0.264 \\
\hline
\end{tabular}




\begin{tabular}{|c|c|c|c|c|c|c|c|c|c|c|c|c|c|c|c|}
\hline E3 & 0.097 & 0.103 & 0.041 & 0.164 & 0.214 & 0.199 & 0.273 & 0.237 & 0.510 & -0.154 & 0.139 & 0.247 & 0.209 & 0.247 & 0.075 \\
\hline E5 & -0.328 & -0.109 & -0.224 & -0.207 & -0.233 & -0.546 & -0.393 & -0.402 & -0.387 & 0.776 & 0.123 & -0.233 & -0.123 & -0.374 & -0.287 \\
\hline E6 & -0.163 & 0.034 & -0.234 & -0.160 & -0.269 & -0.557 & -0.321 & -0.439 & -0.420 & 0.873 & 0.229 & -0.143 & -0.067 & -0.353 & -0.324 \\
\hline E7 & -0.222 & -0.061 & -0.278 & -0.066 & -0.202 & -0.497 & -0.407 & -0.459 & -0.344 & 0.840 & 0.123 & -0.139 & 0.007 & -0.401 & -0.376 \\
\hline E8 & -0.201 & 0.105 & -0.425 & -0.245 & -0.301 & -0.510 & -0.329 & -0.396 & -0.288 & 0.839 & 0.348 & -0.037 & -0.124 & -0.570 & -0.371 \\
\hline E9 & -0.155 & -0.008 & -0.137 & -0.087 & -0.231 & -0.193 & -0.060 & -0.201 & -0.033 & 0.332 & 0.773 & -0.080 & -0.234 & -0.300 & -0.183 \\
\hline E10 & 0.042 & -0.092 & -0.008 & -0.264 & -0.240 & -0.043 & -0.059 & -0.179 & -0.269 & 0.040 & 0.734 & -0.386 & -0.395 & -0.032 & -0.134 \\
\hline E11 & 0.121 & -0.138 & -0.063 & -0.107 & 0.018 & 0.066 & -0.036 & -0.092 & -0.167 & 0.105 & 0.699 & -0.296 & -0.393 & -0.032 & -0.083 \\
\hline F1 & 0.050 & 0.278 & 0.160 & 0.261 & 0.229 & 0.271 & 0.237 & 0.229 & 0.321 & -0.154 & -0.302 & 0.980 & 0.465 & 0.156 & 0.175 \\
\hline $\mathrm{F} 2$ & 0.091 & 0.271 & 0.139 & 0.271 & 0.226 & 0.260 & 0.211 & 0.217 & 0.269 & -0.157 & -0.296 & 0.978 & 0.458 & 0.1416 & 0.166 \\
\hline F3 & -0.026 & 0.037 & 0.081 & 0.144 & 0.128 & 0.183 & 0.211 & 0.118 & 0.190 & -0.087 & -0.394 & 0.401 & 0.865 & 0.303 & 0.062 \\
\hline $\mathrm{F} 4$ & 0.090 & 0.017 & 0.065 & 0.180 & 0.154 & 0.159 & 0.092 & 0.038 & 0.126 & -0.044 & -0.368 & 0.372 & 0.894 & 0.185 & 0.0503 \\
\hline F5 & 0.181 & 0.106 & 0.070 & 0.218 & 0.241 & 0.094 & -0.051 & 0.113 & 0.032 & -0.093 & -0.345 & 0.441 & 0.817 & 0.221 & 0.051 \\
\hline F6 & 0.227 & -0.041 & 0.340 & 0.306 & 0.313 & 0.419 & 0.452 & 0.452 & 0.248 & -0.415 & -0.209 & 0.166 & 0.239 & 0.916 & 0.446 \\
\hline F7 & 0.283 & 0.048 & 0.260 & 0.218 & 0.323 & 0.529 & 0.483 & 0.421 & 0.28 & -0.482 & -0.072 & 0.170 & 0.328 & 0.833 & 0.217 \\
\hline F8 & 0.262 & -0.040 & 0.321 & 0.186 & 0.377 & 0.456 & 0.374 & 0.391 & 0.256 & -0.448 & -0.210 & 0.034 & 0.170 & 0.765 & 0.265 \\
\hline $\mathrm{T} 1$ & 0.176 & -0.102 & 0.578 & 0.477 & 0.251 & 0.429 & 0.427 & 0.345 & 0.286 & -0.411 & -0.196 & 0.174 & 0.064 & 0.399 & 1 \\
\hline
\end{tabular}


By demonstrating the convergent and discriminant validity of the research items, the quality of the constructs was examined, to establish the constructs' validity and reliability, as discussed in next subsequent sections.

\subsubsection{Measurement (Outer) Model - Construct validity.}

Construct validity assesses whether the measures chosen are true measures of the constructs describing the event, and that these measures are actual tools for representing or measuring the construct being investigated (Cronbach, 1971; Gefen \& Straub, 2005; Straub et al., 2000). If constructs are valid, two points are expected: (1) quite high correlations between measures of the same construct using different measurement items, and (2) low correlations between measures of constructs that are expected to differ (Campbell \& Fiske 1959; Hair, 1995; Anderson et al., 1995). For the current study, both convergent and discriminant construct validity were established (Campbell \& Fiske 1959; Cronbach, 1971; Straub, 1989). Construct validity, including both convergent and discriminant validity, was statistically examined by its own procedure, as discussed in the following sections.

\subsubsection{Measurement (Outer) Model- Convergent validity.}

Convergent validity refers to the extent to which a measure correlates, or converges, with other measures of the same construct, indicating that the scale is an appropriate measure of the construct as well as supporting the theoretical position of the construct (Schwab, 2005). Evidence of convergent validity is confirmed "when items thought to reflect a construct converge, or show significant high correlations with one another" (Straub et al., 2004, p.391). In addition, convergent validity is demonstrated when the Average Variance Explained (AVE) value between the constructs is equal to, or exceeds, 0.5 (Fornell \& Larcker, 1981; Hair et al., 2013). However, only one construct 'technical risks' showed low AVE score (.468) which is below the acceptable level, as highlighted in the same table. Thus, this construct was potential for elimination. To address this issue, one associated item with this construct (E3) which had very low item loading was eliminated to check whether the AVE score could exceed the threshold of (.5) (this was discussed in section 5.5.3.1). Indeed, the new AVE score of this construct was (.586), and thus demonstrating a valid construct. As presented in Table 5.9, the AVE for all final constructs in the model was greater than .50, which meets the first requirement of achieving convergent validity, as proposed by Fornell and Larcker (1981), Hair et al. (2013) and Tabchnick and Fidell (2007). 
Another approach to assess the convergent validity of the constructs is to examine the composite reliability of the constructs (Fornell \& Larcker, 1981). All constructs exhibited acceptable to high scores of composite reliability, exceeding the .70 threshold recommended by Barclay et al. (1995) and Nunnally (1978).

Table 5.9 Average Variance Explained and Reliability Estimates of the Constructs

\begin{tabular}{|c||c|c|c||}
\hline Construct & $\begin{array}{c}\text { Average Variance } \\
\text { Explained } \\
\text { (AVE) }\end{array}$ & $\begin{array}{c}\text { Composite } \\
\text { Reliability }\end{array}$ & $\begin{array}{c}\text { Reliability Estimates } \\
\text { (Cronbach's Alpha) }\end{array}$ \\
\hline \hline Propensity to Trust & 0.781 & 0.914 & 0.863 \\
\hline Uncertainty Avoidance & 0.619 & 0.819 & 0.723 \\
\hline Awareness & 0.696 & 0.899 & 0.848 \\
\hline Past Experience & 0.575 & 0.712 & 0.335 \\
\hline Trust Environment & 0.584 & 0.808 & 0.642 \\
\hline Provider's trustworthiness & 0.616 & 0.916 & 0.891 \\
\hline $\begin{array}{c}\text { Trust level in provider's } \\
\text { products and services }\end{array}$ & 0.781 & 0.877 & 0.722 \\
\hline Technical Risks & 0.586 & 0.719 & 0.307 \\
\hline Level of Security & 0.694 & 0.901 & 0.853 \\
\hline Privacy Risks & 0.542 & 0.780 & 0.674 \\
\hline Device capability & 0.729 & 0.843 & 0.782 \\
\hline Device Design Suitability & 0.739 & 0.895 & 0.824 \\
\hline Device Security & 0.707 & 0.878 & 0.800 \\
\hline Trust in Mobile Payments & 1 & 1 & 1 \\
\hline \hline
\end{tabular}

In order to assess the internal consistency, Cronbach's alpha measures need to be examined. In addition, it is recommended to consider the reliabilities of the measurements as a means of providing evidence and support for convergent validity of the constructs (Hair et al., 1998; Tabchnick \& Fidell, 2007).Internal consistency is achieved when reliability estimates are greater than .70 (Barclay et al., 1995; Nunnally, 1978). The .07 threshold is regarded in the IS field reported data to be the most commonly accepted cut off point (Chin et al., 2003). Those measurements that demonstrate low reliability levels should not be further investigated, as the convergent validity would not be achieved (Netemeyer et al., 2003).

As presented in Table 5.9, many scales exhibited acceptable to high reliabilities, with Cronbach's coefficient alpha exceeding the .70 threshold recommended by Field (2005) and Hair et al., (1998), thereby, satisfying the second requirement of convergent validity. However, a few constructs had relatively low reliability scores, such as privacy risks (.674) and trust environment 
(.642), but are still in an acceptable range as their alpha scores were not far from the threshold point, and, thus, were considered for further analysis. Relatively low reliability scores could be due to constructs' nature as newly developed items, and/or to a low number of measuring items associated with these constructs (Field, 2005; Tavakol \& Dennik, 2011). However, two constructs found with low and unacceptable reliability scores; 'past experience' and 'technical risks'. The construct 'past experience' scored the lowest reliability score, as shown in Table 5.9, and was not able to demonstrate reliability

Regarding the 'technical risk' construct, the reliability score of this construct dropped down from .516 to .307 (under the threshold) by deleting the item with the low factor loading (as mentioned earlier in this section), and thus demonstrating no reliability. Another item (B12) that was potential for deletion to increase the AVE score of the construct 'past experience' (see section 5.5.3.1), but was not deleted as there were only two items associated with construct. This practice is not recommended because of having a single-item construct would result in making conventional reliability and convergent validity assessments inappropriate (Hair et al., 2013).

In the current research, only constructs with acceptable validity and reliability scores were considered for further model testing. However, and as discussed previously, two constructs had not addressed the validity and reliability criteria; which are: 'past experience' and 'technical risks'. These constructs were eliminated and were not included in further analysis of the study model. Having provided evidence of the convergent validity of the constructs, the discriminant validity was examined and is detailed in the following section.

\subsubsection{Measurement (Outer) Model - Discriminant validity.}

Discriminant validity examines the extent to which an independent variable is truly distinct from other independent variables in predicting the dependent variable (Hair et al., 1998). In other words, discriminant validity estimates the extent to which a measure does not correlate or converge with other different measures (Campbell \& Fiske, 1959). To demonstrate discriminant validity, items that measure the same construct should correlate together at a higher level than they correlate with items measuring different constructs (Campbell \& Fiske, 1959).

According to Straub et al. (2004), discriminant validity is achieved when the correlation between two composite constructs is not greater than their respective reliability measure. As such, all items with each construct need to be computed into composite variables to examine discriminant 
validity (O'Cass, 2000). This method of computing composite variables for the purpose of examining the existence of discriminant validity has previously been applied and supported within consumer behaviour research (O'Cass, 2000; Shi \& Wright, 2001). In the current study, an inspection of the individual bivariate correlation matrix for the composite constructs resulted in correlations ranging from -0.103 to .764 , and the composite reliability estimates were higher than .78 for the validated constructs. Based on this outcome, all of the correlations between composite constructs were not higher than their respective reliability estimates and, therefore, discriminant validity was demonstrated.

Another popular approach to assess the discriminant validity followed in the current research was through examining the cross-loadings comparisons between constructs. Specifically, the AVE of each latent construct should be higher than the construct's highest squared correlation with any other latent construct (Fornell \& Larcker, 1981; Hulland, 1999). This notion is identical to comparing the square root of the AVE with the correlations between the latent constructs (Fornell \& Larcker, 1981). The square roots of the AVE values of all constructs are calculated, and compared with correlations between constructs. The results in Table 5.10 indicate that all constructs in the research model achieved this criterion as none of the off-diagonal elements exceeded the respective diagonal element (Hulland, 1999). Thus, discriminant validity was demonstrated. 
Table 5.10 Correlation Matrix among Construct Scores

\begin{tabular}{|c|c|c|c|c|c|c|c|c|c|c|c|c|c|c|}
\hline & $\begin{array}{l}\text { Awar } \\
\text { eness }\end{array}$ & $\begin{array}{l}\text { Device } \\
\text { design }\end{array}$ & $\begin{array}{l}\text { Device } \\
\text { capability }\end{array}$ & $\begin{array}{l}\text { Device } \\
\text { security }\end{array}$ & $\begin{array}{l}\text { Level of } \\
\text { security }\end{array}$ & $\begin{array}{c}\text { Past } \\
\text { experie } \\
\text { nce }\end{array}$ & $\begin{array}{c}\text { Privacy } \\
\text { risks }\end{array}$ & $\begin{array}{l}\text { Propensit } \\
\text { y to trust }\end{array}$ & $\begin{array}{c}\text { Provider's } \\
\text { trustworthi } \\
\text { ness }\end{array}$ & $\begin{array}{c}\text { Techni } \\
\text { cal } \\
\text { risks } \\
\end{array}$ & $\begin{array}{c}\text { Trust } \\
\text { Environ } \\
\text { ment }\end{array}$ & $\begin{array}{l}\text { Uncertainty } \\
\text { avoidance }\end{array}$ & $\begin{array}{c}\text { Trust } \\
\text { level in } \\
\text { Products }\end{array}$ & $\begin{array}{c}\text { Trust } \\
\text { in } \\
\text { MP }\end{array}$ \\
\hline Awareness & 0.834 & & & & & & & & & & & & & \\
\hline Device design & 0.085 & 0.86 & & & & & & & & & & & & \\
\hline Device capability & 0.153 & 0.471 & 0.854 & & & & & & & & & & & \\
\hline Device security & 0.370 & 0.281 & 0.152 & 0.841 & & & & & & & & & & \\
\hline Level of security & $\begin{array}{c}- \\
0.355\end{array}$ & -0.089 & -0.158 & -0.516 & 0.833 & & & & & & & & & \\
\hline Past experience & 0.613 & 0.208 & 0.272 & 0.294 & -0.201 & 0.758 & & & & & & & & \\
\hline Privacy risks & $\begin{array}{c}- \\
0.106\end{array}$ & -0.431 & -0.305 & -0.207 & 0.251 & -0.202 & 0.736 & & & & & & & \\
\hline Propensity to trust & 0.188 & 0.087 & 0.071 & 0.293 & -0.269 & 0.163 & -0.042 & 0.884 & & & & & & \\
\hline $\begin{array}{c}\text { Provider's } \\
\text { trustworthiness }\end{array}$ & 0.415 & 0.158 & 0.272 & 0.556 & -0.595 & 0.406 & -0.109 & 0.299 & 0.785 & & & & & \\
\hline Technical risks & 0.253 & 0.140 & 0.302 & 0.303 & -0.427 & 0.154 & -0.188 & 0.056 & 0.457 & 0.765 & & & & \\
\hline Trust Environment & 0.231 & 0.200 & 0.232 & 0.391 & -0.301 & 0.332 & -0.244 & 0.167 & 0.517 & 0.309 & 0.764 & & & \\
\hline Uncertainty avoidance & 0.038 & 0.062 & 0.281 & -0.023 & -0.003 & -0.063 & -0.085 & -0.018 & 0.063 & 0.282 & 0.014 & 0.787 & & \\
\hline Trust level in products & 0.302 & 0.107 & 0.228 & 0.500 & -0.509 & 0.334 & -0.229 & 0.132 & 0.679 & 0.414 & 0.455 & 0.345 & 0.884 & \\
\hline Trust in MP & 0.578 & 0.064 & 0.174 & 0.399 & -0.411 & 0.477 & -0.196 & 0.176 & 0.453 & 0.286 & 0.251 & 0.345 & 0.060 & 1 \\
\hline
\end{tabular}


In summary of the first round PLS (outer) analysis, the measurement model results provided support for the reliability, convergent and discriminant validities of the majority of the constructs and their measures used in the current research, except two of them: 'past experience' and 'technical risks'. In addition, the majority of the items used to measure the constructs demonstrated validity except the item $\mathrm{E} 4$, resulting in the deletion of this item. Given the adequacy of the measurement model excluding the mentioned constructs and items, it was deemed appropriate to proceed with the assessment of the quality of the inner (structural) model.

\subsubsection{Structural (inner) model results.}

An assessment of the structural model was undertaken to determine the significance of the paths and the predictive power of the model. Firstly, a systematic assessment of the structural model was conducted to assess the significance of path coefficients by examining the standard error, t-statistics and confidence interval (Chin, 1998). In addition, Falk and Miller (1992) suggest that the absolute value of a construct's path coefficient can be considered a criterion for evaluating the significance of the individual paths. The standardised regression weights representing the paths' estimates produce an index of the variance in an endogenous variable that explains the particular path. The recommended cut-off point of the variance is $1.5 \%(.015)$ (Falk \& Miller, 1992). Secondly, the predictive power of the model is assessed using $\mathrm{R}^{2}$ value for the endogenous latent variables as a measure of model fit (Chin et al., 2003; Chin, 1998; Hair et al., 1998). In addition, the amount of variance explained by $\mathrm{R}^{2}$ provides an indication of the model fit (Hair et al., 1998) as well as the predictive ability of the endogenous variables (Chin, 1998). Falk and Miller (1992) and Hair et al. (2013) suggest that the minimum level for an individual $\mathrm{R}^{2}$ should be greater than a minimum acceptable level of .10 . In general, $\mathrm{R}^{2}$ values of $0.75,0.50$, or 0.25 for endogenous constructs can be described as respectively substantial, moderate, and weak (Hair et al., 2013).

As indicated earlier, PLS makes no distribution assumptions (Urbach \& Ahlemann, 2010). Therefore, the bootstrapping resampling technique was required to test the effects and statistical significance of the path coefficients, and to estimate standard errors (Chin et al., 2003; Hair et al., 2013). This bootstrapping process involved 5,000 random resamples from the original data set with one tailed test to determine the significant levels of path coefficients (Hair et al., 2013). 
Table 5.11 highlights the hypotheses of the study, and shows the path coefficient between the exogenous and endogenous variables; the average variance accounted for, $\mathrm{R}^{2}$ and bootstrap critical ratios. The bootstrap critical ratios (T Statistics) determined the stability of the estimates and were acceptable at ranges between -1.96 and +1.96 (Chin, 1998). Alternatively, the Average Variance Accounted for (AVA) represented the mean of $\mathrm{R}^{2}$ of the structural model and indicated the overall predictive power of the model (Fornell \& Bookstein, 1982). In the current study, the AVA for the endogenous variables was .46 and the $\mathrm{R}^{2}$ value for the exogenous variable (trust in $\mathrm{m}$ payments) was greater than the Falk and Miller's (1992) recommended level of .10; therefore, it was appropriate to examine the significance of the paths associated with these variables. All of the paths and all variables had bootstrap critical ratios as shown in Table 5.11. The results of each path are interpreted in next section.

Table 5.11 Partial Least Squares Results for the CTMP Model

\begin{tabular}{|c|c|c|c|c|c|c|}
\hline Exogenous variables & $\begin{array}{l}\text { Endogenous } \\
\text { variable }\end{array}$ & $\mathbf{H \#}$ & $\begin{array}{c}\text { Path } \\
\text { Coefficient }\end{array}$ & $\begin{array}{c}\text { Critical } \\
\text { Ratio - } \\
\text { T Statistics } \\
\text { (O/STERR*) }\end{array}$ & P-Value & $R^{2}$ \\
\hline Awareness of M-payments $\rightarrow$ & Trust in MP & H1 & 0.435 & 8.242 & 0.000 & \\
\hline Propensity to Trust $\rightarrow$ & Trust in MP & $\mathrm{H} 2$ & 0.011 & 0.244 & 0.404 & \\
\hline Uncertainty Avoidance $\rightarrow$ & Trust in MP & H3 & -0.161 & 2.586 & 0.005 & \\
\hline Trust Environment $\rightarrow$ & Trust in MP & H5 & 0.031 & 0.508 & 0.306 & \\
\hline Provider's Reputation $\rightarrow$ & Trust in MP & H6 & - & - & - & \\
\hline $\begin{array}{l}\text { Level of Trust in Provider's } \\
\text { Products and Services } \rightarrow\end{array}$ & Trust in MP & $\mathrm{H} 7$ & 0.025 & 0.339 & 0.367 & \\
\hline Provider's trustworthiness $\rightarrow$ & Trust in MP & $\mathrm{H} 8$ & 0.193 & 2.203 & 0.014 & \\
\hline Privacy Risks $\rightarrow$ & Trust in MP & $\mathrm{H} 10$ & -0.125 & 2.658 & 0.004 & \\
\hline Security Level $\rightarrow$ & Trust in MP & H11 & 0.147 & 2.224 & 0.013 & \\
\hline Device Capability $\rightarrow$ & Trust in MP & $\mathrm{H} 12$ & 0.094 & 1.815 & 0.070 & \\
\hline Device Design Suitability $\rightarrow$ & Trust in MP & $\mathrm{H} 13$ & 0.138 & 2.232 & 0.032 & \\
\hline Device Security $\rightarrow$ & Trust in MP & $\mathrm{H} 14$ & 0.093 & 1.570 & 0.059 & \\
\hline \multicolumn{6}{|c|}{ Average Variance Accounted (AVA) for 'Trust in M-Payments' } & .448 \\
\hline$*($ O/STERR $):$ Ori & al Sample & & (iii) & CIIOI & & \\
\hline
\end{tabular}

\subsubsection{Summary of the Hypotheses Results}

The PLS results, as shown in Table 5.11, indicate that awareness of m-payments has a significant positive effect on consumer trust in m-payments $(B=.435, \mathrm{t}=8.242, \mathrm{P}=$ 0.000 ), suggesting that those consumers who have more knowledge about the mpayments services and applications, and how these payments are conducted, are more likely to trust in m-payments. This finding supports H1. Consumer propensity to trust, however, was not found to have a significant influence on consumer trust in $\mathrm{m}$ - 
payments $(B=.011, \mathrm{t}=.244, \mathrm{P}=.404)$; and thus, not supporting $\mathrm{H} 2$. Consistent with $\mathrm{H} 3$, consumer uncertainty avoidance has a significant influence on consumer trust in m-payments $(\beta=-.161, \mathrm{t}=2.586, \mathrm{p}=.005)$, implying that consumer's avoidance of uncertainly perceived m-payment methods and technologies could negatively impact consumer's trust in these payments, thereby supporting $\mathrm{H} 3$. With respect to $\mathrm{H} 4$, the construct 'personal experience' eliminated during the Measurement (outer) model test as it showed low reliability score (as discussed in section 5.5.3.3), and thus excluding this factor and eliminating the hypothesis $\mathrm{H} 9$.

Table 5.11 also shows that the 'trust environment' factor had no significant influence on consumer trust in m-payments $(\beta=.031, \mathrm{t}=.508, \mathrm{p}=.306)$, and thus not supporting H5. With regard to H6, provider's reputation had been merged with provider's trustworthiness due to high cross loadings, and thus reputation was not tested individually. The construct 'Trust level in provider's products and services' was hypothesised as $\mathrm{H} 7$ and was found not to have a significant influences on consumer trust in m-payments, scoring the values $(B=.066, \mathrm{t}=1.311, \mathrm{p}=.367)$, whereas provider's trustworthiness was found to have a significant influence on consumer trust $(B=.193, \mathrm{t}=2.203, \mathrm{p}=0.014)$, and thus its associated hypotheses $(\mathrm{H} 8)$ was supported.

With regard to H9, the construct 'technical risks' was eliminated during the structural 'inner' model tests, as it showed low validity and reliability scores, and thus excluded (see section 5.5.3.3). On the other hand, both hypotheses H10 and H11 associated with the constructs 'Privacy risks' and 'Security level' respectively were supported. These two constructs scored acceptable scores $(B=-.125, \mathrm{t}=2.658, \mathrm{p}=.004)$ and $(\beta=$ $-.147, \mathrm{t}=2.224, \mathrm{p}=.013)$ respectively.

Further results relating to the device characteristics indicate that device capability had no significant influence on consumer trust in m-payments $(\beta=0.094, \mathrm{t}=1.815, \mathrm{p}=$ 0.070); thus not supporting H12. As proposed in H13, design features concerning the device have a significant negative effect on consumer trust in $\mathrm{m}$-payments $(B=-0.138$, $\mathrm{t}=2.232, \mathrm{p}=0.032$ ), suggesting that current mobile devices have design features that could negatively influence consumers' trust in m-payments. This finding supports H15. As for H14, device security had not been found with a significant influence on consumer trust in m-payments $(B=0.093, \mathrm{t}=1.570, \mathrm{p}=0.059)$, thereby not 
supporting H14. In summary, the results from the current study show that six hypotheses (H1, H3, H8, H10, H11, and H13) were supported, whereas five hypotheses (H2, H5, H7, H12 and H14) were not supported, and three hypotheses were not tested (H4, H6, and H9). As for other results, Table 5.11 also shows the Average Variance Accounted (AVA) value for by the endogenous variable in the exogenous variables was 0.448 , considered medium according to Hair et al. (2013). This means that $46 \%$ of the variance in trust in m-payments is explained by the identified constructs.

\subsubsection{Summary of results (Hypotheses H1 - H14)}

The results of the analysis of the proposed CTMP model lend weight to all of the hypotheses for the inner model. Table 5.12 presents a summary of the results of the hypotheses testing.

Table 5.12 Results of Hypotheses Testing

\begin{tabular}{|c|l|c|}
\hline No. & \multicolumn{1}{|c|}{ Hypothesis } & Result \\
\hline H1 & $\begin{array}{l}\text { The more the consumer awareness about mobile payments, the higher the } \\
\text { trust in mobile payments. }\end{array}$ & Supported \\
\hline H2 & $\begin{array}{l}\text { The higher the consumer's propensity to trust, the higher the trust in mobile } \\
\text { payments. }\end{array}$ & Not Supported \\
\hline H3 & $\begin{array}{l}\text { The higher the consumer's uncertainty avoidance the lower the consumers } \\
\text { trust in mobile payments. }\end{array}$ & Supported \\
\hline H4 & $\begin{array}{l}\text { The higher the trust environment, the higher the consumers trust in mobile } \\
\text { payments. }\end{array}$ & Not Supported \\
\hline H5 & $\begin{array}{l}\text { A provider's good reputation has a significant positive influence on } \\
\text { consumers trust in mobile payments. }\end{array}$ & Not tested \\
\hline H6 & $\begin{array}{l}\text { The higher the level of trust in provider's products and services, the higher } \\
\text { the consumers trust in mobile payments. }\end{array}$ & Not Supported \\
\hline H7 & $\begin{array}{l}\text { The higher the provider's trustworthiness, the higher the consumers trust in } \\
\text { mobile payments. }\end{array}$ & Supported \\
\hline H8 & $\begin{array}{l}\text { Perceived technical risks negatively influence consumer trust in mobile } \\
\text { payments. }\end{array}$ & $\begin{array}{l}\text { Not tested } \\
\text { percived privacy risks negatively influence consumer trust in mobile }\end{array}$ \\
\hline H9 & $\begin{array}{l}\text { The higher the perceived security levels in mobile payments, the higher the } \\
\text { consumer trust in mobile payments. }\end{array}$ & Supported \\
\hline H10 \\
trust in mobile payments. \\
\hline H11 & $\begin{array}{l}\text { The more suitable the design of the mobile-device to conduct an m- } \\
\text { in mobighe the higher the consumers trust in mobile payments. }\end{array}$ & Not supported \\
\hline
\end{tabular}

Further, the proposed CTMP model, with an illustration of the path coefficients within the inner model and $\mathrm{R}$ squared value for the endogenous variable, is presented in Figure 5.1 overleaf. The validated manifest variables were also presented in this figure in association with the latent variables. 


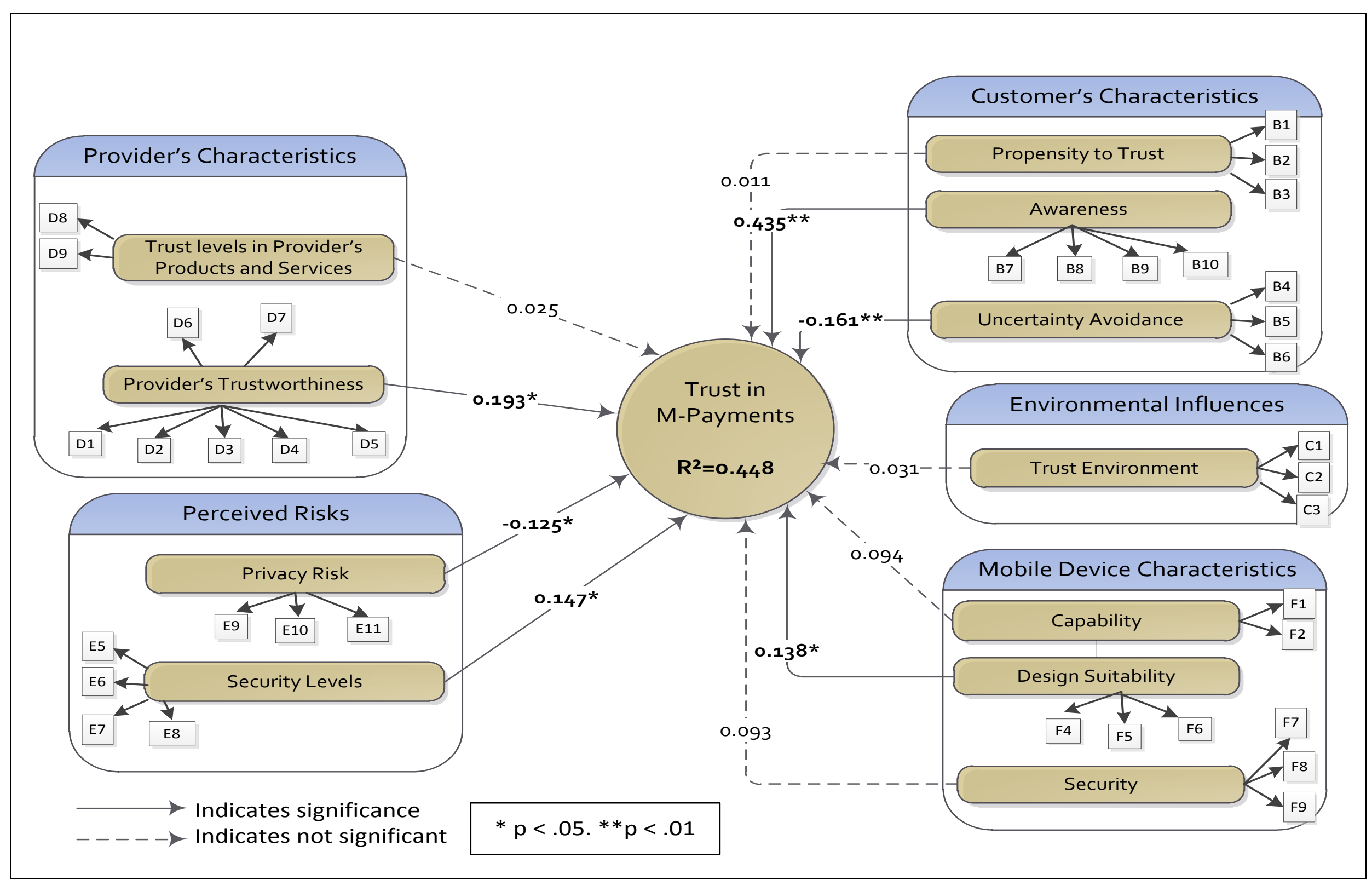

Figure 5.1 Revised CTMP Model with the Quantitative Analysis Results 


\subsection{Chapter Conclusion}

This chapter presented the results of the data analysis obtained from 340 online surveys collected to address the hypotheses of the study. Initially, the data preparation process of editing, coding and transcribing the data were described; then followed by a descriptive statistical overview of the sample participating in the online survey. In addition, the individual data items were considered normally distributed and the common method bias in variance was not detected. Following the presentation of the results of this preliminary analysis, a rationale and discussion for using SEM and PLS were presented. SEM, an advanced confirmatory systematic and comprehensive analysis, was employed to explain the relationships among the variables, and to answer the two research questions. As one of SEM's popular approaches, PLS was considered appropriate for the current research because it allowed for the exploration of the hypothesised relationship among the constructs. In addition, it facilitated simultaneous tests of the measurement and structural models.

The PLS model was then analysed and interpreted in two sequential stages. Firstly, the reliability and validity of the measurement model was presented and, secondly, an examination of the structural model was undertaken by interpreting the path coefficients and identifying the adequacy of the research model. Importantly, the results of the measurement model indicated that two constructs out of 14 and one item out of 43 were not found to be valid and reliable. The results of the structural model analysis indicated that six research hypotheses were supported, whereas five hypotheses were not supported and three hypotheses were not tested. The factors that found to have a significant influence on trust on m-payments are: consumer awareness, uncertainty avoidance, provider's trustworthiness, privacy risks, security level, and the design features concerning the device. These results provide a foundation for the discussion in the following chapter (Chapter Six), where an additional interpretation of the results is presented, along with a discussion of the implications of the results. 


\section{CHAPTER SIX \\ Discussion of Research Findings}

\subsection{Chapter Overview}

Chapter Six provides a synthesis and discussion of the research findings, to address the research objective and associated research questions that centred upon exploring the factors that influence consumer trust in m-payments. This chapter reviews the major findings and provides combined discussions of the perceived factors which influence trust, revealed in both the qualitative phase (focus group interviews discussed in Chapter Three) and the quantitative phase (survey findings discussed in Chapter Five) along with the literature (Chapter Two) reviewed in the current research.

\subsection{Summary of the Research Model based on the Qualitative}

\section{Findings}

The qualitative findings (presented in Chapter Three) supported the proposed CTMP model proposed in Chapter Two which was developed on the basis of the extant literature of consumer trust in m-payments. The CTMP model included five groups of total 13 factors, categorised as follows: Consumer characteristics (consumer awareness, propensity to trust, uncertainty avoidance), environmental influences (trust environment), provider's characteristics (provider's trustworthiness, and provider's reputation), perceived risks (security levels, privacy risks), and mobile-device characteristics (functionality, design features, security). In addition, the participants during the focus group sessions identified two new factors: trust level in provider's products and services, and perceived technical risks.

The perceived degree of influence for each factor varied amongst participants. For instance, a large majority of participants agreed that consumer provider's reputation has strong influence on their trust in m-payments. The majority agreed on the influence of consumer awareness and perceived security levels on their trust, whereas many participants considered propensity to trust, trust environment, provider's trustworthiness, perceived technical risks with influence on trust in m-payments. In addition, some of the participants perceived the factors: consumer uncertainty avoidance and perceived privacy risks, with influence on trust in m-payments, whereas trust level in provider's products and services and mobile-device security were 
perceived by only few participants to have influence in trust in m-payments in the Emirates. The degree of consensus on the discussed factors among participants was highlighted in the CTMP model according to the thicknesses of the arrows linking each factor and trust in mpayments, as shown in Figure 6.1.

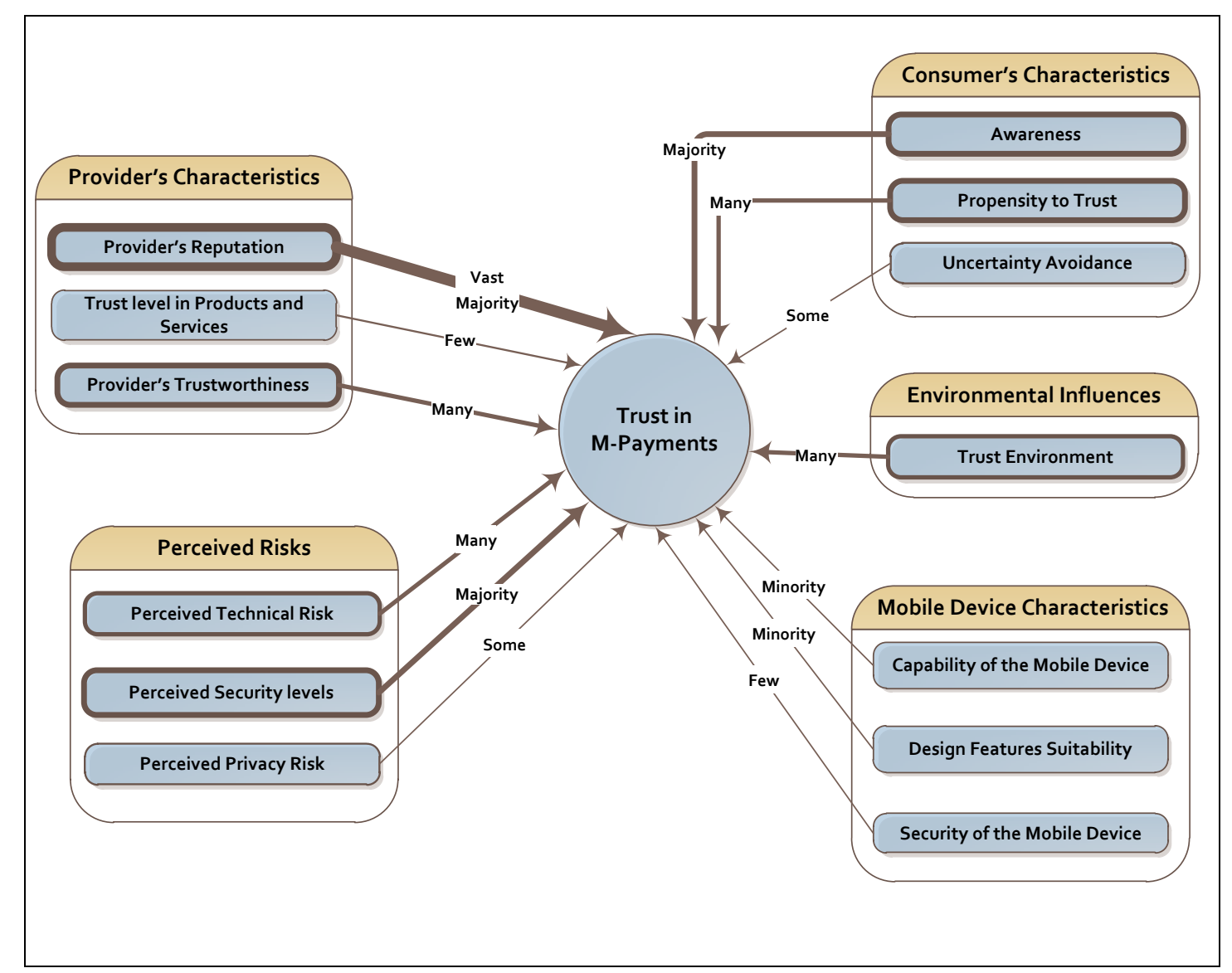

Figure 6.1 The CTMP Model Based on the Qualitative Findings

\subsection{Summary of the Research Hypotheses and Model based on the Quantitative Findings}

The following section provides a discussion by comparing the results reported in Chapters Three and Five, with the existing literature reviewed in Chapter Two. The CTMP model (Consumer Trust in Mobile Payments) and the set of propositions explaining the factors of consumer trust in m-payments were developed in section 2.7.3 of this thesis. This model comprehensively integrates aspects from the parent disciplines of mobile payments and consumer trust, together with conceptual, exploratory and empirical literature conducted in the immediate discipline of trust in m-payments. Afterwards, the proposed CTMP model was theoretically and empirically tested. Starting with the first method in the current research, the 
model was qualitatively explored and revised, as shown in Figure 6.1, and the hypotheses derived from the model were presented for further analysis. Following the qualitative phase, the model was quantitatively tested in the second phase of the study (Figure 5.1). Final results of the hypotheses are presented in Table 6.1. Overall, the findings provide support for many of the hypothesised relationships between trust and its influential factors.

A comparison of the results with the extant literature is framed within the context of the hypotheses developed to address the major research objective, which was: To understand the factors influencing consumer trust in $\mathrm{B} 2 \mathrm{C}$ mobile payments in the Emirates. Moreover, this comparison details the confirmation/disconfirmation of each hypothesis in the existing literature, and specifies whether these hypotheses have been speculated upon, implied, mentioned without empirical investigation, or examined in prior research studies. Furthermore, a discussion is presented regarding the contribution of this research as being consistent or inconsistent with past research and whether it has advanced the existing theory by contributing further to the literature. Alternatively, findings from this research pertaining to issues concerning which there has been no prior research are considered to contribute additional insight and knowledge to current understandings of consumer trust in m-payments. Importantly, the current research makes viable contributions that both advance and add to existing knowledge of trust in m-payments.

Table 6.1 Results of Hypotheses Testing

\begin{tabular}{|c|c|c|}
\hline No. & Hypothesis & Result \\
\hline \multicolumn{3}{|c|}{ Consumer characteristics (H1-H4) } \\
\hline H1 & $\begin{array}{l}\text { The more the consumer awareness about mobile payments, the higher the trust in mobile } \\
\text { payments. }\end{array}$ & Supported \\
\hline $\mathrm{H} 2$ & The higher the consumer's propensity to trust, the higher the trust in mobile payments. & Not Supported \\
\hline $\mathrm{H} 3$ & $\begin{array}{l}\text { The higher the consumer's uncertainty avoidance the lower the consumers trust in mobile } \\
\text { payments. }\end{array}$ & Supported \\
\hline \multicolumn{3}{|c|}{ Trust environment (H5) } \\
\hline $\mathrm{H} 4$ & The higher the trust environment, the higher the consumers trust in mobile payments. & Not Supported \\
\hline \multicolumn{3}{|c|}{ Provider characteristics (H6-H10) } \\
\hline H5 & $\begin{array}{l}\text { A provider's good reputation has a significant positive influence on consumers trust in mobile } \\
\text { payments. }\end{array}$ & Not tested \\
\hline H6 & $\begin{array}{l}\text { The higher the level of trust in provider's products and services, the higher the consumers trust } \\
\text { in mobile payments. }\end{array}$ & Not supported \\
\hline $\mathrm{H} 7$ & The higher the provider's trustworthiness, the higher the consumers trust in mobile payments. & Supported \\
\hline \multicolumn{3}{|c|}{ Perceived risks (H11-H13) } \\
\hline $\mathrm{H} 8$ & Perceived technical risks negatively influence consumer trust in mobile payments. & Not tested \\
\hline $\mathrm{H} 9$ & Perceived privacy risks negatively influence consumer trust in mobile payments. & Supported \\
\hline
\end{tabular}




\begin{tabular}{|c|l|c|}
\hline No. & \multicolumn{1}{|c|}{ Hypothesis } & Result \\
\hline H10 & $\begin{array}{l}\text { The higher the perceived security levels in mobile payments, the higher the consumer trust in } \\
\text { mobile payments. }\end{array}$ & Supported \\
\hline \multicolumn{2}{|l|}{} \\
Mobile-device characteristics (H14-H16) & $\begin{array}{l}\text { Not Supported } \\
\text { payments. }\end{array}$ & Supported \\
\hline H11 & $\begin{array}{l}\text { The more suitable the design of the mobile-device to conduct an m-payment, the higher the } \\
\text { consumers trust in mobile payments. }\end{array}$ & Not Supported \\
\hline H13 & $\begin{array}{l}\text { The higher the security of the mobile device, the higher the consumers trust in mobile } \\
\text { payments. }\end{array}$ & $\begin{array}{l}\text { *Not supported hypotheses had been tested and were found insignificant. } \\
* * \text { Not tested hypotheses had failed to be included in the structural/inner model test due to low reliability and validity } \\
\text { measures. }\end{array}$
\end{tabular}

The findings, presented in Chapter Five, provided useful insights into the factors that influence trust in m-payments from a consumer perspective. Many factors were empirically found to have an influence on trust in m-payments, while some others did not. As shown in Table 6.1, the CTMP model was generally supported (Figure 6.2). The factors found to have significant influence on consumer trust in m-payments, in descending order according to influence values, are: awareness, provider's trustworthiness, uncertainty avoidance, perceived security risks, mobile-device design suitability, and perceived privacy risks. There were two factors that found to have a negative influence on consumer trust (which their path coefficient were found with negative signs), are uncertainty avoidance, and perceived privacy risks (ordered descending according to their influence values). On the other side, five factors; namely propensity to trust, trust environment, trust level in provider's products and services, mobile-device capability, and mobile-device security were found to have no significant influence on consumer trust in mpayments, and thus their associated hypotheses were not supported and they were not included in the revised CTMP model. The construct perceived technical risks, however, was eliminated in early analysis stages before testing their influence on trust due to their inability to demonstrate validity and reliability.

In terms of viewing the factors with the most and least influence in each of the five predetermined groups (consumer characteristics, environmental influences, provider characteristics, perceived risks and device characteristics), the dominant consumer-relating factor was consumer awareness, while provider's trustworthiness was considered the most provider's influential characteristic. As for the perceived risks, security level had the strongest effect, whereas the factor 'mobile-device design suitability' was found to have the greatest influence in amongst all device characteristics. Regarding the environmental influences, trust environment was not found to have significant influence on consumer trust in m-payments in 
the Emirates. All factors which have significant influence in consumer trust in mobile payments in the Emirates are shown in Figure 6.2. The $\mathrm{R}^{2}$ value, which demonstrates the average variance assumed of the endogenous variable in the model, accounted for 0.448 . This means that $44.8 \%$ of the variance in trust in m-payments is explained by the identified factors, which can be described as a 'medium' proportion of an endogenous construct's variance that is explained by its predictor constructs (Hair et al., 2013).

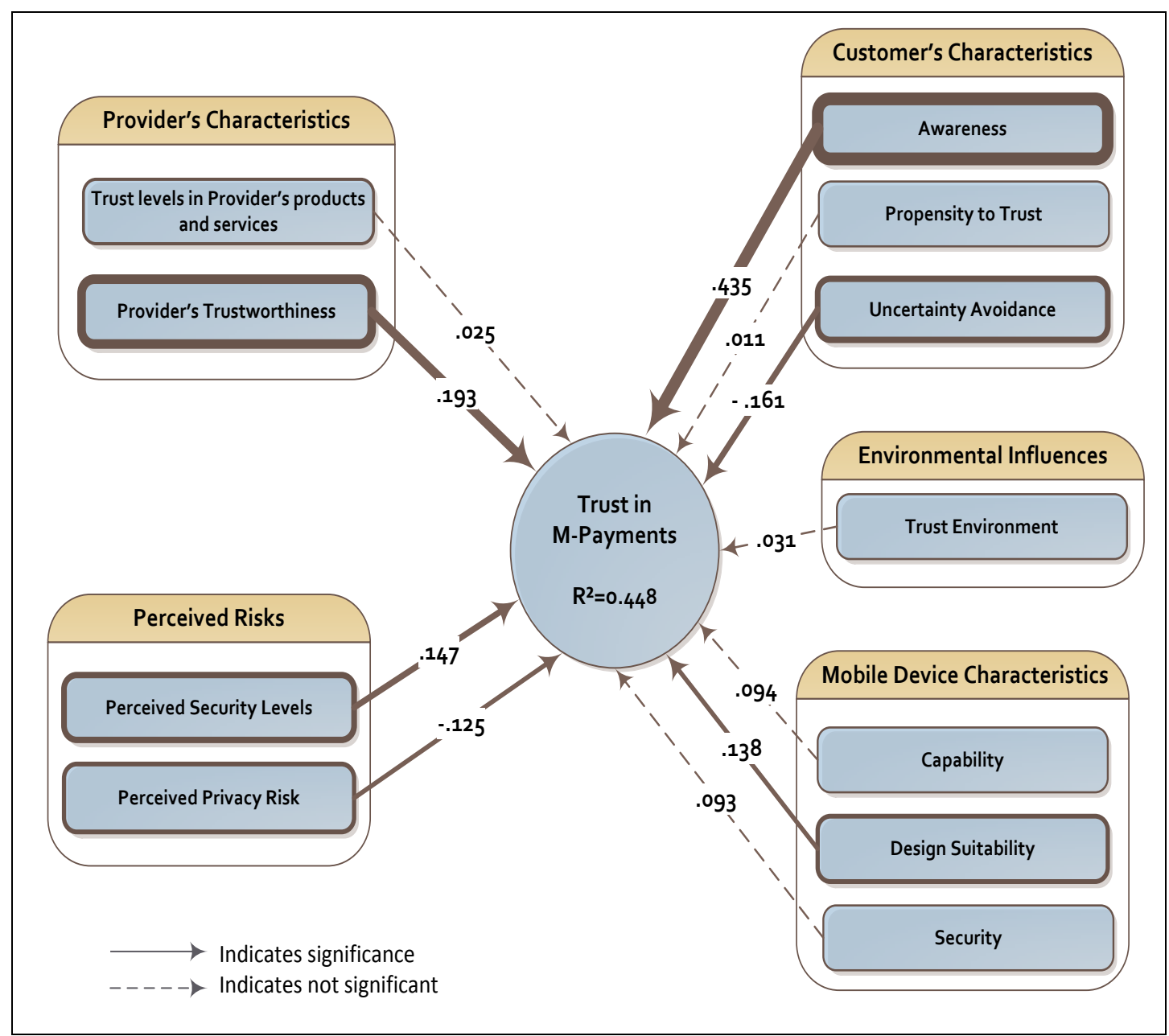

Figure 6.2 The CTMP Model Based on the Quantitative Findings

\subsection{Discussion of the Hypotheses Results}

In the following section, the relationships between the factors and trust in m-payments are discussed in relation to each research hypothesis, excluding the ones which were not supported and the others were eliminated earlier in Chapter Five. Therefore, this discussion includes only the hypotheses that were empirically supported. The factors that are associated with these hypotheses in their relating groups are:

- Consumer characteristics (Awareness (H1), Uncertainty avoidance (H3))

- Provider characteristics (Provider's trustworthiness (H7)) 
- Perceived risks (Perceived security levels (H10), Perceived privacy risks (H9))

- Mobile-device characteristics (Mobile-device design suitability (H12))

Each factor is discussed in detail with respect to the results found in the qualitative and quantitative results of this research and with regard to the extant literature of trust in mpayments. In addition, a justification of the insignificant factors of trust was given, by considering the sample chosen and the context of the Emirates.

\subsubsection{Consumer characteristics.}

The group of factors relating to consumer characteristics included consumer awareness, propensity to trust, and uncertainty avoidance. Consumer awareness was found to be the most influential consumer characteristic on trust in m-payments $(B=0.435)$, and the dominant factor of trust in the current study, followed by uncertainty avoidance which accounted for around the half of influence extent of consumer awareness had $(\beta=-0.161)$. However, propensity to trust was found insignificant to consumer trust in m-payments in the Emirates. The subsequent sections discuss the hypotheses associated with the influence of the significant factors on consumer trust in m-payments (awareness (H1) and uncertainty avoidance (H3) respectively), whereas the insignificant factor were justified afterwards.

\subsubsection{Results of $\mathrm{H1}$ - The more the consumer awareness about mobile payments, the higher the trust in mobile payments $(\beta=0.435)$.}

Awareness of m-payments was hypothesised to have a significant influence on consumer trust in m-payments (see Chapter Three, Figure 3.1). The findings in Chapter Five (section 5.6.3.2) provided support for this relationship, in that the more the consumers' awareness about mpayments the higher the trust in m-payments. Consequently, those consumers who are aware of m-payment services and applications in the Emirates and who are knowledgeable about the nature and the way m-payments are conducted are more likely to have a better understanding and a clearer picture of m-payments and, consequently, higher levels of trust in m-payments. Given that consumers who are aware of m-payments may also have an understanding of the approaches employed by m-payment providers and the procedures of using m-payments services and applications; it appears plausible that they would consider trusting m-payments. Conversely, those consumers who have limited or no understanding of the provided m-payment applications and services, or who are unaware of the options, methods and processes of such applications and services, are less likely to trust in m-payments or use them. This suggests that those individuals with little or no knowledge about m-payments may be unfamiliar with these 
forms of payment and/or may be suspicious of them and, as a result, be less likely to trust in these.

This finding is in broad agreement with the qualitative results identified in this research (Chapter Three, section 3.4.8.1). The majority of the perceptions during the focus group sessions indicated that consumer awareness has a strong positive influence on trust in mpayments, expressing the strong relationship between awareness of m-payments and trusting it, and indicating that trusting m-payments mainly depends on how much consumers know about it, its characteristics, applications, and details about its processes. In addition, it was identified that several sources of knowledge (such as education, profession and media) could contribute to the consumer's knowledge about m-payments, describing people with no sufficient understanding of m-payment applications and services or who are unfamiliar with its methods and processes are less likely to trust in mobile payments.

This finding supports the view that there is a solid link between consumer awareness and consumer trust in m-payments. For instance, as discussed in Chapter Two (section 2.5.5.1), previous trust research found that awareness has a positive influence on consumer trust in $\mathrm{m}$ commerce (Alqatan et al., 2012; Piao et al., 2012; Yeh \& Li, 2009) or on consumer perceptions about m-payments (Kim et al., 2010). The results here provide further support for this view, namely, that consumers who are aware of m-payments will have higher trust levels with respect to m-payments than less aware consumers. As such, the findings (presented in Chapters Three and Five), build on existing research and indicate that consumer awareness significantly influences consumer trust within the context of m-commerce and, specifically, m-payments.

\subsubsection{Results of $\mathrm{H3}$ - The higher the consumer's uncertainty avoidance the lower the consumers trust in mobile payments $(\beta=-0.161)$.}

Consumer uncertainty avoidance was hypothesised to influence a consumer's trust in mpayments, as shown in the theoretical model delineated in Figure 3.1, Chapter Three. As demonstrated by the results (Chapter Five), this relationship was supported suggesting that consumer's uncertainty avoidance in m-payments exerted a significant negative influence on consumer trust in m-payments. This implies that those consumers with high uncertainty avoidance towards new technology and payments are less likely to trust in m-payments, and vice versa. The qualitative findings, as discussed in section (3.4.1.7), provided support for this hypothesis, implying that some of the perceptions indicated that consumers who have high levels of uncertainty avoidance towards new electronic payments are less likely to trust in m- 
payment services and applications. In addition, some of the focus group participants agreed that they know people in the Emirates who have some kind of resistance to change and are slow to trust and adopt new technology and in general. Those people prefer to stick to follow the traditional ways when conducting a monetary transaction, as they perceive mobile payments a new payment approach.

The findings presented in Chapter Three and Chapter Five address the recommendation suggested by few studies of empirically examining the direct influence of consumer uncertainty avoidance on trust in m-payments. For example, Min and Li (2009) found uncertainty avoidance to have significant moderating effect on the relationship between subjective norms and m-commerce adoption, such that this relationship was stronger for individuals with high uncertainty avoidance. The researchers suggested that individuals with high uncertainty avoidance look into their environment or their network members for cues to suggest whether m-commerce adoption is appropriate. In a similar approach, Sikolia et al. (2010) examined that role of uncertainty avoidance in trusting m-banking services in North America and Africa, and found it to have a significant influence on consumers trust. Therefore, the current research finding extends the existing m-commerce literature by providing a richer perspective on consumer's uncertainty avoidance as a key factor in influencing trust in m-payments.

A further factor of consumer characteristics; 'propensity to trust' was not found to have a significant influence on consumer trust in m-payments in the Emirates. It seems that this psychological dimension of trust (proposed by McKnight et al. (2001) and discussed in Chapter Two) was not important for the sampled consumers, maybe because those people tend to be more rational and more knowledge-based decision makers about trust in m-payments rather than depending on their personal traits and/or emotions to form their trust in m-payments.

\subsubsection{Environmental influences (Trust Environment).}

The trust environment factor was not found to have a significant influence on consumer trust in m-payments. The two items in this construct; trust in family and trust in society were not found effective when viewed across the sample. This may in fact be due to the multiple nationalities of the participants in the Emirates. The 'trust environment' factor would work better with a culturally homogenous population, for instance, by using a large sample drawn from a monocultural nationality (Connolly \& Bannister, 2007). Therefore, the current research does not provide evidence that consumer trust in the Emirates is trust-environment dependent. 


\subsubsection{Provider characteristics.}

Provider characteristics included three factors: provider's reputation, level of trust in provider's products and services, and provider's trustworthiness. By adding the items of 'reputation' construct to the construct 'trustworthiness' for statistical purposes, provider's trustworthiness was found to have significant influence on consumer trust in m-payments $(B=0.193)$. The factors 'level of trust in products and services' was tested and found with no significant influence on consumer trust. The subsequent sections discuss hypotheses associated with the factors of provider's trustworthiness on consumer trust in m-payments (H7), and afterwards, a justification for not supporting the hypotheses relating the insignificant factors is given.

\subsubsection{Results of H7 - The higher the provider's trustworthiness, the higher the consumers trust in mobile payments $(\beta=0.193)$.}

Provider's trustworthiness was hypothesised in Chapter Three (Figure 3.1) to have a significant positive influence on trust in m-payments. The quantitative results in Chapter Five provided support for this hypothesis suggesting that there is a strong positive significant relationship between provider's trustworthiness and trust in m-payments. Therefore, consumers who perceive their m-payment provider to be high trustworthy will be more likely to trust in the provided m-payments. Conversely, those consumers who tend to perceive their m-payment provider as low trustworthy may place less trust in m-payments.

Provider's trustworthiness included four repeatedly-cited attributes: honesty, competence, benevolent, and predictive, in addition to the dimension 'reputation' which was added in this research due to the high cross-loading results (as discussed in section 5.5.3.1). This psychological factor was statistically found to have a significant influence on consumer trust in m-payments. In consistence with this quantitative finding, provider's trustworthiness was also argued by many participants to have a powerful influence on trust in m-payments, by indicating that it is important to feel that the provider is honest in order to trust in its products and services, and that the provider should show full competency and high ability to perform its tasks efficiently. This finding is considered original as very scant studies, if any, have examined the relationship between the provider's trustworthiness and trust in m-payments. As discussed earlier in the literature review (section 2.6.5.3), provider's trustworthiness (also called 'trust beliefs in provider') has been mostly studied as a measurement of consumer trust itself (Chandra et al., 2010; Cho et al., 2007; Li \& Yeh, 2010; Meng et al., 2008; Piao et al., 2012; Susanto et al., 2012; Xin et al., 2013; Xu et al., 2005; Yeh \& Li, 2009). Therefore, this 
finding provides a richer perspective on provider's trustworthiness as a source for influencing consumer's trust within the m-payments context.

However, the finding of the reputation items is consistent with earlier findings in $\mathrm{m}$-commerce and m-payment trust literature, as discussed in section (2.5.5.3). For instance, Xin et al. (2013) empirically found that perceived reputation of m-payment vendors has strong significant effects on consumer trust in m-payments. This finding is in line with previous research in m-payments conducted by Chandra et al. (2010); namely that the perceptions on reputation of mobile service providers have significant relationships with consumer trust. Similarly, the reputation of a mobile service provider was found to have a significant influence on consumer initial trust and trust performance in m-payments ( $\mathrm{Li} \& \mathrm{Li}, 2008$ ). Moreover, Liu et al. (2009) reported a significant relationship between a mobile service provider's reputation and consumer trust in m-banking. Furthermore, Mogenahalli et al. (2008) found that the reputation of the mobile commerce vendor has a positive influence on consumers' predictability and integrity trust in mcommerce. This finding is in broad agreement with the qualitative results identified in this research (Chapter Three, section 3.4.8.3). A large majority of the perceptions on provider's reputation indicated that provider's reputation has a strong influence on trust in m-payments, expressing the robust relationship between reputation in the mobile service provider and consumer trust in its m-payment services, and indicating that trusting m-payments is mostly based on how consumers see the service provider. In addition, it was identified that if the general reputation of the provider is not good then consumers may not trust in its services, and thus a bad provider's reputation may result in an aversion to trusting this provider and its $\mathrm{m}$ payment services.

Overall, the current finding appears to add a substantial dimension in the m-payment literature, by showing the positive association between provider's trustworthiness and trust in mpayments in the m-payment context, and by confirming the significant influence of provider's reputation on trust in m-payments.

\subsubsection{Perceived risks.}

The group of perceived risks included two factors: security levels and privacy risks. However, another type of risks 'perceived technical risks' was included to this group as it was perceived by many participants in the focus group sessions as a factor of consumer trust in m-payments 
(as discussed in Chapter 3). However, the influence of this new factor 'perceived technical risks' on consumer trust was not tested during the preliminary quantitative testing due to low validity and reliability values, and the two other constructs (security levels and privacy risks) were found to have a significant influence on trust. The factor 'perceived security levels' was found with more influence on consumer trust than the 'perceived privacy risks' factor $(B=$ 0.147 and -0.125 respectively). The subsequent sections discuss the hypotheses associated with each factor on consumer trust in m-payments (H10 and $\mathrm{H} 9$ respectively).

\subsubsection{Results of H10 - The higher the perceived security levels in mobile} payments, the higher the consumer trust in mobile payments $(\beta=0.147)$.

Perceived security levels were hypothesised in Figure 3.1 (Chapter Three) to have a significant influence on trust in m-payments. The results in Chapter Five provided support for this hypothesis suggesting that perceived security levels significantly influence consumer trust in m-payments. This finding is consistent with the qualitative results found in this research (Chapter Three, section 3.4.8.4), as many participants showed concerns regarding the security risks which might be associated with m-payments. Indeed, the majority of the perceptions on security levels indicated its influence on their trust in m-payments, expressing the strong relationship between them, and indicating that trusting in m-payments is mostly based on securing these payments against safety breaches such as hacking and exploiting its vulnerabilities for stealing financial information. In addition, it was perceived that controlling unauthorised access and unmaintained data security are other security protections that may result in decreasing the perceived risks that could increase consumer trust in m-payment services.

The findings presented here are also very consistent with earlier findings in $\mathrm{m}$-commerce trust literature. For instance, Xin et al. (2013) empirically found perceived security risks to have strongly significant negative effects on consumer trust in m-payments. Similarly, Zhou (2011) and Chandra et al. (2010) found that perceived security risks have significant negative effects on initial trust in m-payments. These findings are in line with previous trust research in mcommerce by and Piao et al. (2012), confirming the strong negative relationship between perceived security risks and trust in m-commerce. Scnnnusanto et al. (2012) also found that security risks are significantly associated with trust in smartphone for m-banking transactions. Thus, the findings in the current research extend existing $\mathrm{m}$-commerce research by demonstrating and confirming that perceived security risks influence a consumer's trust within the context of m-payments. 


\subsubsection{Results of H9 - Perceived privacy risks negatively influence consumer trust in mobile payments $(\beta=\mathbf{- 0 . 1 2 5})$.}

Perceived privacy risks were hypothesised in Figure 3.1 (Chapter Three) to have a significant influence on trust in m-payments. The quantitative results in Chapter Five provided support for this hypothesis suggesting that there is a significant influence of perceived privacy risks on trust in m-payments. However, consumers in the Emirates seem to perceive privacy risks with a significant positive influence on their trust in m-payments. Although they perceive it to have a significant influence to their trust in m-payments, consumers may feel positively towards some privacy options that control vulnerable positions and private information and details. This finding is consistent with the qualitative results found in this research (Chapter Three, section 3.4.8.4), although not too many of the participants perceived privacy risks with influence on their trust in m-payments. Participants who agreed on this factor expressed their concerns about their activities and details to be tracked either by the provider of m-payments or by an external party. They also indicated that in some m-payments that require users to put the credit card details and/or the address details, the provider may be sharing their private information with other parties, which makes their financial details vulnerable to others.

The findings presented here are consistent with earlier findings in m-payment and m-commerce trust literature. For instance, Hollingsworth and Dembla (2013) found that accepting perceived privacy risks significantly influence on consumer trust in m-commerce. In addition, Piao et al. (2012) investigated the role of the privacy option available on the WAP website that controls the mobile transaction and found it to have a significant influence on consumer trust in $\mathrm{m}$ commerce. By combining perceived privacy risks with security risks in one construct, Amoroso and Magnier-Watanabe (2011) found that this construct is to have a significant negative influence on trusting and adopting m-wallets. Hillman et al. (2011) in their qualitative study also found that interviews' participants were associating some privacy risks and concerns with trust in m-commerce. From another perspective, device-based privacy enhancing features were found with impact on consumer trusting beliefs in mobile location-based services (Xu et al., 2005). Thus, the findings in the current research extend existing m-commerce research by demonstrating and confirming that perceived privacy risks influence a consumer's trust within the context of m-payments.

\subsubsection{Mobile-device characteristics.}

The group of mobile-device characteristics included three factors: capability, design suitability, and security. The design suitability of the mobile device was the only factor which found to 
have a significant influence on trust in m-payments $(\beta=0.138)$ among other device characteristics. The other two device characteristics; device capability and device security were not found having a significant influence on trust in the current research. The next sub section discusses the hypothesis associated with the influence of mobile-device design features on consumer trust in m-payments (H12). Afterwards, a justification of the findings of the insignificant factors was give.

\subsubsection{Results of H12 - The more suitable the design of the mobile-device to conduct an m-payment, the higher the consumers trust in mobile payments $(\beta=0.138)$.}

The factor 'device design suitability' was hypothesised in Figure 3.1 (Chapter Three) to have a significant influence on trust in m-payments. The results in Chapter Five (section 5.6.3.2) provided support for this hypothesis suggesting that the more suitable the design of the mobile device to conduct an m-payment, the higher the consumers trust in m-payments. This path was not very strong in the CTMP model, though, it indicates that the perceived design suitability concerning the mobile device was seen to significantly influence consumer trust in making mpayments.

This finding is consistent with earlier findings derived from the qualitative phase in Chapter Three (sections 3.4.8.5). Perceptions on the mobile-device design indicated that some design features can significantly influence trust in conducting payments through these devices, either in a positive or a negative way. For example, small sized screens and touch screens can result in entering incorrect numbers and amounts of money, or in transferring sums of money to someone else's account, which may decrease consumer trust in m-payments, whereas devices with suitable screen designs and comfortable keypads may increase consumer trust in mpayments. This situation is not surprising given that, as discussed in the literature in Chapter Two (section 2.5.5.5), some design-related issues such as tiny multifunction keypads, small interfaces, low-resolution displays and ineffective navigation options are major challenges with respect to m-commerce trust (Mogenahalli et al., 2008; Zhou, 2011). In addition, Min et al. (2008) empirically found that the user interface of the mobile device, ease of input and navigation, and readability of the display can affect general trust attitudes surrounding mcommerce. These design limitations could be more challenging especially in this research where most participants who felt happiest with m-payments were older, and older people suffer from eyesight problems. 
Overall, the findings of the current research enrich the m-commerce literature, as scant studies have examined the relationship between the design features associated with mobile devices and trust in m-payments, by providing a richer perspective on the device-design features as a source for influencing consumer's trust within the m-commerce context and, specifically m-payments.

Regarding the other two factors relating to the mobile device characteristics; mobile-device capability and mobile-device security were found with no significant influence on consumer trust in m-payments. A plausible explanation for this finding is that the built-in functions and features embedded in current mobile device are something not to concern about nowadays, especially that many mobile device (including smartphones) integrate multifunction of a mobile device with an advanced communication and computing-enabled features abilities (Susanto et al., 2012), and are relatively secured by encryption software (Xin et al., 2013). This result is also consistent with the qualitative data findings in Chapter Three which showed that mobiledevice capability and security were perceived with influence in trust by only few participants.

\subsection{Research Findings Summary}

The current results confirm the examined CTMP model (in Figure 6.3) to be a valid representation of factors of consumer trust in m-payments. Firstly, the qualitative results confirm the preliminary CTMP model proposed by reviewing the trust literature (Figure 2.5), which included 14 factors in five groups: Consumer characteristics (consumer awareness, propensity to trust, uncertainty avoidance), environmental influences (trust environment), provider's characteristics (reputation and provider's trustworthiness), perceived risks (security levels, privacy risks), and mobile-device characteristics (capability, design suitability, and security). In addition, two new factors emerged during the qualitative analysis phase (in Chapter 3); 'trust level in provider's products and services' and 'perceived technical risks', resulting in a qualitatively validated factorial model, associated with 14 hypotheses presented for further analysis. Afterwards, the CTMP model was quantitatively tested and validated by using a more representative sample of people in the Emirates. The quantitative findings revealed seven supporting hypotheses, associated with the factors: consumer awareness, consumer's uncertainty avoidance, provider's trustworthiness, perceived security levels, perceived privacy risks, and mobile-device design suitability. The quantitative findings also revealed five non-supporting hypotheses due to their insignificance, associated with the factors (consumer propensity to trust, trust environment, trust levels in provider's products and services, mobile-device capability, and mobile-device security), and one not tested hypotheses 
that were associated with the factors: perceived technical risks, as it failed to be included in the structural/inner CTMP model test due to low reliability and validity measures.

The results of the current research contribute significantly to knowledge concerning the factors that influence consumer trust in m-payments. For instance, the current findings provide richer perspective on consumer's uncertainty avoidance as a newly discovered factor of trust in mpayments, and extend our understanding of the influence of this factor, as its studies, though scant, has been with regard to m-commerce adoption. The factor mobile-device design suitability is a further example, and it is believed that previous research has not empirically examined the influence of this factor on consumer trust in m-payments. In addition, the current results indicate a strong influence in the perceived relationship between perceived security levels and privacy risks and trust in m-payments, and thus provide a richer perspective on these factors with regard to consumer trust. The type of contribution for each factor with regards to the literature is shown in the following table (Table 6.2).

Table 6.2 Research results contribution to literature

\begin{tabular}{|c|c|c|c|}
\hline & Factor & Literature & Contribution \\
\hline \multirow{2}{*}{$\begin{array}{l}\text { Consumer } \\
\text { Characteristics }\end{array}$} & Awareness & $\begin{array}{l}\text { Scant research in m-payments } \\
\text { which that had studied this } \\
\text { construct (Kim et al., 2010), } \\
\text { whereas it was found in many } \\
\text { research in the m-commerce and e- } \\
\text { commerce literature. }\end{array}$ & $\begin{array}{l}\text { Provides confirmation to } \\
\text { m-payment literature, and } \\
\text { provides richer perspective } \\
\text { in m-payments }\end{array}$ \\
\hline & $\begin{array}{l}\text { Uncertainty } \\
\text { avoidance }\end{array}$ & $\begin{array}{l}\text { This construct has not been studied } \\
\text { yet in the context of m-payments, } \\
\text { and was found investigated very } \\
\text { few in m-commerce (Min and Li, } \\
\text { 2009) and mobile banking (Sikolia } \\
\text { et al., 2010) }\end{array}$ & $\begin{array}{l}\text { Original to m-payments } \\
\text { literature }\end{array}$ \\
\hline $\begin{array}{l}\text { Provider } \\
\text { Characteristics }\end{array}$ & $\begin{array}{l}\text { Provider's } \\
\text { trustworthiness }\end{array}$ & $\begin{array}{l}\text { This construct has not been studied } \\
\text { yet in the context of m-payments } \\
\text { as an independent factor that } \\
\text { influence trust, as it has been } \\
\text { mostly studied as a measurement } \\
\text { of consumer trust }\end{array}$ & $\begin{array}{l}\text { Original to m-payments } \\
\text { literature }\end{array}$ \\
\hline $\begin{array}{l}\text { Perceived } \\
\text { Risks }\end{array}$ & $\begin{array}{l}\text { Perceived security } \\
\text { levels }\end{array}$ & $\begin{array}{l}\text { Scant research in m-payments } \\
\text { which that had studied this } \\
\text { construct (Chandra et al., 2010; Hu } \\
\text { et al., 2008; Zhou, 2011). }\end{array}$ & $\begin{array}{l}\text { Provides confirmation to } \\
\text { m-payment literature, and } \\
\text { This finding confirms that } \\
\text { perceived security risks } \\
\text { influence a consumer's } \\
\text { trust within the context of } \\
\text { m-payments, and provides } \\
\text { richer perspective. }\end{array}$ \\
\hline
\end{tabular}




\begin{tabular}{|c|c|c|c|}
\hline & Factor & Literature & Contribution \\
\hline & $\begin{array}{l}\text { Perceived privacy } \\
\text { risks }\end{array}$ & $\begin{array}{l}\text { Scant research in m-payments } \\
\text { which that had studied this } \\
\text { construct (Amoroso and Magnier- } \\
\text { Watanabe, 2011), whereas it exists } \\
\text { widely in the m-commerce } \\
\text { literature (Au and Kauffman, } \\
\text { 2008; Chandra et al., 2010; } \\
\text { Hillman et al., 2011; } \\
\text { Hollingsworth and Dembla, 2013). }\end{array}$ & $\begin{array}{l}\text { This finding provides } \\
\text { confirmation to m- } \\
\text { payment literature, and } \\
\text { affords richer perspective } \\
\text { in m-payments. }\end{array}$ \\
\hline $\begin{array}{l}\text { Mobile-Device } \\
\text { Characteristics }\end{array}$ & $\begin{array}{l}\text { Device design } \\
\text { Suitability }\end{array}$ & $\begin{array}{l}\text { This construct has not been studied } \\
\text { yet in the context of m-payments, } \\
\text { and it has been indicated in very } \\
\text { few m-commerce studies } \\
\text { (Mogenahalli et al., 2008; Min et } \\
\text { al., 2008; Zhou, 2011). }\end{array}$ & $\begin{array}{l}\text { Original to m-payments } \\
\text { literature }\end{array}$ \\
\hline
\end{tabular}

Therefore, the current research findings fill an identified gap in the extant m-payment literature. Additionally, the current research findings make a regional contribution to knowledge (discussed in a separate section, subsequent chapter) as it is believed that the factors of consumer trust in m-payments have not yet been studied in the Emirates specifically, and in the Middle Eastern Arab countries generally. 


\section{CHAPTER SEVEN \\ Research Conclusion and Implications}

\subsection{Chapter Overview}

This chapter concludes the major findings of the perceived factors that influence consumer trust revealed in both the qualitative phase (focus group interviews in Chapter Three) and the quantitative phase (survey findings in Chapter Five) along with the existing literature (Chapter Two) reviewed in the current research. In addition, the significance of the research results with regard to the Emirates and the Middle East and Arab region is discussed. The research theoretical and practitioner implications are also presented here, along with the research limitations and direction for future research.

\subsection{Research Conclusion}

The literature shows that there is lack of, or low, trust in m-payments, and that we do not clearly understand trust and what influence it from consumers' perspective. The current study sought firstly to present the conceptual Model of Consumer Trust in Mobile Payments (CTMP) by incorporating variables synthesised from the m-commerce, e-commerce and consumer trust literature, and exploratory analysis. Secondly, this study empirically validated the model from the consumer's perspective. The result was the development and empirical validation of the CTMP model.

This empirical validation of the research model has established that the CTMP model provides the first comprehensive m-payments trust theory. The research findings presented in the CTMP model included five categories of factors, as mentioned below. The factors underlined were found to have a significant influence on consumer trust in m-payments in the Emirates.

- Consumer characteristics ( $\underline{\text { awareness}}, \underline{\text { uncertainty avoidance, }}$ propensity to trust)

- Provider characteristics (provider's trustworthiness, Trust level in provider's products and services)

- Mobile-device characteristics (design suitability, capability, security)

- Perceived risks (security risks,

As mentioned in Chapter 5, the factors within each group had differing extents of influence on consumer trust in m-payments. In descending order, they are as follows: consumer awareness; provider's trustworthiness; consumer's uncertainty avoidance; perceived security levels; 
mobile-device design suitability; and perceived privacy risks. The factor which found to have the dominant positive influence on consumer trust is consumer awareness, followed by provider's trustworthiness, perceived security level, and devices-design suitability. On the other hand, two valid factors were found to have a negative influence on consumer trust: uncertainty avoidance (with the greatest extent of influence), and perceived privacy risks. The dominant consumer-related factor was consumer awareness, while provider's trustworthiness was considered the most influential characteristic with regard to the provider. As for the perceived risks, security levels had the strongest effect, whereas the factor 'mobile-device design suitability' was found to have the greatest influence amongst all device characteristics. Environmental influences, i.e. the trust environment, was not found to have a significant influence on consumer trust in m-payments in the Emirates. As discussed previously in Chapter 6 , the 'trust environment' factor would work better with a culturally homogenous population, for instance, by using a large sample drawn from a mono-cultural nationality (Connolly \& Bannister, 2007). Whereas the Emirates is multicultural society and includes non-homogenous population, the current research does not provide evidence that consumer trust in the Emirates is trust-environment dependent.

\subsection{Significance of the Research Results}

Consumer awareness, which means familiarisation of consumers with m-payment services, applications, procedures and methods, was found to be the most influential with regard to trust in m-payments. Consumer trust in m-payments is difficult to establish without having a sufficient level of awareness to recognise the different m-payments services and applications available in the Emirates, their associated technologies (credit card, pre-paid credit, m-wallet, etc.) and how these payments work by using their mobile devices. This kind of knowledge has the potential to make m-payments more recognisable and familiar to a large segment of the population, especially those with no technological background, and make trust and acceptance in this regard common place. In addition, uncertainty avoidance was found to have a negative impact on consumer trust in the Emirates. Although this factor was not found to have been tested previously in the context of m-payments, this result was not surprising since the Middle East and Arab culture scores high in uncertainty avoidance in general. As discussed in Chapter 6 (Section 6.4.1.2), consumer uncertainty avoidance could generate resistance to change towards m-payments, and decrease trust levels to adopt them in the Emirates. 
The second largest influence on consumer trust in m-payments is the trustworthiness of the mpayments provider, i.e. how consumers perceive them and their standing. As mentioned earlier in Section (2.3.6), m-payment providers in the Emirates are primarily the two telecom operators Etisalat and Du. Provider's trustworthiness can directly influence consumers' trust in mpayment services, especially where there is no prior personal experience of them. This result emphasises the significant role of the provider in influencing consumer trust in m-payments in the Emirates.

The perception of both security levels and privacy risks were shown to have the potential to significantly impact the development of consumer trust in mobile payments. The findings revealed that perceived security levels have a stronger impact on consumer trust in m-payments than perceived privacy risks. This is because consumers have greater concerns about software and hardware security levels in the form of the protection against hacking, malware, and viruses which may lead to loss of payment, than their concerns about the disclosure of private data (personal, financial, or commercial).

The design suitability of the mobile devices was also found to influence consumers' trust in mpayments in the Emirates. In specific, the appropriateness of design characteristics to conduct an m-payment, such as the device size, the resolution of the screen, and the layout of the keypad (normal or touch) could impact consumer trust, as m-payment transactions begin with the mobile device itself.

Importantly, in the absence of previous scholarly research, the CTMP model provides for better understanding of which factors build consumers trust in the region and to what extent they contribute. Furthermore, given that the population in the Emirates includes a rich tapestry of Middle Eastern and Arab peoples (as discussed in Section 5.3), the results found in the current research could well be generalised to Middle Eastern Arab countries in future research.

\subsection{Research Implications}

The current research highlights the need for a critical examination of the factors of consumer trust in m-payments, in order to apply creative approaches and strategies within the dynamic field of m-commerce. Several aspects have theoretical and practical implications. 


\subsubsection{Theoretical implications.}

From a theoretical perspective, the study provides new information on the influence of consumer-related factors on trust in m-payments. It has established a proven theory, the CTMP model, in both the m-payments and consumer trust research fields.

The CTMP model, which was based on the revised conceptual model developed in Figure 3.1 (Chapter Three), provides researchers with an overall theoretical model from which to examine trust in m-payments from a consumer perspective. More specifically, the model moves beyond the current m-payment trust models as it incorporates the determinants related to electronic payments, online and offline m-payments models and consumer trust research

The CTMP model also provides a rich and insightful perspective by investigating consumer trust towards several types of m-payments. Overall, this research presents a wider and more holistic view of the factors that influence consumer trust by extending from online m-payments to offline m-payments and other types that exist in the Emirates.

In addition, the study extends existing theory via the empirical exploration and validation of the new factors during the qualitative phase (trust level in provider's products and services, perceived technical risks) and during the quantitative phase (device design suitability, device capability and device security) in the context of m-payments. To the researcher's knowledge, the investigation of these factors had not been empirically examined in the m-payment trust literature.

Moreover, the study makes a strong contribution to the current m-payment literature by incorporating mobile-device characteristics in the CTMP model. As shown by the current findings, the mobile-device characteristics (particularly design suitability) were found to be a significant indicator of consumer trust in m-payments, especially in the qualitative findings.

This research has developed a validated and reliable survey questionnaire instrument, to measure perceived consumer trust in m-payments. The survey questionnaire was validated using expert panels, card sorting technique, and a series of pilot tests. Therefore, the instrument developed in this research could make a contribution to theoretical research within the field of m-payments. 
In summary, the current findings have advanced our understanding of consumer trust in mpayments. The empirical testing provided validation of one theory (the CTMP model) from the consumer's standpoint, within the context of m-payments, which appears not to have been attempted previously in the Middle East region and Arab countries. As such, the current research integrates both earlier m-payment research associated with consumer trust aspects as well as the findings of the qualitative phase, which examined the determinants and factors of consumer trust in m-payments. In doing so, the CTMP model provides a valuable theoretical example for m-payment effectiveness models (from a consumer trust perspective) by highlighting the factors that influence consumer trust in m-payments and the power effect and direction of these factors on trust in m-payments. For this reason, the proposed model offers a broad and comprehensive perspective on what influences consumer trust in m-payments in the Emirates, and in Arab countries in general. Accordingly, the current research has advanced our knowledge within the m-payments and consumer trust domains, as well as contributing to the acceptance and use of m-payments in practice, as discussed in the subsequent section.

\subsubsection{Practical implications.}

The findings highlight the need for practitioners to understand that consumer trust in mpayments represents a critical aspect of consumers' responses to such payments, which could impact their acceptance and usage of associated systems (as discussed in Chapter 2, section 2.6.1). The findings suggest that particular consumer-related factors (awareness, propensity to trust and uncertainty avoidance) along with provider-related factors (trustworthiness and reputation), perceived risks (security levels and privacy concerns) and a mobile-device-related factor (design suitability) in turn significantly impact consumers' trust in m-payments.

As identified by the study's findings, consumers' awareness plays the dominant role in their trust in m-payments. Therefore, m-payment providers, mobile operators and involved financial institutions should educate the consumers, increase their awareness about these services and how to use them in order clear consumers' trust barriers.

The CTMP model also emphasises mobile-device design features. Trusting the mobile device is important for conducting a payment by using it. However, to ensure that consumers trust their mobile devices for payments, it is suggested that mobile firms and technology providers need to consider the layout design of the mobile device, such as screen size, keypad layout, and the built- in options when manufacturing the devices in order for these to function in a compatible and appropriate manner with respect to payments. 
Accordingly, the current study provides practitioners with insights into consumers and the factors that influence their trust in m-payments in order to accept and use them.

\subsection{Research Limitations}

As with all research, it is important to acknowledge the limitations of the study. Any research applying the survey-based method is prone to the inherent limitation of measurement errors (Bryman \& Bell, 2007). Specifically, the limitation concerns the type of questionnaire used in this research. Recording the opinions, observations and perceptions of a subset of the Emirates population at a defined time means that the causality of consumer trust in m-payments in the Emirates can only be inferred, but cannot be proven (Yee \& Niemeier, 1996). As a consequence, this limits the statistical capability to estimate a greater range of conditional probabilities of consumer trust in m-payments in the Emirates. Nevertheless, the measurement errors were minimised, as indicated by the study's good validity and reliability results reported (Chapter Five), and a future study could be conducted in a longitudinal fashion, which would make possible stronger causal conclusions.

Another limitation relates to the language. Most of the focus groups were conducted in Arabic, and then translated into English for the data analysis. There might be shortcomings in translating the data transcriptions. The questionnaire was firstly developed in English and then translated into Arabic. Action was taken to deal with this limitation, as discussed in section (3.4.4) and section (4.3.1.3) respectively.

The limitations discussed here are identified for the purpose of acknowledging their existence, and to pinpoint and inform future research opportunities, rather than to reduce the significance of the study's findings or the validity and reliability of the methods used.

This research has been also limited to exploring the factors that influence consumer trust in mpayments in the principal cities of four of the seven emirates (Dubai, Abu Dhabi, Al-Ain and Sharjah). The Emirates is home to numerous international technology industries and financial organisations, making it an appropriate location to carry out this research. Abu Dhabi is the capital city, the largest in area, and the country's centre of political and cultural activities. Dubai is the commercial city, the largest in population and the second largest in area. Al-Ain is the second largest city in 'the Abu Dhabi Emirate', and the fourth largest city in the Emirates 
(Geohive, 2009), as well as Sharjah which is considered the third largest Emirate. These cities form a triangle that could be considered the heart of the Emirates.

\subsection{Future Research}

The limitations noted above provide a basis for future research strategies. As the data collection process was focused on the Emirates as an Arab country in the Middle East, it would sound logical to extend the study in the first instance to consumers in non-Arab countries in the Middle East, such as Israel and Turkey. Further afield, the CTMP model of this study could be tested in other countries in Europe, America and Australasia, and in other developing countries in which m-payments have been recently adopted in the MENA (Middle East and North Africa) region. As a result, this would allow researchers to examine whether the findings hold true in other regions, and thus provide greater support for the generalisability of the findings of the study. Given that the replication of this study is possible since the instrument demonstrates validity and reliability, which would foster its usability not only for understanding consumer trust in m-payments in different countries, but also for comparing consumer trust in different countries through cross-cultural studies, or measuring consumer trust in one or more specific m-payment services provided by telecommunication operator(s) within a specific country.

The current study used a cross-sectional survey to examine the CTMP model. Future research could fruitfully replicate and validate the findings with other research designs, which would also allow for the examination of the causal relationship among the factors influencing trust in the CTMP model.

As this research focused on general m-payment services, future research may be needed to extend our investigation using specific types of m-payment (online, offline, SMS-based payments, hardware-based payments, credit card-based payments, and others). Such investigation would assist in validating the findings to certain types of m-payment. However, the choice of general m-payment services was justified in the current study, as discussed in Chapter Two, as this study targets the general trust perceptions of the consumers in the Emirates, without specifying certain types or forms of m-payment.

\subsection{Chapter Summary}

In summary, this research provides a clearer understanding of consumer trust in m-payments by identifying the factors that influence consumer trust in the Emirates. A new constellation of 
factor influences, the CTMP model, was constructed from factors that influence trust in mpayments classified into logical groups. This allows a more comprehensive view of the factor structure at work in m-payments trust.

In addition, this research had some practical implications associated with m-payments practitioners including the m-payments providers (telecommunication companies), media parties (such as advertisers), as well as mobile-device manufactures. Some research limitations associated with the research instrument, language issues and geographical considerations were addressed in the current research and can now form a methodological framework for future research in addition to the proposed future research focus of refining the CTMP model in other contexts and regions. 


\section{References}

Abu Bakar, F., \& Osman, S. (2005). Towards the future of mobile commerce (m-commerce) in Malaysia. Paper presented at the Proceedings of IADIS: IADIS International Conference, Web based Communities, Algarve, Portugal.

Ahmed, S., \& More, A. V. (2011). Mobile commerce: gate way to successful business. Indian Journal of Commerce \& Management Studies, 2(3), 109-115.

Alhosni, N. A., Ali, S., \& Ashrafi, R. (2010). The key success factors to mobile commerce for Arab countries in Middle East. Paper presented at the Proceedings of the 12th International Conference on Information Integration and Web-based Applications \& Services, Paris, France.

Alsultanny, Y. (2012). Opportunities and challenges of m-commerce in Bahrain. Journal of Database Marketing \& Customer Strategy Management, 19(1), 31-38. doi: 10.1057/dbm.2012.2

Alqatan, S., Singh, D., \& Kamsuriah, A. (2012). Study on success factors to enhance customer trust for mobile commerce in small and medium-sized tourism enterprises (SMTEs) -- A conceptual model. Journal of Theoretical \& Applied Information Technology, 46(2), 550.

Al-Mamari, M. (2007). Mobile commerce development in Oman. Unpublished master's thesis, The University of Sheffield. Available from http://dagda.shef.ac.uk/dissertations/200607/External/Al-Mamari_Mohammed_MScIS.pdf

Amoroso, D. L., \& Magnier-Watanabe, R. (2012). Building a research model for mobile wallet consumer adoption: the case of mobile Suica in Japan. Journal of Theoretical and Applied Electronic Commerce Research, 7(1), 94-110. doi: 10.4067/s0718-18762012000100008

Andam, Z. R. (2003). E-commerce and e-business. EPrimer for the Information Economy, Society and Polity Series UNDP Asia-Pacific Development Information Programme (UNDP-APDIP). Available at http://en.wikibooks.org/wiki/ECommerce_and_E-Business

Andreou, A. S., Chrysostomou, C., Leonidou, C., Mavromoustakos, S., Pitsillides, A., Samaras, G., \& Schizas, C. (2002). Mobile commerce applications and services: a design and development approach. I the Proceedings of the First International Conference on Mobile Business, Athens.

Araujo, I., \& Araujo, I. (2003). Developing trust in Internet commerce. Paper presented at the Proceedings of the 2003 conference of the Centre for Advanced Studies on Collaborative research, Toronto, Ontario, Canada.

Ary, D., Jacobs, L., Razavieh, A., \& Sorensen, C. (2009). Introduction to Research in Education: Cengage Learning.

Asif, S. Z. (2010). Next generation mobile communications ecosystem: technology management for mobile communications: Wiley.

Au, Y. A., \& Kauffman, R. J. (2008). The economics of mobile payments: Understanding stakeholder issues for an emerging financial technology application. Electronic Commerce Research and Applications, 7(2), 141-164. doi: http://dx.doi.org/10.1016/j.elerap.2006.12.004

Austrade (Australian Trade Commission). (2010). "E-business versus e-commerce". Austrade (Australian Trade Commission), from http://www.austrade.gov.au/ebusiness-vsecommerce/default.aspx/.

Awad, N. F., \& Ragowsky, A. (2008). Establishing trust in electronic commerce through online word of mouth: an examination across genders. Journal of Management Information Systems, 24(4), 101-121. doi: 10.2753/mis0742-1222240404.

Ayass, T. (2008). Investigation of the antecedents of an e-commerce trust model: University of Phoenix.

Ba, S., Whinston, A., \& Zhang, H. (1998). The design of a trusted third party for electronic commerce transactions. Paper presented at the AMCIS 1998 Proceedings.

Bagozzi, R. P., \& Yi, Y. (1991). Multitrait-Multimethod Matrices in Consumer Research. Journal of Consumer Research, 17(4), 426-439. doi: 10.2307/2626837.

Balasubramanian, S., Peterson, R., \& Jarvenpaa, S. (2002). Exploring the implications of m-commerce for markets and marketing. Journal of the Academy of Marketing Science, 30(4), 348-361. doi: $10.1177 / 009207002236910$. 
Barakat, S., \& Sheikh, A. E. (2010). Trust and user acceptance of mobile advertising. Paper presented at the European, Mediterranean \& Middle Eastern Conference on Information Systems, Abu Dhabi, UAE.

Barclay, D., Higgins, C., \& Thompson, R. (1995). The Partial Least Squares (PLS) approach to causal modeling: personal computer adoption and use as an illustration. Technology studies, 2(2), 285309. doi: citeulike-article-id:5760069.

Barnes, S. J. (2002). The mobile commerce value chain: analysis and future developments. International Journal of Information Management, 22(2), 91-108. doi: http://dx.doi.org/10.1016/S02684012(01)00047-0.

Barnes, S. J., \& Huff, S. L. (2003). Rising sun: iMode and the wireless Internet. Communications of the ACM, 46(11), 78-84. doi: 10.1145/948383.948384.

Belanger, F., Hiller, J. S., \& Smith, W. J. (2002). Trustworthiness in electronic commerce: the role of privacy, security, and site attributes. The Journal of Strategic Information Systems, 11(3-4), 245-270. doi: http://dx.doi.org/10.1016/S0963-8687(02)00018-5.

Bell, H., \& Tang, N. K. H. (1998). The effectiveness of commercial Internet Web sites: a user's perspective. Internet Research, 8(3).

Benamati, J., Serva, M. A., \& Fuller, M. A. (2006). Are trust and distrust distinct constructs? an empirical study of the effects of trust and distrust among online banking users. Paper presented at the HICSS '06. In proceedings of the 39th Annual Hawaii International Conference on System Sciences, Hawaii, US.

Benbasat, I., Gefen, D., \& Pavlou, P. (2008). Special issue: trust in online environments. Journal of Management Information Systems, 24(4), 5-11. doi: 10.2753/mis0742-1222240400.

Bhattacherjee, A. (2002). Individual trust in online firms: scale development and initial test. Journal of Management Information Systems, 19(1), 211-241.

Bhatti, T. (2007). "Exploring factors influencing the adoption of mobile commerce." Journal of Internet Banking \& Commerce, 12(3), 1-9.

Biemans, W. G. (2003). A picture paints a thousand numbers: a critical look at b2b product development research. Journal of Business \& Industrial Marketing, 18(6), 514-528. doi: $10.1108 / 08858620310492392$

Blumer, H. (1962). Society as Symbolic Interaction. In A. M. Rose (Ed.), Human behavior and social process: an interactionist approach: Houghton-Mifflin.

Boon, S., \& Holmes, J. (1991). The dynamics of interpersonal trust: Resolving uncertainty in the face of risk. Cooperation and prosocial behaviour, 190-211. doi: citeulike-article-id:6338042.

Borchers, A. (2001). Trust in Internet shopping: A test of a measurement instrument, Proceedings of the 7th Americas Conference on Information Systems, Boston, pp. 799-803.

Boudreau, M.-C., Ariyachandra, T., Gefen, D., \& Straub, D. W. (2004). Validating IS positivist instrumentation: 1997-2001 The Handbook of Information Systems Research (pp. 15-26): IGI Global.

Bryman, A. (2008). Social research methods: Oxford University Press.

Bryman, A., \& Bell, E. (2007). Business research methods: Oxford University Press.

Buckler, F., \& Buxel, H. (1999). Mobile commerce report. (pp. 7): Durlacher Research Ltd. From http://www.profitstation.de/metafacts/presse/M-Commerce.htm.

Buhan, D., Cheong, Y. C., \& Tan, C.-L. (2002). Mobile payments in m-commerce: Telecom Media Networks. From http://www.cgey.com/tmn/pdf/MobilePaymentsinMCcommerce.pdf

Carat, G. (2002). EPayment systems database: trends and analysis electronic payment systems observatory (ePSO). Seville, Spain: Institute for Prospective Technological Studies. Fromhttp://ftp.jrc.es/EURdoc/eur20264en.pdf

Carr, M. (2008). Mobile payment systems and services: An Introduction: IDRBT.

Cavana, R. Y. (2000). Applied business research: qualitative and quantitative methods. Australia edition. John Wiley: Milton, Qld.

Cavaye, A. L. M. (1996). Case study research: a multi-faceted research approach for IS. Information Systems Journal, 6(3), 227-242. doi: 10.1111/j.1365-2575.1996.tb00015.x.

Central Intelligence Agency (2013). The world factbook, Middle East, United Arab Emirates, https://www.cia.gov/library/publications/the-world-factbook/geos/ae.html. 
Chan, E. S. K., \& Swatman, P. M. C. (2000). Electronic commerce careers: a preliminary survey of the online marketplace. Paper presented at the 13th International Bled Electronic Commerce Conference, Bled, Slovenia.

Chandra, S., Srivastava, S., \& Theng, Y. (2010). Evaluating the role of trust in consumer adoption of mobile payment systems: an empirical analysis. Communications of the Association for Information Systems, 27(1).

Chang, S.-J., Witteloostuijn, A. v., \& Eden, L. (2010). From the editors: common method variance in international business research. Journal of International Business Studies, 41(2), 178-184. doi: 10.1057/jibs.2009.88.

Chellappa, R. K. (2001). Consumers' Trust in Electronic Commerce Transactions: The Role of Perceived Privacy and Perceived Security. Master, Emory University Atlanta, the U.S. (GA 30322-2710).

Chellappa, R. K., \& Pavlou, P. A. (2002). Perceived information security, financial liability and consumer trust in electronic commerce transactions. Logistics Information Management, 15(5/6), 358-368. doi: 10.1108/09576050210447046

Chen, S., \& Dhillon, G. (2003). Interpreting dimensions of consumer trust in e-commerce. information technology and management, 4(2-3), 303-318. doi: 10.1023/a:1022962631249

Chen, Y.-H., \& Barnes, S. (2007). Initial trust and online buyer behaviour. Industrial Management \& Data Systems, 107(1).

Cheon Hong, M. (2008). The Study on the security services in mobile payment systems. Third International Conference on the Convergence and Hybrid Information Technology, 2008. ICCIT '08, Busan, South Korea.

Cheung, C., \& Lee, M. (2000). Trust in Internet shopping: a proposed model and measurement instrument. Paper presented at the Proceedings of the 2000 America's Conference on Information Systems (AMCIS), Paper 406.

Chin, W. W. (1998). The partial least squares approach for structural equation modeling Modern methods for business research (pp. 295-336). Mahwah, NJ, US: Lawrence Erlbaum Associates Publishers.

Chin, W. W., Marcolin, B. L., \& Newsted, P. R. (1996). A partial least squares latent variable modeling approach for measuring interaction effects: results from a Monte Carlo simulation study and an electronic-mail emotion/adoption study. Information Systems Research, 14(2), 29. doi: 10.1287/isre.14.2.189.16018.

Chiravuri, A., \& Nazareth, D. (2001). Consumer trust in electronic commerce: an alternative framework using technology acceptance. Paper presented at the Seventh Americas Conference on Information Systems, Boston, USA.

Cho, D.Y., Kwon, H.J. and Lee, H.Y. (2007), Analysis of trust in internet and mobile commerce adoption, Proceedings of the 40th Hawaii International Conference on System Science, Hawaii, USA.

Chua, W. F. (1986). Radical developments in accounting thought. The Accounting Review, 61(4), 601632. doi: $10.2307 / 247360$.

Churchill, G. A., \& Iacobucci, D. (2009). Marketing research: methodological foundations: Cengage Learning.

Clarke, R. (2008). A risk assessment framework for mobile payments. Bled eCommerce Conference, University of Maribor, Slovenia, pp. 63-77.

Cody-Allen, E., \& Kishore, R. (2006). An extension of the UTAUT model with e-quality, trust, and satisfaction constructs. Paper presented at the Proceedings of the 2006 ACM SIGMIS CPR conference on computer personnel research: Forty four years of computer personnel research: achievements, challenges the future, Claremont, California, USA.

Cohen, J. (1988). Statistical Power Analysis for the Behavioral Sciences: L. Erlbaum Associates.

Colquitt, J., Scott, B., \& LePine, J. (2007). Trust, trustworthiness, and trust propensity: A meta-analytic test of their unique relationships with risk taking and job performance. Journal of Applied Psychology, 92(4), 909-927. doi: citeulike-article-id:9094003.

Coltman, T., Devinney, T. M., Midgley, D. F., \& Venaik, S. (2008). Formative versus reflective measurement models: Two applications of formative measurement. Journal of Business Research, 61(12), 1250-1262. doi: http://dx.doi.org/10.1016/j.jbusres.2008.01.013. 
Connolly, R., \& Bannister, F. (2007). Consumer trust in electronic commerce: social \& technical antecedents. International Journal of Social Sciences, 2(4), 221. doi: 31672014.

Conway, J. M., \& Huffcutt, A. I. (2003). A review and evaluation of exploratory factor analysis practice in organizational research. Organizational Research Methods, 6(2).

Cook, A., \& Goette, T. (2006). Mobile electronic commerce: what is it? Who uses it? And why use it? Communications of the IIMA, 6(4), 49-58.

Cook, J.D., Hepworth, S.J., Wall, T.D. \& Warr, P.B. (1981). Experience of work: A compendium and review of 249 measures and their use. New York: Academic Press.

Cooper, D. R., \& Schindler, P. S. (2006). Business Research Methods: McGraw-Hill Irwin.

Corbitt, B. J., Thanasankit, T., \& Yi, H. (2003). Trust and e-commerce: a study of consumer perceptions. Electronic Commerce Research and Applications, 2(3), 203-215. doi: http://dx.doi.org/10.1016/S1567-4223(03)00024-3.

Costello, A., \& Osborne, J. (2005). Best practices in exploratory factor analysis: Four recommendations for getting the most from your analysis. Practical Assessment, Research \& Evaluation, 10, 173178. doi: citeulike-article-id:7599621.

Creative research systems - Research Aids: Sample Size Calculator. from http://www.surveysystem.com/sscalc.htm.

Creswell, J. W. (2009). Research design: qualitative, quantitative, and mixed methods approaches: SAGE Publications.

Creswell, J. W., \& Clark, V. L. P. (2011). designing and conducting mixed methods research: SAGE Publications.

Creswell, J. W., \& Miller, D. L. (2000). Determining Validity in Qualitative Inquiry. Theory into Practice, 39(3), 124-130. doi: 10.2307/1477543

Cronin, M. J. (2004). Mobile commerce. The Internet encyclopedia: John Wiley \& Sons, Inc.

Crotty, M. (1998). The Foundations of Social Research: Meaning and Perspective in the Research Process: SAGE Publications.

Cyr, D. (2008). Modeling web site design across cultures: relationships to trust, satisfaction, and eloyalty. Journal of Management Information Systems, 24(4), 47-72. doi: 10.2753/mis07421222240402.

Dahlberg, T., Mallat, N., Ondrus, J., \& Zmijewska, A. (2008). Past, present and future of mobile payments research: A literature review. Electronic Commerce Research and Applications, 7(2), 165-181. doi: http://dx.doi.org/10.1016/j.elerap.2007.02.001.

Dai, H., \& Palvi, P. C. (2009). Mobile commerce adoption in China and the United States: a crosscultural study. SIGMIS Database, 40(4), 43-61. doi: 10.1145/1644953.1644958.

Dai-Yon, C., Hyun Jung, K., \& Hyoung-Yong, L. (2007). Analysis of trust in Internet and mobile commerce adoption. Paper presented at the 40th Annual Hawaii International Conference on System Sciences, 2007. HICSS 2007, Hawaii, USA.

Davis, D. L., \& Cosenza, R. M. (1993). Business research for decision making: Wadsworth.

Davis, F. D., Bagozzi, R. P., \& Warshaw, P. R. (1989). User acceptance of computer technology: a comparison of two theoretical models. Management Science, 35(8), 982-1003. doi: $10.2307 / 2632151$.

Deakins, E., \& Chou, C. (2004). Cross-cultural transaction trust and security in m-commerce: multiitem scale development: Department of Management Systems, University of Waikato.

Deitel, H. M. (2002). Wireless Internet \& mobile business: How to program: Prentice Hall.

Dellinger, A. B., \& Leech, N. L. (2007). Toward a unified validation framework in mixed methods research. Journal of Mixed Methods Research, 1(4), 309-332.

Denscombe, M. (2007). Communities of practice and mixed methods research: a research paradigm based on reflexive pragmatism. Paper presented at the International Mixed Methods Conference, Cambridge, UK.

Denzin, N., \& Lincoln, Y. (1994). Introduction: Entering the field of qualitative research. In N. D. a. Y. Lincoln (Ed.), Handbook of Qualitative Research (pp. 1-17): Thousand Oaks: Sage Publications.

Deutsch, M. (1977). The resolution of conflict: constructive and destructive processes: Yale University Press, USA. 
Dillman, D. A., \& Bowker, D. (2001). The web questionnaire challenge to survey methodologists. In U.-D. Reips and M. Bosnjak (eds.). In U.-D. Reips \& M. Bosnjak (Eds.), Dimensions of Internet Science. Lengerich, Germany: Pabst Science.

Dillman, D. A., Smyth, J. D., Christian, L. M., O'Neill, A. C. (2008). Will a mixed-mode (mail/Internet) procedure work for random household surveys of the general public? Paper presented at the American Association for Public Opinion Research (AAPOR) 63rd Annual Conference.

Dillon, W. R., Madden, T. J., \& Firtle, N. H. (1990). Marketing Research in a Marketing Environment: McGraw-Hill Education.

Dimoka, A. (2010). What does the brain tell us about trust and distrust? evidence from a functional neuroimaging study. MIS Quarterly, 34(2), 373-396.

Djahantighi, F. S., \& Fakar, E. (2010). Factors affecting customer's trends for reservation foreign hotels via Internet in Iran. International Bulletin of Business Administration, 7. doi: 10.1016/s10715819(03)00043-0.

Dohan, D. and Sanchez-Jankowski, M. (1998). Using Computers to Analyze Ethnographic Field Data: Theoretical and Practical Considerations. Annual Review of Sociology, Vol 24, pp 477-498.

Doney, P. M., \& Cannon, J. P. (1997). An examination of the nature of trust in buyer-seller relationships. Journal of Marketing, 61(2), 35-51. doi: 10.2307/1251829.

Doney, P. M., Cannon, J. P., \& Mullen, M. R. (1998). Understanding the influence of national culture on the development of trust. The Academy of Management Review, 23(3), 601-620. doi: $10.2307 / 259297$.

Donner, J. (2007). M-banking and m-payments services in the developing world: complements or substitutes for trust and social capital. Paper presented at the at the Annual Meeting of the International Communication Association in San Francisco, CA, USA.

Dumas, J. (1998). Usability testing methods: subjective measures: part ii - measuring attitudes and opinions, The Common Ground, The Newsletter of the Usability Professionals, pp. 4-8.

Everitt, B. S., \& Dunn, G. (2001). Applied multivariate data analysis: Wiley.

Falk, R. F., \& Miller, N. B. (1992). A primer for soft modeling: University of Akron Press.

Farhat, R. (2014). PinPay leads mobile payments trend in Lebanon. WAMDA. Retrieved from http://www.wamda.com/2014/08/pinpay-leads-mobile-payments-trend-lebanon

Featherman, M. S., \& Pavlou, P. A. (2003). Predicting e-services adoption: a perceived risk facets perspective. International Journal of Human-Computer Studies, 59(4), 451-474. doi: http://dx.doi.org/10.1016/S1071-5819(03)00111-3.

Feng, H., Hoegler, T., Stucky, W. (2006). Exploring the critical success factors for mobile commerce, Paper presented at the international conference on mobile business (ICMB 2006), Paper 40, doi:10.1109/ICMB.2006.15

Field, A. P. (2005). Discovering statistics using SPSS: (and sex, drugs and rock ' $n$ ' roll), London: SAGE Publications.

Fielding, N., \& Lee, R. (1998). Computer analysis and qualitative research, London: SAGE Publications.

Flick, U. (2006). An Introduction to Qualitative Research, London: SAGE Publications.

Fontana, A., \& Frey, J. H. (1998). Interviewing: the art of science In N. K. Denzin \& Y. S. Lincoln (Eds.), Collecting and interpreting qualitative data: Thousand Oaks, CA: Sage.

Fornell, C., \& Bookstein, F. L. (1982). Two structural equation models: LISREL and PLS applied to consumer exit-voice theory. Journal of Marketing Research, 19(4), 440-452. doi: $10.2307 / 3151718$.

Fornell, C. \& Larcker, D. (1981). Structural equation models with unobservable variables and measurement error. Journal of Marketing Research, 18 (1), 39-50.

Forza, C. (2002). Survey research in operations management: a process-based perspective. International Journal of Operations \& Production Management, 22(2), 152-194. doi: $10.1108 / 01443570210414310$

Freeze, R., \& Ronald, D. (2007). An assessment of formative and reflective constructs in IS research. Paper presented at the 15th European Conference on Information Systems, St. Gallen, Switzerland, Paper 171.

Friedman, B., Peter H. Khan, J., \& Howe, D. C. (2000). Trust online. Communications of the ACM, 43(12), 34-40. doi: 10.1145/355112.355120 
Fukuyama, F. (1995). Trust: the social virtues and the creation of prosperity: Free Press.

Fung, R. K. K., \& Lee, M. K. O. (1999). EC-trust (trust in electronic commerce): Exploring the antecedent factors. Paper presented at the Proceedings of the Fifth Americas Conference on Information Systems, Milwaukee: Omnipress.

Gallivan, M. J. (1997). Value in triangulation: A comparison of two approaches for combining qualitative and quantitative methods. In A. Lee, J. Liebenau \& J. DeGross (Eds.), Information Systems and Qualitative Research (pp. 417-443): Springer, USA.

Gefen, D. (2000). E-commerce: the role of familiarity and trust. Omega, 28(6), 725-737. doi: http://dx.doi.org/10.1016/S0305-0483(00)00021-9

Gefen, D., \& Heart, T. H. (2006). On the need to include national culture as a central issue in ecommerce trust beliefs (pp. 1-30): IGI Global.

Gefen, D., \& Straub, D. (2005). A practical guide to factorial validity using PLS-graph: tutorial and annotated example. Communications of The AIS, 16(5).

Gefen, D., Karahanna, E., \& Straub, D. W. (2003). Trust and TAM in online shopping: An integrated Model. MIS Quarterly, 27(1), 51-90. doi: 10.2307/30036519

Gefen, D., Rose, G. M., \& Warkentin, M. (2004). Cultural diversity and trust in IT adoption: a comparison of potential e-voters in the USA and South Africa. Journal of Global Information Management, 13(1), 54-78.

Geohive. (2005). United Arab Emirates - General Information, from http://www.geohive.com/cntry/uae.aspx

Gerpott, T. J., \& Kornmeier, K. (2009). Determinants of customer acceptance of mobile payment systems. International Journal of Electronic Finance, 3(1), 1-30. doi: 10.1504/ijef.2009.024267

Ghinea, G., \& Angelides, M. (2004). A User perspective of quality of service in m-commerce. Multimedia Tools and Applications, 22(2), 187-206. doi: 10.1023/B:MTAP.0000011934.59111.b5

Ghosh, A. K., \& Swaminatha, T. M. (2001). Software security and privacy risks in mobile e-commerce. Communications of the ACM, 44(2), 51-57. doi: 10.1145/359205.359227

Gibbs, A. (1997). Focus groups. Social Research Update, 19.

Glaser, B. G., \& Strauss, A. L. (1967). The Discovery of Grounded Theory: Strategies for Qualitative Research: Aldine Publishing, NY.

Goeritz, A. S. (2006). Incentives in web studies: Methodological issues and a review. International Journal of Internet Science, 1(1).

Goode, A. (2006). Mobile commerce strategies: ticketing, retail, payment \& security (2 ed.): Juniper Research.

Gouda, I. (2014). The Future of Mobile Payment in the Middle East. Finances StackStreet. Retrieved from StackStreet website: http://stackstreet.com/future-mobile-payment-middle-east/

Goodhue, Dale L., Lewis, William, \& Thompson, Ron. (2012). Does PLS have advantages for small sample size or non-normal data?, MIS Quarterly, 36(3), pp.981-1001.

Gorman, G. E., Clayton, P. R., Shep, S. J., \& Clayton, A. (2005). Qualitative research for the information professional: A Practical Handbook: Facet.

Grabner-Kräuter, S., \& Kaluscha, E. (2003). Empirical research in on-line trust: a review and critical assessment. International Journal of Human-Computer Studies, 58(6), 783-812. doi: citeulikearticle-id:749877.

Grami, A., \& Schell, B. (2004). Future trends in mobile commerce: Service offerings, technological advances and security challenges. Proceedings Second Annual Conference on Privacy, Security and Trust, October 13-15, Wu Centre, University of New Brunswick, Fredericton, New Brunswick, Canada. doi: citeulike-article-id:4027813.

Grover, V. (2000). A tutorial on survey research: From constructs to theory. From http://www.umdnj.edu/idsweb/idst6000/MIS-SUVY.htm

Guadagnoli, E., \& Velicer, W. F. (1988). Relation to sample size to the stability of component patterns. [doi:10.1037/0033-2909.103.2.265]. 103, 265-275. doi: 10.1037/0033-2909.103.2.265

Guangming, Y., \& Yuzhong, M. (2011). A research on the model of factors influencing consumer trust in mobile business. Paper presented at the International Conference on $\mathrm{E}$-Business and $\mathrm{E}$ Government (ICEE), Shanghai, China, p.1-5. 
Guba, E., \& Lincoln, Y. (1994). Competing paradigms in qualitative research (pp. 105-117): Thousand Oaks, CA: Sage.

Gupta, P., \& Kumar, P. R. (2000). The capacity of wireless networks. Information Theory, IEEE Transactions on, 46(2), 388-404. doi: 10.1109/18.825799

Haenlein, M., \& Kaplan, A. M. (2004). A beginner's guide to Partial Least Squares analysis. Understanding Statistics, 3(4), 283-297. doi: 10.1207/s15328031 us0304_4

Haiqi, F., Hoegler, T., \& Stucky, W. (2006). Exploring the critical success factors for mobile commerce. Paper presented at the International Conference on Mobile Business, 2006. ICMB '06., Copenhagen, Denmark.

Hair, J. F., Hult, G. T. M., Ringle, C., \& Sarstedt, M. (2013). A Primer on Partial Least Squares Structural Equation Modeling (PLS-SEM), London : SAGE Publications.

Hair, J., Tatham, R., Anderson, R., \& Black, W. (1998). Multivariate Data Analysis (5th Edition): Prentice Hall.

Harris, P., Rettie, R., \& Rettie, R. (2005). Adoption and usage of m-commerce: a cross-cultural comparison of Hong Kong and the United Kingdom. Journal of Electronic Commerce Research, 6(3).

Hart, P., \& Saunders, C. (1997). Power and trust: critical factors in the adoption and use of electronic data interchange. Organization Science, 8(1), 23-42.

Hart, P., \& Saunders, C. (1997). Power and trust: critical factors in the adoption and use of electronic data interchange. Organization Science, 8(1), 23-42.

Head, M. M., \& Hassanein, K. (2002). Trust in e-commerce: Evaluating the impact of third-party seals. Quarterly Journal of Electronic Commerce, 3(3).

Hennink, M. M. (2007). International focus group research: a handbook for the health and social sciences: Cambridge University Press.

Herche, J., \& Engelland, B. (1996). Reversed-polarity items and scale unidimensionality. Journal of the Academy of Marketing Science, 24(4), 366-374. doi: 10.1177/0092070396244007.

Herzberg, A. (2003). Payments and banking with mobile personal devices. Communications of the ACM, 46(5), 53-58. doi: citeulike-article-id:10593982.

Hillman, S., Neustaedter, C., \& Bowes, J. (2001). Exploring "Soft" trust in mcommerce activities: An exploratory diary and interview study Technical Report. Surrey, BC, Canada: Connections Lab, Simon Fraser University.

Hinkin, T. R. (1998). A brief tutorial on the development of measures for use in survey questionnaires. Organizational Research Methods, 1(1), 104-121. doi: 10.1177/109442819800100106

Hoelter, J. W. (1983). Factorial invariance and self-esteem: Reassessing race and sex differences. Social Forces, 61(3), 834-846. doi: 10.2307/2578137.

Hoffman, D. L., Novak, T. P., \& Peralta, M. (1999). Building consumer trust online. Communications of the ACM, 42(4), 80-85. doi: 10.1145/299157.299175.

Hofstede, G. H. (2001). Culture's consequences: Comparing values, behaviors, institutions and organizations across nations: SAGE Publications.

Hollingsworth, C. L., \& Dembla, P. (2013). Toward an understanding why users engage in mcommerce. Paper presented at the Southern Association for Information Systems, March 8th9th, Savannah, GA, USA.

Hornung, C.A., (1977). Social Status, Status Inconsistency and Psychological Stress, American Sociological Review, 42 (4), pp. 623-638.

Howard, G. S. (1994). Why do people say nasty things about self-reports? Journal of Organizational Behavior, 15(5), 399-404. doi: 10.1002/job.4030150505

Hoyle, R. H. (ed.) (1995). Structural Equation Modeling. Thousand Oaks, CA.: SAGE Publications.

Hsieh, C. (2007). Mobile commerce: Assessing new business opportunities. Communications of the IIMA, 7(1).

Hsu, C.-L., \& Lu, H.-P. (2004). Why do people play on-line games? An extended TAM with social influences and flow experience. Information \& Management, 41(7), 853-868. doi: http://dx.doi.org/10.1016/j.im.2003.08.014 
Hsu, C.-L., Lu, H.-P., \& Hsu, H.-H. (2007). Adoption of the mobile Internet: An empirical study of multimedia message service (MMS). Omega, 35(6), 715-726. doi: http://dx.doi.org/10.1016/j.omega.2006.03.005

Hu, W.-S., Lee, C.-w., \& Yeh, J.-h. (2004). Mobile commerce systems. In N. Shi (Ed.), Mobile commerce applications: London: Idea Group Publishing.

$\mathrm{Hu}, \mathrm{X} ., \mathrm{Li}, \mathrm{W} .$, \& $\mathrm{Hu}, \mathrm{Q}$. (2008). Are Mobile payment and banking the killer apps for mobile commerce? Paper presented at the Proceedings of the 41st Annual Hawaii International Conference on System Sciences,.

Huang, W., Wang, Y., \& Day, J. (2008). Global Mobile Commerce: Strategies, Implementation and Case Studies (Vol. Hershey, PA, USA): IGI Global.

Hulland, J. (1999). Use of partial least squares (PLS) in strategic management research: a review of four recent studies. Strategic Management Journal, 20(2), 195-204. doi: 10.1002/(sici)10970266(199902)20:2<195::aid-smj13>3.0.co;2-7

Igbaria, M., Zinatelli, N., Cragg, P., \& Cavaye, A. L. M. (1997). Personal computing acceptance factors in small firms: a structural equation model. MIS Quarterly, 21(3), 279-305. doi: $10.2307 / 249498$

International Communication Union. (2010). Key global telecom indicators for the world telecommunication service sector, from http://www.itu.int/ITU/ict/statistics/at_glance/KeyTelecom.html

Islam, M. A., Khan, M. A., Ramayah, T., \& Hossain, M. M. (2011). The Adoption of mobile commerce service among employed mobile phone users in Bangladesh: Self-efficacy as a moderator. International Business Research, 4(2).

Jarvenpaa, S. L., Tractinsky, N., \& Saarinen, L. (1999). Consumer trust in an Internet store: A crosscultural validation. Journal of Computer-mediated Communication, 5(2).

Jarvenpaa, S., Tractinsky, N., \& Vitale, M. (2000). Consumer trust in an Internet store. Information Technology and Management, 1(1-2), 45-71. doi: 10.1023/a:1019104520776

Jinlong, Z., Wei, L., \& Guangming, Y. (2011). Research on management system of perceived risk of B2C mobile commerce. Paper presented at the Proceedings of the 7th International Conference on Innovation \& Management, Chiba, Japan.

Johnson, B., \& Christensen, L. B. (2004). Educational research: quantitative, qualitative, and mixed approaches, Research Edition: Allyn \& Bacon.

Johnson-George, C., \& Swap, W. C. (1982). Measurement of specific interpersonal trust: Construction and validation of a scale to assess trust in a specific other. Journal of Personality and Social Psychology, 43(6), 1306-1317. doi: 10.1037/0022-3514.43.6.1306

Joubert, J., \&Van Belle, J.P. (2009). The importance of trust and risk in m-commerce: A South African perspective. Paper presented at the Proceedings Pacific Asia Conference on Information Systems (PACIS), Hyderabad, India, Paper 96.

Jukic, N., Sharma, A., Jukic, B., \& Parameswaran, M. (2003). M-Commerce: A Location-Based Value Proposition Managing E-Commerce and Mobile Computing Technologies (pp. 19-27): IGI Global.

Junglas, I. A., \& Watson, R. T. (2006). The U-constructs: Four information drives. Communications of AIS, 17(26), 569-592.

Juniper Research, J. (2010). Mobile payments market to quadruple in next five years, from http://www.mobilecommercedaily.com/2010/05/06/mobile-payments-market-to-quadruple-innext-five-years-study

Juniper-Research. (2012). Press Release: Mobile payments to reach $\$ 1.3$ tn annually by 2017 , as NFC and physical goods sales accelerate. Mobile Content and Applications, from http://www.juniperresearch.com/viewpressrelease.php?pr=332

Kao, D. T. (2009). The Impact of Transaction Trust on Consumers' Intentions to Adopt M-Commerce: A Cross-Cultural Investigation. CyberPsychology \& Behavior, 12(2), 225. doi: 37580629

Karnouskos, S. (2004). Mobile payment: A journey through existing procedures and standardization initiatives. Communications Surveys \& Tutorials, IEEE, 6(4), 44-66. doi: 10.1109/comst.2004.5342298 
Karnouskos, S., \& Focus, F. (2004). Mobile payment: A journey through existing procedures and standardization initiatives. Communications Surveys \& Tutorials, IEEE, 6(4), 44-66. doi: $10.1109 /$ comst.2004.5342298

Katerattanakul, P., \& Siau, K. (2003). Creating a virtual store image. Communication of the ACM, 46(12), 226-232. doi: 10.1145/953460.953504

Keramati, A., Taeb, R., Larijani, A. M., \& Mojir, n. (2011). A combinative model of behavioural and technical factors affecting 'Mobile'-payment services adoption: an empirical study. The Service Industries Journal, 32(9), 1489-1504. doi: 10.1080/02642069.2011.552716

Khasawneh, A.M. (2009). The key success to mobile internet in the Middle East: wireless set to take the lead. International Journal of Business Information Systems, 4(4), 477-488.

Khidhir, A. (2014). Will Mobile Wallets make UAE cashless?. Finextra. Retrieved from http://www.finextra.com/blogs/fullblog.aspx?blogid=101262.

Kim, C., Mirusmonov, M., \& Lee, I. (2010). An empirical examination of factors influencing the intention to use mobile payment. Computers in Human Behavior, 26(3), 310-322. doi: http://dx.doi.org/10.1016/j.chb.2009.10.013.

Kim, K., \& Prabhakar, B. (2000). Initial trust, perceived risk, and the adoption of Internet banking. Paper presented at the Proceedings of the twenty first international conference on Information systems, p. 537-543, Brisbane, Australia.

Kim, S. H. (2008). Moderating effects of Job Relevance and Experience on mobile wireless technology acceptance: Adoption of a smartphone by individuals. Information \& Management, 45(6), 387393. doi: http://dx.doi.org/10.1016/j.im.2008.05.002.

Kim, S., \& Noh, M. J. (2012). Determinants influencing consumers' trust and trust performance of social commerce and moderating effect of experience. Information Technology Journal, 11(10), $1369-1380$.

King, N, \& Horrocks, C. (2010). Interviews in Qualitative Research. London: Sage Publications.

Kolsaker, A., \& Payne, C. (2002). Engendering trust in e-commerce: a study of gender-based concerns. Marketing Intelligence \& Planning, 20(4), 206-214. doi: 10.1108/02634500210431595

Komiak, S. Y. X., \& Benbasat, I. (2008). A Two-Process view of trust and distrust building in recommendation agents: A Process-Tracing Study. Journal of the Association for Information Systems, 9(12), 2.

Kounelis, I., \& Loeschner, J. (2012). Trust in mobile commerce. Paper presented at the Proceedings of the User-Centered Trust in Interactive Systems Workshop: a Workshop from NordiCHI

Kramer, R. M. (1999). Trust and distrust in organizations: Emerging perspectives, enduring questions. Annual Review of Psychology, 50(1), 569-598. doi: doi:10.1146/annurev.psych.50.1.569

Kumar, D., Martin, D., \& O'Neill, J. (2011). The times they are a-changing': mobile payments in India. Paper presented at the Proceedings of the SIGCHI Conference on Human Factors in Computing Systems, Vancouver, BC, Canada.

Kumar, V., Aaker, D. A., \& Day, G. S. (1999). Essentials of Marketing Research: Wiley.

Lai, T. (2004). Service quality and perceived value's impact on satisfaction, intention and usage of Short Message Service (SMS). Information Systems Frontiers, 6(4), 353-368. doi: 10.1023/B:ISFI.0000046377.32617.3d.

Lawshe, C. H. (1975). A Quantitative Approach to Content Validity. Personnel Psychology, 28(4), 563575. doi: 10.1111/j.1744-6570.1975.tb01393.x.

Lee, A. S., \& Sarker, S. (2008). A schema for relating and combining quantitative, qualitative, positivist, and interpretive research methods in the discipline of information systems. Unpublished Manuscript, IS department, LSE.

Lee, K. C., \& Chung, N. (2009). Understanding factors affecting trust in and satisfaction with mobile banking in Korea: A modified DeLone and McLean's model perspective. Interacting with Computers, 21(5-6), 385-392. doi: http://dx.doi.org/10.1016/j.intcom.2009.06.004

Lee, K. S., Lee, H. S., \& Kim, S. Y. (2007). Factors influencing the adoption behavior of mobile banking: A South Korean perspective. Journal of Internet Banking \& Commerce, 12(2), 1. doi: 26644506

Lee, M. K. O., \& Turban, E. (2001). A trust model for consumer Internet shopping. International Journal of Electronic Commerce, 6(1), 75-91. 
Lee, Y. E., \& Benbasat, I. (2003). Interface design for mobile commerce. Communications of the ACM, 46(12), 48-52. doi: 10.1145/953460.953487.

Lewicki, R. J. (2006). Trust, trust development, and trust repair The handbook of conflict resolution: Theory and practice (Vol. 2, pp. 92-119). Hoboken, NJ, US: Wiley Publishing.

Lewicki, R. J., McAllister, D. J., \& Bies, R. J. (1998). Trust and distrust: New relationships and realities. The Academy of Management Review, 23(3), 438-458. doi: 10.2307/259288

Lewis, J. D., \& Weigert, A. J. (1985). Social atomism, holism, and trust. The Sociological Quarterly, 26(4), 455-471. doi: 10.2307/4106098.

Li, Y.-M., \& Yeh, Y.-S. (2010). Increasing trust in mobile commerce through design aesthetics. Computers in Human Behavior, 26(4), 673-684. doi: http://dx.doi.org/10.1016/j.chb.2010.01.004.

Li, Z., \& Li, M. (2008). Research on influencing factors of consumer initial trust based on mobile commerce. Paper presented at the International Symposium on Electronic Commerce and Security, 263 - 267, Guangzhou, China.

Lin, H.-H., \& Wang, Y.-S. (2006). An examination of the determinants of customer loyalty in mobile commerce contexts. Information \& Management, 43(3), 271-282. doi: http://dx.doi.org/10.1016/j.im.2005.08.001

Lindell, M. K., \& Whitney, D. J. (2001). Accounting for common method variance in cross-sectional research designs. [doi:10.1037/0021-9010.86.1.114]. 86, 114-121. doi: 10.1037/00219010.86.1.114.

Liu, Z., Min, Q., \& Ji, S. (2009). An empirical study on mobile banking adoption: The role of trust. Paper presented at the Second International Symposium on Electronic Commerce and Security (ISECS '09), 7 - 13, Nanchang, China.

Lu, J., Yu, C. S., \& Liu, C. (2005). Facilitating conditions, wireless trust and adoption intention. Journal of Computer Information Systems, 46(1).

Lu, J., Yu, C.-S., Liu, C., \& Yao, J. E. (2003). Technology acceptance model for wireless Internet. Internet Research, 13(3), 206-222. doi: 10.1108/10662240310478222.

Luarn, P., \& Lin, H.-H. (2005). Toward an understanding of the behavioral intention to use mobile banking. Computers in Human Behavior, 21(6), 873-891. doi: http://dx.doi.org/10.1016/j.chb.2004.03.003.

Lyberg, L., Biemer, P., Collins, M., Leeuw, E. d., Dippo, C., Schwarz, N., \& Trewin, D. (1997). Survey measurement and process quality. New York: Wiley.

MacCallum, R. C., \& Austin, J. T. (2000). Applications of Structural Equation Modeling in psychological research. Annual Review of Psychology, 51(1), 201-226. doi: doi:10.1146/annurev.psych.51.1.201.

MacDonald, D. J. (2003). NTT DoCoMo's I-mode: Developing Win-Win relationships for mobile commerce mobile commerce: Technology, theory and applications (pp. 1-25): IGI Global.

Malhotra, N. K. (2004). Marketing Research.: An Applied Orientation with SPSS: Pearson/PrenticeHall.

Mallat, N. (2007). Exploring consumer adoption of mobile payments - A qualitative study. The Journal of Strategic Information Systems, 16(4), 413-432. doi: http://dx.doi.org/10.1016/j.jsis.2007.08.001

Mallat, N., Rossi, M., \& Tuunainen, V. K. (2004). Mobile banking services. Commutations of the ACM, 47(5), 42-46. doi: 10.1145/986213.986236

Mallat, N., Rossi, M., Tuunainen, V., \& Öörni, A. (2008). An empirical investigation of mobile ticketing service adoption in public transportation. Personal and Ubiquitous Computing, 12(1), 57-65. doi: 10.1007/s00779-006-0126-z

Manochehri, N. N., \& AlHinai, Y. S. (2008). Mobile-phone users' attitudes towards' mobile commerce \& services in the Gulf Cooperation Council countries: Case study. Paper presented at the International Conference on Service Systems and Service Management, Melbourne, Australia.

MasterCard. (2012). Mobile Payments Readiness Index, from http://mobilereadiness.mastercard.com/about/\#readiness

Mathew, J., Sarker, S., \& Varshney, U. (2004). M-commerce services: Promises and challenges. Communications of AIS, 14(26). doi: 16744372 
Mayer, R. C., Davis, J. H., \& Schoorman, F. D. (1995). An integrative model of organizational trust. The Academy of Management Review, 20(3), 709-734. doi: 10.2307/258792

McKnight, D. H., \& Chervany, N. L. (2001a). Trust and distrust definitions: One bite at a time. In R. Falcone, M. Singh \& Y.-H. Tan (Eds.), Trust in Cyber-societies (Vol. 2246, pp. 27-54): Springer Berlin Heidelberg.

McKnight, D. H., \& Chervany, N. L. (2001b). What trust means in e-commerce customer relationships: An interdisciplinary conceptual typology. International Journal of Electronic Commerce, 6(2), 35-59.

McKnight, D. H., \& Chervany, N. L. (2006). Reflections on an initial trust building model. In A. Zaheer \& R. Bachmann (Eds.), Handbook of trust research.: Edward Elgar Publishing.

McKnight, D. H., Choudhury, V., \& Kacmar, C. (2002). Developing and validating trust measures for ecommerce: an integrative typology. Information Systems Research, 13(3), 334-358. doi: 10.1287/isre.13.3.334.81.

McKnight, D. H., Kacmar, C. J., \& Choudhury, V. (2004). Dispositional trust and distrust distinctions in predicting high-and low-risk Internet expert advice site perceptions. e-Service Journal, 3(2), 35. doi: 16113848.

McMurray, R., Cheater, F. M., Weighall, A., Nelson, C., Schweiger, M., \& Mukherjee, S. (2004). Managing controversy through consultation: a qualitative study of communication and trust around MMR vaccination decisions. The British Journal of General Practice, 54(504).

Mellinger, G. D. (1956). Interpersonal trust as a factor in communication. The Journal of Abnormal and Social Psychology, 52(3), 304-309. doi: 10.1037/h0048100.

Meng, D., Min, Q., \& Li, Y. (2008). Study on trust in mobile commerce adoption - A conceptual model. Paper presented at the International Symposium on Electronic Commerce and Security, Guangzhou, p.246 - 249.

Miles, M. B., \& Huberman, A. M. (1994). Qualitative data analysis: an expanded sourcebook: SAGE Publications.

Miller, A. S., \& Mitamura, T. (2003). Are surveys on trust trustworthy? Social Psychology Quarterly, 66(1), 62-70. doi: 10.2307/3090141

Min, Q., Li, Y., \& Ji, S. (2009). The effects of individual-level culture on mobile commerce adoption: An empirical study. Paper presented at the Proceedings of the Eighth International Conference on Mobile Business, Dalian, p. 305 - 312.

Mingers, J. (2001). Combining IS research methods: Towards a pluralist methodology. Information Systems Research, 12(3), 240-240. doi: citeulike-article-id:8918412

Misra, S., \& Wickamasinghe, N. (2004). Security of a mobile transaction: A trust model. Electronic Commerce Research, 4(4), 359-372. doi: 10.1023/B:ELEC.0000037082.39182.3a

Mogenahalli, S., Mahatanankoon, P., \& Lim, B. B. L. (2008). Influence of trust predictors on different dimensions of trust in m-commerce. Issues in Information Systems, 9(2).

Moody, G. D., Galletta, D., \& Lowry, P. B. (2010). Unifying conflicting models of trust and distrust for enhanced understanding and predictive power in organizational relationships: Proposing the Unified Trust-Distrust model. Paper presented at the Proceedings of JAIS Theory Development Workshop, All Sprouts Content. Paper 361.

More, G. C., \& Benbasat, I. (1991). Development of an instrument to measure the perceptions of adopting an information technology innovation. Information Systems Research, 2(3), 192.

Morgan, D. L. (1997). Focus groups as qualitative research: SAGE Publications.

Morgan, D. L., Krueger, R. A., \& King, J. A. (1998). Planning focus groups: SAGE Publications.

Moshin, M., Mudtadir, R., \& Ishaq, A. F. M. (2003). Mobile commerce - the emerging frontier: exploring the prospects, application and barriers to adoption in Pakistan. Paper presented at the International Workshop on Frontiers of IT, Islamabad.

Müller-Veerse, F. (2000). Mobile commerce report. From http://www.dad.be/library/pdf/durlacher1.pdf, 18.05.2005

Naef, M. \& Schupp, J. (2009). Measuring trust: Experiments and surveys in contrast and combination. SOEP Papers on Multidisciplinary Panel Data Research No. 167. Berlin: DIW Berlin.

Netemeyer, R. G., Bearden, W. O., \& Sharma, S. (2003). Scaling procedures: Issues and applications: SAGE Publications. 
Neuman, W. L. (2005). Social research methods: Quantitative and qualitative approaches. (6 ed.). Boston, MA Allyn \& Bacon.

Ngai, E. W. T., \& Gunasekaran, A. (2007). A review for mobile commerce research and applications. Decision Support Systems, 43(1), 3-15. doi: http://dx.doi.org/10.1016/j.dss.2005.05.003

Nunnally, J. C. (1967). Psychometric theory: McGraw-Hill.

Nyshadham, E. A. (2000). Privacy policies of air travel web sites: a survey and analysis. Journal of Air Transport Management, 6(3), 143-152. doi: http://dx.doi.org/10.1016/S0969-6997(00)00007-7

O'Cass, A., \& Pecotich, A. (2005). The dynamics of voter behavior and influence processes in electoral markets: a consumer behavior perspective. Journal of Business Research, 58(4), 406-413. doi: http://dx.doi.org/10.1016/j.jbusres.2003.08.003

OECD. (2008). Policy guidance for addressing emerging consumer protection and empowerment issues in mobile commerce. From http://www.oecd.org/dataoecd/50/15/40879177.pdf

Orlikowski, W. J., \& Baroudi, J. J. (1991). Studying information technology in organizations: research approaches and assumptions. qualitative research in information systems. Information Systems Research, 2(1). doi: 10.4135/9781849209687

Parsons, J., \& Cole, L. (2005). What do the pictures mean? Guidelines for experimental evaluation of representation fidelity in diagrammatical conceptual modeling techniques. Data \& Knowledge Engineering, 55(3), 327-342. doi: http://dx.doi.org/10.1016/j.datak.2004.12.008

Park, C.-H., \& Kim, Y.-G. (2003). Identifying key factors affecting consumer purchase behavior in an online shopping context. International Journal of Retail \& Distribution Management, 31(1), 1629. doi: 10.1108/09590550310457818

Park, J., \& Sujin, Y. (2006). The moderating role of consumer trust and experience: value driven usage of mobile technology. International Journal of Mobile Marketing, 1(2),24-37.

Pavlou, P. A. (2003). Consumer acceptance of electronic commerce: integrating trust and risk with the Technology Acceptance Model. International Journal of Electronic Commerce, 7(3), 101-134.

Pavlou, P. A., \& Chai, L. (2002). What drives electronic commerce across cultures? A cross-cultural empirical investigation of the theory of planned behavior. Journal of Electronic Commerce Research, 3(4),240-253.

Peterson, R. (2000). A meta-analysis of variance accounted for and factor loadings in Exploratory Factor Analysis. Marketing Letters, 11(3), 261-275. doi: 10.1023/a:1008191211004

Piao, C., Wang, S., \& Yang, F. (2012). Research on trust evaluation model for mobile commerce based on structural equation modeling. Paper presented at the Proceedings of the IEEE Ninth International Conference on e-Business Engineering.

Pickard, A. J. (2007). Research methods in information: Facet.

Pinsonneault, A., \& Kraemer, K. L. (1993). Survey research methodology in management information systems: an assessment. Journal of Management Information Systems, 10(2), 75-105.

Podsakoff, P., MacKenzie, S., Lee, J., \& Podsakoff, N. (2003). Common method biases in behavioral research: A critical review of the literature and recommended remedies, 88(5), 879-903. doi:10.1037/0021-9010.88.5.879. 88, 879-903.

Popper, K. R. (2002). The logic of scientific discovery: Routledge.

Portz, K., Strong, J., \& Sundby, L. (2001). To trust or not to trust: the impact of the webtrust on the perceived trustworthiness of a web site. Review of Business Information Systems, 5(3), 35-49.

Pousttchi, K., \& Wiedemann, D. G. (2007). What Influences Consumers' Intention to Use Mobile Payments? LA Global Mobility Round table. doi: citeulike-article-id:4575690

Pousttchi, K. (2004). An Analysis of the Mobile Payment Problem in Europe. Published in: Multikonferenz Wirtschaftsinformatik (MKWI), Essen, März 2004 : pp. 260-268.

Powell, R. A., \& H.M., S. (1996). Methodology Matters V: Focus Groups. . International Journal for Quality in Health Care, 8(5).

Powell, R. A., Single, H. M., \& Lloyd, K. R. (1996). Focus groups in mental health research: Enhancing the validity of user and provider questionnaires. International Journal of Social Psychiatry, 42(3), 193-206.

Qingfei, M., Decai, M., \& Qiuyan, Z. (2008). An empirical study on trust in mobile commerce adoption. Paper presented at the IEEE International Conference on Service Operations and Logistics, and Informatics, IEEE/SOLI 2008, Beijing, p.659- 664. 
Rahmati, N. (2004). An overview of the impact of national culture on the adoption of mobile commerce. In J. Chen (Ed.), Proceedings of the Fourth International Conference on Electronic Business (ICEB 2004), p. 751-756, Beijing, China.

Ratnasingam, P. (2000). The influence of power on trading partner trust in electronic commerce. Internet Research, 10(1).

Rea, L. M., \& Parker, R. A. (1992). Designing and conducting survey research: a comprehensive guide: Jossey-Bass Publishers.

Real, W. H. (1962). Upward communication in industrial hierarchies. Human Relations, 15(1), 3-15. doi: $10.1177 / 001872676201500101$

Rehman, S. U., \& Coughlan, J.-L. (2011). Building trust of mobile users and their adoption of mcommerce. World Academy of Science, Engineering and Technology, 75(105). doi: 60801434

Rempel, J. K., Holmes, J. G., \& Zanna, M. P. (1985). Trust in close relationships. Journal of Personality and Social Psychology, 49(1), 95-112. doi: 10.1037/0022-3514.49.1.95

Roberts, J., Merrilees, B., Herington, C., \& Miller, D. (2010). Building retail tenant trust: neighbourhood versus regional shopping centres. International Journal of Retail \& Distribution Management, 38(8), 597-612. doi: 10.1108/09590551011057426

Rokeach, M. (1973). The nature of human values: Free Press.

Rotter, J. B. (1980). Interpersonal trust, trustworthiness, and gullibility. American Psychologist, 35(1), 1-7. doi: 10.1037//0003-066x.35.1.1

Rouibah, K. (2007). Does mobile payment technology Mnet attract potential consumers? The case of Kuwait. Paper presented at the Proceedings of ACIS, Toowoomba, Australia.

Rouibah, K. (2009). The failure of mobile payment: evidence from quasi-experimentations. Paper presented at the Proceedings of the Euro American Conference on Telematics and Information Systems: New Opportunities to increase Digital Citizenship, Prague, Czech Republic.

Rouibah, K. (2012). Trust Factors Influencing Intention to Adopt Online Payment in Kuwait. Paper presented at the Southern Association for Information Systems Conference, Paper 35, Atlanta, USA.

Saghafi, F., Mohammadi, N., \& Fasanghari, M. (2009). Mobile services model for diabetic patient based on $4 C$ method. Paper presented at the 2nd Conference of Electronic City, p.24-25, Iran.

Saint-Germain, M. A., Bassford, T. L., \& Montano, G. (1993). Surveys and Focus Groups in Health Research with Older Hispanic Women. Qualitative Health Research, 3(3), 341-367. doi: 10.1177/104973239300300306

Salam, A. F., Iyer, L., Palvia, P., \& Singh, R. (2005). Trust in e-commerce. Communications of the ACM, 48(2), 72-77. doi: 10.1145/1042091.1042093

Salo, J., \& Karjaluoto, H. (2007). A conceptual model of trust in the online environment. Online Information Review, 31(5), 604-621. doi: 10.1108/14684520710832324

Schonlau, M., Ronald D., J. F., \& Elliott, M. N. (2002). Conducting research surveys via e-mail and the web: RAND Corporation.

Schoorman, F. D., Mayer, R. C., \& Davis, J. H. (2007). An integrative model of organizational trust: Past, present, and future. The Academy of Management Review, 32(2), 344-354. doi: $10.2307 / 20159304$

Schreiber, J. B., Nora, A., Stage, F. K., Barlow, E. A., \& King, J. (2006). Reporting Structural Equation Modeling and Confirmatory Factor Analysis results: A review. The Journal of Educational Research, 99(6), 323-338. doi: 10.3200/joer.99.6.323-338

Schwab, D. P. (2004). Research Methods for Organizational Studies: Taylor \& Francis.

Scornavacca, E., Barnes, S. J., \& Huff, S. L. (2005). Mobile Business Research, 2000-2004: Emergence, Current Status, and Future Opportunities. Paper presented at the Proceedings of European Conference of Information System (ECIS), Paper 59.

Seale, C., \& Silverman, D. (1997). Ensuring rigour in qualitative research. European Journal of Public Health, 7(4), 379-384.

Sekaran, U. (2003). Research methods for business. WSEAS transactions on information science and applications, 7(5), 661-670.

Shahibi, M. S., \& Fakeh, S. K. W. (2011). Security factor and trust in e-commerce transactions. Australian Journal of Basic \& Applied Sciences, 5(12). 
Shi, X., \& Wright, P. C. (2001). Developing and validating an international business negotiator's profile: The China context. Journal of Managerial Psychology, 16(5), 364-389. doi: 10.1108/eum0000000005523

Shim, S., Eastlick, M. A., Lotz, S. L., \& Warrington, P. (2001). An online pre-purchase intentions model: The role of intention to search. Journal of Retailing, 77(3), 397-416. doi: http://dx.doi.org/10.1016/S0022-4359(01)00051-3

Shin, B., \& Lee, H. G. (2005). Ubiquitous computing-driven business models: A case of SK Telecom's financial services. Electronic Markets, 15(1), 4-12. doi: 10.1080/10196780500034871

Siau, K., \& Shen, Z. (2003). Building consumer trust in mobile commerce. Communications of the $A C M, 46(4)$.

Siau, K., Lim, E. P., \& Shen, Z. (2001). Mobile commerce: promises, challenges, and research agenda. Journal of Database Management, 12(3), 4-13. doi: 10.4018/jdm

Siau, K., Sheng, H., \& Nah, F. (2003). Development of a framework for trust in mobile commerce. Paper presented at the Proceedings of the Second Annual Workshop on HCI Research in MIS, Seattle, WA.

Siau, K., Sheng, H., Nah, F., \& Davis, S. (2004). A qualitative investigation on consumer trust in mobile commerce. International Journal of Electronic Business, 2(3), 283-300. doi: 10.1504/ijeb.2004.005143

Siddiqui, H. N., \& ., N. S. U. I. S. (2008). Investigation of Intention to Use E-commerce in the Arab Countries: A Comparison of Self-efficacy, Usefulness, Culture, Gender, and Socioeconomic Status in Saudi Arabia and the United Arab Emirates: Nova Southeastern University. From http://search.proquest.com/docview/194127355?accountid=14782

Sikolia, D., Weiser, M., Biros, D., \& Romano Jr, N. C. (2010). Trust in mobile banking: The effect of culture. Paper presented at the Fifth Midwest Association Conference for Information Systems, Paper 4, Oklahoma, USA.

Silverman, D. (1993). Beginning Research. Interpreting Qualitative Data. Methods for Analysing Talk, Text and Interaction. London: Sage Publications.

Singh, K. (2007). Quantitative social research methods: SAGE Publications.

Sitkin, \& Roth. (1993). Explaining the limited effectiveness of legalistic "remedies" for trust/distrust. Organization Science, 4(3), 367-392. doi: citeulike-article-id:697175

Slife, B. D., \& Williams, R. N. (1995). What's behind the research?: Discovering hidden assumptions in the behavioral sciences: SAGE Publications.

Smith, M. J. (1988). Contemporary Communication Research Methods: Wadsworth Publishing Company.

Smyth, R. (2004). Exploring the usefulness of a conceptual framework as a research tool: A researcher's reflections. Issues In Educational Research, 14(2), 167-180.

Sreenivasan, J., \& Noor, M. N. M. (2010). A conceptual framework on mobile commerce acceptance and usage among Malaysian consumers: The influence of location, privacy, trust and purchasing power. WSEAS Transactions on Information Science and Applications, 7(5).

Stack, L. C. (1978). Trust. In H. London \& J. J. E. Exner (Eds.), Dimensions of personality (pp. 561599). New York: John Wiley \& Sons.

Stewart, D. W., Shamdasani, P. N., \& Rook, D. W. (2007). Focus groups: Theory and practice: SAGE Publications.

Straub, D. W. (1989). Validating instruments in MIS research. MIS Quarterly, 13(2), 147-169. doi: $10.2307 / 248922$

Straub, D. W., Boudreau, M.-C., \& Gefen, D. (2004). Validation guidelines for is positivist research. Communications of the Association for Information Systems, 13( 24), 380-427.

Strauss, A. L. (1987). Qualitative Analysis for Social Scientists: Cambridge University Press.

Strauss, A., \& Corbin, J. M. (1998). Basics of qualitative research: Techniques and procedures for developing Grounded Theory: SAGE Publications.

Stewart, K. J. (2006). How Hypertext Links Influence Consumer Perceptions to Build and Degrade Trust Online. Journal of Management Information Systems, 23(1), 183-210. doi: 10.2753/MIS0742-1222230106

Strong, K., \& Weber, J. (1998). The Myth of the trusting culture: A global, empirical assessment. Business \& Society, 37(2), 157-183. doi: 10.1177/000765039803700203 
Susanto, A., Younghoon, C., Hangjung, Z., \& Myeong-Cheol, P. (2012). The role of trust and security in Smartphone banking continuance. Paper presented at the IEEE International Conference on Systems, Man, and Cybernetics (SMC), p. 2133 - 2138, Seoul, South Korea.

Sushil, S., \& Verma, N. (2010). Questionnaire validation made easy. European Journal of Scientific Research, 46(2), 172. doi: 55421119

Tabachnick, B. G., \& Fidell, L. S. (2001). Using multivariate statistics: Allyn and Bacon.

Tarasewich, P., \& Warkentin, M. (2000). Issues in wireless E-commerce. Communications of the Association for Information Systems, 1(1), 21-25. doi: 10.1145/844302.844307

Tarasewich, P., Nickerson, R. C., \& Warkentin, M. (2001). Wireless/Mobile e-commerce: technologies, applications, and issues. Paper presented at the Americas Conference on Information Systems, Paper 87,p. 435-438, San Francisco, USA.

Tashakkori, A., \& Teddlie, C. (2003). Handbook of mixed methods in social \& behavioral research: SAGE Publications.

Teo, T. S. H., \& Pok, S. H. (2003). Adoption of WAP-enabled mobile phones among Internet users. Omega, 31(6), 483-498. doi: http://dx.doi.org/10.1016/j.omega.2003.08.005

Thair, A., Luo, S., \& Peter, S. (2010). Consumer acceptance of mobile payments: An empirical study. Paper presented at the 4th International Conference on New Trends in Information Science and Service Science (NISS), p. 533 - 537, Gyeongju, South Korea.

The Arab World Competitiveness Report. (2011). In A. Gurría \& K. Schwab (Eds.). A Time of Opportunities: The Competitiveness Performance of the Arab World. The World Economic Forum and the OECD, Geneva, Retrieved from http://www3.weforum.org/docs/WEF_AWC_Report_2011-12.pdf

The Economist (2014). Why does Kenya lead the world in mobile money?, Retrieved from http://www.economist.com/blogs/economist-explains/2013/05/economist-explains-18

The Logic Group (2013). Trust remains the biggest barrier to mobile payments. The Technology Landscape 2013, p. 1-54, Britain: Ipsos MORI.

The PAYPERS, (2014). Africa, Middle East trust cash-on-delivery as payment method in B2C ecommerce, insights in payments - Online Payments. Retrieved from http://www.thepaypers.com/online-payments/africa-middle-east-trust-cash-on-delivery-aspayment-method-in-b2c-ecommerce/755249-3

Ticehurst, B., \& Veal, A. J. (2005). Business research methods: A managerial approach: AddisonWesley Longman, Incorporated.

Tiwari, R. G., Husain, M., Srivastava, V., \& Singh, K. (2011). A hypercube novelty model for comparing E-commerce and M-commerce. Paper presented at the Proceedings of the International Conference on Communication, Computing \& Security, p. 616-619, Rourkela, Odisha, India.

Tiwari, R., \& Buse, S. (2007). The mobile commerce prospects: A strategic analysis of opportunities in the banking sector; research project mobile commerce: Hamburg University Press.

Tiwari, R., Buse, S., \& Herstatt, C. (2006). From electronic to mobile commerce: Opportunities through technology convergence for business services. Asia Pacific Tech Monitor, 23(5), 38-45.

Treiblmaier, H., \& Filzmoser, P. (2010). Exploratory factor analysis revisited: How robust methods support the detection of hidden multivariate data structures in IS research. Information \& Management, 47(4), 197-207. doi: http://dx.doi.org/10.1016/j.im.2010.02.002

Turban, E., King, D., Lee, J., Warkentin, M., \& Chung, H. M. (2008). Review of electronic commerce. In B. Horan (Ed.), Electronic commerce 2008: a managerial perspective (pp. 920). New Jersey: Prentice Hall.

Uchenna Cyril, E., Gerald Goh Guan, G., John, A., \& Samson, A. T. (2008). Modelling user trust and mobile payment adoption: a conceptual framework. Communications of the IBIMA, 3(29), 224231.

UNCTAD. (2002). E-Commerce and development report 2002, from http://www.state.gov/r/pa/ei/bgn/5444.htm

Urbach, N., \& Ahlemann, F. (2010). Structural Equation Modeling in information systems research using Partial Least Squares Journal of Information Technology Theory and Application (JITTA), $11(2), 2$. 
Urbaczewskj, A., Valacich, J., \& Jessup, L. (2003). Mobile computing opportunities and challenges, Communications of the ACM, 46(12), 35-40.

Van Dyke, T. P., Midha, V., \& Nemati, H. (2007). The effect of consumer privacy empowerment on trust and privacy concerns in e-commerce. Electronic Markets, 17(1), 68-81. doi: 10.1080/10196780601136997

Vance, A., Elie-Dit-Cosaque, C., \& Straub, D. (2008). Examining trust in information technology artifacts: The effects of system quality and culture. Journal of Management Information Systems, 24(4), 73-100. doi: 10.2753/mis0742-1222240403

Varshney, U., \& Vetter, R. (2002). Mobile commerce: Framework, applications and networking support. Mobile Networks and Applications, 7(3), 185-198. doi: 10.1023/a:1014570512129

Vatsavayi, V. K., \& Mukkamala, R. V. (2008). M-commerce payment systems. In W. W. Huang, Y. Wang \& J. Day (Eds.), Global mobile commerce (Vol. 1, pp. 432). Information Science-an imprint of IGI Global.

Veijalainen, J. (2007). Autonomy, heterogeneity, trust, security, and privacy in mobile P2P environments. International Journal of Security and Its Applications, 1(1).

Venkatesh, V., \& Davis, F. D. (2000). A theoretical extension of the Technology Acceptance Model: Four longitudinal field studies. Management Science, 46(2), 186-204. doi: 10.2307/2634758

Venkatesh, V., Morris, M. G., Gordon, B. D., \& Davis, F. D. (2003). User acceptance of information technology: Toward a unified view. MIS Quarterly, 27(3), 425-478. doi: 10.2307/30036540

VeriSign. (2007). Mobile commerce services driving mobile commerce adoption: best practices for a $\begin{array}{llll}\text { comprehensive, secure mobile commerce strategy. From } & \end{array}$ http://www.VeriSign.com/static/DEV040159.pdf.

Vinzi, V., Trinchera, L., \& Amato, S. (2010). PLS path modeling: From foundations to recent developments and open issues for model assessment and improvement. In V. Esposito Vinzi, W. W. Chin, J. Henseler \& H. Wang (Eds.), Handbook of Partial Least Squares (pp. 47-82): Springer Berlin Heidelberg.

Walsham, G. (1995). The Emergence of Interpretivism in IS Research. Information Systems Research, 6(4), 376. doi: 4431320

Wang, W., \& Benbasat, I. (2004). Trust and distrust building processes in online recommendation agents: A process-tracing analysis. MIS Division. Sauder School of Business, University of British Columbia. Vancouver.

Wang, Y., Lo, H. P., Chi, R., \& Yang, Y. (2004). An integrated framework for customer value and customer-relationship-management performance: a customer-based perspective from China. Managing Service Quality, 14(2), 169-182. doi: 10.1108/09604520410528590

Welch, W. W., \& Barlau, A. B. (2013). Addressing Survey Nonresponse Issues: Implications for ATE Principal Investigators, Evaluators, and Researchers. Retrieved from DECA, University of Colorado: http://www.colorado.edu/ibs/decaproject/pubs/index.html

Wei, T. T., Marthandan, G., Chong, A. Y.-L., Ooi, K.-B., \& Arumugam, S. (2009). What drives Malaysian m-commerce adoption? An empirical analysis. Industrial Management \& Data Systems, 109(3), 370-388. doi: 10.1108/02635570910939399

Wei-Chang, K., \& Yu-Ting Caisy, H. (2006). Modeling initial and repeat online trust in B2C ecommerce. Proceedings of the 39th Annual Hawaii International Conference on System Sciences (HICSS '06), Paper 6.

Wiedmann, K.-P., Hennigs, N., Varelmann, D., \& Reeh, M.-O. (2010). Determinants of consumers' perceived trust in IT-ecosystems. Journal of Theoretical and Applied Electronic Commerce Research, 5(2), 137-154. doi: 10.4067/s0718-18762010000200009

Williamson, K., \& Johanson, G. (2013). Research Methods: Information, Systems and Contexts: Tilde University Press.

Wold, H. (1980). Model construction and evaluation when theoretical knowledge is scarce. In J. K. J. B. Ramsey (Ed.), Evaluation of Econometric Models (pp. 47-74). New York Academic Press.

Wong, K.K. (2013). Partial Least Squares Structural Equation Modeling (PLS-SEM) Techniques Using SmartPLS, Marketing Bulletin, 24(1), available at http://marketing-bulletin.massey.ac.nz 
Wong, Y., \& Hsu, C. (2008). A confidence-based framework for business to consumer (B2C) mobile commerce adoption. Personal and Ubiquitous Computing, 12(1), 77-84. doi: 10.1007/s00779006-0120-5

Wu, I.-L., \& Chen, J.-L. (2005). An extension of Trust and TAM model with TPB in the initial adoption of on-line tax: An empirical study. International Journal of Human-Computer Studies, 62(6), 784-808. doi: http://dx.doi.org/10.1016/j.ijhcs.2005.03.003

Wu, J.-H., \& Wang, S.-C. (2005). What drives mobile commerce? An empirical evaluation of the revised technology acceptance model. Inf. Manage., 42(5), 719-729. doi: 10.1016/j.im.2004.07.001

Xin, H., Techatassanasoontorn, A. A., \& Tan, F. B. (2013). Exploring the influence of trust on mobile payment adoption. Paper presented at the Pacific Asia Conference on Information Systems (PACIS 2013), Paper 143, Jeju island, South Korea.

Xu, H., Teo, H.-H., \& Tan, B. C. Y. (2005). Predicting The Adoption Of Location-Based Services: The Role Of Trust And Perceived Privacy Risk. Paper presented at the Twenty-Sixth International Conference on Information Systems, Paper 71, Las Vegas, USA.

Yan, A. W., Md-Nor, K., Abu-Shanab, E., \& Sutanonpaiboon, J. (2009). Factors that affect mobile telephone users to use mobile payment solution. International Journal of Economics and Management 3(1), 37-49.

Yan, Z., \& Holtmanns, S. (2008). Trust modeling and management: From social trust to digital trust computer security, privacy and politics: Current Issues, Challenges and Solutions (pp. 290323): IGI Global.

Yang, U.-I. (2007). Mobile payment provider services - the case of South Korea and Austria. Unpublished master's thesis, Seoul National University. From http://www.ec.tuwien.ac.at/ dorn/Thesis/Masters/Yang.pdf

Yao, G., \& Li, Q. (2008). The impact of familiarity and reputation on consumer trust in e-commerce. Paper presented at the 4th International Conference on Wireless Communications, Networking and Mobile Computing,(WiCOM '08), p.1-5, Dalian, China.

Yaseen, S. G., \& Zayed, S. (2010). Exploring determinants in deploying mobile commerce technology: Amman stock exchange. Paper presented at the International Conference on Information Society (i-Society), p.612-620, London, UK.

Yee, J., D. Niemeier. (1996). Advantages and disadvantages: Longitudinal vs. repeated cross-section surveys. Project Battelle, 94(16).

Yeh, Y. S., \& Li, Y.-M. (2009). Building trust in m-commerce: contributions from quality and satisfaction. Online Information Review, 33(6), 1066-1086. doi: 10.1108/14684520911011016

Yen, D. C., \& Lancaster, S. (2008). The Future of m-commerce: The role of Bluetooth and WiMax. In W. W. Huang, Y. Wang \& J. Day (Eds.), Global mobile commerce (Vol. 1, pp. 4332). NY: Information Science Reference.

Yin, R. K. (1994). Case study research: design and methods. (2 ed. Vol. 5): Thousand Oaks: Sage Publications.

Zhang, J., \& Yuan, Y. (2002). M-commerce versus Internet-based e-commerce: the key differences. Paper presented at the Americas Conference on Information Systems, Paper 261, 1892-1901.

Zhihong, L., \& Minxia, L. (2008). Research on influencing factors of consumer initial trust based on mobile commerce. Paper presented at the International Symposium on Electronic Commerce and Security, p. 263 - 267, Guangzhou, China.

Zhou, T. (2011). The effect of initial trust on user adoption of mobile payment. Information Development, 27(4), 290-300.

Zikmund, W. G. (2008). Business research methods: Thomson/South-Western.

Zikmund, W. G., \& Babin, B. J. (2007). Exploring marketing research: Thomson/South-Western.

Zmijewska, A., Lawrence, E., \& Steele, R. (2004). Towards understanding of factors influencing user acceptance of mobile payment systems. Paper presented at the Proceedings of the International Conference on IADIS WWW/Internet, Madrid, Spain. 


\section{Appendices}

- Appendix A-Focus Group Protocol

- Appendix B -Focus Group Interview Guide

- Appendix C - Consent Forms for Focus Group Participation (in English and Arabic)

- Appendix D - List of Main Codes and Categories

- Appendix E - Information Sheet and Questionnaire Surveys (in English and Arabic)

- Appendix F - Normality through Skewness Measures

- Appendix G-Cross Tabulating between Age and Usage

- Appendix H - Consumer Age Statistics 


\section{Appendix A-Focus Group Protocol}

\section{Focus Group Protocol}

To organise the focus groups, the researcher and the external moderator will follow Pickard's (2007) basic protocol design, to do the following:

1. Contact the participants for each of the four focus groups.

2. Select and book a venue with appropriate equipment. The equipment will include a video recorder, an audio recorder, a flip chart, pens, a briefing sheet and a disclaimer. A request for consent to use these facilities should be obtained.

3. Prepare and send invitations in advance with venue location and time. Each focus group will be conducted out of work hours.

4. Room and facilities must be set up and checked at least 30 minutes before.

5. Participants will be asked to arrive 10 minutes early.

6. When the participants arrive, the researcher will introduce himself to the participants, welcome them and inform them about the research. Then he will introduce the external moderator.

Then, the moderator will introduce himself, and then perform the following:

7. Welcome the participants, and perform an ice-breaking activity.

8. Inform the participants about the research goals, privacy issues, and some instructions about moderating the focus group. He will also inform them about a few rules before starting each session (one person talking at a time, loud and clear speaking, usage of names tags, and others).

9. Open the discussion questions.

10. Facilitate interaction between group members, encourage all the participants to share the discussion, and ensure that every participant is taking part in the discussion during the session. This will make the discussion more effective and less biased.

11. Ensure that the discussion is focused on the topic and the research question.

12. Keep the discussion on track. Each focus group session is anticipated to last for 90 minutes. Extra times (up to 30 minutes) would be given in case of requiring details or extending the discussion.

13. Encourage the group members to develop new ideas from their perceptions and experiences. Probe for more detail if needed (the researcher would also take part in this if necessary).

14. Thank all participants. Remind them of the next stage (sending them the transcript of the interview for checking).

15. The group members will be invited for dinner. This is to encourage people to participate and is also consistent with culture in the Emirates. 


\section{Appendix B -Focus Group Interview Guide}

\section{Focus Group Interview Guide}

The following questions will be used during the focus group interviews. The interview will start with asking some demographic questions. Next, the participants will be asked about their trust in m-payments. Then, the questions that are related to the CTMP model will be discussed.

(a) Questions (Demographic information)

1) Age, Gender, Nationality, Educational level, Profession

(b) Introductory question

2) To what extent you trust paying by mobile phones? Why? Why not?

\section{(c) Factors influencing trust in m-payments}

\section{Consumer's Characteristics}

3) Tell me as much as you can about the kinds of people who are likely to trust mpayments?

\section{Environmental Influences (Cultural and Social)}

4) What factors do you think influence the trust people have in m-payments?

Provider's Characteristics (M-payment Provider)

5) What kinds of organisation and what kinds of behaviour can alter the trust that mpayment users might have in the providing company?

\section{Mobile Device Characteristics}

6) Talk about your requirements for devices and networks so that you can have trust in mpayments.

\section{M-Payment Perceived Risk}

7) What specific kinds of risk are most likely to occur, and how much does each limit your trust in m-payment?

\section{(d) Comments and other factors}

8) Do you have any further comments related to the discussed factors that influence consumer trust in m-payments?

9) Can you think of new factors that can influence consumer trust in m-payments?

Note: as the focus group interviews are semi-structured, other points may emerge and will be discussed during the sessions. 


\title{
Appendix C - Consent Forms for Focus Group Participation (in English and Arabic)
}

\author{
Customer Trust in Mobile Payments in the Emirates \\ Consent To Participation In Research
}

Please read carefully the following. Then, fill the followed gaps to indicate agreement:

- I agree to take part in this research.

- I have been provided with an explanation of this research project. I have had an opportunity to ask questions and have them answered to my satisfaction.

- I understand that any information I provide will be kept confidential to the researcher and his supervisors.

- I understand that the published results will not use my name, and that no opinions will be attributed to me in reports or publications based on this research.

- I can receive a summary of the results of this research when it is completed.

- I understand that all raw data will be destroyed two years after the conclusion of this research.

- I understand that data will be used as part of a $\mathrm{PhD}$ thesis, which will be deposited in the VUW institutional repository.

- I understand that research findings may be published in academic or professional journals and presented at international conferences.

- I agree to be contacted if further questions are required.

Name of the participant:

Signature:

Email address:

Phone number:

Session date and time: 


\section{ثقة الزبون في الدفع عبر الموبايل في الامارات}

\section{موافقة للمشاركة للبحث}

يرجى قر اءة النقاط التالية بتمعن. بعد المو افقة قم بتعبئة البيانات اللاحقة.

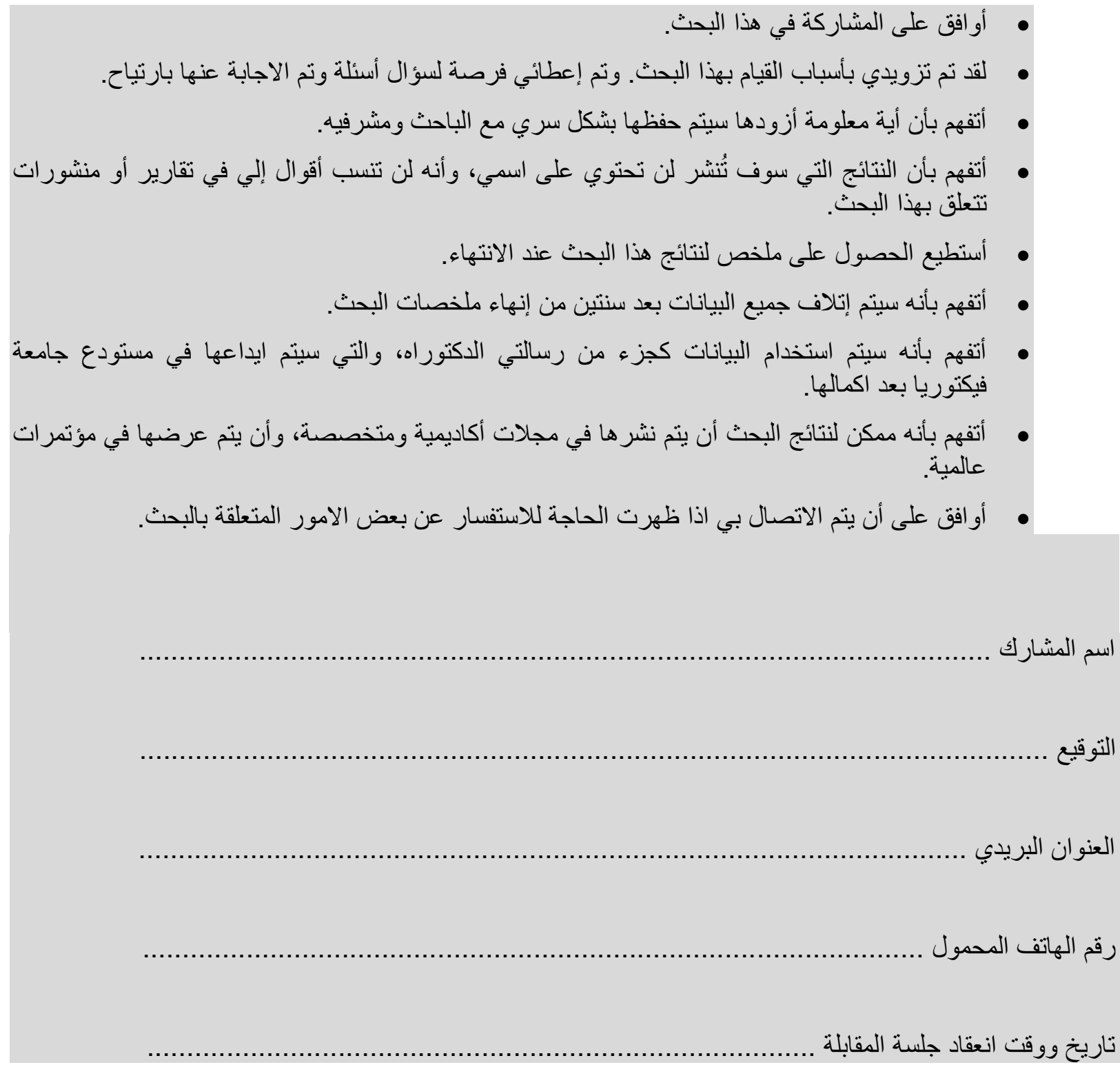




\section{Appendix D - List of Main Codes and Categories}

\section{List of Codes -Data Analysis of Focus Groups}

\section{Category1: Awareness}

Codes: understanding m-payments, own perception, knowledge about m-payments, educating customers, knowing m-payment services

Category 2: Past experience

Codes: using m-payments, positive experience, negative experience, my previous experience, first time trial

Category3: Propensity to Trust

Codes: personal belief, intrinsic attribute, tendency to trust, willing to trust

Category4: Consumer Age

Codes: older generations, young people, mature people, person's age

Category5: Consumer Gender

Codes: males, females, gender

Category6: Trust Environment

Codes: cultural background, literacy, living atmosphere, high-trust culture, low-trust culture, multi-nationality society

Category7: Uncertainty Avoidance

Codes: person's mentality, open-minded, afraid from new technology, conservative

Category8: Provider's Reputation

Codes: image, goodwill, bad reputation, reputable company

Category9: Provider's Trustworthiness

Codes: provider's integrity, provider's capability, provider's dependability, experienced staff, helpful staff

Category10: Trust in Provider's Products and Services

Codes: provider's brands recognition, provider's products, provider's services, Provider's applications

Category11: Financial Risks

Codes: amount of money, micro payments, macro payments,

Category 12: Technical Risks

Codes: technical fault, network servers malfunction, network disconnected, payment process speed

Category13: $\underline{\text { Security Risks }}$

Codes: hacking, safe, safeguard software, stealing digital money, credit card protection

Category14: Privacy Risks

Codes: personal information, credit card information, exposed to others, tracking behaviour, private purchase details

Category15: Device Capability

Codes: smartphones, battery life, payments setup, mobile applications, payments capabilities

Category16: Device Design Suitability

Codes: touch-screen mobiles, small screens, vision accuracy,

Category17: Device Security

Codes: viruses, unauthorised device access, device thefts, built-in features, device brands, passwords, locked devices, lost devices 


\section{Appendix E - Originally cited and adapted items as in literature}

\begin{tabular}{|c|c|c|c|}
\hline Construct & Items from literature & Modified items used in this study & Reference(s) \\
\hline \multirow{3}{*}{$\begin{array}{l}\text { Propensity to } \\
\text { trust }\end{array}$} & $\begin{array}{l}\text { "It is easy for me to trust a person / } \\
\text { thing" }\end{array}$ & It is easy for me to trust a person. & $\begin{array}{l}\text { Lee \& Turban } \\
\quad(2001)\end{array}$ \\
\hline & $\begin{array}{l}\text { "My tendency to trust a person/thing is } \\
\text { high" }\end{array}$ & My tendency to trust a person is high. & $\begin{array}{l}\text { Lee \& Turban } \\
\text { (2001) }\end{array}$ \\
\hline & $\begin{array}{l}\text { "I tend to trust a person/thing, even } \\
\text { though I have little knowledge of it". }\end{array}$ & $\begin{array}{l}\text { I tend to trust a person, even though I have } \\
\text { little knowledge about him/her. }\end{array}$ & $\begin{array}{l}\text { Lee \& Turban } \\
\quad(2001)\end{array}$ \\
\hline \multirow{3}{*}{$\begin{array}{l}\text { Uncertainty } \\
\text { avoidance }\end{array}$} & $\begin{array}{l}\text { "I am cautious in using new technologies } \\
\text { to do my work." }\end{array}$ & $\begin{array}{l}\text { I am always cautious in trying new } \\
\text { technologies. }\end{array}$ & Kim et al. (2009) \\
\hline & $\begin{array}{l}\text { "If possible, it is better to avoid using } \\
\text { new technologies for financial } \\
\text { transactions." }\end{array}$ & $\begin{array}{l}\text { If possible, it is always better to avoid } \\
\text { using new technologies for financial } \\
\text { transactions. }\end{array}$ & Kim et al. (2009) \\
\hline & $\begin{array}{l}\text { "In a new business relationship, I have to } \\
\text { be careful until I see the evidence of a } \\
\text { firm's trustworthiness" }\end{array}$ & $\begin{array}{l}\text { In a new commercial relationship, I have } \\
\text { to be careful until I see the evidence of a } \\
\text { firm's trustworthiness. }\end{array}$ & Kim et al. (2009) \\
\hline \multirow[t]{2}{*}{ Awareness } & $\begin{array}{l}\text { "I am familiar with buying books on the } \\
\text { Internet" }\end{array}$ & I am very familiar with mobile payments. & Gefen (2006) \\
\hline & $\begin{array}{l}\text { "I am familiar with the processes of } \\
\text { purchasing books on the internet". }\end{array}$ & $\begin{array}{l}\text { I am aware of the steps required to } \\
\text { conduct a mobile payment. }\end{array}$ & Gefen (2006) \\
\hline \multirow[t]{2}{*}{ Past experience } & $\begin{array}{l}\text { "I have positive experiences of using the } \\
\text { Internet" }\end{array}$ & $\begin{array}{l}\text { I have positive experience(s) in } \\
\text { conducting mobile payments in the } \\
\text { Emirates. }\end{array}$ & $\begin{array}{c}\text { Connolly and } \\
\text { Bannister (2007) }\end{array}$ \\
\hline & $\begin{array}{l}\text { "I have good experiences of using the } \\
\text { Internet". }\end{array}$ & $\begin{array}{l}\text { I have negative experience(s) in } \\
\text { conducting mobile payments in the } \\
\text { Emirates. }\end{array}$ & $\begin{array}{l}\text { Connolly and } \\
\text { Bannister (2007) }\end{array}$ \\
\hline \multirow[t]{2}{*}{$\begin{array}{c}\text { Trust } \\
\text { environment }\end{array}$} & $\begin{array}{l}\text { "A high degree of trust exists in my } \\
\text { family". }\end{array}$ & A high degree of trust exists in my family. & $\begin{array}{c}\text { Connolly and } \\
\text { Bannister (2007) }\end{array}$ \\
\hline & "I am living in a high trust society". & I am living in a high-trust society. & \\
\hline \multirow{5}{*}{$\begin{array}{l}\text { Provider's } \\
\text { trustworthiness }\end{array}$} & $\begin{array}{l}\text { "Sellers in Amazon's auction are in } \\
\text { general dependable" }\end{array}$ & $\begin{array}{l}\text { I believe that my provider of mobile } \\
\text { payments is honest (that is the provider } \\
\text { makes reliable decisions and honours the } \\
\text { terms that it guarantees). }\end{array}$ & $\begin{array}{l}\text { Mcknight et al. } \\
\text { (2002) }\end{array}$ \\
\hline & $\begin{array}{l}\text { "Sellers in Amazon's auction are in } \\
\text { general reliable" }\end{array}$ & $\begin{array}{l}\text { I believe that my provider of mobile } \\
\text { payments is benevolent (that is the } \\
\text { provider takes the customer's benefit into } \\
\text { consideration when making decisions } \\
\text { concerning the customer's information). }\end{array}$ & $\begin{array}{l}\text { Mcknight et al. } \\
\quad(2002)\end{array}$ \\
\hline & $\begin{array}{l}\text { "Sellers in Amazon's auction are in } \\
\text { general honest" }\end{array}$ & $\begin{array}{l}\text { I believe that my provider of mobile } \\
\text { payments is predictable (that is the } \\
\text { provider's actions in given circumstances } \\
\text { can be predicted from its past behaviours). }\end{array}$ & $\begin{array}{l}\text { Mcknight et al. } \\
\text { (2002) }\end{array}$ \\
\hline & $\begin{array}{l}\text { "LegalAdvice.com is competent and } \\
\text { effective in providing legal advice" }\end{array}$ & $\begin{array}{l}\text { I believe that my provider of mobile } \\
\text { payments is competent (that is the } \\
\text { provider's ability to achieve the expected } \\
\text { result and deliver on its promises). }\end{array}$ & $\begin{array}{l}\text { Mcknight et al. } \\
\text { (2002) }\end{array}$ \\
\hline & $\begin{array}{l}\text { "Sellers in Amazon's auction are in } \\
\text { general trustworthy" }\end{array}$ & $\begin{array}{l}\text { Overall, I believe that my provider of } \\
\text { mobile payments is trustworthy. }\end{array}$ & $\begin{array}{l}\text { Mcknight et al. } \\
(2002)\end{array}$ \\
\hline \multirow{2}{*}{$\begin{array}{l}\text { Provider's } \\
\text { reputation }\end{array}$} & $\begin{array}{l}\text { "This Web retailer has a reputation for } \\
\text { dependability". }\end{array}$ & $\begin{array}{l}\text { I believe that my provider of mobile } \\
\text { payments has a reputation for being } \\
\text { trustworthy. }\end{array}$ & Kim et al. (2009) \\
\hline & $\begin{array}{l}\text { "Provider's products and services are } \\
\text { reputable" }\end{array}$ & $\begin{array}{l}\text { I believe that my provider of mobile } \\
\text { payments has reputable products and } \\
\text { services. }\end{array}$ & Kim et al. (2009) \\
\hline \multirow{2}{*}{$\begin{array}{l}\text { Trust level in } \\
\text { provider's } \\
\text { products and } \\
\text { services } \\
\end{array}$} & $\begin{array}{l}\text { "I feel that A company branded product } \\
\text { fulfils its practical function" }\end{array}$ & $\begin{array}{l}\text { I believe that the branded products and } \\
\text { services offered by my provider are } \\
\text { trustworthy. }\end{array}$ & Yeh and $\mathrm{Li}(2008)$ \\
\hline & "I trust in products and services I have & I trust in products and services that I have & Pavlou (2003) \\
\hline
\end{tabular}




\begin{tabular}{|c|c|c|c|}
\hline & received from this web retailer" & received from my m-payments provider. & \\
\hline \multirow[b]{2}{*}{ Technical risks } & $\begin{array}{l}\text { "In general, this website worked very } \\
\text { well technically" }\end{array}$ & $\begin{array}{l}\text { I believe that mobile payments work very } \\
\text { well technically. }\end{array}$ & $\begin{array}{l}\text { Wiedmann et al. } \\
\text { (2010) }\end{array}$ \\
\hline & $\begin{array}{l}\text { "Internet vendors usually ensure that } \\
\text { transactional information is protected } \\
\text { from accidentally altered or destroyed } \\
\text { during transmission on the Internet" }\end{array}$ & $\begin{array}{l}\text { I believe that mobile payments are } \\
\text { susceptible to being accidentally altered or } \\
\text { destroyed during transmission over the } \\
\text { telecommunication network. }\end{array}$ & $\begin{array}{c}\text { Connolly and } \\
\text { Bannister (2007) }\end{array}$ \\
\hline \multirow{5}{*}{$\begin{array}{l}\text { Level of } \\
\text { Security }\end{array}$} & $\begin{array}{l}\text { "Purchasing on this web site will not } \\
\text { cause financial risks". }\end{array}$ & $\begin{array}{l}\text { I believe that conducting mobile payments } \\
\text { can present financial risks. }\end{array}$ & $\begin{array}{l}\text { Chen \& Barnes } \\
\quad \text { (2007) }\end{array}$ \\
\hline & $\begin{array}{l}\text { "In general, the mobile technology } \\
\text { provides a robust and safe environment } \\
\text { to perform mobile payments". }\end{array}$ & $\begin{array}{l}\text { I believe that mobile technology provides } \\
\text { a robust and safe environment to perform } \\
\text { a mobile payment. }\end{array}$ & $\begin{array}{l}\text { Chandra et al. } \\
\text { (2010) }\end{array}$ \\
\hline & $\begin{array}{l}\text { "The monetary information that I provide } \\
\text { on this web site is well protected" }\end{array}$ & $\begin{array}{l}\text { I believe that the monetary information } \\
\text { that I provide on the mobile device while } \\
\text { conducting a payment is well protected } \\
\text { from hackers and penetrators. }\end{array}$ & $\begin{array}{l}\text { Chen \& Barnes } \\
\text { (2007) }\end{array}$ \\
\hline & $\begin{array}{l}\text { "I feel confident that encryption and } \\
\text { other technological safeguards on the } \\
\text { mobile technology make it safe for me to } \\
\text { make mobile payments". }\end{array}$ & $\begin{array}{l}\text { I feel confident that encryption and other } \\
\text { technological safeguards on mobile } \\
\text { technology make it safe for me to make } \\
\text { mobile payments. }\end{array}$ & $\begin{array}{l}\text { Chandra et al. } \\
\text { (2010) }\end{array}$ \\
\hline & $\begin{array}{l}\text { "I believe transaction conducted through } \\
\text { m-commerce will be secure" }\end{array}$ & $\begin{array}{l}\text { In general, I believe mobile payments are } \\
\text { secure. }\end{array}$ & Wei et al. (2008) \\
\hline \multirow{3}{*}{ Privacy risks } & $\begin{array}{l}\text { "I have no privacy concerns using the } \\
\text { system" }\end{array}$ & $\begin{array}{l}\text { I have privacy concerns regarding mobile } \\
\text { payments. }\end{array}$ & $\begin{array}{c}\text { Connolly and } \\
\text { Bannister (2007) } \\
\end{array}$ \\
\hline & $\begin{array}{l}\text { "This web site does not apply my } \\
\text { personal information for other purposes" }\end{array}$ & $\begin{array}{l}\text { I believe that my mobile payment provider } \\
\text { may use my personal information without } \\
\text { permission. }\end{array}$ & $\begin{array}{l}\text { Chandra et al. } \\
\text { (2010) }\end{array}$ \\
\hline & $\begin{array}{l}\text { "Internet vendors will not divulge } \\
\text { consumers' personal data to other } \\
\text { parties" }\end{array}$ & $\begin{array}{l}\text { I feel concerned about divulging my } \\
\text { personal and financial data to other } \\
\text { parties. }\end{array}$ & $\begin{array}{c}\text { Connolly and } \\
\text { Bannister (2007) }\end{array}$ \\
\hline \multirow[t]{2}{*}{$\begin{array}{l}\text { Device } \\
\text { capability }\end{array}$} & $\begin{array}{l}\text { "I worry about the performance of my } \\
\text { mobile assistant". }\end{array}$ & $\begin{array}{l}\text { I have concerns about the performance of } \\
\text { my mobile device when it comes to } \\
\text { conducting a mobile payment. }\end{array}$ & $\begin{array}{l}\text { Chandra et al. } \\
\text { (2010) }\end{array}$ \\
\hline & $\begin{array}{l}\text { "I worried about the performance of my } \\
\text { mobile assistant" }\end{array}$ & $\begin{array}{l}\text { I am afraid that my mobile device may not } \\
\text { have the ability to conduct a payment. }\end{array}$ & $\begin{array}{c}\text { Wiedmann et al. } \\
\text { (2010) }\end{array}$ \\
\hline
\end{tabular}




\title{
Appendix F - Information Sheet and Questionnaire Surveys (in English and Arabic)
}

\author{
Customer Trust in Mobile Payments in the Emirates \\ Information to Participants \\ Thank you for accessing this questionnaire - before you proceed, please read the \\ information below: \\ - The goal of this research is to understand the factors that influence customer trust in \\ mobile payments in the Emirates. \\ - Your participation is voluntary, and you are implying consent to participate by \\ completing and submitting this survey. \\ - To be able to complete this questionnaire, you should feel (at least) slightly familiar \\ with mobile payments. \\ - This survey is anonymous, and no information that would identify you is being \\ collected. Only aggregate data will be used in any presentations and publications that \\ result from this research. \\ - The questionnaire should take around 15-20 minutes to complete. \\ - This research is a part of a doctoral study, which will be deposited in the VUW \\ institutional repository on completion. \\ - This study has been approved by the Human Ethics Committee of the School of \\ Information Management at Victoria University of Wellington. \\ - All raw data will be kept confidential to the researcher and the two supervisors: \\ Associate Professor Hans Lehmann and Mr Tony Hooper. Throughout the project, raw \\ data will be kept under password and/or lock protection and destroyed two years after \\ the conclusion of the project. \\ - Research findings may be published in academic or professional journals and presented \\ at international conferences. A summary of the key findings will be provided to you and \\ all other research participants upon request.
}

Thank you for your time and cooperation.

Ahmed Shuhaiber

ahmed.shuhaiber@vuw.ac.nz

Mobile phone:

For queries or further information, do not hesitate to contact me on my cell phone or on the email above. Or you can contact my supervisors: Dr Hans Lehmann (hans.lehmann@vuw.ac.nz), or Mr Tony Hooper (tony.hooper@vuw.ac.nz). 


\section{Section1: Demographic data}

Question A: What is your gender?

○ Male

○ Female

Question B: What is your age?
$0<20$
O $\quad 20-29$
O 30-39
O 40-49
○>=50

Question C: What is your highest level of education?

Less than high school

High School

College degree

$\bigcirc$ University degree

$\bigcirc$ Higher education

Question D: What is your marital status?

$\bigcirc$ Single, never married

O Married

○ Separated

O Divorced

O Widowed

O

Question E: What is your profession?
O Employee
O Worker
O Civil servant
$\bigcirc$ Self-employed
○ Student
$\bigcirc$ Other, Please specify

Question E: What is your nationality?

Middle Eastern

East Asian

Pacific Islander

African

European

American

Other, Please specify

Question F: In which Emirate/city do you live?
Abu Dhabi
O Ajman
O Al-Ain
O Dubai
○ Fujairah
○ Ras Al-Khaimah 
○ Sharjah

○ Umm al-Quwain

\section{Introductory Questions about mobile payments}

1) How do you describe your experience in conducting mobile payments:
$\bigcirc$ Had no experience
$\bigcirc$ One-time user
Few-times user
O Many-times user
Continued/regular user

2) What kind of mobile-payment services and applications do you use regularly? (Choose as many as you want to)

\section{Mobile banking}

Downloading audio \& video files

Paying bills (for electricity, water)

Entertainment (downloading online games)

Paying traffic registrations and fines.

Downloading audio \& video files

None
Voting to TV channels

Booking air tickets

Online shopping

Paying charity

Telecommunication services (mobile credit)

Paying for parking

Other(s), please specify

3) What amount of money are you willing to trust when you make a mobile payment (in Dirhams)?

Less than 100

(c) $100-500$

$500-1000$

$1000-5000$

More than 5000

4) In general, what level of trust do you have in mobile payments in the Emirates (give a score from 1 to 10 )

Low Level of Trust

High Level of Trust

1 2 3 4 5 6 7 8 9 
Section 2: Your perceptions on the personal characteristics and experiences relating trust in mobile payments.

\begin{tabular}{|c|c|c|c|c|c|c|c|c|c|c|}
\hline \multirow[t]{2}{*}{ Code } & \multirow{2}{*}{$\begin{array}{l}\text { Please specify the extent to which you } \\
\text { agree or disagree with the following } \\
\text { statements }\end{array}$} & \multicolumn{5}{|c|}{ Most strongly disagree } & \multicolumn{4}{|c|}{ Most strongly agree } \\
\hline & & 1 & 2 & 3 & 4 & $\begin{array}{c}5 \\
\text { Neutral }\end{array}$ & 6 & 7 & 8 & 9 \\
\hline B1 & It is easy for me to trust a person. & & & & & & & & & \\
\hline B2 & My tendency to trust a person is high. & & & & & & & & & \\
\hline B3 & $\begin{array}{l}\text { I tend to trust a person, even though I have little } \\
\text { knowledge about him/her. }\end{array}$ & & & & & & & & & \\
\hline B4 & $\begin{array}{l}\text { I am always cautious in trying new } \\
\text { technologies. }\end{array}$ & & & & & & & & & \\
\hline B5 & $\begin{array}{l}\text { If possible, it is always better to avoid using } \\
\text { new technologies for financial transactions. }\end{array}$ & & & & & & & & & \\
\hline B6 & $\begin{array}{l}\text { In a new commercial relationship, I have to be } \\
\text { careful until I see the evidence of a firm's } \\
\text { trustworthiness. }\end{array}$ & & & & & & & & & \\
\hline B7 & I am very familiar with mobile payments. & & & & & & & & & \\
\hline B8 & $\begin{array}{l}\text { I am aware of mobile payments applications in } \\
\text { the Emirates. }\end{array}$ & & & & & & & & & \\
\hline B9 & $\begin{array}{l}\text { I am aware of mobile payments services in the } \\
\text { Emirates. }\end{array}$ & & & & & & & & & \\
\hline B10 & $\begin{array}{l}\text { I am aware of the steps required to conduct a } \\
\text { mobile payment. }\end{array}$ & & & & & & & & & \\
\hline B11 & $\begin{array}{l}\text { I have positive experience }(s) \text { in conducting } \\
\text { mobile payments in the Emirates. }\end{array}$ & & & & & & & & & \\
\hline B12 & $\begin{array}{l}\text { I have negative experience(s) in conducting } \\
\text { mobile payments in the Emirates. }\end{array}$ & & & & & & & & & \\
\hline
\end{tabular}

Section 3: Your perceptions on the environmental influences relating to trust in mobile payments.

\begin{tabular}{|c|c|c|c|c|c|c|c|c|c|c|}
\hline \multirow[t]{2}{*}{ Code } & \multirow{2}{*}{$\begin{array}{l}\text { Please specify the extent to which you } \\
\text { agree or disagree with the following } \\
\text { statements }\end{array}$} & \multicolumn{5}{|c|}{ Most strongly disagree } & \multicolumn{4}{|c|}{ Most strongly agree } \\
\hline & & 1 & 2 & 3 & 4 & $\begin{array}{c}5 \\
\text { Neutral }\end{array}$ & 6 & 7 & 8 & 9 \\
\hline $\mathrm{C} 1$ & A high degree of trust exists in my family. & & & & & & & & & \\
\hline $\mathrm{C} 2$ & I am living in a high-trust society. & & & & & & & & & \\
\hline C3 & $\begin{array}{l}\text { People in my society always tend to avoid } \\
\text { trusting in new payment methods, such as } \\
\text { mobile payments. }\end{array}$ & & & & & & & & & \\
\hline
\end{tabular}


Section 4: Your perceptions on the characteristics of the m-payments provider relating to trust in mobile payments.

\begin{tabular}{|c|c|c|c|c|c|c|c|c|c|c|}
\hline \multirow[t]{2}{*}{ Code } & \multirow{2}{*}{$\begin{array}{l}\text { Please specify the extent to which you } \\
\text { agree or disagree with the following } \\
\text { statements }\end{array}$} & \multicolumn{5}{|c|}{ Most strongly disagree } & \multicolumn{4}{|c|}{ Most strongly agree } \\
\hline & & 1 & 2 & 3 & 4 & $\begin{array}{c}5 \\
\text { Neutral }\end{array}$ & 6 & 7 & 8 & 9 \\
\hline D1 & $\begin{array}{l}\text { I believe that my provider of mobile payments is } \\
\text { honest (that is the provider makes reliable decisions } \\
\text { and honours the terms that it guarantees). }\end{array}$ & & & & & & & & & \\
\hline D2 & $\begin{array}{l}\text { I believe that my provider of mobile payments is } \\
\text { benevolent (that is the provider takes the customer's } \\
\text { benefit into consideration when making decisions } \\
\text { concerning the customer's information). }\end{array}$ & & & & & & & & & \\
\hline D3 & $\begin{array}{l}\text { I believe that my provider of mobile payments is } \\
\text { predictable (that is the provider's actions in given } \\
\text { circumstances can be predicted from its past } \\
\text { behaviours). }\end{array}$ & & & & & & & & & \\
\hline D4 & $\begin{array}{l}\text { I believe that my provider of mobile payments is } \\
\text { competent (that is the provider's ability to achieve } \\
\text { the expected result and deliver on its promises). }\end{array}$ & & & & & & & & & \\
\hline D5 & $\begin{array}{l}\text { Overall, I believe that my provider of mobile } \\
\text { payments is trustworthy. }\end{array}$ & & & & & & & & & \\
\hline D6 & $\begin{array}{l}\text { I believe that my provider of mobile payments has a } \\
\text { reputation for being trustworthy. }\end{array}$ & & & & & & & & & \\
\hline D7 & $\begin{array}{l}\text { I believe that my provider of mobile payments has } \\
\text { reputable products and services. }\end{array}$ & & & & & & & & & \\
\hline D8 & $\begin{array}{l}\text { I believe that the branded products and services } \\
\text { offered by the provider are trustworthy. }\end{array}$ & & & & & & & & & \\
\hline D9 & $\begin{array}{l}\text { I trust in products and services that I have received } \\
\text { from my m-payments provider. }\end{array}$ & & & & & & & & & \\
\hline
\end{tabular}

Section 5: Your perceptions on the perceived risks relating to trust in mobile payments.

\begin{tabular}{|c|c|c|c|c|c|c|c|c|c|c|}
\hline \multirow[t]{2}{*}{ Code } & \multirow{2}{*}{$\begin{array}{l}\text { Please specify the extent to which you } \\
\text { agree or disagree with the following } \\
\text { statements }\end{array}$} & \multicolumn{5}{|c|}{ Most strongly disagree } & \multicolumn{4}{|c|}{ Most strongly agree } \\
\hline & & 1 & 2 & 3 & 4 & $\begin{array}{c}5 \\
\text { Neutral }\end{array}$ & 6 & 7 & 8 & 9 \\
\hline E1 & $\begin{array}{l}\text { I believe that mobile payments work very well } \\
\text { technically. }\end{array}$ & & & & & & & & & \\
\hline E2 & $\begin{array}{l}\text { I believe that mobile payments are susceptible } \\
\text { to being accidentally altered or destroyed during } \\
\text { transmission over the telecommunication } \\
\text { network. }\end{array}$ & & & & & & & & & \\
\hline E3 & $\begin{array}{l}\text { I believe that mobile payments are protected } \\
\text { from technical malfunctions and issues. }\end{array}$ & & & & & & & & & \\
\hline E4 & $\begin{array}{l}\text { I believe that conducting mobile payments can } \\
\text { present financial risks. }\end{array}$ & & & & & & & & & \\
\hline E5 & $\begin{array}{l}\text { I believe that mobile technology provides a } \\
\text { robust and safe environment to perform a } \\
\text { mobile payment. }\end{array}$ & & & & & & & & & \\
\hline E6 & $\begin{array}{l}\text { I believe that the monetary information that I } \\
\text { provide on the mobile device while conducting }\end{array}$ & & & & & & & & & \\
\hline
\end{tabular}




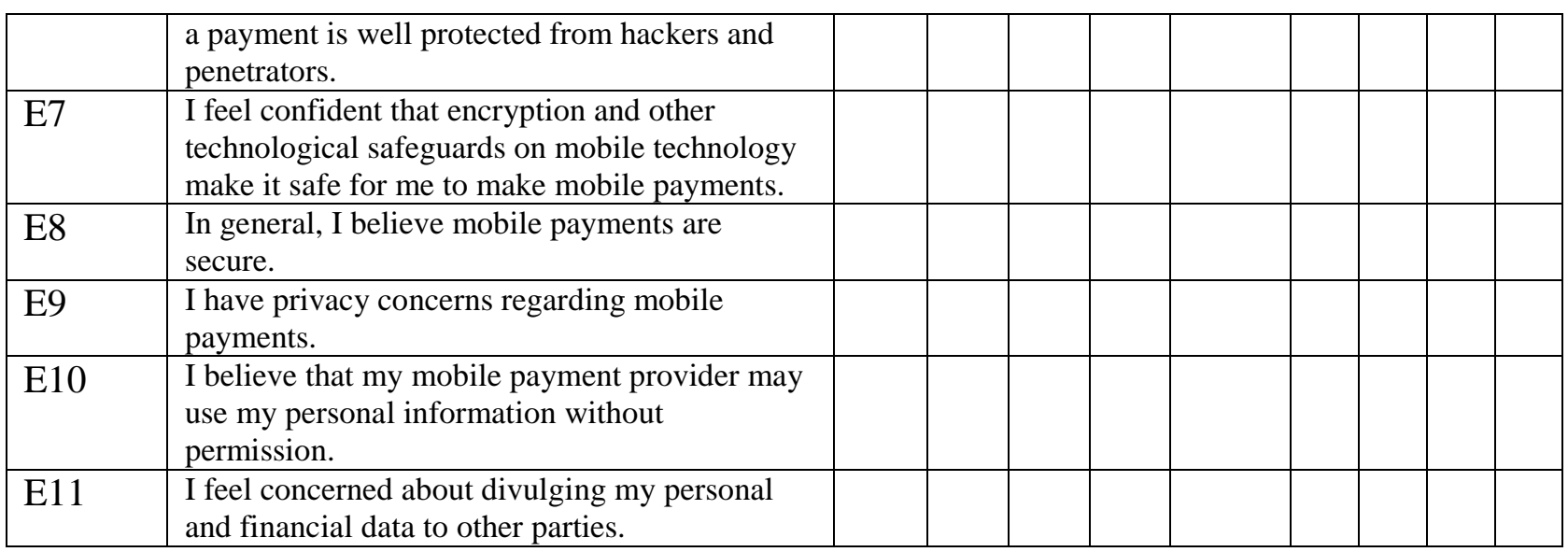

Section 6: Your perceptions on the mobile characteristics relating to trust in mobile payments.

\begin{tabular}{|c|c|c|c|c|c|c|c|c|c|c|}
\hline \multirow[t]{2}{*}{ Code } & \multirow{2}{*}{$\begin{array}{l}\text { Please specify the extent to which you } \\
\text { agree or disagree with the following } \\
\text { statements }\end{array}$} & \multicolumn{4}{|c|}{ Most strongly disagree } & \multicolumn{5}{|c|}{ Most strongly agree } \\
\hline & & 1 & 2 & 3 & 4 & $\begin{array}{c}\mathbf{5} \\
\text { Neutral }\end{array}$ & 6 & 7 & 8 & 9 \\
\hline F1 & $\begin{array}{l}\text { I have concerns about the performance of my } \\
\text { mobile device when it comes to conducting a } \\
\text { mobile payment. }\end{array}$ & & & & & & & & & \\
\hline $\mathrm{F} 2$ & $\begin{array}{l}\text { I am afraid that my mobile device may not have } \\
\text { the ability to conduct a payment. }\end{array}$ & & & & & & & & & \\
\hline F3 & $\begin{array}{l}\text { I believe that the design of a mobile device can } \\
\text { enable it to conduct a payment. }\end{array}$ & & & & & & & & & \\
\hline F4 & $\begin{array}{l}\text { I believe that the screen design of a mobile } \\
\text { device can enable it to conduct a payment. }\end{array}$ & & & & & & & & & \\
\hline F5 & $\begin{array}{l}\text { I believe that the keypad design of a mobile } \\
\text { device can enable it to conduct a payment. }\end{array}$ & & & & & & & & & \\
\hline F6 & $\begin{array}{l}\text { I believe that mobile devices are secure enough } \\
\text { for conducting a payment. }\end{array}$ & & & & & & & & & \\
\hline F7 & $\begin{array}{l}\text { I believe that mobile devices contain software } \\
\text { that can secure the device and make the data } \\
\text { stored unavailable to others. }\end{array}$ & & & & & & & & & \\
\hline F8 & $\begin{array}{l}\text { I believe that no one can get access to the data } \\
\text { on my mobile without my permission. }\end{array}$ & & & & & & & & & \\
\hline
\end{tabular}

Thank you for your time completing this survey

If you would like to enter the prize draw for a (100Dhs gift voucher) from Carrefour shopping store, please provide your email address in the following blank box.

Email address: 


\section{ثقة الزبون في الدفع عبر الموبايل فى الامارات

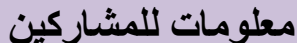

أشكركم للوصول إلى هذه الدراسة ـ قبل البدء، أرجو قراءة النقاط التالية:

أنا اسمي أحمد شحيبر، طالب دكتور اه في جامعة فيكتوريا في ويلينغتون/ نيوزلنة لند في قسم ادارة المعلومات. الهدف من هذه الدر اسة فهم العو امل التي تؤثر في ثقة الزبائن بالدفع عبر الموبايل بين الثركات و الزبائن في الامار ات العربية المتحدة. تعد هذه الاستبانة جزء مهم لحصولي على درجة الدكتور اه. مشاركتكم في هذه الدر اسة تطو عية. استكمال هذه الاستبانة تعني ضمنا المو افقة على المشاركة. لتكون قادر على استكمال هذا الاستبيان، يجب أن تشعر (على الأقل) أنك على دراية قليلة بالدفع عبر الموبايل. مشاركتكم في هذه الدر اسة لن تعلن، كم ولن يتم جمع أب معلومات من شأنها أن تحدد هويتكم. سوف تستخدم البيانات المجمعة فقط في العروض و المنشور ات التي تتعلق بهذا البحث. إكمال هذا الاستبيان يستغرق حو الي 15-20 دقيقة. تم اعتماد هذه الدر اسة من قبل لجنة الأخلاقيات الإنسانية في كلية إدارة المعلومات في جامعة فيكتوريا في ويلينغتون. سوف ينم التعامل بجميع البيانات بشكل سري من قبل الباحث ومشرفيه د. هانز ليمان و السيد توني هوبر. خلال هذه الدر اسة، سيتم حفظ البيانات بكلمة سر و/أو تأمين حماية مادية لها، ثم سيتم تلفها بعد سنتين من انتهاء

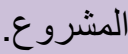

سيتم ايداع هذه الدراسة في مكتبة جامعة فيكتوريا بعد إكمالها. بالإضافة الى ذلك، ممكن لنتائج البحث أن يتم نشر ها في مجلات أكاديمية ومتخصصة، وأن تعرض في مؤتمر ات عالمية. سيتم إرسال ملخص من هذه النتائج لكم بناء على طلبكم.

$$
\text { أنشكركم على وقتكم وتعاو نكم }
$$
بريد الكتروني: ahmed.shuhaiber@vuw.ac.nz أو aمول 
العوامل المؤثرة في ثقة الزبائن في الدفع عبر الموبايل: دراسة في دولة الامارات العربية المتحدة

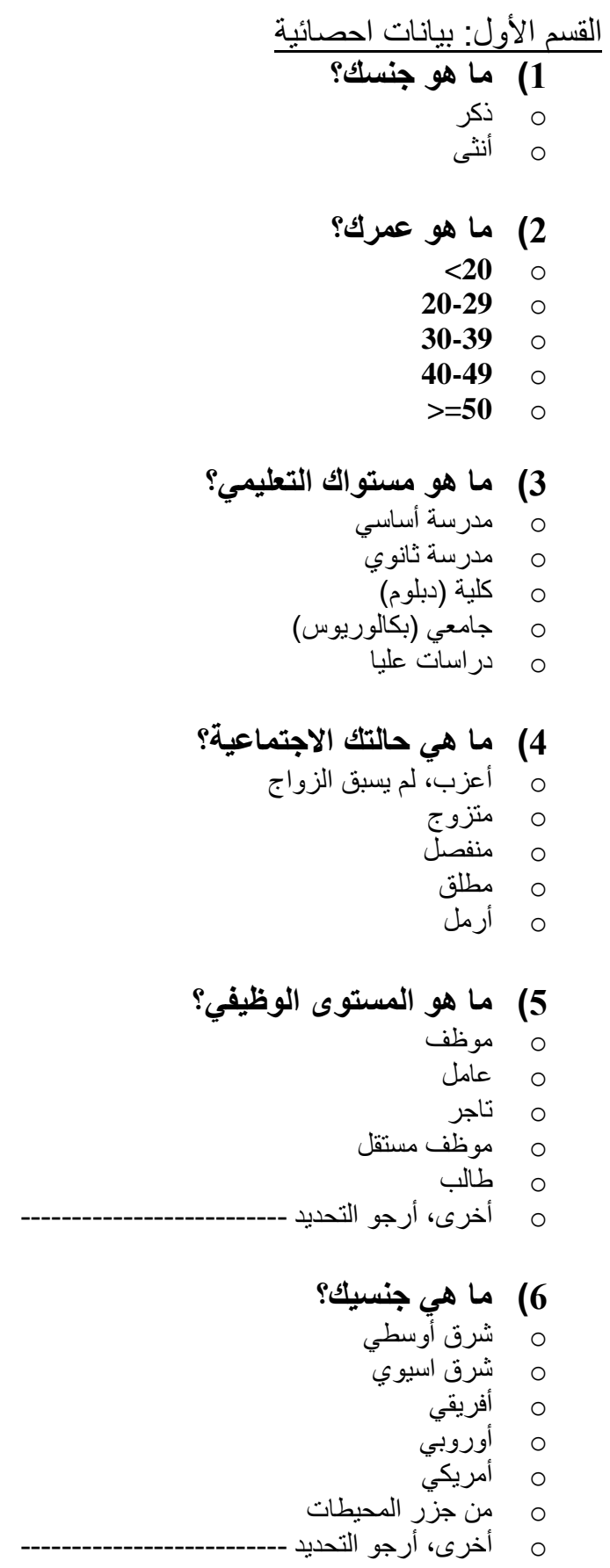


أسئلة افتتاحية عن الدفع عبر الموبايل

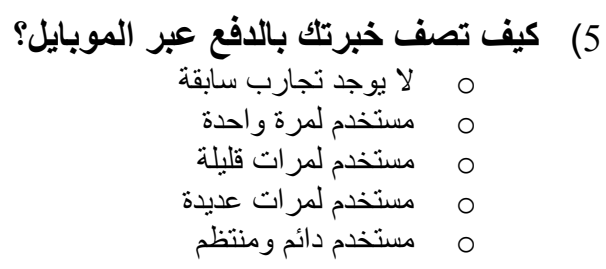

6) أي من خدمات أو تطبيقات الدفع عبر الموبايل تستخدم أو ترغب بالاستخدام؟

الخدمات البنكية عبر الموبايل

تحميل ملفات صوتية وفيديو من الإنترنت

$$
\text { دفع فو اتير (مياه، كهرباء) }
$$$$
\text { لأغر اض التسلية وتحميل الألعاب }
$$$$
\text { دفع اشتر اكات ومخالفات السير }
$$

أشتر اكات أخبار أو مجمو عات اجتماعية

لا يوجد

$$
\text { التصويت لقنوات تلفزيونية }
$$$$
\text { حجز تذاكر سفر }
$$$$
\text { التسوق عبر الإنترنت }
$$$$
\text { دفع زكاة وتبر عات }
$$

خدمات شركة الاتصالات ( مثل شحن الرصيد)

الدفع لمو اقف السيار ات

أخرى، أرجو التحديد

$$
\begin{aligned}
& \text { 7) ما هي القيمة المالية التي تثث بدفعها عبر الموبايل (بالدرهم)؟ } \\
& \text { م أقل من } 100 \\
& 500-100 \text { ○ } \\
& 1000-500 \quad \circ \\
& 5000-1000 \\
& \text { م أكبر من } 5000
\end{aligned}
$$

8) بشكل عام، إلى أي درجة تثث بالدفع عبر الموبايل في الامارات؟ أعط درجة من 1 إلى 10

ثقة كبيزة

7
6 6 4

\section{ثقة قليلة}

3

2 
القسم الثانى: رأيك وتصورك عن الخصائص الثخصية والخبرات السابقة للزبون وأثرها على الثقة في الدفع عبر الموبايل

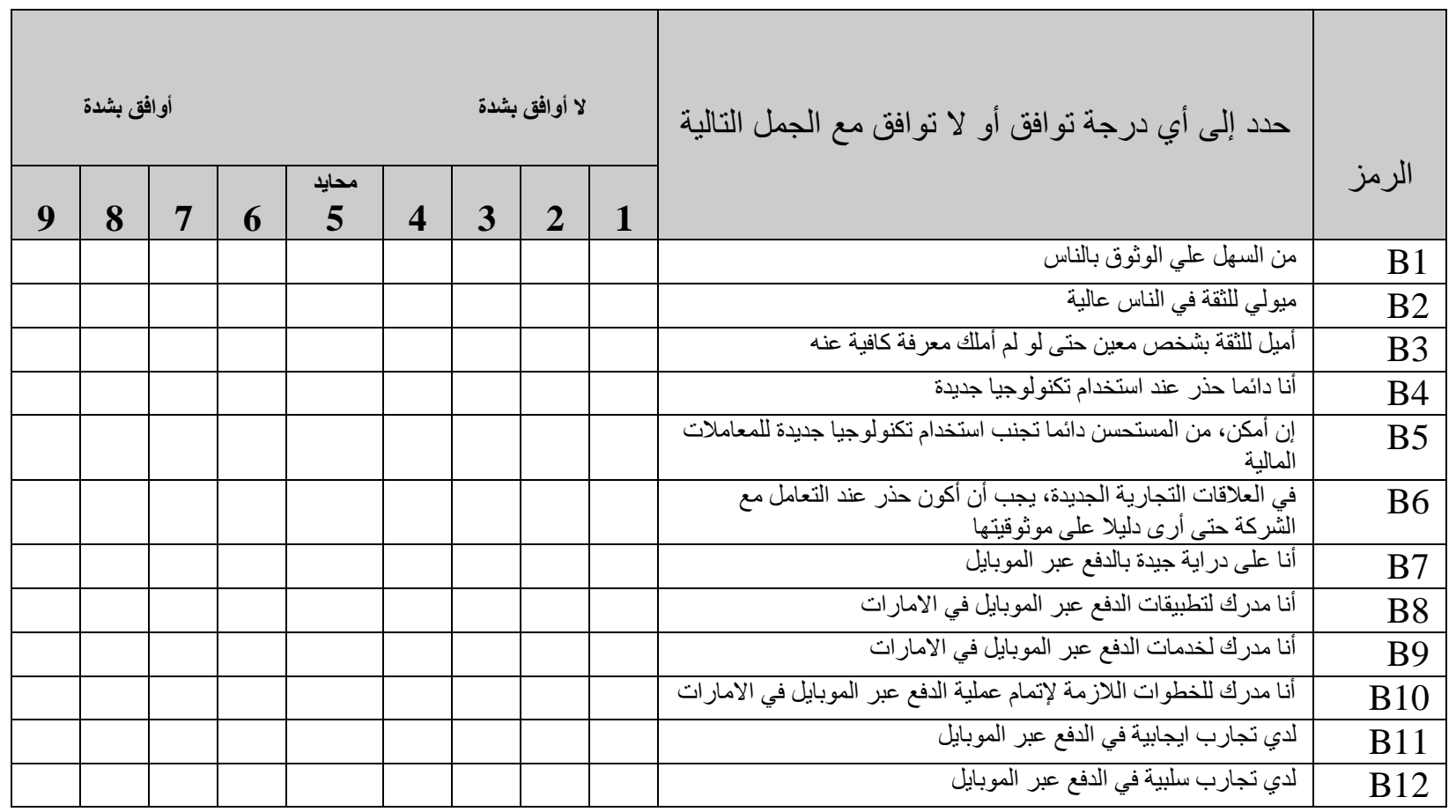

القسم الثالث: رأيك وتصورك عن العو امل الاجتماعية و الثقافية المحيطة بالزبون و أثر ها على الثقة في الدفع عبر الموبايل

\begin{tabular}{|c|c|c|c|c|c|c|c|c|c|c|}
\hline \multicolumn{4}{|c|}{ 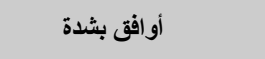 } & \multicolumn{5}{|c|}{ لا أوافق بشدة } & \multirow{2}{*}{ حدد إلى أي درجة تو افق أو لا تو افق مع الجمل التالية } & \multirow{2}{*}{ 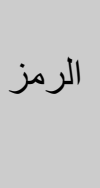 } \\
\hline 9 & 8 & 7 & 6 & 5 & 4 & $\mathbf{3}$ & 2 & 1 & & \\
\hline & & & & & & & & & لاى أفر اد عائلتي درجة عالية من الثقة & $\mathrm{C} 1$ \\
\hline & & & & & & & & & أنا أعيش وسط مجتمع يتميز بالثقة العالية بين أفراده & $\mathrm{C} 2$ \\
\hline & & & & & & & & & عبر الموبايل مجتمعي دائما يميلون لتجنب الثقة بطرق دفع جديدة، مثل الدفع & $\mathrm{C} 3$ \\
\hline
\end{tabular}

القسم الر ابع: رائك وتصورك عن خصائص الثركة المزودة لخدمة الدفع عبر الموبايل و أثر ها على ثقة الزبون فى الدفع

\begin{tabular}{|c|c|c|c|c|c|c|c|c|c|c|}
\hline \multicolumn{3}{|c|}{ 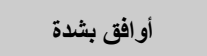 } & \multicolumn{6}{|c|}{ 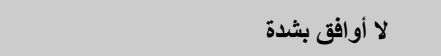 } & \multirow{2}{*}{ حدد إلى أي درجة تو افق أو لاتو افق مع الجمل التالية } & \multirow{2}{*}{ 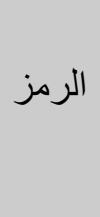 } \\
\hline 9 & 8 & 7 & 6 & محايد & 4 & 3 & 2 & 1 & & \\
\hline & & & & & & & & & 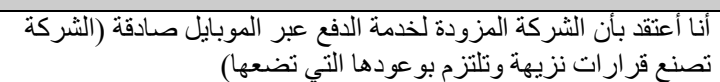 & D1 \\
\hline & & & & & & & & & 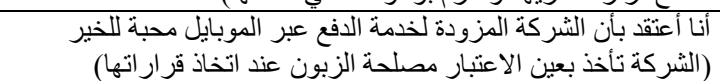 & D2 \\
\hline & & & & & & & & & أنا أعتقد بأن تصرفات الثركة المزودة لخدمة الدفع عبر الموبايل قابلة & D3 \\
\hline
\end{tabular}




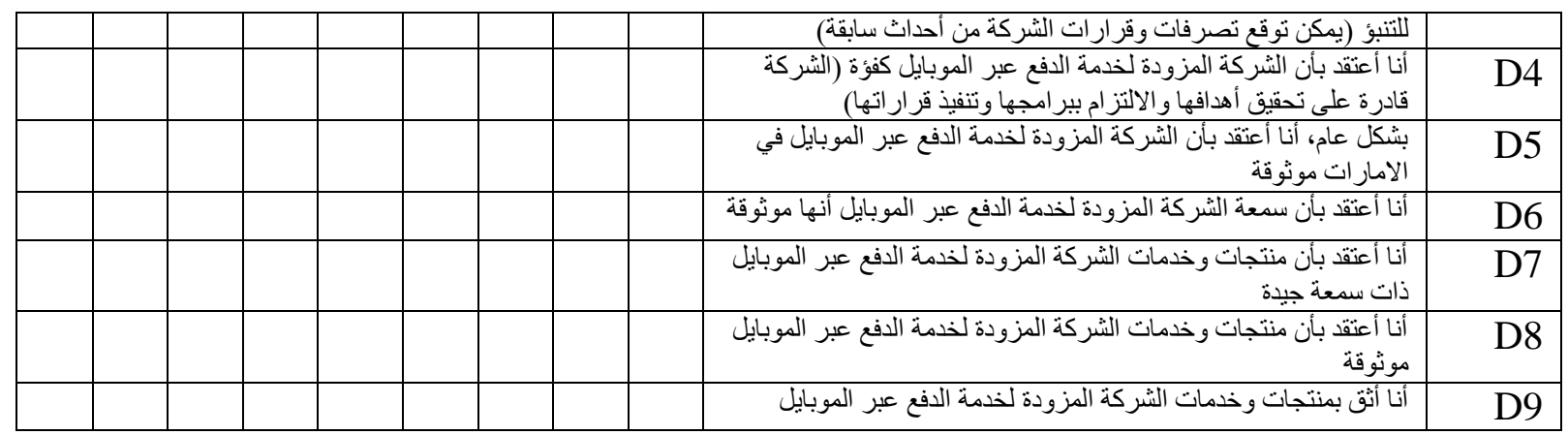

القسم الخامس: رأيك عن المخاطر المتصورة المتعلقة بالدفع عبر الموبايل و أثرها على ثقة الزبون بها

\begin{tabular}{|c|c|c|c|c|c|c|c|c|c|c|}
\hline \multicolumn{3}{|c|}{ أوافق بثدة } & \multicolumn{6}{|c|}{ 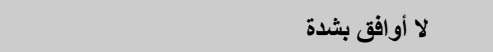 } & \multirow{2}{*}{ حدد إلى أي درجة توافق أو لا تو افق مع الجمل التالية } & \multirow{2}{*}{ 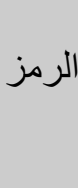 } \\
\hline 9 & 8 & 7 & 6 & محايد & 4 & 3 & 2 & 1 & & \\
\hline & & & & & & & & & أنا أعتقد بأن عملية الدفع عبر الموبايل تعمل تقنياً بشكل جيد جدا & E1 \\
\hline & & & & & & & & & أثناء أنتقالها عبر شملية الدفع عبر الاتصالات بايل عرضة للتندمير أو التبديل & E2 \\
\hline & & & & & & & & & أفنا أعتقد بأن عملية الدفع عبر الموبايل محمية من الأعطال و المشاكل & E3 \\
\hline & & & & & & & & & أنا أعتقد بأن الدفع عبر الموبايل يثرتب عليه مخاطر مالية & E4 \\
\hline & & & & & & & & & ألنا أعتقد بأن تكنولو جيا الموبايل تعتبر بيئة امنة ومتينة للقيام بعطلية & E5 \\
\hline & & & & & & & & & 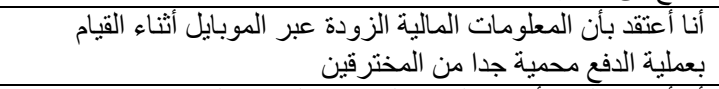 & $\overline{\mathrm{E} 6}$ \\
\hline & & & & & & & & & 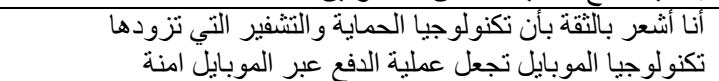 & E7 \\
\hline & & & & & & & & & بشكل عام، أنا أعتقا بأن عملية الدفع عبر الموبايل امنة & E8 \\
\hline & & & & & & & & & لدي مخاوف تتعلق بالخصوصية اتجاه الدفع عبر الموبايل & $\overline{\mathrm{E} 9}$ \\
\hline & & & & & & & & & 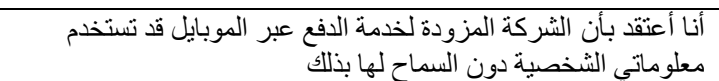 & E10 \\
\hline & & & & & & & & & والثمالية بالقلق اتجاه أخرى عبر الموبايل بسبب نثر معلوماتي الثخصبة & $\overline{E 11}$ \\
\hline
\end{tabular}

القسم السادس: رأيك وتصورك عن خصائص جهاز الموبايل وأثر ها على ثقة الزبون في الدفع عبره

\begin{tabular}{|c|c|c|c|c|c|c|c|c|c|c|}
\hline \multicolumn{3}{|c|}{ 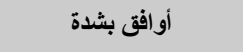 } & & \multicolumn{5}{|c|}{ لا لا أوافق بثدة } & \multirow{2}{*}{ حدد إلى أي درجة نوافق أو لا تو افق مع الجمل التالية } & \multirow{2}{*}{ 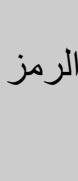 } \\
\hline 9 & 8 & 7 & 6 & 5 & 4 & 3 & 2 & 1 & & \\
\hline & & & & & & & & & أنا أشعر بالقلق اتجاه أداء جهاز الموبايل لللفحع من خلاله & F1 \\
\hline & & & & & & & & & يعمل بشكل جيد عندها أنسيع جهاز الموبايل أن يؤدي عملية دفح، أو أن لا & $\mathrm{F} 2$ \\
\hline & & & & & & & & & أنا أعتقد بأن تصميم جهاز الموبايليمكنه من القيام بإجراء عملية دفع & F3 \\
\hline & & & & & & & & & دفع أنقأ بأن تصميم شاشَّة جهاز الموبايل يمكنه من القيام بإجراء عملية & $\mathrm{F} 4$ \\
\hline & & & & & & & & & عأنا أتثقد بأن تصميج لوحة مفاتيح جهاز الموبايل بمكنه من القيام باجراء & F5 \\
\hline & & & & & & & & & أنا أعتقا آن جهاز الموبايل امن بشكل كافي للقيام بالدفع من خلاله & F6 \\
\hline
\end{tabular}




\begin{tabular}{|l|l|l|l|l|l|l|l|r|r|}
\hline & & & & & & & & F7 \\
\hline & & & & & & & & F8 \\
\hline
\end{tabular}

شكراً جزيلاُ لوقتكم الذي قضيتموه للمشاركة في هذه الدراسة

إذا رغبت بالدخول في السحب على القسيمة الثر ائية من أسواق الكارفور، قم بكتابة عنو انك البريدي في المكان المخصص في الاسفل العنوان البريدي : 


\section{Appendix G - Normality through Skewness Measures}

\begin{tabular}{|c|c|c|c|c|c|}
\hline \multicolumn{6}{|c|}{ Descriptive Statistics } \\
\hline \multirow{2}{*}{ Item Code } & \multirow{2}{*}{$\begin{array}{c}\text { N } \\
\text { Statistic }\end{array}$} & \multicolumn{2}{|c|}{ Skewness } & \multicolumn{2}{|c|}{ Kurtosis } \\
\hline & & Statistic & $\begin{array}{l}\text { Std. } \\
\text { Error }\end{array}$ & Statistic & $\begin{array}{l}\text { Std. } \\
\text { Error }\end{array}$ \\
\hline B1_Propensity1 & 340 & -.076 & .132 & -.722 & .264 \\
\hline B2_Propensity2 & 340 & .131 & .132 & -.645 & .264 \\
\hline B3_Propensity3 & 340 & .050 & .132 & -.811 & .264 \\
\hline B4_UncerAvoid1 & 340 & -.157 & .132 & -1.042 & .264 \\
\hline B5_UncertAvoid2 & 340 & -.481 & .132 & -.596 & .264 \\
\hline B6_UncertAvoid3 & 340 & -.427 & .132 & -.046 & .264 \\
\hline B7_Awareness1 & 340 & -1.009 & .132 & .527 & .264 \\
\hline B8_Awareness2 & 340 & -.798 & .132 & -.368 & .264 \\
\hline B9_Awareness3 & 340 & -.692 & .132 & -.386 & .264 \\
\hline B10_Awareness4 & 340 & -.768 & .132 & -.140 & .264 \\
\hline B11_ExperiencePos & 340 & -.868 & .132 & -.069 & .264 \\
\hline B12_ExperienceNeg & 340 & -.758 & .132 & -.048 & .264 \\
\hline C1_Environment1 & 340 & -.635 & .132 & -.599 & .264 \\
\hline C2_Environment2 & 340 & -.588 & .132 & -.082 & .264 \\
\hline C3_Environment3 & 340 & -.502 & .132 & -.332 & .264 \\
\hline D1_Trustworthiness1 & 340 & -.691 & .132 & -.160 & .264 \\
\hline D2_Trustworthiness 2 & 340 & -.673 & .132 & .250 & .264 \\
\hline D3_Trustworthiness 3 & 340 & -.502 & .132 & -.502 & .264 \\
\hline D4_Trustworthiness 4 & 340 & -.439 & .132 & -.403 & .264 \\
\hline D5_Trustworthiness 5 & 340 & -.706 & .132 & -.212 & .264 \\
\hline D6_Reputation1 & 340 & -.863 & .132 & -.150 & .264 \\
\hline D7_Reputation2 & 340 & -.831 & .132 & .135 & .264 \\
\hline D8_Products2 & 340 & -.519 & .132 & -.488 & .264 \\
\hline D9_Products3 & 340 & -.330 & .132 & -.884 & .264 \\
\hline E1_RiskTEchnical1 & 340 & -.550 & .132 & -.402 & .264 \\
\hline E2_RiskTechnical2 & 340 & -.409 & .132 & -.832 & .264 \\
\hline E3_RiskTechnical3 & 340 & -.414 & .132 & -.409 & .264 \\
\hline E4_RiskSecurity1 & 340 & .054 & .132 & -.920 & .264 \\
\hline E5_RiskSecurity2 & 340 & -.333 & .132 & -.265 & .264 \\
\hline E6_RiskSecurity3 & 340 & -.475 & .132 & -.466 & .264 \\
\hline E7_RiskSecurity4 & 340 & -.608 & .132 & -.056 & .264 \\
\hline E8_RiskSecurity5 & 340 & -.412 & .132 & -.625 & .264 \\
\hline E9_RiskPrivacy1 & 340 & -.290 & .132 & -.704 & .264 \\
\hline E10_RiskPrivacy2 & 340 & .108 & .132 & -.647 & .264 \\
\hline E11_RiskPrivacy3 & 340 & -.273 & .132 & -.687 & .264 \\
\hline F1_MobCapability1 & 340 & -.092 & .132 & -.637 & .264 \\
\hline F2_MobCapability2 & 340 & .204 & .132 & -.773 & .264 \\
\hline F3_MobDesign1 & 340 & -.106 & .132 & -1.015 & .264 \\
\hline F4_MobDesign2 & 340 & -.307 & .132 & -.803 & .264 \\
\hline
\end{tabular}




\begin{tabular}{|l|l|l|r|r|r|} 
F5_MobDesign3 & 340 & -.046 & .132 & -.851 & .264 \\
F6_MobSecurity1 & 340 & -.608 & .132 & .025 & .264 \\
F7_MobSecurity2 & 340 & -.496 & .132 & -.270 & .264 \\
F8_MobSecurity3 & 340 & -.253 & .132 & -.792 & .264 \\
TrustScore & 340 & -.587 & .132 & -.359 & .264 \\
Valid N (listwise) & 340 & & & & \\
\hline
\end{tabular}




\section{Appendix H - Cross Tabulating between Age and Usage}

\section{Multiple Comparisons}

Dependent Variable: Trust Measure

\begin{tabular}{|c|c|c|c|c|c|c|c|}
\hline \multirow{2}{*}{\multicolumn{2}{|c|}{ (I) What is your age? }} & \multirow[t]{2}{*}{ (J) What is your age? } & \multirow[b]{2}{*}{$\begin{array}{c}\text { Mean Difference } \\
(\mathrm{I}-\mathrm{J}) \\
\end{array}$} & \multirow[b]{2}{*}{$\begin{array}{l}\text { Std. } \\
\text { Error }\end{array}$} & \multirow[b]{2}{*}{ Sig. } & \multicolumn{2}{|c|}{$\begin{array}{c}\text { 95\% Confidence } \\
\text { Interval }\end{array}$} \\
\hline & & & & & & $\begin{array}{l}\text { Lower } \\
\text { Bound }\end{array}$ & $\begin{array}{l}\text { Upper } \\
\text { Bound }\end{array}$ \\
\hline \multirow[t]{20}{*}{ Scheffe } & \multirow[t]{4}{*}{ Less than 20} & $20-30$ & -.899 & .394 & .269 & -2.12 & .32 \\
\hline & & $31-40$ & $-1.909^{*}$ & .382 & .000 & -3.09 & -.73 \\
\hline & & $-41-50$ & $-1.659^{*}$ & .528 & .045 & -3.29 & -.02 \\
\hline & & $\begin{array}{l}\text { Greater than } \\
50\end{array}$ & -1.909 & .663 & .084 & -3.96 & .15 \\
\hline & \multirow[t]{4}{*}{$20-30$} & Less than 20 & .899 & .394 & .269 & -.32 & 2.12 \\
\hline & & $31-40$ & $-1.010^{*}$ & .258 & .005 & -1.81 & -.21 \\
\hline & & $-41-50$ & -.760 & .446 & .575 & -2.14 & .62 \\
\hline & & $\begin{array}{l}\text { Greater than } \\
50\end{array}$ & -1.010 & .600 & .587 & -2.87 & .85 \\
\hline & \multirow[t]{4}{*}{$31-40$} & Less than 20 & $1.909^{*}$ & .382 & .000 & .73 & 3.09 \\
\hline & & $20-30$ & $1.010^{*}$ & .258 & .005 & .21 & 1.81 \\
\hline & & $-41-50$ & .250 & .436 & .988 & -1.10 & 1.60 \\
\hline & & $\begin{array}{l}\text { Greater than } \\
50\end{array}$ & .000 & .592 & 1.000 & -1.84 & 1.84 \\
\hline & \multirow[t]{4}{*}{$41-50$} & Less than 20 & $1.659^{*}$ & .528 & .045 & .02 & 3.29 \\
\hline & & $20-30$ & .760 & .446 & .575 & -.62 & 2.14 \\
\hline & & $-31-40$ & -.250 & .436 & .988 & -1.60 & 1.10 \\
\hline & & $\begin{array}{l}\text { Greater than } \\
50\end{array}$ & -.250 & .695 & .998 & -2.41 & 1.91 \\
\hline & \multirow{4}{*}{$\begin{array}{l}\text { Greater than } \\
50\end{array}$} & Less than 20 & 1.909 & .663 & .084 & -.15 & 3.96 \\
\hline & & $20-30$ & 1.010 & .600 & .587 & -.85 & 2.87 \\
\hline & & $-31-40$ & .000 & .592 & 1.000 & -1.84 & 1.84 \\
\hline & & $41-50$ & .250 & .695 & .998 & -1.91 & 2.41 \\
\hline
\end{tabular}

*. The mean difference is significant at the 0.05 level. 


\section{Appendix I - Consumer Age Statistics}

What is your age? ${ }^{*}$ How do you describe your experience in conducting mobile payments: Cross tabulation Count

\begin{tabular}{|c|c|c|c|c|c|c|c|}
\hline & \multicolumn{5}{|c|}{ How do you describe your experience in conducting mobile payments: } & \multirow[b]{2}{*}{ Total } \\
\hline & & $\begin{array}{c}\text { Had no } \\
\text { experience }\end{array}$ & One-time user & Few-times user & Many-times user & $\begin{array}{l}\text { Continued/ } \\
\text { regular user }\end{array}$ & \\
\hline \multirow{5}{*}{$\begin{array}{l}\text { What is your } \\
\text { age? }\end{array}$} & Less than 20 & 15 & 6 & 6 & 3 & 3 & 33 \\
\hline & 20-30 & 27 & 15 & 29 & 20 & 11 & 102 \\
\hline & $31-40$ & 6 & 18 & 43 & 32 & 36 & 135 \\
\hline & $41-50$ & 3 & 0 & 9 & 6 & 6 & 24 \\
\hline & Greater than 50 & 3 & 3 & 3 & 3 & 0 & 12 \\
\hline Total & & 54 & 42 & 90 & 64 & 56 & 306 \\
\hline
\end{tabular}

